Portland State University

PDXScholar

$1-1-2010$

\title{
The Foundation to Collaborate: Understanding the Role of Participant Interests
}

Tia S. Henderson

Portland State University

Follow this and additional works at: https://pdxscholar.library.pdx.edu/open_access_etds Let us know how access to this document benefits you.

\section{Recommended Citation}

Henderson, Tia S., "The Foundation to Collaborate: Understanding the Role of Participant Interests" (2010). Dissertations and Theses. Paper 2.

https://doi.org/10.15760/etd.2

This Dissertation is brought to you for free and open access. It has been accepted for inclusion in Dissertations and Theses by an authorized administrator of PDXScholar. Please contact us if we can make this document more accessible: pdxscholar@pdx.edu. 
The Foundation to Collaborate:

Understanding the Role of Participant Interests

by

Tia Henderson

A dissertation submitted in partial fulfillment of the requirements for the degree of

Doctor of Philosophy

in

Urban Studies and Planning

Dissertation Committee:

Connie P. Ozawa, Chair

Sy Adler

Charles Heying

Barry Messer

Craig Shinn

Portland State University

(C)2010 


\begin{abstract}
Collaborative processes are widely used to harness resources for addressing community problems. Despite their positive potential, collaborative projects can fragment. Sources of fragmentation include participant misperception of facts, difficulties in defining the problem, and misunderstandings among stakeholders. Disruptions from these elements may impede a group's progress in fostering and implementing agreements. Theoretical and empirical research from conflict resolution has shown that discussing participant interests and the use of facilitation techniques can help negotiators engage in innovative problem solving. Interests are participants' underlying needs, concerns, and desires that shape how individuals perceive issues and the stances they take. Less attention has been given to designing multi-party collaborative processes so that participant interests are explicitly defined and addressed.
\end{abstract}

This comparative case study used mixed methods to examine the role of interests on the evolution of five successfully implemented multi-party collaborative cases. The research examined how participant interests were identified, how facilitation techniques were used, and how stakeholders' interests were addressed in each case. Results show that in all cases, identifying participant interests helped participants understand the central problems, seek information, and use creative problem solving. The use of 
techniques such as clarifying questions and shared learning experiences in the context of regular face-to-face meetings fostered participant understanding of the issues and each others' interests. In four of the five cases, participants' understanding of other stakeholders' interests affected their perspective on the issues, improved understanding of individual barriers, shaped the agreement, and motivated participants to stay committed to the project.

Project staff members and participant leaders used facilitation techniques for identifying actors' substantive interests and clarifying issues. These techniques addressed participant relationship and process interests. In the cases with higher levels of fragmentation, participant interests were connected to values, individuals used competitive bargaining tactics, and trust influenced the willingness of participants to share interests. Facilitation techniques were crucial for encouraging trust building among stakeholders and for managing disruptions. These findings indicate that managers will increase problem solving capacity in collaborative processes by explicitly using negotiation-based facilitation techniques to identify and address participant interests. 


\section{DEDICATION}

To Burton Miles for helping students find personal treasure in their own backyards; viva el Alchemist! 


\section{ACKNOWLDEGEMENTS}

This research would not have been possible without the innovative and dedicated collaborative work occurring in Oregon. I would like to thank the participants of each of the case studies that agreed to be included in this research. Thank you for sharing your time, efforts, and insights with me. This dissertation is a compilation of your experiences and lessons dealing with complex problems; while confidentially prevents me from naming you here, I am inspired and encouraged by who you are. I would also like to thank Oregon Solutions and Sustainable Northwest staff members, project managers, and conveners for helping diverse groups improve how they work together. Kim Travis, Therese Hampton, Keith Tymchuk, Dick Townsend, Commissioner Mark Labhart, Senator Betsy Johnson, Pete Dalke, Dean Hal Salwasser, Jack Roberts, Gail Achterman, Scott Aycock, Cylvia Hayes, Joshua Proudfoot, Steve Greenwood, Renee Magyar, and Martin Goebel thank you for supporting my research efforts through answering endless questions and connecting me to participants.

My efforts in completing this body of work were supported and directed by my committee: advisor Dr. Connie Ozawa, Dr. Sy Adler, Dr. Charles Heying, Dr. Barry Messer, and Dr. Craig Shinn. Thank you for giving me the push and guidance when I needed it.

This effort would not have been possible without the support of my colleagues at Portland State University - especially those in the Institute of 
Portland Metropolitan Studies. Thank you to Dr. Sheila Martin for providing me with moral support, cubicle space, and on-going work as a graduate student.

Thank you to my friends - who are very much like my family. My mentor and friend, Chris Drake's unwavering belief in me nudged me forward even when my doubt caused me to falter. Tauna Wamsley, Heather Barnes, and Elena Kelley have been tireless listeners and provided me with constant support. I greatly appreciate the last two years shared with Elan Ho. He grounded me and provided a needed sounding board. My list of generous friends who have shared words of wisdom, cheerleading, or commiseration is lengthy: Cheryl Hollatz-Wisely, Etta Martin, Lynn Marshall, Rachel Wagner, Erin Tirone, Kelly Haines, Alissa Green, Moriah McSherry McGrath, Gretchen Luhr, Elizabeth Robb-Schmitz, Bobby Cochran, Liza Mylott, Kiirsten Flynn, Larry, Lynn and Kim Powe, and Sarah and Bruce Ho are a few that are appreciated. I also thank my mother for instilling in me the value of education. 


\section{TABLE OF CONTENTS}

\begin{tabular}{|c|c|}
\hline ABSTRACT.. & \\
\hline DEDICATION............. & \\
\hline ACKNOWLEDGEMENTS. & iv \\
\hline LIST OF TABLES............ & \\
\hline LIST OF FIGURES........ & xiii \\
\hline Chapter One Introduction.. & \\
\hline 1.1 Problem Statement.... & 2 \\
\hline 1.2 The Rise of Collaboration in Community Problem-Solving............ & 6 \\
\hline 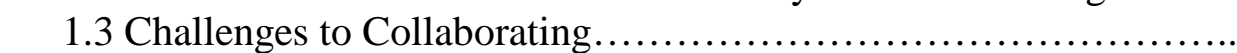 & 10 \\
\hline 1.4 Characterizing Successful Collaboration $\ldots \ldots \ldots \ldots \ldots \ldots \ldots \ldots \ldots \ldots \ldots \ldots \ldots \ldots \ldots$ & 11 \\
\hline 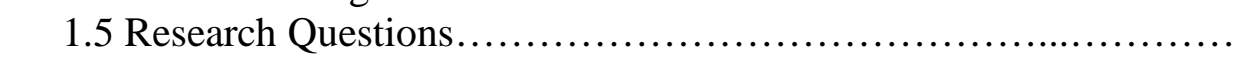 & 13 \\
\hline Chapter Two Literature Review... & 17 \\
\hline 2.1 Interests and Conflict................... & 17 \\
\hline 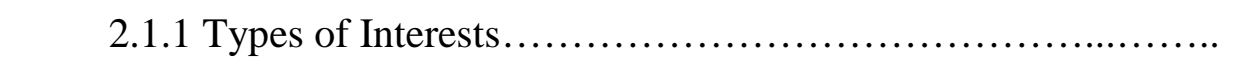 & 19 \\
\hline 2.1.2 Interests as a Context for Problem Solving in Negotiation..... & 21 \\
\hline 2.2 Collaborative Behavior & 30 \\
\hline 2.2.1 Relationships and Trust.. & 34 \\
\hline 2.2.2 Characterizing Collaboration........ & 37 \\
\hline 2.2.3 Collaboration and Community Capacity... & 39 \\
\hline 2.2.4 Collaboration Models.............................. & 43 \\
\hline 2.2.5 Forces of Disruption in Collaborative Processes................ & 47 \\
\hline 2.3 Facilitation: Managing Problem, People and Process................. & 53 \\
\hline 2.3.1 Learning in Multi-party Collaboration............... & 54 \\
\hline 2.3.2 Facilitators, Mediators, and Conveners $\ldots \ldots \ldots \ldots \ldots \ldots \ldots \ldots \ldots \ldots \ldots \ldots \ldots \ldots$ & 56 \\
\hline 2.3.3 Communication.................. & 58 \\
\hline 2.3.4 Social Techniques.. & 59 \\
\hline 2.4 Gap in Theory............ & 61 \\
\hline 2.5 Research Aims.... & 63 \\
\hline Chapter Three Research Design and Methods. & 65 \\
\hline 3.1 Exploratory Comparative Case Study... & 65 \\
\hline 3.1.1 Collaborative Program Case Population... & 68 \\
\hline 3.1.2 Variables........................... & 70 \\
\hline 3.1.3 Case Study Selection.................. & 73 \\
\hline 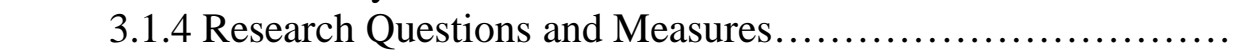 & 77 \\
\hline 3.2 Data Collection and Analysis............... & 79 \\
\hline 3.2.1 Pilot Case..................... & 80 \\
\hline 3.2.2 Document Review............. & 80 \\
\hline 3.2.3 Semi-structured Interviews.... & 81 \\
\hline 3.2.4 Follow-up Survey............. & 85 \\
\hline 3.2.5 Cross-case Analysis. & 92 \\
\hline 3 Validity and Relighility & \\
\hline
\end{tabular}


Chapter Four Case Results.............................................. 96

4.1 Lane Clean Diesel Case Narrative................................. 97

4.1.1 Problem Description ......................................... 97

4.1.2 Origins of the Collaborative Effort.......................... 98

4.1.3 The Collaborative Process................................. 99

4.1.4 Current Status of the Collaborative............................ 101

4.1.5 Lane Clean Diesel Within Case Analysis.................... 102

4.1.5a Research Question One: Identifying Interests.............. 102

4.1.5b Research Question Two: Facilitation...................... 106

4.1.5c Research Question Three: Role of Interests.............. 112

4.1.5d Research Question Four: How Were Interests Addressed... 116

4.2 Reduced Engine Idling at Truckstops Case Narrative.............. 121

4.2.1 Problem Description....................................... 121

4.2.2 Origins of the Collaborative Effort......................... 122

4.2.3 The Collaborative Process.................................. 124

4.2.4 Current Status of the Collaborative........................... 126

4.2.5 Reduced Engine Idling Within Case Analysis................. 126

4.2.5a Research Question One: Identifying Interests............. 126

4.2.5b Research Question Two: Facilitation..................... 133

4.2.5c Research Question Three: Role of Interests............... 140

4.2.5d Research Question Four: How Were Interests Addressed... 144

4.3 Lakeview Biomass Energy Facility Case Narrative................ 149

4.3.1 Problem Description......................................... 149

4.3.2 Origins of the Collaborative Effort......................... 151

4.3.3 The Collaborative Process.................................. 154

4.3.4 Current Status of the Collaborative........................... 156

4.3.5 Lakeview Biomass Facility Within Case Analysis............. 159

4.3.5a Research Question One: Identifying Interests............. 159

4.3.5b Research Question Two: Facilitation..................... 164

4.3.5c Research Question Three: Role of Interests.............. 171

4.3.5d Research Question Four: How Were Interests Addressed 175

4.4 Tillamook Flooding Reduction Case Narrative.................. 186

4.4.1 Problem Description...................................... 186

4.4.2 Origins of the Collaborative Effort.......................... 191

4.4.3 The Collaborative Process..................................... 195

4.4.4 Current Status of the Collaborative............................ 202

4.4.5 Tillamook Flooding Reduction Within Case Analysis.......... 209

4.4.5a Research Question One: Identifying Interests.............. 209

4.4.5b Research Question Two: Facilitation..................... 216

4.4.5c Research Question Three: Role of Interests............... 232

4.4.5d Research Question Four: How Were Interests Addressed... 236

4.4.6 Summary......................................... 247

4.5 Lakeview Stewardship Group Case Narrative................... 250 
4.5.1 Problem Description...................................... 250

4.5.2 Origins of the Collaborative Effort......................... 252

4.5.3 The Collaborative Process.................................... 257

4.5.4 Current Status of the Collaborative........................... 260

4.5.5 Lakeview Stewardship Group Within Case Analysis........... 261

4.5.5a Research Question One: Identifying Interests.............. 261

4.5.5b Research Question Two: Facilitation..................... 267

4.5.5c Research Question Three: Role of Interests............... 277

4.5.5d Research Question Four: How Were Interests Addressed 281

Chapter Five Cross-Case Results.................................. 285

5.1 Survey Results......................................... 285

5.1.1 Research Question One: Identifying Interests................ 285

5.1.2 Research Question Two: Facilitation....................... 288

5.1.3 Research Question Three: Role of Interests................. 304

5.1.4 Research Question Four: How Were Interests Addressed...... 307

5.1.5 Influence of Project Role and Interview Experience........... 309

5.2 Cross-case Analyses........................................ 310

5.2.1 Research Question One: Identifying Interests................ 310

5.2.2 Research Question Two: Facilitation...................... 315

5.2.3 Research Question Three: Role of Interests................ 321

5.2.4 Research Question Four: How Were Interests Addressed...... 331

5.2.5 Disruption Sources, Interests, and Facilitation................. 336

Chapter Six Discussion............................................. 342

6.1 Research Question One: How Interests Were Identified........... 342

6.1.1 Substantive Interests: The Basis of Integrative Bargaining.... 344

6.1.2 Relationship and Process Interests: The Basis for Substantive Learning ............................................ 345

6.2 Research Question Two: Managing People and Process............. 346

6.3 Research Question Three: The role of interests in collaborative processes................................................... 347

6.3.1 Interests and Problem Solving............................... 349

6.4 Research Question Four: How interests are addressed............ 352

6.4.1Trust and Relationships.................................. 353

6.5 Alternate Explanations and Related Findings.................... 354

6.5.1 Better Alternative to a Negotiated Agreement................. 355

6.5.2 Individuals................................................ 357

6.5.3 Individual Learning...................................... 358

6.5.4 Leadership............................................ 358

6.5.5 Power and Representation................................ 359

6.5.6 Unaddressed Interests.................................... 361

6.6 Limitations and Future Research............................... 362

6.7 Implications for Collaborative Practice....................... 365

Chapter Seven Conclusion.......................................... 369 
Chapter Eight References............................................. 373

APPENDICES .................................................... 384

Appendix A : Case Selection Materials............................. 384

A.1 : Potential Fragmentation Survey........................... 384

A.2 : Screening Criteria for Cases.............................. 386

Appendix B: Case Protocol........................................ 394

Appendix C: Data Collection Instruments.......................... 399

C.1: Staff Interview............................................... 399

C.2: Participant Interview........................................ 401

C.3: Staff Follow-up Survey Example........................... 403

C.4: Participant Follow-up Survey Example....................... 408

C.5: Specific Interests Used in the Follow Up Survey............... 413

Appendix D: HSRRC Letters................................... 415

D.1: Interview Letter....................................... 415

D.2: Follow-up Survey Email................................... 417

Appendix E: Social Technique Summary List......................... 419

Appendix F: Survey Statistics Results.............................. 432 


\section{LIST OF TABLES}

Table 1 Characteristics of successful multi-party environmental collaborative and consensus-building processes............ 12

Table 2 Distributive and integrative bargaining elements (adapted from Daniels and Walker, 2001).......................... 26

Table 3a Example of a disagreement............................ 27

Table 3b Example of the relationship among issues, interests, and positions............................................. 28

Table $4 \quad$ The collaborative process............................... 44

Table 5 Collaborative processes: success and fragmentation elements........................................ 50

Table 6 Key facilitative elements that may contribute to uncovering interests in negotiations............................... 59

Table $7 \quad$ Sources of evidence and their functions..................... 68

Table 8 Sustainable Community Objectives of the Sustainability

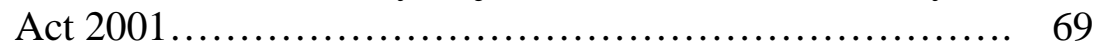

Table $9 \quad$ Case study selection criteria............................. 74

Table 10 Case screening survey sub-elements..................... 75

Table 11 Analyzed cases...................................... 76

Table 12 Numbers of interviewed participants in each case............ 82

Table 13a Interview questions relating to interests.................. 83

Table 13b Interview questions relating to facilitation techniques........ 83

Table 13c Interview questions related to problem substance............ 84

Table 13d Interview questions related to context. ................... 84

Table 14 Major code categories, symbols, and example sub-codes used in analyzing interviews. ........................... 85

Table 15a Demographic questions in the Follow Up Survey............ 87

Table 15b Explanatory text in the follow up survey................... 87

Table 15c Facilitation questions in the Follow Up Survey.............. 88

Table 15d Interests questions in the Follow Up Survey................ 89

Table 16 Survey respondents by case........................... 90

Table 17 Participant profile of all survey respondents............... 91

Table 18 Research elements to improve validity and reliability....... 95

$\begin{array}{lll}\text { Table } 19 \text { Interests identified in the Lane Clean Diesel collaboration... } & 102\end{array}$

Table 20 Follow-up survey responses of "important" interests........ 105

Table 21 Lane Clean Diesel Summary: Interest findings............. 105

Table 22 Lane Clean Diesel: Facilitation elements.................. 107

Table 23 Lane Clean Diesel: Participant interests' impact on the process. ............................................ 112

Table $24 \quad$ Reduced Engine Idling: Identified interests. ................. 127

Table 25 Reduced Engine Idling: Follow-up survey responses of important interests.................................... 128 
Table 26

Table 27

Table 28

Table 29

Table 30

Table 31

Table 32

Table 33

Table 34

Table 35

Table 36

Table 37

Table 38

Table 39

Table 40

Table 41

Table 42

Table 43

Table 44

Table 45

Table 46

Table 47

Table 48

Table 49

Table 50

Table 51

Table 52

Table 53

Table 54

Table 55

Table 56

Table 57

Table 58
Reduced Engine Idling Summary: Interest findings.........

Reduced Engine Idling: Facilitation elements.

133

Reduced Engine Idling: Participant interests' impact on the process.

141

Lakeview Biomass: Identified interests

160

Biomass: Follow-up survey responses of important interests

163

Biomass Summary: Interest findings ....................... 164

Lakeview Biomass: Techniques............................ 165

Biomass: Participant interests' impact on the process....... 171

Regulations and agencies affecting Tillamook Basin........ 191

Tillamook Flood Reduction: Financial commitments and expenditures (May 23, 2007 meeting; Addendum to DoC, January, 2009)

Tillamook Flood Reduction: Project Team membership..... 198

Tillamook Flood Reduction project list..................... 201

Tillamook Flood Reduction: Participant interests........... 210

Tillamook: Follow-up survey responses of "important"

interests................................................... 211

Tillamook: Summary interest themes..................... 215

Tillamook: Techniques that helped address interests........ 217

Tillamook: Disruptive elements............................ 228

Tillamook: Participant interests' impact on process......... 232

LSG: Identified interests................................. 262

LSG: Follow-up survey responses of "important" interests.. 266

LSG: Themes on interests.................................. 267

LSG: Key facilitation elements............................. 269

LSG: Participant interests' impact on the collaborative process.

277

Survey results of participant understanding each other's interests

286

Important substantive interests by case confirmed in the survey

287

Important relationship and process interests confirmed in the survey.

288

Information sub-types: case specific results................. 292

Meeting sub-types: case specific results.................... 294

Verbal communication sub-types: case specific results..... 297

Visual communication sub-types: case-specific responses... 300

Shared experience sub-types: case specific results........... 303

Importance of participants' understanding each others'

interests.................................................

305

Tillamook: Importance of participants' understanding each

134 (1)

3

5

1

5

0

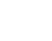


others' interests.................................... 306

Table 59 Participants' perspective on understanding interests........ 307

Table $60 \quad$ Staff perspective on participant interests................ 308

Table 61 Projects developed common ground and addressed interests 308

Table 62 Summary: Interest themes from all cases................. 311

Table 63 Integrative statement examples from the five cases........ 313

Table 64 Techniques that supported understanding interests and issues............................................... 316

Table 65 Participant interests' impact on the collaborative (interviews) ..................................... 327

Table 66 Importance of understanding other participants' interests (survey results)........................................ 328

Table 67 Tillamook substantive interests based on survey responses.. 329

Table 68 Summary of cases and primary disruption types........... 337

Table 69 Collaborative process framework elements most directly influenced (in bold face) by participant interests........... 348 


\section{LIST OF FIGURES}

Figure 1 Sources of conflict ..................................... 18

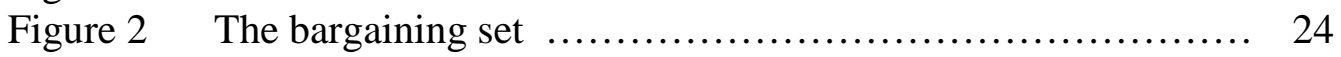

Figure 3 The Core Relationships. Applied to social dilemmas as an explanation for trusting behavior and cooperation (Ostrom, 1998, p. 13)............................................... 32

Figure 4 The Dual Concerns model (Pruitt and Rubin, 1986) and the Kilmann-Thomas conflict orientations (1977)................ 33

Figure 5 Elements of community capacity and community resiliency constructs ............................................ 41

Figure 6 Iterative process framework for cooperative interorganizational relationship................................. 46

Figure 7 Defining strategic alliances across a continuum of integration.............................................. 47

Figure $8 \quad$ Exploratory mixed methods research design................. 67

Figure 9 Independent variable relationships. ........................ 72

Figure 10 Research variables..................................... 72

Figure 11 Lane Clean Diesel Image (Lane Regional Air Pollution Authority)............................................. 97

Figure 12 Lane Clean Diesel Project: How interests were addressed ...... 116

Figure 13 Reduced Engine Idling Image (Image from Shorepower Technologies)............................................ 121

Figure 14 Reduced Engine Idling: How substantive interests were addressed................................................ 145

Figure 15 Reduced Engine Idling: How relationship interests were addressed........................................... 146

Figure 16 Biomass Project: How participant substantive interests were addressed. ........................................... 176

Figure 17 Biomass project: How relationship and process interests were addressed................................................ 177

Figure 18 Tillamook Bay (Tillamook Bay Watershed Council)............. 186

Figure 19 Flood example one (Tillamook County website).................. 188

Figure 20 Flood example two (PIVOT website) ........................ 188

Figure 21 Project Exodus (NHC Duration Analysis, Sept. 1, 205 2009).

Figure 22 Tillamook: Substantive stakeholder interests addressed by priority projects...................................... 238

Figure 23 Tillamook: How projects addressed participants' substantive

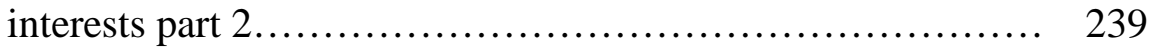

Figure 24 Tillamook Flooding Reduction: Selected public agency interests, positions and preferred projects. .................. 240

Figure 25 Tillamook Flood Reduction: Selected community interests, 
issues, positions and preferred projects. ................... 241

Figure 26 Tillamook: Interests addressed by facilitation elements........ 245

Figure 27 Image of Lakeview Stewardship Unit (LCRI)............... 250

Figure 28 Lakeview Stewardship Group: How interests were addressed.. 282

Figure 29 Types of helpful participants.............................. 290

Figure 30 Survey results: information that helped participants understand issues......................................... 291

Figure 31 Helpful meeting types.................................. 293

Figure 32 Helpful verbal communication types, survey responses for all cases................................................. 296

Figure 33 Helpful visual communication............................. 298

Figure 34 Helpful shared experiences.............................. 302

Figure 35 Example substantive interests and corresponding outputs all cases................................................. 332

Figure 36 Cases addressed relationship and process concerns............... 335

Figure 37 Indirect participant interest assessment potential.............. 350

Figure 38 Direct participant interest assessment potential. ............... 351

Figure 39 Adapted Core Relationships diagram (Ostrom,1998).......... 253 


\section{CHAPTER ONE}

We want the maximum good per person; but what is good? To one person it is wilderness, to another it is ski lodges for thousands...Comparing one good to another is, we usually say, impossible because goods are incommensurable. Incommensurables cannot be compared... Ruin is the destination toward which all men rush, each pursuing his own best interest in a society that believes in the freedom of the commons. Freedom in a commons brings ruin to all.

Garrett Hardin, 1968

\section{$\underline{\text { 1. Introduction }}$}

The Garret Hardin quote above highlights four difficulties in working through environmental issues that can be applied to many community problems. First, if we consider that any person's "good" as common vernacular for intertwined values ${ }^{1}$ and interests, then comparing one person's "good" to another's can lead to a perception of conflict ${ }^{2}$. "Interests" are broadly defined here as a party's ${ }^{3}$ underlying desires, fears, principles, concerns, needs, or what a party seeks to achieve within a negotiation beyond reaching an agreement (Fisher, Ury, \& Patton, 1991; D. M. Kolb \& Williams, 2003; Lax \& Sebenius, 1986, 2006). Second, the logic that each party can maximize his or her use of finite natural resources without negative consequences is faulty. Third, if each party seeks to maximize his or her "good," these actions will also conflict with one another. The sum of these scenarios leads us to the most pressing

1 "Values" are beliefs that contribute to a party's position on an issue.

2 "Conflict" means that a difference exists resulting in incompatible actions.

3 The terms "actors" and "parties" are used interchangeably to describe any individual acting on behalf of themselves or as a representative of an organization. Organizations may include governments, businesses, non-profits, etc. 
challenge: if we do not find a way to work through such conflicts, and parties continue to use natural resources indiscriminately, no one party will be able to gain what it wants and we, the greater public, lose natural resources. Our ability to work together and the long-term use of natural resources are then compromised.

\subsection{Problem Statement}

The purpose of this research is to explore the applicability of integrative bargaining theory to multi-party collaborative practice. The use of collaborative methods has grown tremendously over the past few decades across disciplines and types of organizations (Austin, 2000; Koontz \& Thomas, 2006; Mattessich \& Monsey, 1992; Ring \& Van de Ven, 1994; Roussos \& Fawcett, 2000). Collaborative processes suffer from fragmentation related to multiple issues, multiple parties, and technical information (Conklin, 2006; Daniels \& Walker, 2001). This is a problem because if fragmentation successfully disrupts and disables a process, it can impede progress in resolving complex social and environmental problems. Further, failed collaboration attempts can weaken trust and social capital among the public and private sectors, two elements that shape collective action. If planners, community developers, social activists, natural resource advocates, and public managers want to help communities solve problems, they need an improved understanding of collaboration dynamics. 
The antidote to fragmentation is building coherence through increasing shared understanding among participants of the issues, the information, and the individuals (Conklin, 2006). Interests pertain to the individual side of how stakeholders approach their role in collaborative processes. Each participant in a collaborative process has concerns and desires that shape a view of their or their organization's stake in the outcome. For example, interests contribute to how stakeholders perceive issues. They shape participants' bargaining positions and perceptions of the success of potential solutions (Lax \& Sebenius, 1986). The consensus-building field approaches collaboration from a conflict standpoint where a facilitator helps mediate emerging conflict among multiple parties (Susskind, 1999). Conflict is not an assumed pre-condition in other collaboration literature and interests are not emphasized in collaboration frameworks. The influence of interests on the outcomes of collaborative processes has not been examined sufficiently. We have only a small amount of evidence that discussion of interests can improve participant understanding of issues in collaborative processes that are not centered on achieving consensus (Leach \& Pelkey, 2001; Ozawa, 1991).

Collaboration practice is a broad field that encompasses partnership arrangements, multi-party stakeholder processes, participatory planning processes, and loosely affiliated coalitions. The field draws upon an equally diverse array of theory. Practioners and researchers cite communication theory, learning theory, policy mediation theory, negotiation theory, and systems 
theory among others (i.e. Daniels \& Walker, 2001; Gray, 1989). Theory in the collaboration field is fragmented and underdeveloped. Research that helps clarify the use and application of specific theory, such as negotiation, can help practitioners make conscious choices about processe design. This research draws heavily from the environmental collaboration field as it is a literature base that draws connections across the public and private sectors while also wrestles with the impacts of decisions on economic, social, and environmental outcomes. Theorists from the conflict resolution and negotiation fields posit that interests are the basis for negotiating conflict and recommend facilitation techniques to explicitly discuss interests in environmental disputes (Fisher, et al., 1991; Lax \& Sebenius, 1986; Pruitt, 1981; Pruitt \& Lewis, 1975; Raiffa, Richardson, \& Metcalfe, 2002; Susskind, McKearnan, \& Thomas-Larmer, 1999a). The bulk of experimental work on interests examines two party scenarios using undergraduate students as subjects for negotiation behavior (Pruitt, 1981; Pruitt, 1983; Pruitt \& Carnevale, 1993; Pruitt \& Lewis, 1975) . Negotiation, or bargaining ${ }^{4}$, is a process to resolve divergent interests through joint problem solving involving two or more parties (Pruitt, 1981; Pruitt \& Carnevale, 1993). From this work, and extensive descriptive studies in conflict resolution, we know that interests are the basis for joint problem solving in negotiation and participants create value through addressing divergent interests (Carpenter \& Kennedy, 1988; Fisher, et al., 1991; Lax \& Sebenius, 1986).

\footnotetext{
${ }^{4}$ Negotiation is a form of bargaining. These two terms are used interchangeably although specific types of bargaining will be qualified where appropriate.
} 
There is a need for further empirical work examining interests within multiparty collaboration scenarios.

We have some evidence that explicitly discussing interests can improve collaborative problem-solving (Ozawa, 1991, 1993; Susskind, et al., 1999a). The conflict resolution and negotiation literature focus on addressing established disputes (Carpenter \& Kennedy, 1988; Pruitt, 1981; Pruitt \& Carnevale, 1993; Raiffa, 1982, 1983). The consensus-building literature addresses pre-existing conflict and emerging conflict (Susskind, et al., 1999a). The collaboration literature only touches on explicitly considering conflict; authors recommend a mediator to handle adversarial situations (Gray, 1989; Julian, 1994; Margerum, 1999a; Mattessich \& Monsey, 1992; Vaaland, 2004; Wondolleck \& Yaffee, 2000). This is an important gap in the literature because collaborative processes have the potential to deal with differences before they become disputes. Specifically, we need to better understand how the dynamics of addressing interests can help collaboration participants strengthen a collaboration process. Are interests as important for encouraging joint problem solving when people collaborate as they are in established dispute settings? Planners, facilitators, managers and participants of collaborative processes will benefit from knowing if and how identifying and addressing interests can strengthen cohesion in collaborative processes. Although collaborative processes that inform community decision-making and policy development are 
commonly employed in the US, the complexity of the problems and the diversity of stakeholders require innovative and effective approaches.

\subsection{The Rise of Collaboration in Community Problem-Solving}

Collaborative arrangements allow multiple organizations to make collective decisions responding to multiple interests. Urban and rural communities in the U.S. are faced with a range of social, environmental, and economic issues. To give just a few examples, disparities are widening between social groups with respect to health, access to health care, food outlets, and clean environments (Kaplan, Haan, Syme, Minkler, \& Winkleby, 1987; Picket \& Pearl, 2000; Zenk \& Schulz, 2005); the natural environment has been degraded by extractive industry and development (Dynesius \& Nilsson, 1994); and disinvestment has crippled residential and commercial districts of de-industrializing cities (Dreier, Mollenkopf, \& Swanstrom, 2004; Jargowsky, 1997; Wilson, 1982). These problems are set against a backdrop of declining civic involvement, which Putnam's (2000) survey research has correlated with decreases in trusting behavior, educational outcomes, good governance, and numerous other measures.

Collaborative efforts among government and civil society are emerging to address community dilemmas. Collaborative community development efforts combine the financial resources and policy expertise of top-down programs with the social capital and community information of bottom-up programs (Roussos \& Fawcett, 2000). While not always expressly stated, 
multi-party collaborative efforts are often aimed at collective action, in contrast to top-down programs which have been criticized for treating communities as though they are deficient in skills, knowledge, and experience (Beazley, Griggs, \& Smith, 2004). Cross-sector collaborative strategies may be viewed as a component of community development practice, specifically aimed at building the capacity of communities to act on their own behalf.

Collaboration is being used to support problem solving on environmental problems due to the increasingly complex nature of issues such as clean air, clean water, forest management, watershed management and land use (Bingham, 1986; Cheng \& Mattor, 2006; Connick \& Innes, 2001; Koontz \& Thomas, 2006; Leach \& Pelkey, 2001; Sabatier, et al., 2005; Wondolleck \& Yaffee, 2000). Barbara Gray's (1985) definition of collaboration as "1) the pooling of appreciations and/or tangible resources, 2) by two or more stakeholders, 3) to solve a set of problems which neither can solve individually" is used as a guideline here (p.2). Note collaboration arrangements in this research include cross-sector representation. Collaboration has grown as an alternative approach of environmental decision making for several reasons. Environmental problems are the result of efforts from multiple individuals and organizations - and thus require integrated efforts beyond what any one organization or individual can accomplish (Innes, Gruber, Neuman, \& Thompson, 1994; Margerum, 1999a; Wondolleck \& Yaffee, 2000). Organizations and individuals are increasingly competing for use of 
natural resources, leading to conflict (Carr, Selin, \& Schuett, 1998; Cortner \& Moote, 1999; Michaels, 2001; Wondolleck \& Yaffee, 2000). Conflict in natural resource problems can lead to impasse at the policy and program implementation levels (Wondolleck \& Yaffee, 2000). Legislative methods of addressing natural resource issues and related conflict are expensive and inflexible (Wondolleck \& Yaffee, 2000). Collaborative endeavors respond to these circumstances because they can harness diverse knowledge and enable coordinated efforts among interdependent parties for achieving a common purpose on complex issues (Bidwell \& Ryan, 2006; Gray, 1989; Imperial, 2005).

During the last four decades, government has included provisions for the public to participate in natural resource management decisions and made collaboration part of agency missions. Federal laws including the National Environmental Policy Act (NEPA) and the National Forest Management Act (NFMA), provide opportunities for citizen groups to challenge agency decisions through outreach programs and legal provisions. The vision of the Department of Interior's 2007-2012 strategic plan emphasizes partnership: "Communication, consultation, and cooperation, all in the service of conservation and community.” The forest-planning rule issued January 2005 requires responsible USDA Forest Service officials to "provide opportunities for the public to collaborate and participate openly and meaningfully in the planning process..." (Revised 36 Code of Federal Regulations $§ 219.9(a)$ ). 
Based on these policies, advocacy groups, businesses, and private individuals are entering into multi-party collaboration processes and contributing to decisions. This is important because the policies require agencies give stakeholder groups a role in decision making. As a result, diverse groups have political power and a stake in determining outcomes on natural resource management decisions.

Ad-hoc multi-party collaborative groups have also increased in order to implement natural resource management decisions. For example, as many as 400 collaborative watershed initiatives existed in the western United States alone by the year 2000, more than four times the number in 1995 (Kenney, 1997). In Oregon, multiple not-for-profit and university-based organizations contribute to environmental collaboration including Sustainable Northwest in Portland, Oregon Solutions at Portland State University, and Resource Innovations at University of Oregon. In 2007, the Oregon Legislature approved $\$ 1.2$ million to triple the number of Oregon Solutions projects across the state; this indicates the growing investment of public dollars to finance multi-party collaborative endeavors (PCI, 1997). Oregon Solutions provides teams of staff members to assist communities in defining issues, developing strategies, and formulating agreements to address problems, including environmental projects. The program has assisted over 40 multi-party collaborative projects across the state since 2001 (OS, 2009). 
Multi-party environmental collaboration is increasingly complex, not unlike community health and planning issues. Seven attributes of environmental multi-party collaboration are: multiple parties, multiple issues, cultural differences, deeply held values and worldviews, scientific and traditional knowledge, legal requirements, and lobbies that can influence decisions (Daniels \& Walker, 2001; Lang, 1991). These elements contribute to difficulties in multi-party environmental collaboration. Collaboration is growing as a practice; how can we intentionally craft successful processes to manage these difficulties?

\subsection{Challenges to Collaborating}

Despite new mandates and increased attention to this practice, researchers report challenges impeding successful collaboration (Boddy \& Macbeth, 2000; Davenport, Leahy, Anderson, \& Jakes, 2007; Habron, 2003; Schuett, Selin, \& Carr, 2001). Collaborative participants may struggle with differences in missions, differences in understanding, conflicting roles, overlapping responsibilities and competing statutory objectives (Imperial, 2005; Poncelet, 2001). Collaborative processes often suffer from disruptions, and have difficulty moving forward, due to such factors as interpersonal relationships and differences in perspective about the problem (Coughlin, Hoben, Manskopf, \& Quesada, 1999). Implementation of agreed upon plans, programs, and actions is also problematic as participants often fail to commit to integrated approaches (Hooper, 1995; Margerum, 1999b). 
If differences are not addressed, they can lead to disputes.

Collaboration involves conflict either explicitly or implicitly through differences; however participants may avoid acknowledging and managing it. Poncelet (2001) describes collaborators' tendency to minimize conflict or diffuse it based on a prominent cultural model that conceptualizes the partnership process as "fundamentally nonconflictual in nature." This mindset delegitimizes conflictual approaches to environmental action which impedes "radical thinking and innovative environmental solutions (Poncelet, 2001)."

Managers, collaborators, and planners need methods to facilitate the discussion of participant differences in order to manage disruptions.

Practitioners and theorists recommend facilitators and facilitation techniques to help improve communication, help participants understand the issues, and uncover their interests (Lewicki \& Litterer, 1985; Tamara Pearson d'Estrée, 2003; Sabatier, et al., 2005; Susskind \& Cruikshank, 2006). It is important to think of how collaboration processes are conducted if we are to work through community dilemmas. When groups better understand what individuals really care about, it can build coherence in a process. How can project managers help participants contribute effectively?

\subsection{Characterizing Successful Collaboration}

How do we know if a collaborative process is "successful"?

Researchers report that positive outcomes are possible from collaborative processes. These outcomes include trust built between stakeholders and 
agencies; programs and plans that meld societal and ecosystem perspectives

(Golet, Roberts, Luster, \& Werner, 2006); increases in scientific knowledge about the natural environment (Brogden, 2003); access to critical data and creative decision-making (Ozawa, 1991); and gains in social and political capital through relationship building (Connick \& Innes, 2001; Innes \& Booher, 2003; Leach \& Sabatier, 2003).

\section{Coughlin and colleagues (1999) identified four core elements of} successful collaborative outcomes. Pearson d'Estree and Colby's (2000) survey of the environmental conflict resolution field resulted in six general categories of outcome success for consensus building processes. These two sets of categories are listed in table 1 . Combining these lists, we see that in Table 1 Characteristics of successful multi-party collaborative and consensus-building processes

\begin{tabular}{|c|c|}
\hline Coughlin et al. 1999 & Pearson d'Estree and Colby 2000 \\
\hline 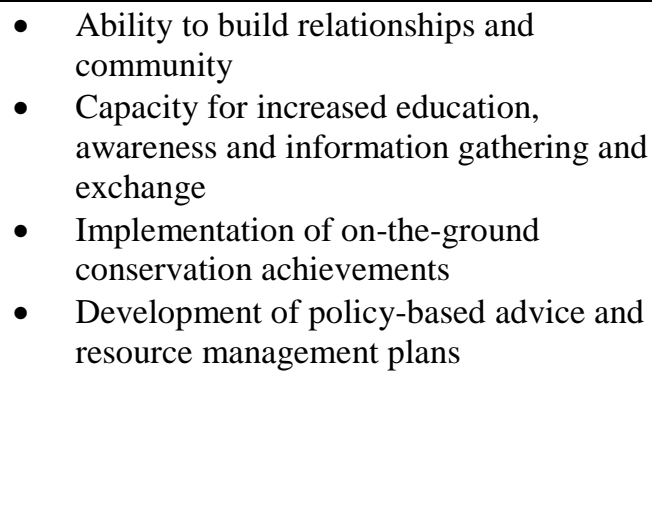 & 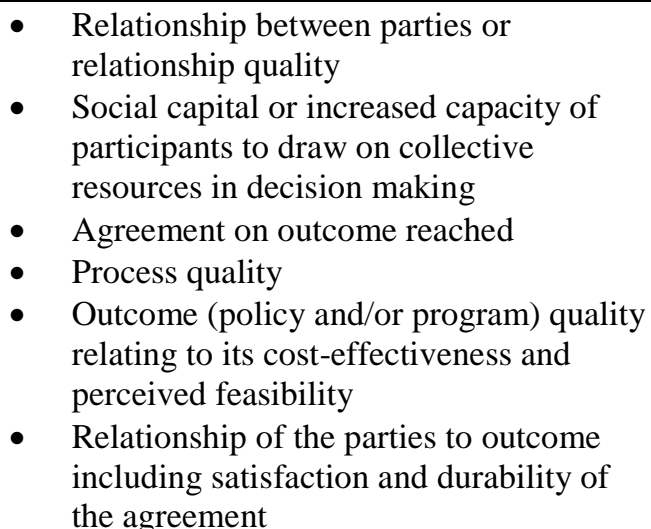 \\
\hline
\end{tabular}

addition to relationships, the capacity for collaborators to make decisions, come to agreement and implement these agreements is important. Five outcomes are used here in considering a collaborative project's relative success. 
1. Process Structure \& Maintenance: Diverse participants stay engaged, includes adequate representation.

2. Relationships: Relationships are built, includes trust and commitment.

3. Decision-Making Capacity: Participants have the capacity to learn, gather and exchange information enabling them to develop options and decide.

4. Agreement: Participants can reach broad agreement or a series of agreements; agreements are durable.

5. Policy or Program Implementation: The group is able to move beyond agreement to implementation.

Given that multi-party collaborations must contend with differences in perceptions, objectives, cultures, values, information and issues how do groups attain successful outcomes? In a meta-analysis of watershed partnerships, the most frequently recurring themes to success are 1) adequate funding, 2) effective leadership and management, 3) interpersonal trust, and 4) committed participants (Leach \& Pelkey, 2001). Beyond these four, evidence suggests facilitation techniques from conflict resolution are also a contributing factor to success (Leach \& Pelkey, 2001). Do facilitation techniques help groups focus on interests? Does focusing on interests help participants improve their decision-making capacity? Is the practice of identifying and addressing interests a component of leadership? When collaborators address each other's interests does this help build trust and participant commitment? This research begins to examine these questions.

\subsection{Research Questions}

Instead of successful collaborations occurring unpredictably, or by accident, collaborative project managers seek to design intentional, deliberate 
processes. Despite extensive data on the role of interests in the conflict resolution and consensus-building fields, interests are relatively unexamined in empirical multi-party collaboration research. Specifically, minimal research exists on the interactive dynamic of how interests are managed and addressed in collaborative processes. This is a potential problem because uncovering and addressing interests, and the facilitation techniques used to do so, may be a foundation for managing conflict, building decision-making capacity, and strengthening collaborative practice.

Can relationships and decision-making capacity be improved by explicitly discussing participant interests? How does a collaborative process work to ensure all participants' interests are discovered and addressed? Are only the substantive interests, such as degree of air quality improvement important to the agreement? Beyond funding, how can the process support members and leaders moving from problem identification through agreement into implementation? This research begins addressing these questions by highlighting how different successful multi-party groups discuss interests as part of problem solving within each collaborative process.

This research explores the role of interests in five multi-party, facilitated, agreement-seeking, collaborative projects focused on community issues that impact social, economic, and environmental outcomes. Collaborative project staff had facilitation training, an element attributed to successful environmental conflict resolution (Leach \& Sabatier, 2003). 
Specifically, the research explores the role that interests play in group identification and solving of problems; it seeks to understand how facilitated social process techniques are used to identify interests; and the project examines how collaborative groups work to address these interests. This research aims to reveal how discussing and addressing participant interests can benefit participants in multi-party collaborative processes. The research answers the following questions.

1. Are interests being identified and generated in collaborative processes?

2. How does managing people and process influence discussion of party's interests?

3. How does discussing interests influence the collaborative processes (e.g. problem conception, resource allocation, commitments, and implementation of agreements)?

4. How do groups address interests?

In order to answer these questions, it is assumed that discussing interests is related to communication methods or facilitation techniques. Interests and facilitation are examined together as interrelated variables.

This chapter introduced the concepts of interests, facilitation, negotiation, and collaborative processes; these are explored further in the next chapter's literature review. The main objective of the Chapter Two is to reveal how negotiation theory is applicable to multi-party collaborative processes. Further, the chapter describes types of interests as well as the facilitation methods that can be used to identify interests. Such techniques may support 
interests being an explicit part of collaborative discussions. The research propositions are presented at the end of Chapter Two.

The research design and methods are described in Chapter Three. The five cases are related to one another through fragmentation type. Case selection criteria are reviewed as well as data collection instruments and analyses.

The cases are introduced and analyzed in Chapter Four; this chapter contains the case findings. Each case narrative presents the history and dynamics of the collaborative process. The case analyses are centered on the research questions. A figure in each case provides a visual map of how different core interests were addressed through the collaborative process.

Chapter Five compares and contrasts the cases based on the research questions. Survey results at the end of the chapter reveal how researcheridentified themes were supported by survey responses.

Chapter Six discusses the findings on interests, the methods for discussing interests, and the impact of discussing interests on different stages of each collaborative process. This chapter also discusses the implications of the findings for collaborative practice.

The paper concludes with Chapter Seven at which point questions raised in the Introduction are revisited. New questions are also posed along with relevant limitations, alternative explanations for the research findings, and suggested future research. 


\section{CHAPTER TWO}

How selfish soever man may be supposed, there are evidently some principles in his nature, which interest him in the fortunes of others, and render their happiness necessary to him, though he derives nothing from it, except the pleasure of seeing it.

Adam Smith, The Theory of Moral Sentiments 1759

\section{$\underline{2 \text { Literature Review }}$}

\subsection{Interests and Conflict}

A conflict exists whenever an underlying disagreement divides two or more parties and incompatible activities occur (Burgess \& Burgess, 1997;

Deutsch, 1973). One party's action is incompatible with another party's action when it prevents, obstructs, interferes or in some way makes the latter less likely or less effective (Deutsch, 1973). In this dissertation, the term 'conflict' means that a difference exists.

Daniels and Walker's (2001) review of multiple theorists' definition of the term "conflict" conclude that conflict situations generally involve eight core elements, sorted into categories below:

- Interdependent parties

- Interaction; communication

- Decision-making or judgment
- Perceived incompatibility among parties

- Differing interests goals, aspirations
- Incentives to cooperate and compete

- Bargaining/negotiation

- Strategy/strategic

behavior

We can see from these categories that negotiation, communication, and interests are fundamental elements for moving through differences. 
The broad definition of interests introduced in the previous chapter is: the underlying desires, fears, principles, concerns, needs, or what a party seeks to achieve within a negotiation beyond reaching an agreement (Fisher, et al., 1991; D. M. Kolb \& Williams, 2003; Lax \& Sebenius, 1986, 2006). This definition makes a distinction between interests and human values. "Values," again, are beliefs that shape a party's position on an issue (Wehr, 1979).

Wehr (1979) explains that conflict arises based on a combination of four factors: facts, a disagreement over what is because of perceptions; values, a disagreement over what should be; interests, a disagreement over who will get what among scarce resources such as power, prestige, money, respect; and 'non-realistic' factors other than the first three such as personality, communication style, or history see figure 1 (p. 20).

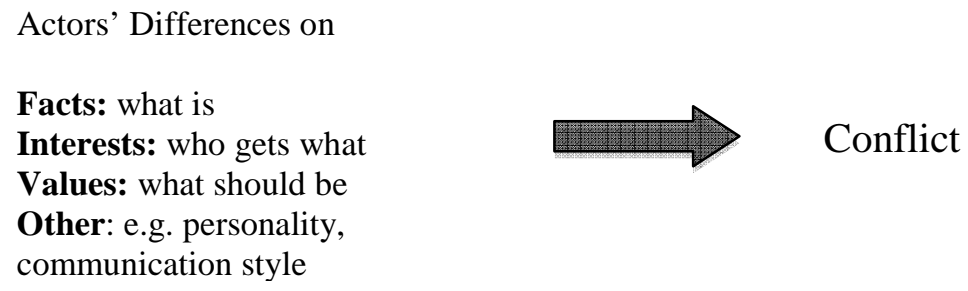

Figure 1. Sources of conflict (Wehr 1979).

This research focuses primarily on interests in conflicts. Wehr (1979) contends that all conflict includes elements of each factor and one is usually the main focus. Theorists argue that value-based conflicts are more difficult to address than interest-based or fact-based conflicts (Susskind, et al., 1999a). In a value-based conflict each side's perception of fairness and feeling of sympathy occurs through its unique value lens. People want what they value 
for everyone - thus may try to impose their values out of concern for what they believe is best for the other side (Susskind, et al., 1999a) which leads to positional wrangling. Note this research also uses the term 'value' to describe measuring worth in a negotiation.

\subsubsection{Types of Interests}

Issues involve different types of interests. Participants may have interests about goals, substantive issues, information, relationships, resources, principles, and the process of how work is accomplished (Burgess \& Burgess, 1997; Follett, 1940; D. M. Kolb \& Williams, 2003; Lax \& Sebenius, 1986; Pruitt \& Carnevale, 1993; Wehr, 1979). People and organizations have both tangible and intangible interests in these same elements. Negotiators' interests go beyond the obvious; self-esteem, feeling respected, and maintaining "face"

often are latent interests in a negotiation (Lax \& Sebenius, 1986). The ability to discuss substantive interests also requires that relationship concerns are being addressed - namely that trust is established among participants (Pruitt, 1981; Wall, 1977).

An interest in an issue is instrumental if favorable terms on the issue affect subsequent dealings on this particular issue. An interest is intrinsic if one values the favorable terms on the issue independent of future dealings, and potentially independent of the specific issue (Lax \& Sebenius, 1986). These interests may not have an obvious or agreed-upon economic value. Lax and Sebenius (1986) differentiate between instrumental and intrinsic interests 
because this can shed light on three fundamental sets of interests: problem, process, and relationships. Interest types are helpful when negotiators seek to unbundle differences in order to create value in a negotiation (Lax and Sebenius 1986). Distinguishing among tangible and intangible interests can also help increase awareness of interests that are important even if they are not obvious.

Problem-based interests are related to tangible or material resources such as money, type of fuel used, or amount of wetlands conserved. Process interests relate to intangible principles of how the negotiation is conducted such as equity and time efficiency. Relationship interests include principles of trust, respect and equity (Lax \& Sebenius, 1986). Note that participants may have relationship concerns connected to process concerns such as a desire for respectful communication. Some negotiators have an interest in a cooperative, respectful negotiating process rather than feeling threatened or verbally abused - although the end agreement may be the same (D. M. Kolb \& Williams, 2003; Lax \& Sebenius, 1986).

Collaboration behavior is related to relationships. Kolb and Williams (2003) introduced the concept of the shadow negotiation, or the relationships of individuals at the table and the power they have, as being fundamental to identifying hidden barriers and opportunities to negotiation. Negotiators often stress the value of their relationships - there can be an intrinsic interest in developing a good relationship (Bush \& Folger, 2005; D. M. Kolb \& Williams, 
2003; Lax \& Sebenius, 1986). Behaviors that cause a perceived loss of selfesteem or face can threaten an entire negotiation. In summary, both tangible and intangible interests in the process, relationships, and the substantive problem should be taken into account in negotiations.

Readers should note that the word "interests" is used loosely in collaborative texts as a noun describing advocacy groups with a narrow focus, or "communities of interest." Communities of interest differ from communities of place or communities of identity in that their commonalities lie in the benefits they receive from natural resources (Wondolleck \& Yaffee, 2000). Each group has a stake in community issues. Such groups often take competitive, win-lose positions. This evolution of the term interests may have disconnected it from its original use - and its potential. This research focuses on the underlying concerns and desires of such advocacy groups.

\subsubsection{Interests as a Context for Problem Solving in Negotiation}

Interests are a foundation for problem solving. Like a set of Russian nesting dolls, interests are packaged in actor's positions on issues, embedded within negotiations, and encompassed in collaborative processes. In her seminal work, Creative Experience, Mary Follett (1924) articulates a theory of integration that is part of the basis for later negotiation theorists' work. The essence of integration is creating new options, based on actors' interests, to resolve a difference. Rather than either person giving in, new possibilities are 
created from the substance of what people care about in order to address divergent party's interests.

When differing interests meet, they need not oppose but only confront each other. The confronting of interests may result in either one of four things: (1) voluntary submission of one side; (2) struggle and the victory of one side over the other; (3) compromise; or (4) integration ...the best way out is when someone invents something new... which unites the desires of both sides... Integration might be considered a qualitative adjustment, compromise a quantitative one. In the former there is a change in the ideas and their action tendencies; in the latter there is mere barter of opposed "rights of way" (Follett, 1924).

Note that integration, or merging compatible interests, requires a change in negotiators' ideas or perspectives.

Since Follett's writings, the practice of inventing new options based on integrative or interest-based negotiation has become an established method in the conflict resolution field. Theorists posit that interests, as a factor in conflict, are the basis for negotiation (Fisher, et al., 1991; Lax \& Sebenius, 1986; Pruitt, 1981; Pruitt \& Lewis, 1975; Raiffa, et al., 2002). Further, interests are the source of substantive information for creative joint-problem solving; 'the measure of negotiation' according to Lax and Sebenius (1986). This status is based on empirical (Pruitt, 1981; Pruitt, 1983; Pruitt \& Lewis, 1975), normative (Colosi, 1983; Fisher, et al., 1991; Lax \& Sebenius, 1986, 2006; Lewicki \& Litterer, 1985; Walton \& McKersie, 1965) and descriptive (Raiffa, 1982, 1983; Raiffa, et al., 2002; Susskind, et al., 1999a) accounts of interestbased bargaining's utility. Much of the experimental work is focused on two- 
party interactions in experiments on college undergraduates (Pruitt \& Lewis, 1975; Pruitt, 1981; Pruitt, 1983). The descriptive accounts include multi-party scenarios.

Negotiation is an "interactive communication process by which two or more parties who lack identical interests attempt to find a way to coordinate their behavior or allocate scarce resources in a way that will make them better off than they could be if they were to act alone" (Docherty \& Campbell, 2004). The field of Alternative Dispute Resolution (ADR) encompasses all forms of resolving disputes outside court-based adjudication. There are 44 different models of conflict, negotiation, and third party processes (Lewicki, Weiss, \& Lewin, 1992). This research's focus is on integrative and distributive negotiation and draws on conflict resolution, consensus-building, and negotiation literature. We bargain, or negotiate, when

1) there is a conflict of interest between two or more parties,

2) there is no fixed set of rules or procedures for resolving the conflict or parties prefer to work outside a set of rules (e.g. a courtroom), and

3) the parties prefer to search for an agreement rather than fight, capitulate, break contact or defer to a higher authority for resolution (Lewicki \& Litterer, 1985).

Negotiation is a choice. Negotiators are interdependent actors with a set of alternatives available to them also known as a BATNA (best alternative to a negotiated agreement-cite). Distributive (win-lose, positional, competitive) and integrative bargaining (win-win, interest-based, cooperative), are negotiation approaches commonly described to managers (Lax \& Sebenius, 1986; Lewicki 
\& Litterer, 1985). Before exploring how these strategies are used in collaboration, it is important to first examine the bargaining landscape.

In figure 2, the potential for bargaining is depicted in the bargaining set, or bargaining range. This figure reveals the point of origin, zero, or the convergence of the vertical and horizontal axes as representing no agreement. At the beginning of any negotiation, the parties do not know what is possible, or where the frontier lies. Both parties have alternatives beyond a negotiated

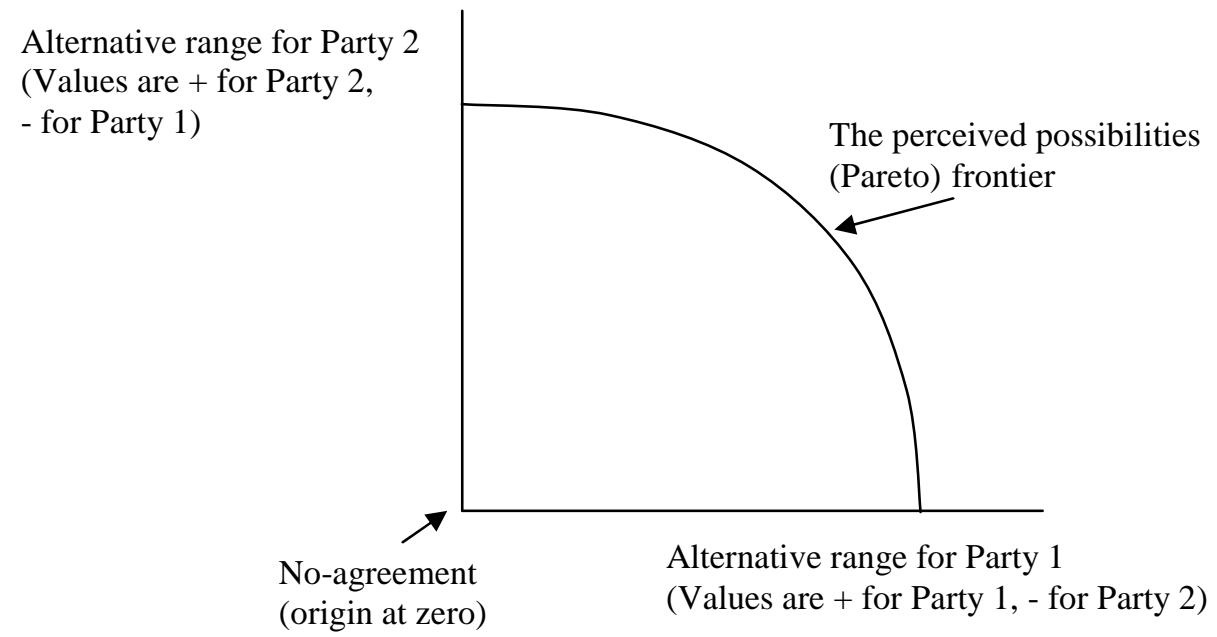

Figure 2. The Bargaining Set (Lax and Sebenius 1986, p. 248). (Alternative ranges for Party 1 and Party 2 assume that both seek to do better than their BATNAs. Moving NE permits both to maximize positive, and minimize negative, values). agreement. Their joint problem is to invent a means to move northeast, and create value (Lax \& Sebenius, 1986). How they move, or the bargaining strategy they take, influences their individual problems of where they end up on the frontier, or how much value they can claim (Lax \& Sebenius, 1986). Notice if Party 1 claims value mostly along the eastern axis, this minimizes 
value for Party 2. The same is true in reverse for Party 2 moving north on the vertical axis.

Distributive bargaining is a method used to reach a settlement that involves a positive bargaining range. The goal in distributive bargaining is to get the most for oneself, with little concern for the outcome of the other. In this framework, each person sticks to their position, and bases concessions on starting, target, and resistance points within a zone of potential agreement (Lewicki \& Litterer, 1985). Parties conceal information and use it strategically as each party wants to maximize their share of the resources (Lewicki \& Litterer, 1985). Distributive bargainers focus on only claiming value. Claiming value can have an adversarial approach: "We are dividing a pie of fixed size and every slice I give to you is a slice I do not get; thus, I need to claim as much of the value as possible by giving you as little as possible" (Lax \& Sebenius, 1986). Distributive bargaining may be appropriate when relationships between parties are short-term, the agreement is a "one-shot" deal, or it is possible to focus on a single issue at a time (e.g. not a "package" deal).

Implied in the figure 2, changing alternatives causes the origin of the axes to shift, impacting what each party gets. When issues change or other aspects of the situation vary, each participant's perception of the bargaining set is transformed (Lax \& Sebenius, 1986). Because interests are so fundamental to conflict, theorists in the dispute resolution field recommend discussing 
different parties' interests and communicating differences as part of any negotiation and agreement-seeking process (Carpenter \& Kennedy, 1988;

Elliott, 1999; Fisher, et al., 1991; D. M. Kolb \& Williams, 2003; Lax \&

Sebenius, 1986).

Table 2 Distributive and integrative bargaining elements (adapted from Daniels \& Walker, 2001).

\begin{tabular}{|c|c|c|}
\hline Feature & Distributive Bargaining & Integrative Bargaining \\
\hline Party's goals & $\begin{array}{l}\text { Win-lose, maximize own share } \\
\text { of benefits (individual gain) }\end{array}$ & $\begin{array}{l}\text { Win-win, increase benefits for all } \\
\text { sides (mutual gain) }\end{array}$ \\
\hline Motivation & Self-interest & Mutual interest \\
\hline $\begin{array}{l}\text { Resource } \\
\text { perception }\end{array}$ & Fixed and limited & $\begin{array}{l}\text { Focus is on how to utilize resources } \\
\text { creatively }\end{array}$ \\
\hline Information & Limited or no disclosure & Shared \\
\hline Communication & $\begin{array}{l}\text { Controlled, selective, purposeful, } \\
\text { tactical }\end{array}$ & Open \\
\hline $\begin{array}{l}\text { Relationship } \\
\text { worth }\end{array}$ & Minimal, present focus & High, future-oriented \\
\hline $\begin{array}{l}\text { Relationship } \\
\text { perception }\end{array}$ & Adversary, opponent, competitor & Collaborator, partner \\
\hline Trust & Limited, guarded & High, requiring reinforcement \\
\hline $\begin{array}{l}\text { Bargaining } \\
\text { Strategy }\end{array}$ & $\begin{array}{l}\text { Maximize share of outcomes, } \\
\text { focus on opponent's position. } \\
\text { Tactics are focused on zone of } \\
\text { potential agreement framed } \\
\text { around target points, resistance } \\
\text { points, anchoring points and a } \\
\text { settlement range. }\end{array}$ & $\begin{array}{l}\text { Problem solving focus on participant } \\
\text { interests. Zone of potential } \\
\text { agreement is widened and diversified } \\
\text { through information sharing. }\end{array}$ \\
\hline
\end{tabular}

Integrative bargaining involves parties being inventive and cooperative

enough that an agreement yields gain to each party, relative to no-agreement

possibilities (Lax \& Sebenius, 1986). See table 2 for differences between

distributive and integrative bargaining. Integrative bargaining is focused on

communication, sharing information, and joint fact-finding to help each party 
understand the other's objectives, and open the view of what is possible.

Integrative bargainers create value. Parties treat the negotiation as a joint

problem; they employ techniques to probe beneath demands or positions for

underlying interests.

Problem solving examples that illustrate reconciling divergent interests range from the mundane to the sophisticated. In an illustrated example below, each member of a couple has different positions about the issue of lawn care and its related sub-issue of pesticide use (table 3a). The two may choose to stick with their positions and engage in distributive tactics.

Table 3a Example of a disagreement

Issue: Pesticide use
Related Issues: lawn care, chemicals, timing of application, weeds
$\begin{array}{ll}\text { Jane's Position: No! } & \text { Tom's Position: Yes! } \\ \text { I don't want any chemicals. } & \text { I want to get rid of the moss and the } \\ & \text { dandelions. }\end{array}$

In table $3 \mathrm{~b}$ Jane and Tom begin to reveal their underlying concerns beyond the stands they've taken. Discussing interests in turn reveals related issues and facts. They both want a "nice" yard although Tom is assuming this means a lawn when Jane would like more landscaping. They both want to shift yard care responsibilities: Tom wants less and Jane wants to be more active. They also have more information about substantive interest, e.g. concern over animal habitat and stream health. Now they have the opportunity to create value in the negotiation. They have options to landscape differently that require less chemicals; they can use non-toxic pest alternatives; and they can also explore 
using less toxic chemicals with short half-lives that will not poison birds or

fish.

Table $3 \mathrm{~b}$ Example of the relationship among issues, interests and positions

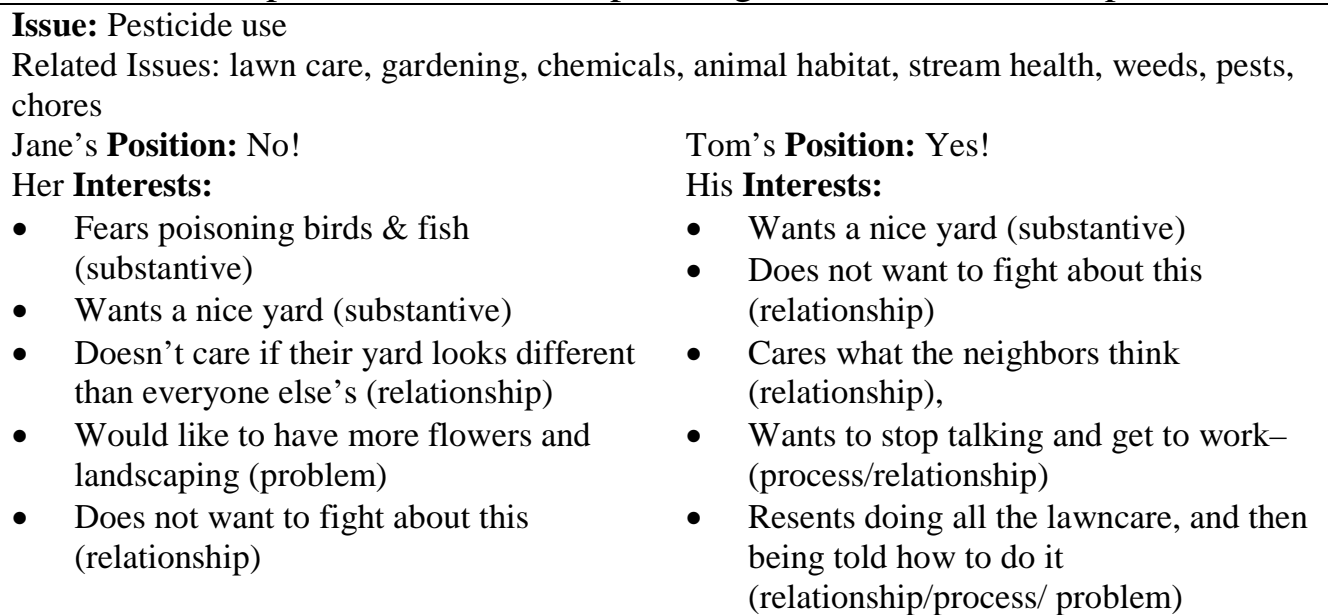

Roger Fisher and colleagues (1991) give a more sophisticated example of the difficult Egyptian-Israeli conflict over where to draw a boundary in the Sinai. Egypt and Israel both maintained positions about where to place the line. For years, the negotiations proceeded inconclusively: each square mile lost to one party was to be the other party's gain. The problem seemed to be ownership of territory with two countries fighting over the boundary. After probing for interests, negotiators learned that Egypt really cared about sovereignty while Israel was concerned with its security. Egypt's view of the problem is that the world needs to recognize its sovereign status. Israel needed to feel that its borders were secure. Negotiators unbundled these interests to craft a creative solution. In the Sinai, this involved creating a demilitarized zone under the Egyptian flag: the zone aided in security, and the flag highlighted Egyptian sovereignty. 
These examples illustrate how interests act as fuel for creative problem solving in negotiation. Creating value can serve two functions: 1) it is part of crafting an agreement that is more satisfactory to all participants, and 2) it can reduce potential conflict within bargaining processes (Lewicki \& Litterer, 1985; Lewicki, et al., 1992). Negotiation theorists claim that going beyond position-based bargaining to interests-based negotiation contributes to fair, wise and efficient agreements (Fisher, et al., 1991; Follett, 1940; Susskind \& Cruikshank, 2006).

The image of using either distributive or integrative bargaining in a negotiation is incomplete. People may use both strategies at different times on the same issue, with the same parties, for different reasons. Thomas Schelling (1960) introduced this blend of cooperative and competitive behavior as mixed-motive conflict. However, in the economic perspective parties are motivated to compete for a better agreement and concede to reach compromise. Lax and Sebenius (1986) stress that value creating and value claiming are linked and both processes are always present. "No matter how much creative problem solving enlarges the pie, it must still be divided; value that has been created must be claimed. And if the pie is not enlarged, there will be less to divide; there is more value to be claimed if one has helped create it first" (Lax \& Sebenius, 1986). Pruitt (1981) notes that creative problem solving cannot occur if one party is yielding. Yielding behavior just encourages the other party to take a firmer position. Lax and Sebenius shift the 
focus to enlarging the pie through discussing interests and joint information sharing. Pruitt (1981) suggests that in order to generate value for good problem solving, there has to be both trust and firmness (Wall, 1977).

Follett acknowledges that differences will always pose challenges and that not all of them can be integrated. She contends that there are fewer irreconcilable activities than we think, although it often takes "ingenuity, a 'creative intelligence,' to find integration (Follett, 1924)." The tough part of integration is teasing apart interests from issues and positions. Interests are connected to actors' understanding of the problem and potential methods for addressing it.

\subsection{Collaborative Behavior}

Creating and claiming value in negotiation is a microcosm of collaborative behavior. A theoretical debate has existed since at least the fourth and fifth centuries B.C. about the rationale and ability for human kind to act collectively and in favor of common goods such as maintaining political peace (Coleman, 1986; Gintis, Bowles, Boyd, \& Fehr, 2005; Mansbridge, 1990). The argument that all humans are self-interested is the basis for Adam Smith's economic theory, social contract theory, and rational choice theory positing that individuals always seek to maximize their benefits and minimize their costs. On the other side of the debate are social choice theory and public choice theory that posit humans are also concerned with issues beyond material interests such as the welfare of others, and how ones actions are perceived, that 
enable them to act as a collective (E. Ostrom, 1998; E. Ostrom, Gardner, \& Walker, 1994; E. Ostrom \& Ostrom, 1977).

The details of this debate are beyond the scope of this dissertation. It is important to note that there is rationale for acting competitively, and rationale for acting cooperatively: both impact one's interests. The oft-cited prisoner's dilemma, a subject of game theory, reveals a situation where acting in ones immediate self interest produces an outcome that makes both individuals worse off (Hofstadter, 1985; Mansbridge, 1990). In situations of extended prisoner's dilemma, the strategy that works best in game theory competition is using equivalent retaliation or tit-for-tat (Hofstadter, 1985). The player using this strategy acts cooperatively first, and then mirrors the behavior of their opponent so that cooperative behaviors are rewarded and competitive behaviors are punished. This extended play is a proxy for maintaining a longterm relationship. This relates to the utility of trust in cooperative relationships.

Ostrom (1998) suggests that cooperation develops out of core relationships that grow from each participant having a reputation of being trustworthy, acting so, and engaging in reciprocal ways that reinforce this reputation (see figure 3). She cites other research revealing, "a reputation for being trustworthy, or for using retribution against those who do not keep their agreements or keep up their fair share, becomes a valuable asset" (E. Ostrom, 1998). 
Negotiation theorists debate the need for trust in negotiation. One side argues that trust is fundamental for participants to reveal their interests; likewise mistrust inhibits collaboration (Deutsch, 1973; Lewicki \& Litterer, 1985; Pruitt, 1981). People who are mistrustful act defensively which can involve deception, hiding information, and less communication (Lewicki \& Litterer, 1985). Trust and respect are part of relationship and process interests as trust relates to how parties act toward one another and requires reinforcement.

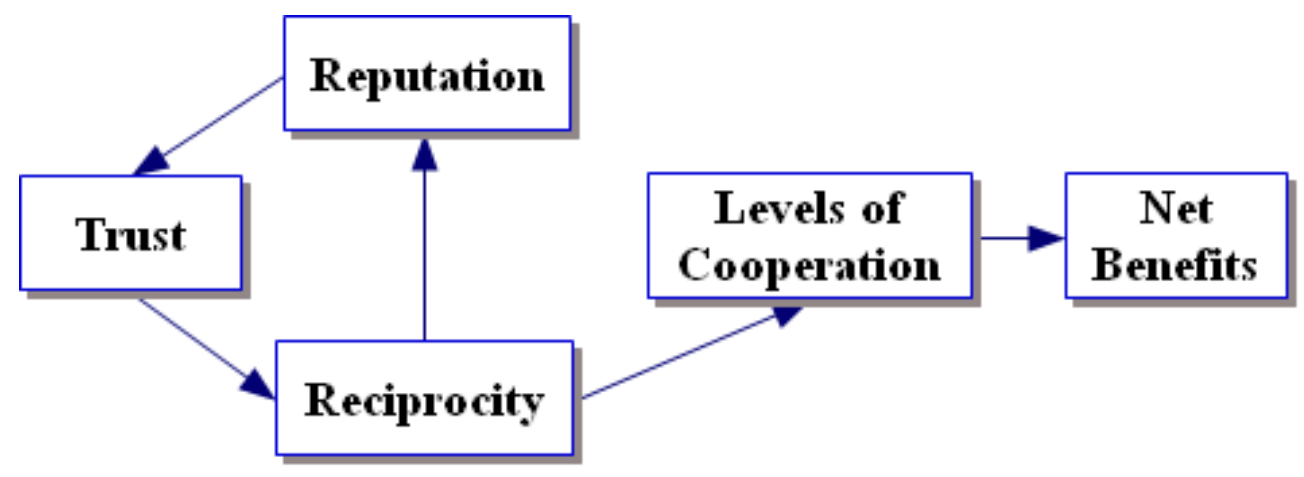

Figure 3. The Core Relationships. Applied to social dilemmas as an explanation for trusting behavior and cooperation (Ostrom, 1998, p. 13).

Other game theorists argue that empathetic trust is neither necessary, nor a guarantee for cooperation (Raiffa, et al., 2002). Instead, they cite repeated plays of the prisoner's dilemma, where two parties are engaged in interactions where both will have a higher gain over time if they cooperate (without communicating with each other) than if they defect. This is operational trust, meaning that they act in a trustworthy fashion whether or not they like each other. Collaborators may have a relationship interest in feeling 
parties are trustworthy, and this is also a component that helps participants feel comfortable sharing substantive interests. However, trust is not a guarantee that participants will engage in integrative problem solving.

Participants may not always engage in trusting, or trustworthy ways which can impact the process. Killman and Thomas (1977) found in their research that people use two personality dimensions when negotiating: assertiveness in maintaining preferred solutions or outcomes, and cooperativeness shown toward another to achieve collective goals. The dual concern model also based on empirical research (Pruitt \& Rubin, 1986) posits similarly that participants will behave in certain ways, such as discussing problems or contending, based on concern about their own outcomes versus concern about another's outcomes (see figure 4).

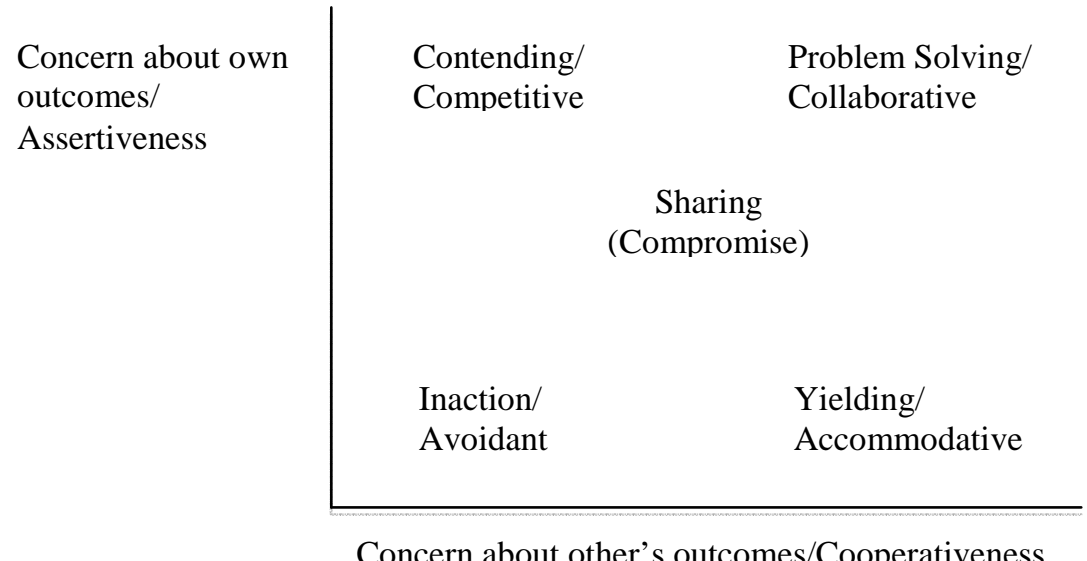

Figure 4. The Dual Concerns model (Pruitt and Rubin, 1986) and the KilmannThomas conflict orientations (1977).

The message is that people can be helpful or difficult when negotiating; and it is possible for individuals to behave in both ways. In distributive 
bargaining, people may engage in tactics such as starting with high demands, conceding slowly, exaggerating the value of concessions, minimizing the benefits of the other's concessions, arguing forcefully, retaliating, and using intimidation (Lax \& Sebenius, 1986). Susskind and Field (1996) describe "difficult" behaviors such as cutting people off, holding onto inflexible win-lose positions, competing for attention, grandstanding, invalidating other participant's concerns, being hyper-critical, attempting to sabotage the process, and using stalling tactics (Susskind \& Field, 1996). The result of these different negotiator personality types is that agreements can occur without identifying interests or conducting joint information searches to attain mutual gains. It may also be possible to encourage negotiators to act both assertively and cooperatively in order to attain collaborative, problem-solving behavior.

\subsubsection{Relationships and Trust}

Collaboration can move actors beyond one-sided strategies or tit-fortat exchanges. Negotiation theorists argue that relationship preconditions shape collaboration (D. M. Kolb \& Williams, 2003; Susskind \& Field, 1996). Collaboration implies a sharing, connection, and mutualism in approaching differences. Four factors that contribute to collaboration all focus on building trust in a relationship: connection, admitting fault and addressing the other side's perspective, encouraging stakeholder participation, and mutual exchanges (Kolb \& Williams 2003). 
Connection, a first precondition, occurs primarily within the shadow negotiation. This can take place the evening before an actual negotiation meeting where discussion is about families, friends, sports or other social topics. The connection establishes that people are in this process, not an actual enemy. This is true for organizations as well. Connection occurs when a spokesperson reaches out and says how moved she is for a family's loss on behalf of a potentially liable company. These meetings, or small communication pieces, also allow each party to get an emotional take on the other. At all times negotiators assess how willing the other person is to work with others, how aggressive they are, how self-interested, how yielding. The initial shadow negotiation elements are complex and have to do with building comfort among the parties. Trust, however, does not come only from connection.

Slovic (1999) notes that trust is asymmetrical, it is easy to lose and hard to gain. Trust is a person's expectation that other persons and institutions in social relationships "can be relied upon to act in ways that are competent, predictable, and caring" (Kasperson, Golding, \& Kasperson, 1999). Kasperson and colleagues (1999) argue that social trust cannot be completely or permanently attained, in fact should not be, "it must be continuously maintained and reinforced through networks of civic engagement and norms of reciprocity". Norms of reciprocity and trust also help build social capital. 
Social capital is a property that exists with individuals, through their relationships, and becomes a community-level variable based on participation in collective networks. Multi-party collaboration processes can become social networks, and positively impact community social capital. The idea of social capital is that available resources (capital) accrue to people by virtue of their mutual acquaintance and recognition (social) that can be used for a variety of productive activities (Bourdieu, 1985; Coleman, 1990). Bourdieu's definition of social capital, seen as the most theoretically refined by Portes (1998) and Sobel (2002), is "the aggregate of the actual or potential resources which are linked to possession of a durable network of more or less institutionalized relationships of mutual acquaintance and recognition" (Bourdieu, 1985, p. 248). Bourdieu emphasized that social capital is a means to access economic capital including loans, cultural capital including norms of behavior, or institutionalized cultural capital (e.g. political capital) as in reputation (Portes, 1998).

Kasperson and colleagues (1999) explain that in an engaged society, voluntary cooperation is easier to attain because social cooperation can promote civic ends that would otherwise be impossible. They use an example of farmers working together to raise a barn, putting social capital to work through sharing resources, effort, and knowledge. In this example, the barn raising can be considered a problem, and the group coordinates - and cooperates, to build it. Trust is an essential component of social capital, and of 
attaining wise, efficient and fair collaborative agreements. But how do you get to that point? What prevents farmer A from feeling like farmer B is going to take all of his tools? We will return to these questions later.

\subsubsection{Characterizing Collaboration}

Collaborative arrangement types are numerous and diverse. Terms for collaboration include inter-organizational relationship, collaborative planning, collaborative resource management, partnership, joint venture, collective action, consensus-building processes, coalition, joint working, consortiums, strategic alliance, association, networks, councils, taskforces, participatory and multi-party. This is not an exhaustive list. In the business sector, collaborative arrangements are also called change projects, or those intended to implement significant changes in the way an organization works (Boddy \& Macbeth, 2000). These terms are often used indiscriminately in literature to describe multiple individuals' or organizations' involvement in a group decision-making process.

In this research, Barbara Gray's (1985) definition of collaboration as “1) the pooling of appreciations and/or tangible resources, 2) by two or more stakeholders, 3) to solve a set of problems which neither can solve individually" is used as a guideline (p.2). The feature "two or more stakeholders" implies multiple parties from different sectors, such as government and businesses. The act of problem solving is assumed to involve the mutual engagement and shared effort of the participants. Parties' 
interdependence is assumed. Cooperation is implied in this definition and involves individuals working together where no one participating actor has the power to command the behavior of the others (e.g. non-hierarchical).

Coordination is also implied and refers to the efficiencies gained from harnessing disparate resources, goals, and efforts.

Multi-party collaborative processes involve groups working together collectively to reach and implement agreements. A key feature of collaboration is engaging participants with a stake in the problem that have the necessary information to foster understanding of the problem and the resources to address it (Gray, 1989; Lax \& Sebenius, 2006). Many collaborative undertakings work to reach consensus. Consensus refers to the status of agreement among stakeholders on a decision. McKearnan and Fairman (1999) define consensus building as a process seeking unanimous agreement among all participating stakeholders. Consensus has been reached when everyone agrees they can live with whatever is proposed after every effort has been made to meet the interests of all stakeholders (Susskind, et al., 1999b). Consensus is not implied in Gray's definition of collaboration. It is assumed collaborative groups work to achieve broad agreement among participants and that they move forward on an agreement despite one or two dissenters.

Unlike much of the collaboration literature, the consensus-building literature begins with three assumptions. One, stakeholders in an agreement seeking process will generate conflict; two, this conflict must be managed in 
order to move through impasse and the strong emotions that come with it; and three, interests are the basis for negotiating a mutually beneficial agreement for all stakeholder groups (McKearnan \& Fairman, 1999). Exploring interests is the foundation for developing options that maximize joint gains. We will return to this in the section on collaboration models.

The collaborative process includes the dynamic occurring among parties as well as the procedure the group uses to move forward and attain their goals. The collaborative group is the body of decision makers. A fundamental assumption of this dissertation is that the process of collaborating involves a series of issues to be solved, a series of negotiations, and a series of agreements. Collaborating requires effective negotiating. A second assumption is that attending to participants' individual concerns are an important component of the procedures. Parties negotiate differences on substantive issues, perceptions on technical information, and difficulties with interpersonal relating. In short, collaborative groups work on the people, the problem, and the process.

\subsubsection{Collaboration and Community Capacity}

Collaboration has been shown to strengthen human, social and political capital elements highlighted for building community capacity (Connick \& Innes, 2001; Putnam, 2000). Collaborative processes create a possible venue for parties to negotiate what and how resources are directed toward addressing community problems. Community development practitioners work to aid 
communities in their ability to act collectively, a dimension of community capacity. In urban sociology, community capacity is defined as "the interaction of human capital, organizational resources, and social capital existing within a given community that can be leveraged to solve collective problems and improve or maintain the well-being of that community..." (Chaskin et al., 2001, p. 12). Community ${ }^{5}$ capacity has a set of fundamental characteristics (e.g., commitment, ability to solve problems, a sense of community) that operate through the agency of individuals and organizations that perform certain functions (e.g., planning, governance, information, organizing, and advocacy). There are particular strategies that promote community capacity. All of this occurs within a context, or the conditioning influences (e.g., patterns of migration, density, distribution of power and resources) that support or inhibit capacity, or attempts to build it (Chaskin et al., 2001). In sum, community capacity involves capable individuals who are motivated within a supportive context to act collectively. Ostrom (1996) posits that effective coordination between public agencies and the civil society - deemed co-production - is a feature of building capacity in communities. Multi-party collaborative processes involve stakeholder groups from the public, private, and not-forprofit sectors. From these definitions we can see that capacity is required to

\footnotetext{
${ }^{5}$ A community can be constituted by a geographic area, a set of relationships between its members, and/or economic (e.g., local markets), political (e.g., local legislation), or social (e.g., socialization, mutual support) parameters.
} 
collaborate, and the act of successfully collaborating can reinforce, or expand, community capacity.

Donaghue and Sturtevant (2007), social scientists working within the natural science field, deconstruct community capacity and resiliency explaining that the ability of a community to act rests on foundation and mobilizing assets (see figure 5). Assets are commonly understood as forms of capital, be it human, social, economic, or physical. Donaghue and Sturtevant (2007) argue that foundational assets include physical infrastructure, natural resources, and economic capital. Human, social, and political capital are forms of civic and organizational infrastructure known as mobilizing assets. These relational forms of capital are "the social processes and interaction that make up collective action" (Donaghue and Sturtevant, 2007, p. 908).

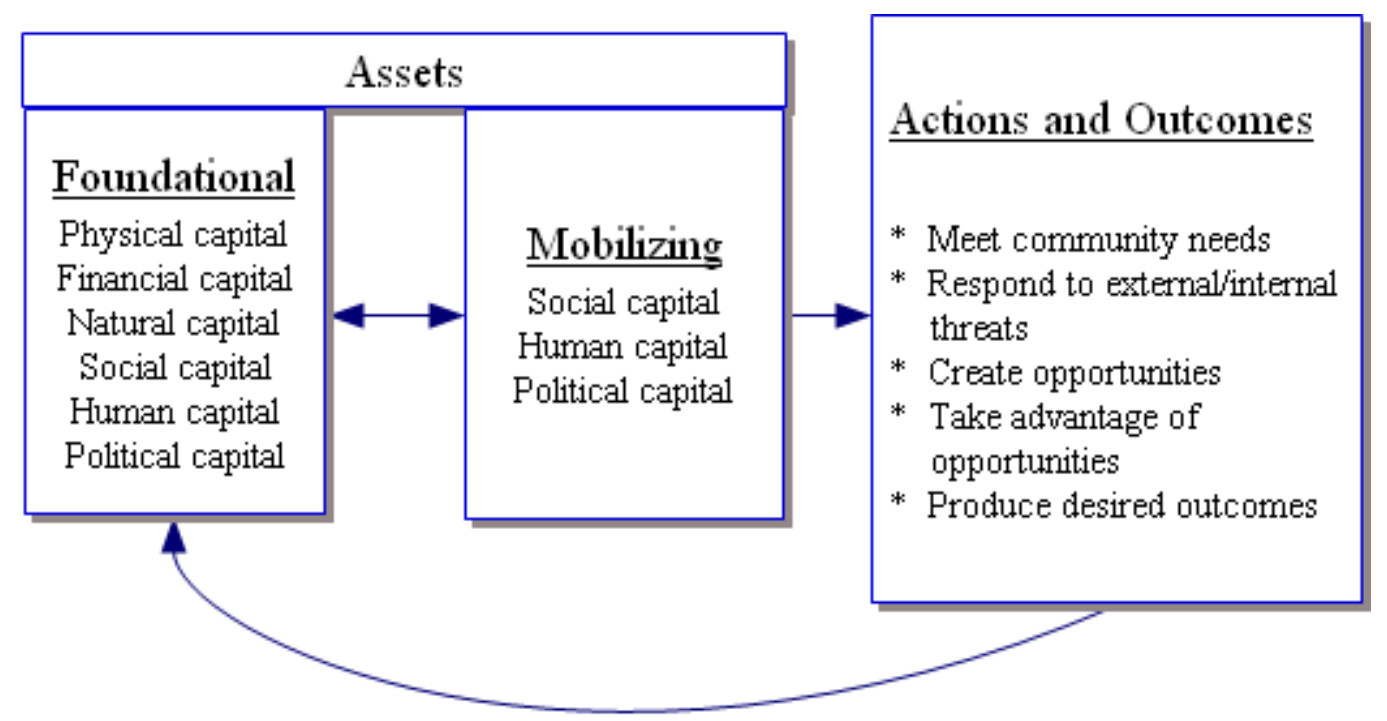

Figure 5. Elements of community capacity and community resiliency constructs (Donoghue and Sturtevant, 2007). 
Figure 5 depicts how each asset type relates to community action. Note that human, political and social capital fall into both foundational and mobilizing asset categories. In order to mobilize, a base of skills, political will, and relationships have to be established. Working relationships and skilled individuals have limited power, or reach, if physical, natural and economic resources are lacking. Achieving and maintaining a healthy community requires its members have the ability to handle problems as they arise to ensure economic, social, and political stability.

Theorists argue for a reintegration of lay knowledge into policy making to make it more responsive to public needs, change how problems are understood, and help remove barriers between professionals and citizens (Lindblom \& Cohen, 1979; Fischer, 2000). Challenges to citizen participation and using lay knowledge include the selection of individuals for involvement, insufficient public awareness of issues, and of practical political goals of participatory ventures' misalignment with theoretical equity and fairness goals (Ventriss \& Kuentzel, 2005; Laurian, 2003; Jason, 2006).

Multi-party collaborative processes address the argument of reintegrating lay knowledge with decision making and policy making. They are also situated in this challenge. When different stakeholder groups interact in order to use both lay knowledge and technical information to solve a problem, they encounter multiple differences in culture, understanding, and norms of behavior. These differences, in addition to challenges in addressing complex 
problems and the advanced scientific knowledge to do so, can inhibit

collaborative potential. These disruptive elements were introduced in the last chapter. We will revisit them later.

\subsubsection{Collaboration Models}

Models of collaboration are relevant in considering the procedures used to guide negotiation within a collaborative process. Different frameworks exist modeling collaborative processes (Julian, 1994; Margerum, 1999a; Moore \& Koontz, 2003; Selin \& Chavez, 1995; Thomson \& Perry, 2006). Theory from negotiation describing interests as being important in a few of these, although the frameworks do not recommend explicitly crafting processes with interests in mind (Gray, 1989; Ring \& Van de Ven, 1994; Wondolleck \& Yaffee, 2000).

Only the consensus-building framework expressly describes interests as a foundation in the stages of consensus building, connected to conflict and negotiation. Consensus building processes involve dispute systems design, where process managers design procedures around diagnosing conflict and using systematic interventions to promote conflict prevention or management (Elliot, 1999). McKearnan and Fairman (1999) describe four stages to developing consensus: preparing, creating value, and producing consensus. Exploring interests is the foundation for creating joint gains, part of the creating value stage. Conflict management is part of all three stages. 
Logsdon (1991) posits that organizations must assess both their interests and their interdependence with other organizations in order to know whether to collaborate. Other collaboration frameworks do not make the leap from harnessing resources to addressing conflict through negotiation. Collaborative practice will be aided by research directly connected to negotiation theory. Few researchers have explicitly explored how interests are addressed in collaboration.

Gray (1989) sites multiple models and scholars whose processes range from three to five steps; there is general agreement across these models about what it takes to get to the table, explore, reach, and implement an agreement. Gray's (1989) three-phase model of collaboration is used as a guideline in this research because the model focuses on joint problem solving and information seeking by participants, "to insure that their interests are represented" (p. 7).

These elements are also the basis for integrative bargaining.

Table 4 The collaborative process (Gray, 1989)

\begin{tabular}{|c|c|c|}
\hline 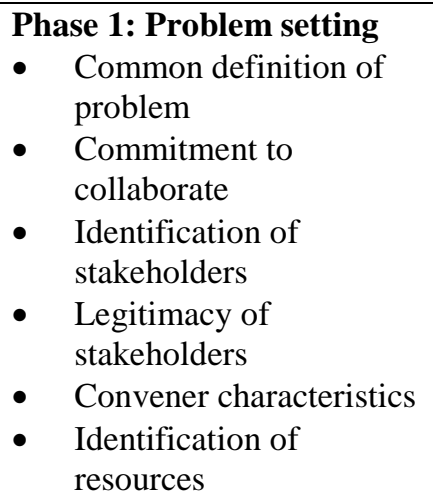 & 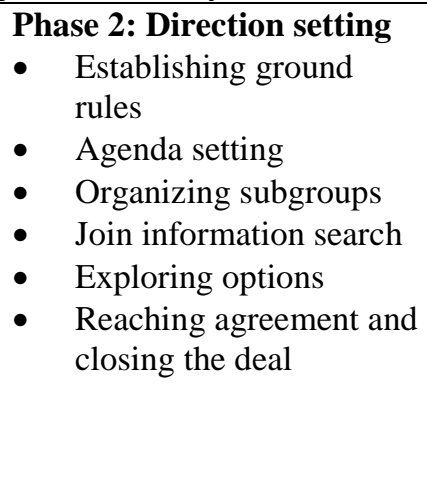 & $\begin{array}{l}\text { Phase 3: Implementation } \\
\text { - } \quad \text { Dealing with } \\
\text { - } \quad \text { Buildingtituencies } \\
\text { - } \quad \text { support } \\
\text { - } \quad \text { Moniternal } \\
\quad \text { agreement and ensuring } \\
\text { compliance }\end{array}$ \\
\hline
\end{tabular}


The three phases vary in length, significance, and difficulty based on the motivation to collaborate, intended outcome, and the strength of convening power. The three phases include problem setting, direction setting, and implementation. Each phase requires procedures and techniques to move through that phase (see table 4).

Ring and Van de Ven's (1994) process framework of the development of cooperative inter-organizational relationships in the private sector is useful because negotiation of joint expectations between the business process and the relationship process among parties is highlighted. The authors note "in the negotiation stage, the parties develop joint expectation about their motivations, possible investments, and perceived uncertainties of a business deal that they are exploring to undertake jointly" (p. 97). The authors explain that this stage is where formal bargaining, or haggling (e.g. distributive tactics) take place and where socio-psychological processes of sense-making, perceptions of trust, and understanding each other's roles are necessary (Ring \& Van de Ven, 1994).

Not all collaborative undertakings are created equal. Thomson and Perry (2006), in their review of collaboration in literature across disciplines, cite other scholars who conclude that cooperation and collaboration differ in "terms of their depth of interaction, integration, commitment, and complexity, with cooperation falling at the low end of the continuum and collaboration at the high end" (p. 23). Thomson and Perry (2006) conclude that true 
collaboration suggests a higher-order level of collective action than cooperation or coordination.

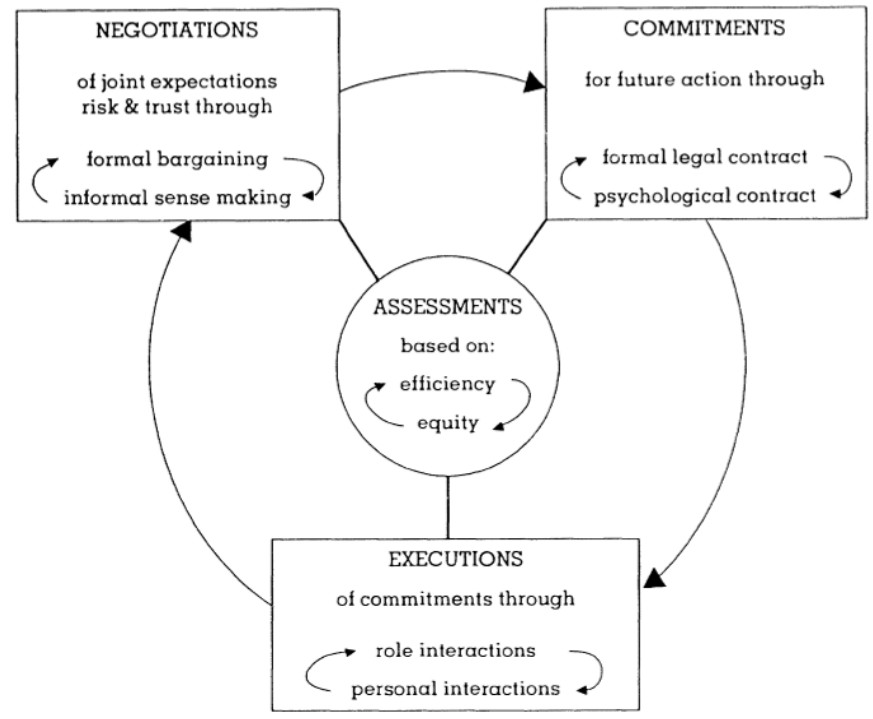

Figure 6. Iterative process framework for cooperative inter-organizational relationships (Ring and Van de Ven, 1994).

Collaboration researchers' describe a continuum of collaborative types based on level of integration. Integration in this context relates to the varying degrees and types of linkages that develop among organizations working together. The level of integration is determined by the intensity of the alliance's process, structure, and purpose (Gajda, 2004). Peterson (1991) argues that the continuum of interaction has three main points 1) cooperation, whereby fully independent parties share information that supports one another's organizational outcomes, 2) coordination, whereby independent parties align activities or co-sponsor events or services that support mutually beneficial goals, to 3) collaboration, where parties give up some degree of 
independence to realize a shared goal. Bailey and Koney (2000) add an additional point 4), coadunation where at least one party gives up its autonomy in an effort to strengthen the surviving organization (see figure 7).

Alternatively, the partnering entities may create a separate autonomous organization may to carry out the group's objectives. These terms are ambiguous; partners working together may exhibit characteristics of cooperation, coordination, and collaboration and use only one term to describe their alliance.

Figure 7. Defining strategic alliances across a continuum of integration (Bailey \& Koney, 2000; Hogue, 1993; N. L. Peterson, 1991) .

\begin{tabular}{|llll|}
$\begin{array}{l}\text { Shared } \\
\text { Information \& } \\
\text { Mutual Support }\end{array}$ & $\begin{array}{l}\text { Common Tasks } \\
\text { \& Compatible } \\
\text { Goals }\end{array}$ & $\begin{array}{l}\text { Integrated } \\
\text { Strategies \& } \\
\text { Collective } \\
\text { Purpose } \\
\downarrow\end{array}$ & $\begin{array}{l}\text { Unified Structure } \\
\text { \& Combined } \\
\text { Cultures }\end{array}$ \\
Cooperation & Coordination & Collaboration & Coadunation \\
\hline Low & \multicolumn{2}{c}{ Formal Integration } & High \\
\end{tabular}

\subsubsection{Forces of Disruption in Collaborative Processes}

In Chapter One we learned that collaborative participants may struggle with differences in missions, differences in understanding, conflicting roles, overlapping responsibilities and competing statutory objectives (Imperial, 2005; Poncelet, 2001). When people think of collaboration, they do not typically think about conflict. Differences can lead to conflict in a collaborative process that creates a barrier to progress. Collaborative processes 
can, and often do, fail in accomplishing their objectives.

Mattessich and Monsey's (1992) synthesis of collaborative literature identified six factors that contribute to successful collaboration:

1) supportive environment,

2) membership (includes adequate representation, trust, and commitment)

3) process structure (includes members with a stake in the process and multiple layers of decision-making)

4) open and frequent communication,

5) purpose that relates to concrete goals and a shared vision, and

6) resources (includes finances and a skilled convener).

In a more recent meta-analysis of watershed partnerships, the most frequently recurring themes to success are 1) adequate funding, 2) effective leadership and management, 3) interpersonal trust, and 4) committed participants (Leach \& Pelkey, 2001). Leach and Pelkey (2001) also suggest that findings from their review indicate facilitation techniques from conflict resolution are also a contributing factor to success, although the specifics are not described. Notice that both sets of findings emphasize relationships among participants (e.g. trust, commitment) and the process structure including leadership, representation, a skilled convener, decision-making, and shared goals. When collaborative processes lack these sets of elements, they do not do as well. Are there also barriers to developing these elements?

Forest Service managers and external partners (e.g. non-profit or business representatives) identified multiple barriers to collaboration in Carr 
and colleagues' 1996 and 1997 studies (1998). Both agency managers and external partners identified agency structure such as difficulties in line item funding, and cultural barriers such as different reward structures, as impeding collaboration (Carr, et al., 1998). Non-structural barriers identified by agency members include: personal agendas sidetracking the process; a perspective that external parties have little incentive as they can pursue the litigation route; and the political nature of the processes. Agency partners were motivated to collaborate based on their mandates and desire to avoid future legislative conflict.

In contrast, external partners felt that collaborative processes are too time-consuming and slow-moving in reaching agreement and implementation (Carr, et al., 1998). The partners felt agency personnel act conservatively in their decisions rather than risking being visionary. External partners are motivated to participate in collaboration, as this is the primary avenue for guiding agency decision making. Yet non-agency partners feel they have too little input. Such diverse perspectives reflect differences in parties' needs and interests in how the collaboration process unfolds.

This study revealed that both agency members and external partners perceive the other group as having little incentive to participate in collaboration. Both groups view the other as having potentially superior alternatives; and yet their objectives are interdependent. It is plausible that 
such participants may collaborate haphazardly and acquire understanding of how their interests relate only on accident.

Conklin (2006) asserts that collaborative processes can fail due to natural forces of fragmentation. Fragmentation is a phenomenon that pulls apart something which is potentially whole. This concept suggests a condition in which the people involved see themselves as more separate than united, and in which information and knowledge are scattered (Conklin, 2006). Rittel and Webber (1973) described societal problems as "tame" or "wicked" in their discussion of planning dilemmas. A tame problem is easy to define and a solution is easy to determine. A 'wicked' problem is one where stakeholders cannot agree on what the problem is, or how to resolve it (Rittel \& Webber, 1973). Conklin (2006) argues that wicked problems, technical complexity, and social complexity are major forces of fragmentation in collaborative processes. Revisiting the lists of factors of success (see table 5), we can see that they create the capacity of participants to manage fragmentation forces.

Table 5 Collaborative processes: success and fragmentation elements

\begin{tabular}{|ll|}
\hline \multicolumn{1}{|c|}{ Elements for Success } & \multicolumn{1}{c|}{ Fragmenting Forces } \\
\hline $\begin{array}{l}\text { Leadership/management } \\
\text { (environment, purpose, process } \\
\text { structure, communication) }\end{array}$ & $\begin{array}{l}\text { Social complexity (understanding } \\
\text { participant's stake in the outcome, culture, } \\
\text { norms, personalities) }\end{array}$ \\
$\begin{array}{l}\text { Resources (includes funding and a } \\
\text { skilled convener). }\end{array}$ & $\begin{array}{l}\text { Problem complexity (understanding the } \\
\text { central problem, sub-issues, options, } \\
\text { barriers) }\end{array}$ \\
$\begin{array}{l}\text { Membership (adequate representation, } \\
\text { trust, and commitment) }\end{array}$ & $\begin{array}{l}\text { Technical complexity (understanding of } \\
\text { facts, scientific information, use of } \\
\text { equipment) }\end{array}$ \\
\hline
\end{tabular}


Collaborative participants may be more likely to address each fragmentation source if they trust each other, have a skilled convener and/or leader, are committed to the process, there is a group goal and concrete objectives, members perceive having a stake in the process, and there is open communication. Other theorists argue that uncertainty and competing risks can disrupt collaboration. Salwasser (2004) maintains there will always be areas of uncertainty in any problem with which stakeholders have to contend.

Problems grow in complexity if they require technical knowledge to understand and address them. Environmental problems involve multiple factors that influence each problem area and objective. For example, addressing air pollution involves weather, a variety of pollution sources and types, gas levels in the atmosphere and cycles of these different gases. Technical complexity can also involve the number of technologies required in a problem and the rate of technological change (Conklin, 2006).

Two additional forces can disrupt collaboration that relate to problem complexity: uncertainty and competing risks. Uncertainty can take two forms (1) we do not know but can learn through observation or research, or (2) we cannot know until it occurs, such as the economic collapse (Salwasser, 2004). Salwasser (2004) maintains there will always be areas of uncertainty in any problem with which stakeholders have to contend. Competing, or conflicting risks, relates to problem objectives. For example a group has the objective to reduce wildfires and an objective to promote wildlife habitat; pursuing the 
short or long term objectives of either affects the potential risk of achieving the other (Salwasser, 2004). Collaboration processes dealing with wicked problems must contend with these additional elements.

Social complexity involves the number and diversity of parties. The more parties involved, and the more different those parties are from one another, the more layers of complexity and interpersonal difficulties (Conklin, 2006). Participants come from different organizations, or departments of the same organization with a variety of goals and objectives that may not be in alignment. Parties also have unique beliefs, ways of knowing, mindset, and negotiation styles that require navigation. Trust and commitment, mentioned earlier, are in the domain of social complexity. Parties have to trust one another, understand their roles, and be able to maintain their distinctive identities as common interests are built (Bardach, 1998).

If relationships are not fostered that deal with the psychological effect of a conflict on parties, namely voicing concerns and addressing them, a conflict worsens. Awareness of an issue goes from people taking sides, to positions forming, polarization, threats are incorporated into the issue, unrealistic goals are established, and new ideas are stalemated in a spiral of unmanaged conflict (Carpenter \& Kennedy, 1988).

Fragmentation can be hidden, for example when stakeholders do not realize that incompatible implied assumptions about the problem exist, and each participant believes their understandings are complete and shared by all 
(Conklin, 2005). Any program manager cannot control all of these factors at once; all participants benefit from having skills to deal with them. Conklin (2005) contends that the antidote to fragmentation is coherence. Coherence amounts to shared understandings and shared commitment. A variety of social communication techniques exist for increasing understanding and commitment among collaborating parties.

\subsection{Facilitation: Managing Problem, People and Process}

Focusing on interests instead of positions, as Fisher and colleagues recommend (1991), requires special communicative techniques and procedures. Researchers and practitioners recommend a neutral third-party facilitator, and the use of special communicative techniques and procedures, as a means of improving negotiation and collaborative processes (Daniels \& Walker, 2001; Lewicki \& Litterer, 1985). Lax and Sebenius (2006) emphasize that parties need to understand their own interests as well as those of other parties. They contend that "negotiators often fail to sort out the truly 'musthave' from the 'important' and from the 'desirable but not critical' (p. 70). Understanding interests is related to learning in a group about the issues and other participants. As participants have interests in their relationships and the process of collaborating, an exploration of how to manage these interests is important. 


\subsubsection{Learning in Multi-party Collaboration}

Daniels and Walker (2001) argue that better decision processes, and better decisions, result from quality learning. The more complex the decisions, the more important it is for people to understand the problem, options, and potential consequences of those decisions based on what they have learned. Three types of learning theory are applicable to collaboration: adult learning, experiential learning, and social learning.

Knowles (1980) posits that adults learn differently than children. There are five assumptions about adult learner characteristics 1) adults have a selfconcept as being a self-directed human being; 2) they accumulate a reservoir or experience that become a resource for learning; 3) their readiness to learn is becomes oriented to their social roles; 4) their time perspective is on immediacy of application of what they've learned and to performancecenteredness; and 5) adults are motivated to learn more by external than internal factors (Knowles, 1980; Knowles et al., 1984). Based on this theory, in a multi-party collaborative process, adults can draw on past experiences and are motivated to apply that information in the context of their social role (e.g. an organization or stakeholder group they represent).

Kolb (1984) synthesized learning theories of Dewey, Lewin and Piaget when he theorized that people learn by doing. The experiential learning process goes through four distinct stages: reflective observation when an individual asks "why?"; abstract conceptualization when the individual 
develops an abstract model of the situation through asking "what?"; active experimentation when an individual applies the new mental model to a situation and asks "how?" in order to problem solve; and concrete experience when the individual applies what is learned (Daniels \& Walker, 2001; D. A. Kolb, 1984). In a multi-party collaboration an individual might ask "what if?" based on applying information to different options that weigh various circumstances such as forest management.

According to Kolb's theory, experiential learning is a process and involves different learning styles. Divergent learners are comfortable being creative, look for patterns and generate alternatives. Assimilative learners are at ease with ordering, classifying, and defining information. They can devise models to test alternatives. Convergent learners are innovative idea-generators who are personally invested as leaders and/or facilitators and can set goals, make criteria and make decisions. Accommodative learners are comfortable taking action. They place emphasis on implementing decisions (Daniels \& Walker, 2001; D. A. Kolb, 1984). Participants in a collaborative process may exhibit a mix of each of these four learning styles and prefer one or two. Daniels and Walker (2001) argue that in a group, a learning team will be more effective when they can draw on these different learning types when making decisions. An ideal team might be four individuals representing welldeveloped abilities from each of the learning styles. The challenge is helping 
the four understand each other, and interact in a way that values each individual's unique contribution (Daniels \& Walker, 2001).

Social learning builds on these, and many other learning theories while also including a social context (Bandura \& Walters, 1963; Bateson, 1972; Blackmore, 2007; Freire, 1970; Ison \& Watson, 2007). Social learning is defined as achieving concerted action in complex and uncertain situations (Ison \& Watson, 2007). This conceptual framework is being tested in Europe in the SLIM (Social Learning for the Integrated Management and sustainable use of water) project. Social learning is appropriate to multi-party collaborative processes addressing resource dilemmas and can be characterized by:

1. Convergence of goals, criteria and knowledge, leading to more accurate mutual expectations, and the building of relations of trust and respect...

2. Co-creation of knowledge needed to understand issues and practices.

3. A change in behaviors, norms and procedures arising from development of mutual understanding of issues as a result of shared actions such as physical experiments, joint fact finding and participatory interpretation (SLIM, 2004).

In sum, adults in multi-party collaborative processes may learn based on past experiences, they do so with different learning styles, and they learn in the context of shared experiences.

\subsubsection{Facilitators, Mediators, and Conveners}

In consensus-building dialogues among multiple parties, Susskind and Cruikshank (2006) recommend a process manager, otherwise known as a “facilitator." It is this person's job to keep participants focused, and on track in 
a meeting; facilitators focus on the process of moving the group toward agreement. Further, these participants can develop experiences, techniques or procedural elements that help participants learn, such as a field trip (Daniels \& Walker, 2001). Susskind and Cruikshank (2006) note that facilitators tend to work with people face-to-face around the table while mediators work with people away from the table and "shuttle among various stakeholder groups between meetings". A mediator delves deeper that a facilitator in that they resolve differences among disputing parties (Arthur, Carlson, \& Moore, 1999; Elliott, 1999). A mediator structures negotiations to generate various forms of interaction including sub-groups, caucuses, and one-on-one discussions. Further, they manage interpersonal dynamics that happen outside of meetings (Elliott, 1999).

There may be a team of facilitators handling interpersonal relationships, research the substance of a dispute, and helping to manage dynamics around the negotiating table. Sabatier and colleagues (2005) cite empirical research on multi-stakeholder watershed partnerships that effective facilitation and coordination was second only to financial resources as the most important factor in determining success in an environmental conflict. In this dissertation, a facilitator, or project manager, is understood to be neutral and use both coordination and mediation skills during collaborative processes. Oregon Solutions was introduced in Chapter One. They use conveners who have political power, or clout, to successfully encourage participants to come 
to meetings. Further, they involve project managers with facilitation skills to help collaborative groups make decisions.

\subsubsection{Communication}

Communication is at the heart of negotiation (Lewicki \& Litterer, 1985) and is the basis for social facilitation techniques. A basic model of human communication involves a two-way transmission of messages between senders and receivers, who then switch roles (Shannon \& Weaver, 1948). A party transmits a message (verbally, in writing, or through nonverbal expressions like facial language or gestures) which is received by a second party. The second party translates the message, assigns it meaning and encodes it to create a response. The second party gives feedback, to assure his understanding of the message, and transmits his own message to the first party who then repeats the cycle.

Even in this very basic model, problems erupt based on the senders', and receivers', objectives and understanding of the message that's been transmitted. This commonly results in misperceptions, and distortions of what has been communicated. Lewicki and Litterer (1985) recommend negotiators check for distortions and errors in perception by asking clarifying open-ended questions that invite the other to explain their thinking. Other techniques to improve communication and manage misperceptions are described in the next section. 


\subsubsection{Social Techniques}

Table 6 Key facilitative elements that may contribute to uncovering interests in negotiations ((Arthur, et al., 1999; Forester, 2001; Lewicki \& Litterer, 1985; Ozawa, 1991, 1993; Susskind \& Cruikshank, 2006)

\begin{tabular}{|c|c|}
\hline $\begin{array}{l}\text { Communicative } \\
\text { techniques }\end{array}$ & $\begin{array}{l}\text { Structuring the timing of when certain topics are } \\
\text { discussed } \\
\text { Creating a list of interests } \\
\text { Creating a list of alternatives or options } \\
\text { Asking probing and clarifying questions, e.g. "what } \\
\text { does that mean to you? What would that look like? } \\
\text { Why is that important to you?" } \\
\text { - Participants argue other party's positions (role } \\
\text { reversal techniques) } \\
\text { Active listening, mirroring and summarizing what } \\
\text { has been said } \\
\text { Following someone else's thoughts rather than } \\
\text { leading } \\
\text { - Responding to another's feelings } \\
\text { discussion }\end{array}$ \\
\hline Meeting techniques & $\begin{array}{l}\text { Face-to-face meetings } \\
\text { Meetings between scientific experts and lay } \\
\text { individuals, } \\
\text { Small groups sub-committees or coalitions for } \\
\text { specific issues } \\
\text { Sequencing of meetings to further discussions } \\
\text { Meeting one-on-one with individuals whose } \\
\text { interests are being compromised }\end{array}$ \\
\hline Props & $\begin{array}{l}\text { Use of figures, schemes, photos, or diagrams to } \\
\text { illustrate options }\end{array}$ \\
\hline $\begin{array}{l}\text { Information } \\
\text { techniques }\end{array}$ & $\begin{array}{l}\text { Joint fact finding } \\
\text { Use of single text document of everyone's } \\
\text { concerns, the issue, and commitments that all } \\
\text { parties review and approve of to track the } \\
\text { negotiation stages }\end{array}$ \\
\hline
\end{tabular}

Social techniques and communicative procedures can help improve understanding among participants and resolve misperceptions (Conklin, 2006; Daniels \& Walker, 2001; D. M. Kolb \& Williams, 2003; Lewicki \& Litterer, 
1985; Senge, 2006; Susskind \& Cruikshank, 2006). Theorists and practitioners describe a variety of different social techniques to help manage people and process, see table 6 . Techniques such as conflict or stakeholder analysis are intentionally aimed at understanding and identifying interests in relation to the problem and stakeholders (Carpenter \& Kennedy, 1988; D. M. Kolb \& Williams, 2003; Susskind \& Cruikshank, 2006; Wehr, 1979).

Some visual and verbal techniques are focused on helping people understand scientific information related to the problem such as presentations by experts, maps, or dialogue mapping (Conklin, 2006; Forester, 2001; Ozawa, 1991; Straus, 1999). Many techniques focus on building understanding among participants to foster more trusting relationships (Arthur, et al., 1999; Bush \& Folger, 2005) and other techniques help keep participants focused on the process of moving deliberations forward such as a single text document (Susskind \& Cruikshank, 2006). Techniques are useful for managing the problem, the people, and the process.

In his studies of cases of planners in the field, Forester (2001) finds that planners build consensus among multiple parties iteratively: "It's a process of trying to understand the needs, trying to understand the opportunities, and trying to understand the red lines of each discipline, what's a taboo, what cannot be done, what they will not accept" (p. 68). A reading of Forester's accounts of different planner's experiences reveals communication techniques are being used in understanding parties' interests. The cases of participatory 
planning also show that listening and relationship building is taking place:

planners use "schemes" (or mock-up scenarios) to communicate alternative approaches to land use problems (p.69), repeated meetings help parties understand the rationale behind a plan (p. 71), they frame what is possible instead of focusing on what is not (p. 72), and they create small group planning subcommittees to solve special issues (p. 75). Forester (2001) reminds government planners that we need, now more than ever, "the sensitive recognition of differences and needs and the thoughtful political construction of practical strategies of response" (pg. 10).

Focusing on interests instead of positions requires special communicative techniques and procedures. Manuals for consensus building and negotiation specify the ability to use communicative techniques and discuss interests (Susskind \& Cruikshank 2006; Lewicki \& Litterer 1985; Arthur et al.1999). It is not clear to what degree these techniques are being incorporated by collaborators as models of collaboration do not place a large emphasis on interests or techniques.

\subsection{Gap in Theory}

This research bridges the gap between negotiation theory and collaborative practice. While it is recognized that participant interests are a fundamental part of negotiation and resolving conflicts, this element is not common in collaboration models. Further, although facilitation techniques have been described as being fundamental to help improve processes, it is 
unclear how they influence the discussion of interests in a collaborative process.

It may be possible for a group to collaborate with one shared interest and not address the interests of one or more participants. In the community barn raising example, a business of local artisans would like the barn facing a direction that makes painting landscapes easier. They have contributed funds for the effort. Suppose the other participants choose to not address their interests because other issues seem more important. If the artisans are cooperative by nature and/or the process has given them the opportunity to understand why it is not feasible to address their interests they may contribute their funds for the good of the community. If not, they may retract them. Further, if they feel ignored they may sabotage the process. Regardless, a collaborative process has occurred and there is an outcome. However, the numbers of committed stakeholders who support the outcome, the number of retained trusting relationships, and the potential for a group to upset the agreement may depend on the quality of the process. How interests are addressed, or not, may contribute to the quality of agreement and the relationships surrounding it.

The central problem this research addresses is the potential for collaborative process to fail because of unmanaged disruptions. It is proposed that faciltiation techniques and integrative bargaining participants can increase their level of shared understanding of the problem, and individual's stake in it. 
It is further proposed that this shared understanding can prevent disruptions from impeding forward progress in collaborative procesess. This literature review established that intersts are a crucial component in two-party negotiations. In this chapter we also learned that facilitation techniques can help negotiators improve their communication and learning experiences. We do not know specifically how the dynamics involved with identifying and addressing interests can help collaboration participants manage conflict and strengthen the collaborating process, or even how necessary it is. Research on collaborative processes has not articulated how individuals gain a common understanding of the problem, and one another's needs, to craft and follow self-organized arrangements (V. Ostrom, 1990).

\subsection{Research Aims}

The primary purpose of this study is to explore the role interests play in successful collaborative processes. Do interests play a role? If so, what is it? This research aims to reveal how discussing and addressing participant interests can benefit participants in multi-party environmental collaborative processes. Could interests be as important for encouraging joint problem solving in multi-party collaboratives as they are in conflict resolution? Are collaborative groups that were successful in implementing their objectives also effective at uncovering participant interests? A secondary aim is to explore if and how specific types of social techniques may help strengthen the collaborative process. Do facilitation techniques contribute to a shared 
understanding of participant interests and problem understanding as this is the basis for creative problem solving? Further, did that understanding help the collaborative groups work to address parties' underlying concerns in creating solutions for each case's collective endeavor? If the dynamic between facilitation and integrative bargaining could be uncovered, it could increase understanding about the gap between process, outputs, and policy outcomes. 


\section{CHAPTER THREE}

\section{$\underline{3 \text { Research Design and Methods }}$}

\subsection{Exploratory Comparative Case Study}

This research is an exploratory comparative case study of collaborative projects using mixed methods of data collection and analysis for each of five cases. A document review, semi-structured interviews, and a closed-ended survey were conducted on each case (see figure 8). The units of analysis include the collaborating group and the process. Both individual perspectives and group dynamics were examined in meeting minutes, agreements, and other documents. Individuals' views on the group and process were collected in interviews. Group responses were examined in the follow-up survey.

The exploratory case study research strategy was used to gain a deeper understanding of complex social phenomena (Yin, 2003). Collaborative processes involve complex problem solving, relationships, and the implementation of agreements that impact social, environmental, and economic outcomes. The goals of the study were 1) to identify and establish whether interests play specific roles in collaborative processes regardless of the collaborative context, and 2) to establish the extent to which facilitative techniques support discussion of interests in collaborative processes. The research questions were centered on understanding if and how participants discussing interests relates to participant decisions extending from the beginning of the collaborative process through implementation. The 'how' 
research questions, the focus on contemporary events, and the inability of the researcher to control the collaborative processes made this research appropriate for an exploratory case study (Gerring, 2007; Yin, 1984, 2003).

A multiple case study design provides a higher degree of certainty about the findings than a single case study (Yin, 2003). Each of the five cases is a literal replication, where the same research protocol was applied and the same results were expected for each case. Such repeated opportunities to explore relationships among the variables are similar to conducting multiple experiments (Hersen \& Barlow, 1976; Yin, 2003). Case selection was based on a theoretical framework from the negotiation and collaboration literature.

Although having multiple cases strengthens the degree of certainty about findings consistent across the cases, multiple types of data were also necessary to increase the legitimacy of data interpretation (Miles \& Huberman, 1994; Onwuegbuzie \& Teddlie, 2003). Research paradigm theorists debate about the ability to mix research methods (Johnson \& Onwuegbuzie, 2004). Proponents argue that mixed methods allow researchers to build on the strengths of both data collection types and enhance data evaluation (Creswell \& Plano Clark, 2007; Greene, Caracelli, \& Graham, 1989; Plano Clark, Creswell, O'Neil Green, \& Shope, 2008). This exploratory study incorporated complementary methods in order to gain a better understanding of the dynamics among the variables within each collaborative case. 
The mixed-methods framework involved an emphasis on the qualitative stage (Creswell \& Plano Clark, 2007; Plano Clark, et al., 2008). The qualitative phase was completed first to identify themes that would be verified in the quantitative phase (see figure 8). A document review provided a context foundation of how the process unfolded in each collaborative project.

Documents included meeting minutes, articles about each project from newspapers, agreement documents, and executive summaries. Semi-structured interviews of staff members and participants provided individual perspectives and a group story.

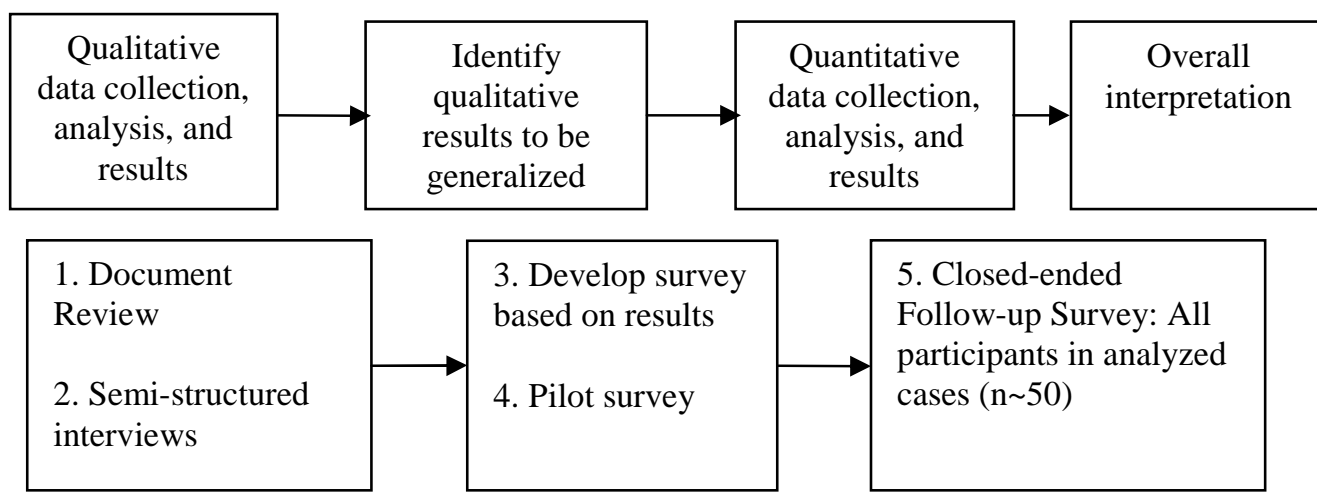

Figure 8. Exploratory mixed methods research design. (Top line is model of mixed-methods design (Creswell and Plano Clark, 2007). Bottom line shows methods used in this research.)

The follow-up survey verified themes from the qualitative analysis (see table 7). The follow up survey complemented the qualitative phase in that it permitted all participants from each case to confirm, enhance, and clarify findings (Greene et al., 1989). See table 7 for sources of evidence and analytical methods. The research protocol was replicated in each of the five cases. 
Table 7 Sources of evidence and their functions

\begin{tabular}{|c|c|c|c|}
\hline Research Goal & Evidence Source & Analytical Method & Data Collection Tool \\
\hline $\begin{array}{l}\text { Develop case } \\
\text { parameters: } \\
\text { problem, people, } \\
\text { process }\end{array}$ & $\begin{array}{l}\text { Documents } \\
\text { (e.g. meeting notes, } \\
\text { project assessment, } \\
\text { executive } \\
\text { summaries, } \\
\text { agreements) }\end{array}$ & $\begin{array}{l}\text { Content analysis } \\
\text { Units of Analysis: } \\
\text { Individual and Group }\end{array}$ & $\begin{array}{l}\text { Web search, document } \\
\text { search, informal } \\
\text { interviews }\end{array}$ \\
\hline $\begin{array}{l}\text { Identify } \\
\text { relationships among } \\
\text { variables }\end{array}$ & $\begin{array}{l}\text { Interviews of } \\
\text { Project Staff } \\
\text { (e.g. facilitators and } \\
\text { conveners) } \\
\text { Interviews of "Key" } \\
\text { Participants }\end{array}$ & $\begin{array}{l}\text { ATLAS.ti software } \\
\text { Coding based on } \\
\text { theory } \\
\text { Pattern matching } \\
\text { Anecdotes } \\
\text { Units of Analysis: } \\
\text { Individual and Group }\end{array}$ & $\begin{array}{l}\text { Recorded, transcribed } \\
\text { semi-structured } \\
\text { interviews (in-person } \\
\text { or by phone) }\end{array}$ \\
\hline Verify findings & $\begin{array}{l}\text { Follow-up survey of } \\
\text { participants and } \\
\text { staff }\end{array}$ & $\begin{array}{l}\text { Descriptive statistics } \\
\text { Unit of Analysis: } \\
\text { Individual and Group }\end{array}$ & $\begin{array}{l}\text { Web-based, closed } \\
\text { ended survey }\end{array}$ \\
\hline
\end{tabular}

\subsubsection{Collaborative Program Case Population}

The research used cases from, or affiliated with, the Oregon Solutions program, introduced in Chapter One. Oregon Solutions is a public/non-profit partnership housed within the National Policy Consensus Center at Portland State University. The Oregon Legislature created the program as part of the 2001 Sustainability Act. The Oregon Solutions (OS) Program conducts participatory, collaborative processes that use 'community governance' for solving community problems based on the "principles of collaboration, integration, and sustainability" (Oregon Solutions, 2008). Projects involve governments, citizens, non-profits and businesses to address community problems. Economic, social and environmental issues are encompassed by Sustainable Community Objectives as set forth in the Sustainability Act (Oregon Solutions, 2008). Table 8 shows relevant environmental objectives addressed in the case studies. 
The Oregon Solutions program provides teams of staff members to assist communities in defining issues, developing strategies, and formulating agreements to address a problem around which a degree of momentum exists. Oregon Solutions staff is trained in the Oregon Solutions governance system and have a diversity of facilitation training. They do not receive Oregon Solutions training in conflict resolution; however individuals may have this skill set from previous work experience. The program has received the Cooperative Conservation Award from the White House and has been designated as one of the Top 50 Innovative Government Programs in America by Harvard University's Kennedy School of Government (Oregon Solutions, 2008). Oregon Solution's use of semi-formal collaborative processes, with the assistance of facilitation staff, offers fruitful terrain for the study of negotiation of interests within multi-party community problem-solving efforts.

Table 8 Sustainable Community Objectives of the Sustainability Act 2001

Economy:

- A resilient economy that provides a diversity of good economic opportunities for all citizens.

- Workers whose knowledge and skills are globally competitive, and supported by lifelong education.

Community:

- Independent and productive citizens.

- Youth who are fully supported by strong families and communities.

- Downtowns and mainstreets that are vital and active.

- Efficient development that saves infrastructure investments and natural resources.

- Available and quality affordable housing.

Environment:

- Healthy urban and rural watersheds and species abundance and diversity.

- Clean and sufficient water for human and natural use.

- Efficient use and reuse of resources, and elimination of harmful toxins in the environment. 
One of the five selected cases was from a different collaborative program, Sustainable Northwest. Sustainable Northwest (SNW) is a non-profit, non-partisan program established by Oregon and Idaho political leaders in 1994. The organization promotes collaborative, community-based projects that seek to balance economic, social, and environmental interests. Projects generally have long-term timelines and receive facilitation assistance from SNW (Martin Goebel, personal communication, 2008). The Lakeview Biomass project was a sub-set of the Lakeview Stewardship Group, a Sustainable Northwest project. As both the Lakeview Biomass and Lakeview Stewardship Group involved separate collaborative processes with minimal overlap in participants they were analyzed as separate cases. The cases examined in this project include: Lane Clean Diesel, Reduced Engine Idling, Lakeview Biomass Facility, Tillamook Flooding Reduction, and the Lakeview Stewardship Group. Details on the cases appear in section 3.1.3.

\subsubsection{Variables}

This project begins with the proposition that participant discussion of interests, through the use of facilitation techniques, shapes the evolution of a collaboration process through building cohesion. Cohesion is defined as shared group understanding of the problem, shared group understanding of the people, and shared group understanding of the process. As cohesion is difficult to measure without analyzing the cases, implementation was used as a proxy dependent variable. Multiple variables influence implementation, such as 
adequate funding, effective leadership and management, committed participants, and some level of interpersonal trust (Leach \& Pelkey, 2001). Testing a causal link between discussion of interests and implementation was beyond the scope of this research. However, the research did seek to explore relationships among participant identification of interests, facilitation techniques, and the role these two play in the evolution of the collaborative process.

Using successful implementation as a dependent variable accomplished two objectives. First, it focused the research on exploring if and how uncovering and addressing interests furthered the movement of the entire process. While it is possible to implement a collaborative process without cohesion, studying how cohesion develops from one collaboration phase to the next is difficult unless the collaborative process reaches the implementation stage. Second, selecting implemented cases helped ensure that other proposed mediating variables required for successful implementation were more likely to be present in the cases. Successful implementation was also used as a sampling frame.

The independent variable under examination is comprised of two related variables (IV). Facilitation techniques (iv) influence whether or not participant interests (dv) are discussed, see figure 9.. These two variables together, potentially have an impact on cohesion (DV). The dependent variables are proposed to relate to at least one mediating variable, cohesion. 
Facilitation Techniques (iv) $\longrightarrow$ Discuss Interests (dv) \} IV

Figure 9. Independent variable relationships.

It could be argued that sources of fragmentation are independent variables and facilitation techniques with discussion of interests are mediating variables. The ability to address fragmentation may or not be present in a group process, and fragmentation can happen at any time. Thus, the research treated interests and facilitation techniques as an independent variable that can influence how a process evolves in relation to changing fragmentation (figure 10).

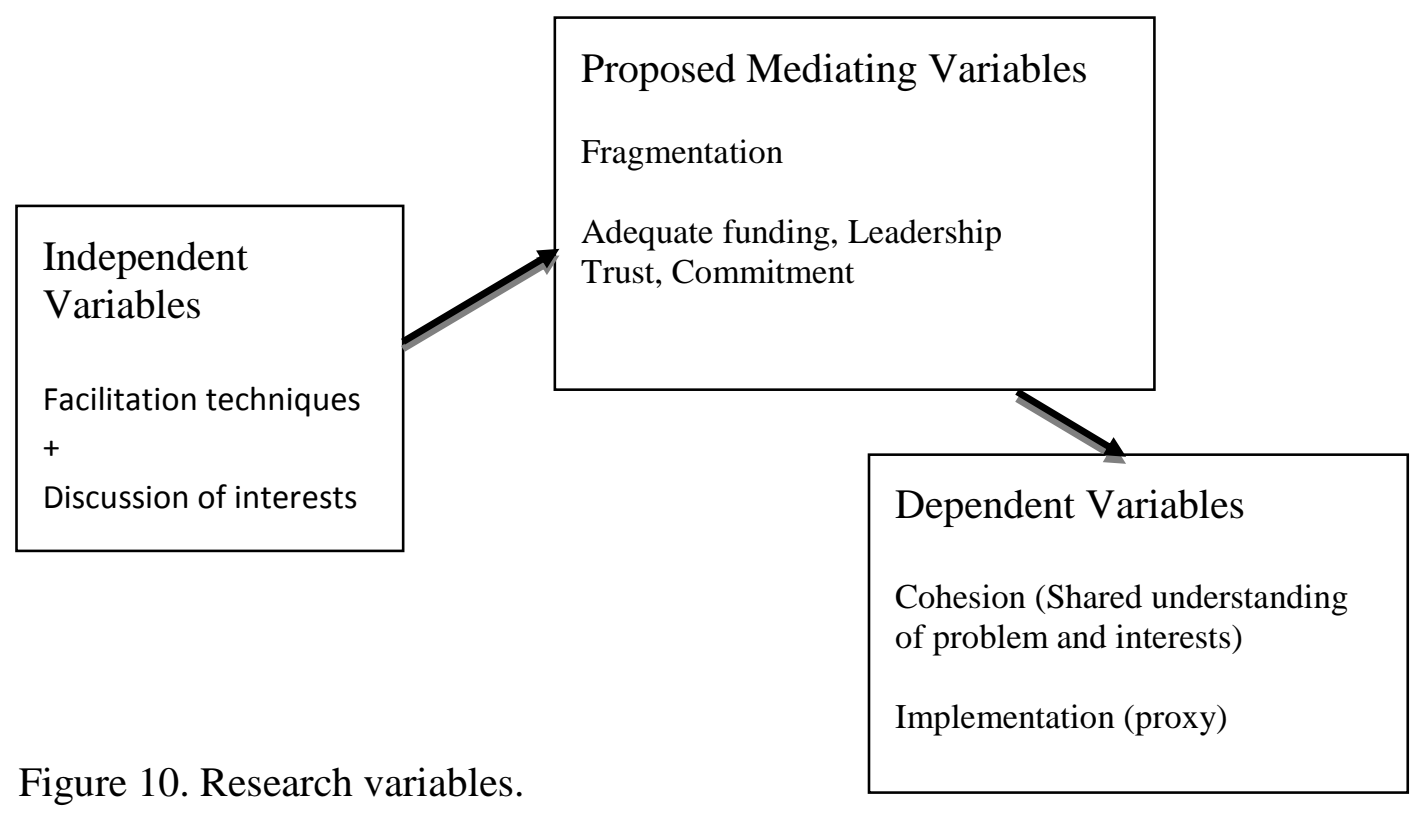

It was assumed from collaboration field practice that all cases would be influenced by at least one fragmentation force such as problem complexity, social complexity, or technical complexity (Conklin, 2006). Additional 
variables such as facilitator, region, scale, potential cost, and participant composition provided context for the core research questions. The diverse set of cases allows the research to draw conclusions from different collaborative contexts.

\subsubsection{Case Study Selection}

The main theory used to select cases were 1) that interests are a basis for problem solving in negotiations (Follett, 1924; Pruitt, 1983; Lax \& Sebenius, 1986) thus cases need to discuss interests, 2) facilitation techniques are helpful in identifying participant interests (Susskind et al., 1999) and therefore cases require facilitation efforts, and 3) collaborative processes suffer from different forms of fragmentation (Conklin, 2006). The cases needed to represent a range of sufficiently complex projects with varying potential for fragmentation. The research goal and relevant theories established the study parameters, the case number, and selection criteria (Yin, 1994; 2003).

Among the cases that met these criteria a set of most-different cases were purposively selected (Yin, 1993; Gerring, 1997). Most different cases are different on all variables other than the independent variable of interest and a relevant dependent variable (Flyvbjerg, 2006; Gerring, 2007). This is an adapted version of the 'most-different' technique in that the cases were different on all variables other than one mediating variable: the fragmentation potential. The five cases represent an ordered set, including cases on the low, middle, and high end of a potential fragmentation scale. All cases used 
facilitation, identified interests to some degree, and were implemented. They differed based on a mediating variable, the potential fragmentation. Also known as the "method of agreement," by John Stuart Mill, this process emphasizes finding similar relationships across contrasting cases (DeFelice, 1986; Mill, 1843). Purposive selection is nonrandom selection when the item of interest is rare (Yin, 1993). Five cases were chosen from a population of twenty short and long-term multi-party collaborative projects focused on community issues.

Case selection was three-phased, see table 9. The first tier of selection identified a population of accessible, documented, collaborative projects dealing with community issues. Oregon Solutions projects, and by extension one Sustainable Northwest project, comprised the initial population. The second tier identified projects that had used facilitation, discussed interests, and had successfully entered, or completed, the implementation phase. Cases that had completed their implementation more than five years ago were rejected to reduce recall bias (Creswell \& Plano Clark, 2007).

Table 9 Case study selection criteria

\begin{tabular}{|c|c|c|}
\hline $\begin{array}{l}\text { Tier 1 = Population of } \\
\text { Collaborative Projects }\end{array}$ & $\begin{array}{l}\text { Tier } 2=\text { Independent and } \\
\text { Dependent Variables }\end{array}$ & $\begin{array}{l}\text { Tier } 3=\text { Variation in } \\
\text { Potential Fragmentation } *\end{array}$ \\
\hline $\begin{array}{ll}\text { - } & \text { Accessible } \\
\text { - } & \text { Multi-party } \\
\text { - } & \text { Documented } \\
\text { - } & \text { Community issues }\end{array}$ & $\begin{array}{ll}- & \text { Facilitated } \\
- & \text { Discuss interests } \\
\text { - } & \text { Implementation phase } \\
\text { - } & \text { Time since } \\
\text { implementation less than } \\
\text { 5 years }\end{array}$ & $\begin{array}{ll}\text { - } & \text { Internal conflict } \\
\text { - } & \text { Socially diverse } \\
\text { - } & \text { Substantively diverse } \\
\text { - } & \text { Information diverse }\end{array}$ \\
\hline
\end{tabular}


The third set of criteria involved potential sources of fragmentation such as internal conflict, diversity of participants, and complexity of technical information based on theory presented in the literature review (page 47).

Table 10 Case screening survey sub-elements

\begin{tabular}{|c|c|c|c|c|}
\hline & Fragmentation Source & $\begin{array}{c}\text { Low } \\
\text { Fragmentation } \\
\text { (1) }\end{array}$ & (2) & $\begin{array}{c}\text { High } \\
\text { Fragmentation } \\
(3)\end{array}$ \\
\hline \multirow{6}{*}{ 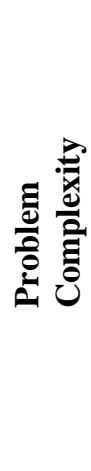 } & Problem Definition & clear, all agree & $\operatorname{mix}$ & fuzzy, \\
\hline & Solution Options & clear, all agree & $\operatorname{mix}$ & fuzzy, \\
\hline & Uncertainty & low & med & high \\
\hline & Conflicting Risks & low & med & high \\
\hline & Number of Participants & $\leq 3$ & $4-5$ & $5<$ \\
\hline & $\begin{array}{l}\text { Perspectives on problem and } \\
\text { solutions }\end{array}$ & aligned & $\operatorname{mix}$ & diverse \\
\hline \multirow{5}{*}{ 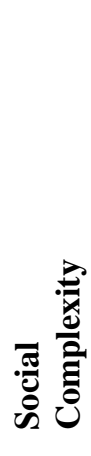 } & Organization's Objectives & single & few & many \\
\hline & $\begin{array}{l}\text { Factors Influencing } \\
\text { Objectives }\end{array}$ & few, controllable & $\operatorname{mix}$ & $\begin{array}{l}\text { many, beyond } \\
\text { control }\end{array}$ \\
\hline & Bargaining Types & mostly & $\operatorname{mix}$ & mostly \\
\hline & Historical Conflict & low & med & high \\
\hline & Potential Conflict & low & med & high \\
\hline \multirow{2}{*}{ 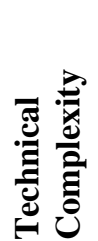 } & Scientific Information & $\begin{array}{l}\text { leads to clear } \\
\text { perspective \& } \\
\text { choice }\end{array}$ & $\operatorname{mix}$ & $\begin{array}{l}\text { informs multiple } \\
\text { perspectives, } \\
\text { choices }\end{array}$ \\
\hline & Decision Making & $\begin{array}{l}\text { single decision } \\
\text { maker }\end{array}$ & $2-3$ & $\begin{array}{l}\text { shared among } \\
\text { group }\end{array}$ \\
\hline
\end{tabular}

A case screening survey (Yin, 1993) was developed to assess areas of potential fragmentation in cases (see Appendix A). Cases were scored for fragmentation following a document review based on the case background; cases received a score in a range between 13 (lowest) and 39 (highest). The 
project manager or convener verified each case's fragmentation score (see

table 10). The project manager of the Pilot case was unavailable to confirm the score, thus it received a score range.

The five selected cases represent scores evenly dispersed between the lowest (13 points) and highest (39) potential fragmentation range (see table 11 for the range). The researcher assumed projects with very low scores would not need facilitation and projects with very high scores would need explicit mediation support. Each project also represents a range of collaborative integration. Integration type is based on normative literature in the collaboration field (see Chapter Two page 47) and was assessed through the document review and a discussion with each case's project manager.

Table 11 Analyzed cases

\begin{tabular}{|c|c|c|c|c|}
\hline Case & Score & $\begin{array}{l}\text { Problem } \\
\text { Focus }\end{array}$ & Timeline & Integration \\
\hline $\begin{array}{l}\text { Lane Clean } \\
\text { Diesel }\end{array}$ & 19 & $\begin{array}{l}\text { Establish ULSD } \\
\text { and biodiesel } \\
\text { market }\end{array}$ & Short term & $\begin{array}{l}\text { Collaboration } \\
\text { (Integrated Strategies \& } \\
\text { Collective Purpose) }\end{array}$ \\
\hline $\begin{array}{l}\text { Reduced Truck } \\
\text { Idling }\end{array}$ & 23 & $\begin{array}{l}\text { Research and } \\
\text { install TCE } \\
\text { technology at } \\
\text { truck stops }\end{array}$ & Short term & $\begin{array}{l}\text { Coordination } \\
\text { (Common Tasks \& } \\
\text { Compatible Goals) }\end{array}$ \\
\hline $\begin{array}{l}\text { Lakeview } \\
\text { Biomass }\end{array}$ & 27 & $\begin{array}{l}\text { Permit and build } \\
\text { biomass facility }\end{array}$ & Short term & $\begin{array}{l}\text { Coordination \& } \\
\text { Collaboration mix }\end{array}$ \\
\hline $\begin{array}{l}\text { Tillamook } \\
\text { Flooding } \\
\text { Reduction }\end{array}$ & 30 & $\begin{array}{l}\text { Permit and } \\
\text { implement flood } \\
\text { reduction projects }\end{array}$ & Long term & Collaboration \\
\hline $\begin{array}{l}\text { Lakeview } \\
\text { Stewardship } \\
\text { Group }\end{array}$ & $35-36$ & $\begin{array}{l}\text { Develop and } \\
\text { implement } \\
\text { adaptive forest } \\
\text { management }\end{array}$ & Long term & $\begin{array}{l}\text { Coadunation } \\
\text { (Unified Structure \& } \\
\text { Combined Cultures) }\end{array}$ \\
\hline $\begin{array}{l}\text { PILOT: } \\
\text { Reedsport } \\
\text { Wave Energy }\end{array}$ & $31-34 ?$ & $\begin{array}{l}\text { Develop permits } \\
\text { for wave energy } \\
\text { plant }\end{array}$ & Short term & Coordination \\
\hline
\end{tabular}




\subsubsection{Research Questions and Measures}

The research involved multiple measures from the interviews, documents, and follow-up survey in order to examine each research question. The propositions, research questions, and measures are detailed here.

Collaborative processes may identify party's interests and help participants develop compatible or shared interests. This may happen to varying degrees, or not at all, in different processes.

1. Are interests being identified and generated in the collaborative process?

Measure 1.1 Participant interview questions about understanding of the problem, as interests are related to the problem.

Measure 1.2 Participant interview questions about evolution of similarities and differences during the negotiation process, as these are the basis for uncovering interests.

Measure 1.3 Convener/OS Staff interviews about the intentions behind communication among participants.

Measure 1.4 Comparison of pre-convening assessment documents (where available) to Document of Cooperation looking for patterns of changes in problem understanding, and stated party interests.

Measure 1.5 Follow up survey questions about unique interests identified in the interviews for each case.

Specific communication techniques in collaboration processes help participants understand the problem, interests, develop options, and establish commitments. These techniques include communicative tools such as a single- 
text documents and different meeting structures (e.g. length of time, frequency, face-to-face).

2. How does managing people and process influence discussion of party's interests?

Measure 2.1 Interview questions about how the group arrived at the outcome. This isolated process elements that were used.

Measure 2.2. Interview questions about what elements of the process helped the group achieve the outcome.

Measure 2.3 Interview questions about what helped them understand the problem.

Measure 2.4 Interview questions about who needed to be present to make this happen, and if anyone was missing.

Measure 2.5 Interview questions about how differences and similarities of interests were addressed.

Measure 2.6 Follow-up survey questions about what facilitation techniques helped with understanding issues and interests based on interviews.

Collaboration between government and public sector participants may expand stakeholder understanding of the problem and the resources needed to address it through discussion and negotiation of one another's interests.

Discussing, acknowledging, and addressing interests may affect participant perceptions of the problem, and views of the potential solutions or resources to needed to implement agreements.

3. If interests are generated, what role do interests play in collaborative processes? 
Measure 3.1 Interview questions about the role of interests in each process.

Measure 3.2 Interview questions about what they think contributed to the outcome.

Measure 3.3 Interview questions about what motivated them to be involved in this process, and what they hoped to get out of it.

Measure 3.4 Follow-up survey questions about the role of interests in the process based on emergent themes.

Identifying interests helps expand problem understanding and gives

participants an opportunity to create value in a negotiation. Groups may use only factual information to address interests, use interests as a basis for proposals, or do both. This question uses some of the same measures as other research questions above.

4. How are interests addressed?

Measure 3.1 Participant and OS staff interview questions about what elements of the process helped achieve the outcome (also 2.2)

Measure 3.2 Participant and OS Staff interview questions about what they think contributed to the outcome (also 3.2)

Measure 3.3 Participants were asked what helped them understand the problem (also 2.3).

Measure 3.4 Follow-up survey questions about if interests were addressed.

\subsection{Data Collection and Analyses}

The research used a standard case study protocol across all cases to strengthen internal validity and help maintain focus on the variables of interest 
(Yin 1993). The research tracked five main elements: 1) the workings of the communication dynamic in the collaboration (i.e. the process); 2) conceptions of individual, shared, and compatible interests; 3) facilitation techniques; 4) individual and group understanding of the problem, the solution, and the resources needed to get things done; and 5) how each group addressed participant interests.

\subsubsection{Pilot Case}

The protocol and all data collection instruments were piloted on a separate case, the Reedsport Wave Energy project. Using a pilot is an established method for improving validity and reliability (Yin 1993).The Reedsport Project was similar in potential fragmentation level to the Tillamook Flooding Reduction project. The pilot case was distinct in its explicit discussion of interests. In order to acquire a permit on a faster timeline from the federal Department of Energy, the investor chose an option requiring a settlement agreement with all stakeholder groups. Explicit discussion of interests was a component of this agreement. Feedback from the project manager, convener, and two participants helped shape and refine all instruments and the research protocol.

\subsubsection{Document Review}

The research used documents for each preliminary case assessment (Yin, 1989; Susskind et al., 1999). Each review included meeting notes, OS project assessments, budgets, grants, Documents of Cooperation (agreement 
documents in the OS program), government records, and press articles

wherever available. This resulted in a written case summary of the context, the process, the players, participant's broad interests, the central problem, main sub-issues and allocated resources. This information, combined with guiding theory (Lax \& Sebenius, 1986), helped establish a code list for the transcribed interviews. The document review also identified potential key participants in each project; these names were compared to those suggested as interviewees by project staff.

\subsubsection{Semi-structured Interviews}

A semi-structured interview guide included items focused on the variables of interest and other potentially relevant variables. Interviews were digitally recorded and transcribed. The researcher conducted interviews with project staff (e.g. facilitators or project managers, and conveners) and key participants. The project manager and at least one co-convener for each case were interviewed first to help identify key participants. Participant sampling criteria were as follows.

1. Consistent attendance,

2. A central role (e.g. leadership, strong dissenters),

3. One engaged participant from each major stakeholder group, and

4. Participants who provided crucial support (e.g. financial backers).

The number of interviews conducted for each case ranged from five to ten, see table 12. In the Tillamook Flooding Reduction project, two additional 
participants contacted the researcher with specific feedback not encompassed by a formal interview based on the survey. Human subjects approval was obtained from the Portland State University Human Subjects Research Review Committee.

Table 12 Numbers of interviewed participants in each case

\begin{tabular}{|llllll|}
\hline & $\begin{array}{l}\text { Lane } \\
\text { Clean } \\
\text { Diesel }\end{array}$ & $\begin{array}{l}\text { Reduced } \\
\text { Engine } \\
\text { Idling }\end{array}$ & $\begin{array}{l}\text { Biomass } \\
\text { Facility }\end{array}$ & $\begin{array}{l}\text { Tillamook } \\
\text { Flooding } \\
\text { Reduction }\end{array}$ & $\begin{array}{l}\text { Lakeview } \\
\text { Stewardship } \\
\text { Group }\end{array}$ \\
\hline Staff: & 2 & 2 & 3 & 2 & 2 \\
Participants: & 3 & 3 & 7 & $6^{*}$ & 6 \\
\hline Total & 5 & 5 & 10 & 8 & 8 \\
\hline
\end{tabular}

*Two additional participants provided feedback and were not interviewed.

Interview measures focused on interests, the substance of the collaboration, and the facilitated process (see tables 13a-d). This feedback informed the analysis. Two additional questions on successful implementation of the agreement provided contextual and process information. The interview included definitions of the terms "interest", "position," and "issue." The interview used an example about a woman asking for a salary increase to illustrate the differences among these concepts. The interview used relevant prompts and few mirroring questions for clarification (Creswell, 1998). 
Table 13aInterview questions relating to interests (P:participant, S:staff) Interest Measures in the Semi-Structured Interviews

P1. What did you, and your organization, hope to get out of being involved in the (project name)?

P5/S7. What were the key interests, desires, or concerns of participants?

Prompt definition if needed: "Interests" are participant needs, desires, or values; or what each person hopes to get out of a negotiated agreement.

Example: A woman wants an increase of $\$ 10,000$ a year in her salary. The salary raise is the issue; her position, or demand is the monetary increase; and her concerns, desires, or interests include financial security, valuing her self worth, etc.

P7/S10. How did interests, desires, or concerns, change among participants during the process?

P9/S12. Do you think differences and similarities of interests influenced how parties understood the problem? How?

S1. What role did discussing participant interests play in this collaboration? What did this look like in your approach?

Table 13b Interview questions relating to facilitation techniques (P:participant, S:staff)

P3/S5. What specifically happened in the collaborative process that helped you understand the central problems?

Prompts: Meetings (face to face, one on one, sub-groups, discussions, experts with lay individuals), timing of conversations, written communications (single text document, list of interests, lists of options, letters, summary memos), group edited documents, joint fact finding, someone asked probing questions, visual aides, etc.

P6/S8. What specifically helped you understand differences and similarities in interests?

Prompts: same as above.

P11/S14. Please describe the collaborative process about how your group arrived at the commitments in the Document of Cooperation (or agreement).

P2. How did you tailor the process to the needs of the project?

P9. Did you do anything to address differences among participants? Please explain. 
Table 13c Interview questions related to problem substance (P:participant, S:staff)

Problem Substance Measures in the Semi-Structured Interview

$\mathrm{P} 2 / \mathrm{S} 4$. What were the central problems, or issues, addressed in this project?

P4/S6. How did the key features of the central problem change during the process?

P8/S11. Can you describe an example of when a key difference started out as a subject of disagreement and then became an area of agreement, or vice versa?

P10/S13. How did the resources allocated to address the central issue change during the process?

Table 13d Interview questions related to context (P:participant, S:staff) Context Questions in the Semi-Structured Interview P12/S15. What elements of the collaboration were key, in your mind, to implementing the DoC? Prompts: parties involved, funding, mediator/convener/facilitator, type of project, history, the DoC commitments, a work plan, etc.

13/16. What could have helped this group better implement what was in the DoC? S2. Can you tell me which individuals where most involved, or were otherwise key to this project? Who should I make sure to interview and why?

Each participant was contacted by phone and email initially for an interview request. Each participant was sent the interview and human subjects form prior to the agreed interview time. Interviews were conducted either in person or over the phone and took between 45 minutes and an hour. The interviews provided a depth of rich understanding about interests and process techniques (Yin, 1989; Creswell, 1998).

Interview transcriptions were coded and analyzed using ATLAS.ti software, version eight. Primary codes were developed on the context, issues, interests, facilitation techniques, people, relationships, and resources in each case. Terms including 'fear,' 'worry,' 'demand,' 'concern,' 'need,' 'desire,' 'motivation,' 'value,' 'want,' 'belief,' 'think,' 'know,' 'key,' 'interest,' 'impact,' and others of this type were used as cues for identifying interests. 
Coding was used as an explanation building and pattern-matching process (Glaser \& Strauss, 1967; Yin, 2003). As this was an exploratory study, the initial propositions were revisited after each case study in an iterative process. The initial major code list was developed on the Reedsport pilot case and sub-codes were tailored to each subsequent case. Visual code relationships were crafted in the ATLAS.ti database for each case. Research notes and memos were also used to keep track of the role of interests and facilitation techniques. See table 14 for the primary codes and secondary example codes for the five cases.

Table 14 Major code categories, symbols, and example sub-codes used in analyzing interviews

\begin{tabular}{|cll|}
\hline Code Symbol & \multicolumn{1}{c|}{ Meaning } & \multicolumn{1}{c|}{ Example } \\
\hline- & Context & -agreedendpoint \\
$!$ & Interest & !fear of mistakes \\
$\#$ & Facilitation technique & \#facetofacemtg \\
$\&$ & Personal trait & \&businessaware \\
$@$ & Central issues/sub-issues & @permitting \\
$\mathrm{R}$ & Relationships & r-trust \\
$\$$ & Resources & \$legislativefunds \\
\hline
\end{tabular}

Interviewed participants reviewed each case narrative and analysis for content errors and to ensure the content was sensitive to the state of relationships in each process. This measure helped protect human subjects in the research and also acted as an initial member check for accuracy.

\subsubsection{Follow-up Survey}

A closed-ended survey was designed to validate information from both interviewed and non-interviewed participants. The survey captured information 
on participant perspectives on the interests and facilitation techniques identified in the qualitative phase of the research. The research used tailored design to create the survey (Dillman, Smyth, \& Christian, 2009). Tailored design involves using motivational features based on social exchange theory. The researcher presented the rewards and costs of taking the survey as well as designing the items to decrease the cost of participation (Dillman, et al., 2009). The participant and staff member versions had minor wording differences for the sake of clarity.

The survey was administered to all participants and project staff of each case. Participants and project staff received an email from the researcher directing them to a participant or staff member version of the survey on the internet. After one week, they received a reminder prompt. After two weeks project staff members followed up with an email to 'active' participants when possible (e.g. Biomass, Lane Clean Diesel, and Tillamook) to encourage survey responses. The Reduced Engine Idling project manager did not respond to phone or email requests following the semi-structured interview. Project managers were consulted to narrow the list to an "active" group including participants with regular meeting attendance. Project Team participant lists included all who attended the first, or a subsequent meeting, and thus listed individuals may not have been actively involved in the process. Project managers reviewed original Project Team lists and adjusted the number of members who were active. Each list was also updated based on retirement, 
relocation, and death. Members of the Biomass, Lane Clean Diesel and

Reduced Truck Idling projects relocated, retired and in some cases were

deceased in the previous three years.

Table 15a. Demographic questions in the Follow Up Survey

P/S1) The organization I was representing in this collaborative process was (choose the best
fit):
P/S2) Number of years I've spent working on the central issues in this project (e.g. flooding
reduction, truck idling)?
P/S15) What is your age?
P/S16) What is your gender?
P/S17) What is your education level?
P/S18) Did Tia Henderson (the student who sent you this survey) interview you?
S3) My role in this process was:

Table 15b Explanatory text in the follow up survey

Questions in this survey are about project issues and participant interests.

"Issues" are the details of the subject your group was working on: e.g. flooding reduction, air pollution, fuels, forest health, jobs

"Interests" are what people really care about underneath any issue. Interests are underlying needs, concerns or desires. Below is a simple example:

Issue: Pesticide use

Related Issues: garden care, chemicals, animal habitat, stream health, weeds, pests

Jane's Position: No! Tom's Position (her husband): Yes!

Her Interests: His Interests:

1) fears poisoning birds \& fish 1) wants a nice yard

2) wants a nice yard $\quad$ 2) does not want to fight with Jane

When you see the word "issues" please think about the details of the subject your group worked on.

When you see the word "interests" please think about the details of what people really cared about

The survey focused on interests and facilitation techniques. The survey used explanatory text to remind readers of the differences between issues, positions, and interests (see table 15b). The Staff and Participant surveys are in Appendix C. Demographic items included questions on organization, age, 
gender, education, whether they had been previously interviewed, and number

of years spent working on the central issue (see table 15a).

Table 15c Facilitation questions in the Follow Up Survey

3) The types of participants that most helped me understand issues in this process include (choose all that apply): a) People with important resources; b) the convener(s); c) the project manager/facilitator; d) Leaders in the project other than the facilitator or convener; e) People who see things like I do; f) People with see things differently than I do

4) The types of information that most helped me understand issues in this process include (choose all that apply): a) Participant presentations (e.g. research, cost-analysis); b) Visiting expert presentation; c) Small project results; d) A monitoring program; e) Meeting minutes; f) Summary documents (e.g. Declaration of Cooperation, MOU)

5) The types of meetings that most helped me understand issues and/or interests in this process include (choose all that apply): a) Face to face; b) Project team (e.g. whole group); c) Sub-committee/sub-group; d) On-site in the community; e) Open to the public; f) Regular meetings; g) Private meetings with a facilitator(s) or convener(s); h) Private meetings with a leader other than the facilitator or convener; i) Side meetings with people who care about the same things; j) Side meetings with people who care about different things

6) The types of verbal communication that most helped me understand issues and/or interests in this process include (choose all that apply): a) Requests for people to explain what they care about; b) Statements of interests: "I am concerned about..."; c) Statements of barriers: "I support this...but am limited by..."; d) Active listening statements: "This is what I heard you say - is that right?"; e) Someone brought things up: "I think we have to look at..."; f) Talking about an issue after getting information; g) Working on a goal statement; $h$ ) Working on a vision statement; i) Reviewing ground rules; j) Discussions during meetings; k) Discussions between meetings; 1) Regular discussions; m) Frequent discussions

7) The types of visual communication that most helped me understand issues and/or interests in this process include (choose all that apply): a) Diagrams; b) Photos/pictures; c) Maps; d) Computer modeling results (e.g. flooding, fires); e) Flip charts of notes; f) Websites

8) The types of shared experiences that most helped me understand issues and/or participant interests include (choose all that apply):a) Field trips to look at on-the-ground conditions; $b$ ) Group reviewing information together; c) Making decisions as a group; d) Writing documents together (e.g. plans, grants); e) Eating meals together; f) Casual meetings on shared bus/van rides out to sites; g) Airplane flights

Participants in each case were asked to validate a list of interests unique

to the project. Thirteen sub-items used Likert statements (3 point scale) on

importance of understanding other participant's interests for making decisions

in the process; and four Likert (4 point scale) statements measured agreement 
on interests, see table $15 \mathrm{~d}$. The Likert items employed forced-choice options to reduce the potential of centrality bias (Dillman et al., 2009). Participants were asked about issue understanding as interviews indicated most substantive interests were discussed with issues and not all participants were clear on the distinction. Participant interests were defined as what people really cared about under the issues.

Table 15d Interests questions in the Follow Up Survey P/S9) The collaborative process in this project helped me better understand my interests. S9) The collaborative process in this project helped me better understand participants' interests.

P10) The collaborative process in this project helped me better understand other participants' interests.

S10) The collaborative process helped participants better understand their individual interests.

S11) The collaborative process helped participants better understand each other's interests.

Below are some of the top interests (what people really cared about) the researcher identified from interviews and documents in this project.

P11/S12) I agree that the following interests (what people really cared about) were important (choose all that apply; add any crucial ones):

P12) How important was understanding other participants' interests to the following:

S13) How important was participant understanding of each others' interests to the following: a) Deciding if I wanted to collaborate; b) Clarifying my interests; c) Determining what information was needed to understand issues; d) Understanding the issues on the table; e) Understanding other participants' barriers; f) Understanding my barriers; g) Understanding options on the table; h) Knowing what I could agree to; i) Finding things we could all agree on; j) Picking a direction to go with the solution; k) Committing resources (e.g. time, funding) to the project; 1) Keeping the process going; $m$ ) Staying involved for the duration of the project

P13) My most important interests (what I really care about under the issues) have been addressed so far in this project.

P14) We found common ground in this project. Common ground means shared interests.

\section{Response rates from the Lakeview Stewardship Group and Tillamook}

projects were high enough to not need additional support. Response rates were low for the Lane Clean Diesel (9\%) and Reduced Engine Idling (27\%) and 
within acceptable ranges for the Biomass (43\%), Tillamook Flooding

Reduction (55\%), and Lakeview Stewardship Group (52\%). Response rates were calculated based on either the original Project Team list or an "Active" list where possible, see table 16 .

Table 16 Survey respondents by case

\begin{tabular}{|lccccc|}
\hline & $\begin{array}{l}\text { Lane } \\
\text { Clean } \\
\text { Diesel }\end{array}$ & $\begin{array}{l}\text { Reduced } \\
\text { Idling }\end{array}$ & $\begin{array}{l}\text { Lakeview } \\
\text { Biomass }\end{array}$ & $\begin{array}{l}\text { Tillamook } \\
\text { Flooding }\end{array}$ & $\begin{array}{l}\text { Lakeview } \\
\text { Stewardship }\end{array}$ \\
\hline $\begin{array}{l}\text { Project Team participants (\#) } \\
\text { Active participants (\#) }\end{array}$ & $\begin{array}{l}47 \\
\text { unk }\end{array}$ & 26 & 62 & 33 & 22 \\
Previously interviewed (\#) & 3 & 5 & 4 & 9 & 5 \\
$\begin{array}{l}\text { Total surveys received (\#) } \\
\begin{array}{l}\text { Response rate of active } \\
\text { participants (\%) }\end{array}\end{array}$ & 4 & 7 & 13 & 18 & 11 \\
$\begin{array}{l}\text { Percent of total received surveys } \\
\text { (\%) }\end{array}$ & 8 & 27 & 43 & 55 & 52 \\
\hline
\end{tabular}

*Lane Clean Diesel response rate calculated with Project Team number. Numbers are rounded.

Despite updating the project lists based on input from project managers, some participants included in the 'active' list for each case replied that they felt they were not as involved as others, were recent additions, or did not remember the process well and therefore did not fill out the survey. Forty seven percent of survey respondents were not previously interviewed and forty nine percent had been interviewed.

Survey respondents were primarily male (79\%), over the age of 41 (86\%), with at least a college education (84\%). The profile for all respondents is in table 17. Respondents from the five cases represented themselves as citizens (13\%), non-profits (15\%), private businesses (18\%), or a government agency (48\%). Nearly half of the responses had no previous exposure to the 
research or researcher. Participants reported a range of time spent working on the central issue in each case, with a minimum of one year, a maximum of 32 years, and a mean of 8.7 years $\left(\mathrm{SD}=8.0, \sigma^{2}=64\right)$

Table 17 Participant profile of all survey respondents

\begin{tabular}{|c|c|c|c|c|c|c|c|}
\hline Gender & $\%$ & Age* & $\%$ & Education* & $\%$ & Affiliation* & $\%$ \\
\hline Men & 79 & $25-40$ & 11 & High school & 4 & Unaffiliated citizens & 13 \\
\hline \multirow{6}{*}{ Women } & 21 & $41-54$ & 34 & Some college & 11 & Private business & 18 \\
\hline & & $55-70$ & 43 & College graduate & 19 & Non-profit & 15 \\
\hline & & $71+$ & 9 & $\begin{array}{l}\text { Some graduate } \\
\text { school }\end{array}$ & 19 & $\begin{array}{l}\text { City or county } \\
\text { government agency }\end{array}$ & 6 \\
\hline & & & & Master's degree & 38 & State government agency & 21 \\
\hline & & & & Doctorate & 8 & $\begin{array}{l}\text { Federal government } \\
\text { agency }\end{array}$ & 21 \\
\hline & & & & & & Other or missing & 8 \\
\hline
\end{tabular}

*1-2 participants did not respond to this item.

Survey Data Analysis

Data were analyzed using SPSS software (version 17.0). Inferential statistics were used to test for differences among cases on each variable; case differences based on exposure to the information from previous interview experience were examined; and case differences between staff members and participants were analyzed. Relevant tests were selected based on variable type (e.g. ordinal or dichotomous), independence of the samples, and normality of sampling distribution.

Given the small sample sizes, parametric tests could not be used because a normal sample distribution could not be assumed. The Likert questions were treated as ordinal data given the small number of options. The survey involved items that asked for dichotomous responses (yes/ no), three categories of responses (Not Very Important, Important, Very Important), or 
four categories of responses (Strong Disagree to Strongly Agree). Pearson's chi-square tests were used to determine if there were differences between cases on the dichotomous variables (Field, 2005). The Kruskal-Wallis test was used to determine if differences existed between the independent cases on the Likert items. Responses are reported in aggregate where there are no differences.

Additional Pearson's chi-square tests were used to determine if there were differences between staff members and participants on all questions types; and if being interviewed had an effect on all types of responses. A Bonferroni correction was not used as the number of follow-up tests ranged between two and four, and alpha inflation is a concern generally on numerous repeated post-hoc tests. Additionally, a Bonferroni correction had the potential to mask case differences that needed to be reported separately through committing a Type 2 error (accepting the null hypothesis when a difference is present) (Olejnik, Li, Supattathum, \& Huberty, 1997)

\subsubsection{Cross Case Analysis}

Each data collection tool allowed the researcher to create a list of individual communicative processes within each collaborative process (or case), and how those dynamics relate to individual interests, problem conception, resource allocation and resulting implementation. Following data collection, individual case reports were generated. Patterns among the independent and moderating variables were examined based on negotiation theory. These patterns were compared across the five cases. 


\subsection{Validity and Reliability}

Several challenges to validity and reliability exist within the research design. The research used a combination of pattern matching and explanation building based on the theoretical framework guiding the interviews and document review (Yin, 1989). The theories together predicted a pattern between interests and problem understanding observed in the conflict resolution field. Additional theory about facilitation techniques expanded this theory into the realm of collaboration. As this was exploratory, other elements were tracked beyond theory-predicted variables such as participant trust. Interview responses resulted in a list of other potential moderating variables influenced by using facilitation techniques; for example, learning, participant commitment to the process, and participant commitment of resources. These elements required explanation building.

Explanation building is noted to be dangerous in that an investigator may "slowly drift away from the original topic of interest" (Yin, 2003). Safeguards to prevent this from happening included strict use of the case study protocol and data collection instruments, writing up each case study following data collection, interview participants' verification of the write-ups, the follow up survey, and using the case write-up as a "chain of evidence" (Yin, 2003).

The research considers alternate explanations for the findings, included in Chapter Six. Further, ATLAS.ti software retains all codes, notes, code diagrams and documents in a database form. Were results found suspect, this 
database could be reviewed by a third party in connection to each case write-up (Yin, 2003).

The research addressed construct and internal validity with a thorough review of theory from multiple disciplines and linking that theory to each data collection instrument, see table 18. The research design included a series of data collection steps that reinforced each other to increase the internal validity and reliability of the data. Document reviews provided a basis of information about the issues, interests, and facilitative techniques employed in each case. Staff and key participant interviews expanded this information and provided emphasis to each variable of interest. For example, all cases used ground rules, but very few individuals brought the technique up as being helpful for understanding participant interests.

Interviewed participant responses were triangulated in order to find corresponding and different responses especially regarding stakeholder group interests and problem understanding. This step helped assure the researcher of the validity of the information. The researcher followed up on inconsistencies through clarifying questions with interviewed participants through email or phone class during the case narrative building process. Interviewed participants also provided feedback following their review of the narrative and analysis that helped clarify, confirm, or alter the analysis. Discrepancies in the narrative prompted further analysis. 
Table 18 Research elements to improve validity and reliability (from Riege, 2003; Yin, 2003)

\begin{tabular}{|llll|}
\hline Construct validity & Internal validity & External validity & Reliability \\
\hline $\begin{array}{l}\text { Multiple sources } \\
\text { of evidence }\end{array}$ & $\begin{array}{l}\text { Participant narrative } \\
\text { review (member } \\
\text { check 1) }\end{array}$ & $\begin{array}{l}\text { Replication logic for } \\
\text { multiple cases }\end{array}$ & $\begin{array}{l}\text { Develop/pilot/refine/use } \\
\text { case study protocol }\end{array}$ \\
$\begin{array}{l}\text { Key informants } \\
\text { review draft case } \\
\text { narrative \& } \\
\text { analysis }\end{array}$ & Pattern matching & $\begin{array}{l}\text { Thick case } \\
\text { description }\end{array}$ & $\begin{array}{l}\text { Record data in case } \\
\text { study database }\end{array}$ \\
& $\begin{array}{l}\text { Researcher self- } \\
\text { monitoring }\end{array}$ & Cross case analysis & $\begin{array}{l}\text { Give full account of } \\
\text { theories/ideas }\end{array}$ \\
(member check 2) & $\begin{array}{l}\text { Specific coding } \\
\text { procedures for coding } \\
\text { and analysis }\end{array}$ & $\begin{array}{l}\text { Link parallel findings } \\
\text { across multiple data } \\
\text { sources }\end{array}$ \\
\hline
\end{tabular}

The research addressed external validity and reliability with the development, pilot, and use of a case study protocol, see Appendix B. The case study database ensures the study could be repeated. The data in this study comes from multiple sources of evidence, ensuring the findings are robust. The qualitative data were emphasized while the quantitative follow-up survey was used as a member check (Creswell, 1998). A member check helps the researcher establish the credibility of her findings and interpretations through soliciting participant views. 


\section{CHAPTER FOUR}

\section{Case Results}

This chapter presents analyses from each case. Each case section gives background including problem description, origins of the collaborative process, the collaborative process history, and its current status. The second half of each section examines each case in relation to the research questions; these are listed and addressed in each narrative. Facilitation techniques and the impacts of interests are examined within Grey's (1989) three stage collaborative process framework (see Chapter Two). The three stages include problem setting, direction setting, and implementation.

Because the project topics are diverse, the cases are presented in order of fragmentation, from low to high, to orient the reader. Recall that potential fragmentation relates to different forces that disrupt collaborative process including social complexity, the substance of the problem, and technical complexity (see Chapter Two, page 47). Cases have potential fragmentation scores in a range from 13 to 39 based on case screening criteria (see Chapter Three, page 73). The order of the cases and their potential fragmentation score is: Case 1, Lane Clean Diesel (19); Case 2, Reduced Truck Idling (23); Case 3, Lakeview Biomass (27); Case 4, Tillamook Flooding Reduction (30); Case 5, Lakeview Stewardship Group (35-36). Document and interview evidence are incorporated into the narratives and analyses. Follow-up survey results are presented within each case where relevant. 


\subsection{Lane Clean Diesel Case Narrative}

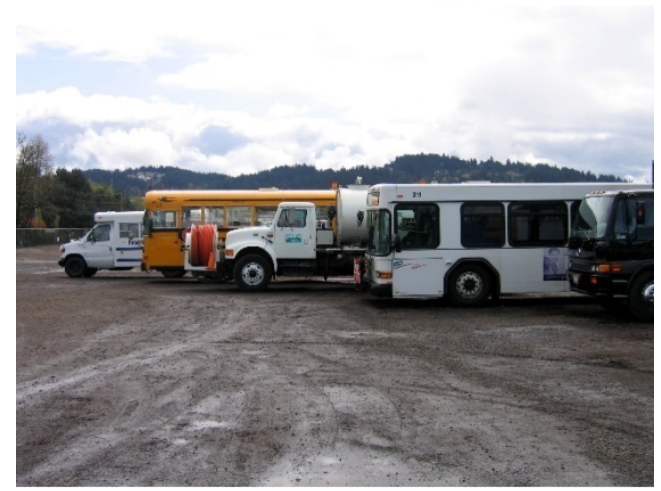

Figure 11. Lane Clean Diesel Image (Lane Regional Air Pollution Authority)

\subsubsection{Problem Description}

Research indicates diesel particulate is responsible for $70 \%$ of cancer risks from ambient air toxics (LCDP, March 2005). Diesel emission particulates contribute to asthma attacks and subsequent sick days as well as community health care (A. Peterson, 2005). Diesel exhaust is listed among the five most hazardous pollutants to children (DoC March 2005). A public desire to reduce air pollution from diesel particulate matter has emerged in favor of using cleaner fuels such as Ultra Low Sulfur Diesel (ULSD) and bio-diesel. ULSD addresses the most significant health-related issue of diesel fuel by reducing particulate matter emissions from $500 \mathrm{ppm}$ sulfur to $15 \mathrm{ppm}$ (DoC March 2005).

In September 2006, the Environmental Protection Agency (EPA) began requiring ULSD fuel as a standard highway diesel fuel. Public agencies were able to partner for pass through grants that would help defray $25-35 \%$ of the 
costs of changing fuel infrastructure or retrofit costs. A Business Energy Tax Credits (BETC) was also available to tax-paying entities to encourage them to shift to cleaner fuels.

In 2004, agency and business leaders in Lane County, Oregon wanted to get ahead of the mandate requirements and begin using ULSD or bio-diesel in their fleets earlier. The challenge was that refiners producing a mix of ULSD only made it available via pipeline to the Tacoma area (distributors had to haul truckloads of fuel to Lane County, which was expensive). ULSD and bio-diesel were not available from fuel suppliers in Lane County. There was a need for a stable, reasonably priced, supply of ULSD and bio-diesel in Lane County.

\subsubsection{Origins of the Collaborative Effort}

The Lane Regional Air Pollution Authority (LRAPA) wanted to bring people together to identify the potential demand for lower emission fuels. Different participants in Lane County, including school districts and public agencies, had expressed a desire to purchase ULSD or bio-diesel in the past, but it was unclear what the total volume of demand might be, and what possibilities existed from the supply side. The idea of the collaborative effort was to provide a setting for a voluntary discussion without a predefined outcome. Sponsors of the project thought agencies, businesses and competing fuel supply companies could come to the table to discuss the potential to meet supply with demand; they were under no obligation. LRAPA received an EPA 
grant to help fund the process and applied to become an Oregon Solutions project.

\subsubsection{The Collaborative Process}

This was a project initiated by the local diesel-using community, the private sector and government. It was a short-term project with a one-time implementation (less than five years) phase. This project involved parties coordinating different inputs in order to establish a market. The focus of participants' problem solving efforts was feasibility. The project is noteworthy because in order to reach an agreement, the group shared research information, shared concerns, and openly helped one another get the best deal out of the agreement. The central problem of matching ULSD and bio-diesel demand with supply did not change over the course of the project. Government agencies personnel, private business representatives and non-profit advocates came to the table if they had an interest in either purchasing, or selling, ULSD or biodiesel.

The group met as a team four times. Additionally, individual participants such as different businesses met in between the scheduled project team discussions. In this project the sponsor acted as a facilitator in addition to the support of two project managers and the convener. The group moved from the problem setting to direction setting phase in just two meetings. Many participants perceived this as a relatively low-risk, voluntary process without conflict. Prior to the first meeting, participants did collectively view regular 
diesel fuel use as an environmental issue. In discussing air pollution consequences related to diesel emissions, participants raised substantive concerns. Some were worried about the negative impacts of different fuel types on engines, the logistics and costs of bringing the fuel from Tacoma, and how to rationalize purchasing a higher-cost fuel before the mandate required it.

Participants shared the work of the project. Participants discussed who else needed to be informed of the process and attempted to bring them in through word of mouth. Different individuals tested fuel types on their fleets and brought results back (compared to 'before' data) to the group in order to share any potential risks to engine performance. The group worked to determine a public relations and brand image that would ensure participants would receive added benefits in participating: recognition and competitive advertising advantage. Participants can use a trademark fuel and bumper stickers advertising their involvement in a something that helps the community through lowered air pollution.

A key component of this project was having participants commit to purchasing a specific volume of fuel based on a certain cost. Different businesses met privately to discuss confidential business information about volume commitments and cost options. The convener requested that participants provide their volume commitments and a point above which they could not commit in order to know the potential range of demand. Notably, a 
number of participants heard about the project and joined in signing the Declaration of Cooperation late in the process.

Different groups contributed resources in order to secure a deal. Both distributors added bulk storage tanks at their distribution sites, providing a stable supply of clean diesel to the community, at a combined cost of more than $\$ 160,000$ in private funds. EPA provided $\$ 15,000$ to each provider to help offset the installation costs (LRAPA, 2009). In another example, government partners found funds to subsidize the cost of the fuel by 5 cents a gallon for public agencies.

\subsubsection{Current Status of the Collaborative}

The market is in place. Participants in this project are actively purchasing the fuel and using the brand "Clean Lane Fuel". 


\subsubsection{Lane Clean Diesel Within-Case Analysis}

\subsection{5 a Research Question One: Identifying Interests}

Interviews indicate participants understood one another's interests.

Participants took advantage of a potential opportunity and were thus willing to

work out the logistics of establishing a market for Ultra Low Sulfur Diesel and

bio-fuel in Lane County. Interests are embedded in document summaries from

the process. While both tangible and intangible interests were identified (table

19), most participants did not distinguish different types of interests.

Table 19 Interests identified in the Lane Clean Diesel collaboration

\begin{tabular}{|c|c|}
\hline Tangible Interests & Intangible Interests \\
\hline $\begin{array}{l}\text { On Substance of Issues: } \\
\text { Economic feasibility. } \\
\text { Fear of ULSD or bio-fuel ruining an engine. } \\
\text { Help create confidence in a fuel product. } \\
\text { Desire to reduce air pollution through } \\
\quad \text { reducing particulate matter. } \\
\text { Fear loss of investment money. } \\
\text { Share information. } \\
\text { Will use of certain types of fuel really result } \\
\quad \text { in lower emissions? } \\
\text { Process: } \\
\text { Accomplish this ahead of the mandate } \\
\text { (timeline). } \\
\text { Opportunities: } \\
\text { Be a year ahead of a mandate. } \\
\text { Learn about the fuel. } \\
\text { Take advantage of mechanical benefits to } \\
\quad \text { cleaner fuel. } \\
\text { Work out technical issues prior to the } \\
\text { mandate. } \\
\text { Add to a "green" marketing strategy. } \\
\text { Expand a market base (fuel suppliers). }\end{array}$ & $\begin{array}{l}\text { On Substance of Issues: } \\
\text { Prevent disadvantaging others in the industry. } \\
\text { Improve environmental health (e.g. reduce air } \\
\text { pollution) } \\
\text { Fear technology is not mature enough. } \\
\text { Relationships: } \\
\text { Have private business information respected } \\
\quad \text { and kept private. } \\
\text { Not feel pressured into a price commitment. } \\
\text { Participant honesty.* } \\
\text { Opportunities: } \\
\text { Capture a business opportunity/don't miss the } \\
\quad \text { opportunity. } \\
\text { Be "green". } \\
\text { Improve public relations. } \\
\text { Be ahead of the competition. }\end{array}$ \\
\hline
\end{tabular}

*This was expressed in interviews, but may not have been explicitly mentioned during the process.

Interests were discussed in this project in relation to the logistics of establishing a market for Ultra Low Sulfur Diesel. Participant interests were 
linked to objectives. The first quote below reveals different concerns from

environmental non-profits and local government agencies. Each party's

concerns are related to the actual issue of an ULSD market.

Well, we had some people there who were strong advocates of moving toward bio-fuel... We had folks from the public sector who were trying to figure out how they could meet some of the broader community desire to move in that direction, but still very sensitive to what the cost implications were because they were dealing with finite budgets....(P13).

The second quote illustrates a local business' marketing interests

related to an environmental ethic.

...I think our goal...was one, to get educated, then too, in the event we could jump ahead of the game and get ourselves and others committed to a volume of ultra low sulfur diesel, at a price that may have been a little more competitive, and we were anxious to be a part of that....we were partially looking at this as a way to develop an identity as the first private company to take a step towards something like this.... very much part of the labeling strategy to help set us apart, not only from our competitors, but really anybody in the private sector.... (P46).

Participant interests were also linked to the substance of specific

issues including economic feasibility, reducing air pollution, and the logistics of obtaining and using the fuel. Below, a participant describes

the perspective of the private buyers and sellers versus the agencies.

The [buyer's] key concern was 'will this ruin my engine?' so we did some education on this...The sellers, their key concern was if I switch a tank over and dedicate it and you guys don't buy it, then I'm going to lose a bunch of money, so I'm not going to dedicate this tank to this [unless] you are going to give me longer time prices or terms for our contract... what about the agencies? I think they just needed to meet a price point, that's really their main concern, because the agencies were there 
because they wanted to demonstrate environmental

responsibility... it was just a matter of getting the right price (P14).

Participant concerns stretched beyond the financial bottom line (see table 20).

In the quote below, an individual acknowledges the role an environmental ethic played in relation to building community support for the different businesses involved.

...I would say the central [concern] that we spent a lot of time on was ...was the political/public relations advantage of doing things greener, and how do we actually make the dollars and cents work out so that we're not expecting people to financially support a green solution that maybe from a dollars and cents standpoint doesn't make sense.... (P17).

Participants indirectly mentioned interests in interpersonal relationships during interviews. Several participants noted that people's honesty was a big factor in the success of implementing this collaborative project. "Definitely honesty of the participants, we all had to be willing to share gallonages, cost concerns, reasons for committing, that sort of thing" P46. Businesses also mentioned appreciating the voluntary nature of this collaboration, as they did not feel pressured to commit to a price that would not work for them. Participants did not explicitly mention process interests beyond wanting to complete the work and establish a market before the upcoming mandate. In the follow up survey, staff and participants were asked whether or not they agreed that specific interests identified in the interviews were important. The four respondents, one staff and three participants, emphasized 
the importance of reducing air pollution. Respondents were split on three substantive concerns: the desire to buy cost-efficient ULSD/biodiesel, and the desire for green marketing, a concern for cost feasibility of the fuel types. The respondents were also split on two relationship concerns: a desire for honesty and that business information be kept private. Three concerns highlighted in interviews were not supported by this small sample, see table 20 below.

Table 20 Follow-up survey responses of "important" interests

\begin{tabular}{|ll|}
\hline \multicolumn{1}{|c|}{ Lane Clean Diesel (n=4) } & \multicolumn{1}{|c|}{} \\
\hline Desire to buy cost-efficient ULSD and/or biodiesel in Lane County & Yes \\
Concern demand is too low for ULSD and/or biodiesel in Lane County & 50 \\
Concern fuel types will ruin engine & 0 \\
Want green marketing benefits (e.g. profits, public relations) & 0 \\
Concern about cost feasibility to buy ULSD and/or biodiesel & 50 \\
Concern business information fbe kept private & 50 \\
Want to work out technical kinks prior to mandate & 50 \\
Did not want to feel pressured into a price commitment & 25 \\
Desire for honesty & 0 \\
Reduce air pollution & 50 \\
Other text (one response: & 100 \\
Wanted to do a better job doing the right thing & \\
\hline
\end{tabular}

In summary (see table 21), participants described substantive, relationship and process interests in the interviews. Participants brought up substantive concerns during meetings.

Table 21 Lane Clean Diesel Summary: Interest findings

\begin{tabular}{|ll|}
\hline Interest Types & Identified tangible interests in substance and process \\
& Identified intangible relationship and process interests \\
Theorified shared interest \\
Themes & Interests discussed in relation to central problem and sub-issues \\
& Interests intertwined with issues and positions \\
& No conflict present \\
& Integrative and positional behavior present \\
\hline
\end{tabular}

Participants identified most relationship and process concerns during interviews; it is unclear how explicit these were during the process. Interests 
were intertwined with issues. Participant interests related to organization or program objectives. The group developed a shared interest in creating a branding campaign. The group also shared a desire to reduce air pollution, although in interviews this was less important to private business owners than it was to agency personnel. Agency personnel were invested in clean air mandates such as the Clean Air Act. Businesses were concerned about air quality from the perspective of doing "a good thing" that would also help business.

\subsection{5b Research Question Two: Facilitation}

This project convened five years ago and participants expressed having limited memory on the specifics in the process. This section summarizes elements participants recall as being helpful in contributing to the strength of the process. Forces of disruption are identified at the end of this section. Facilitation elements are summarized in table 22 on the next page.

\section{Pre-Collaboration}

A project assessment helped the project managers and convener understand the logistics of the problem and interests of different participants prior to convening the first meeting. The sponsor especially provided the project staff with feedback about different potential limitations of businesses and public agencies. The project assessment was not as formal as a stakeholder or conflict assessment typically used in alternative dispute resolution. 
Table 22 Lane Clean Diesel: Facilitation elements

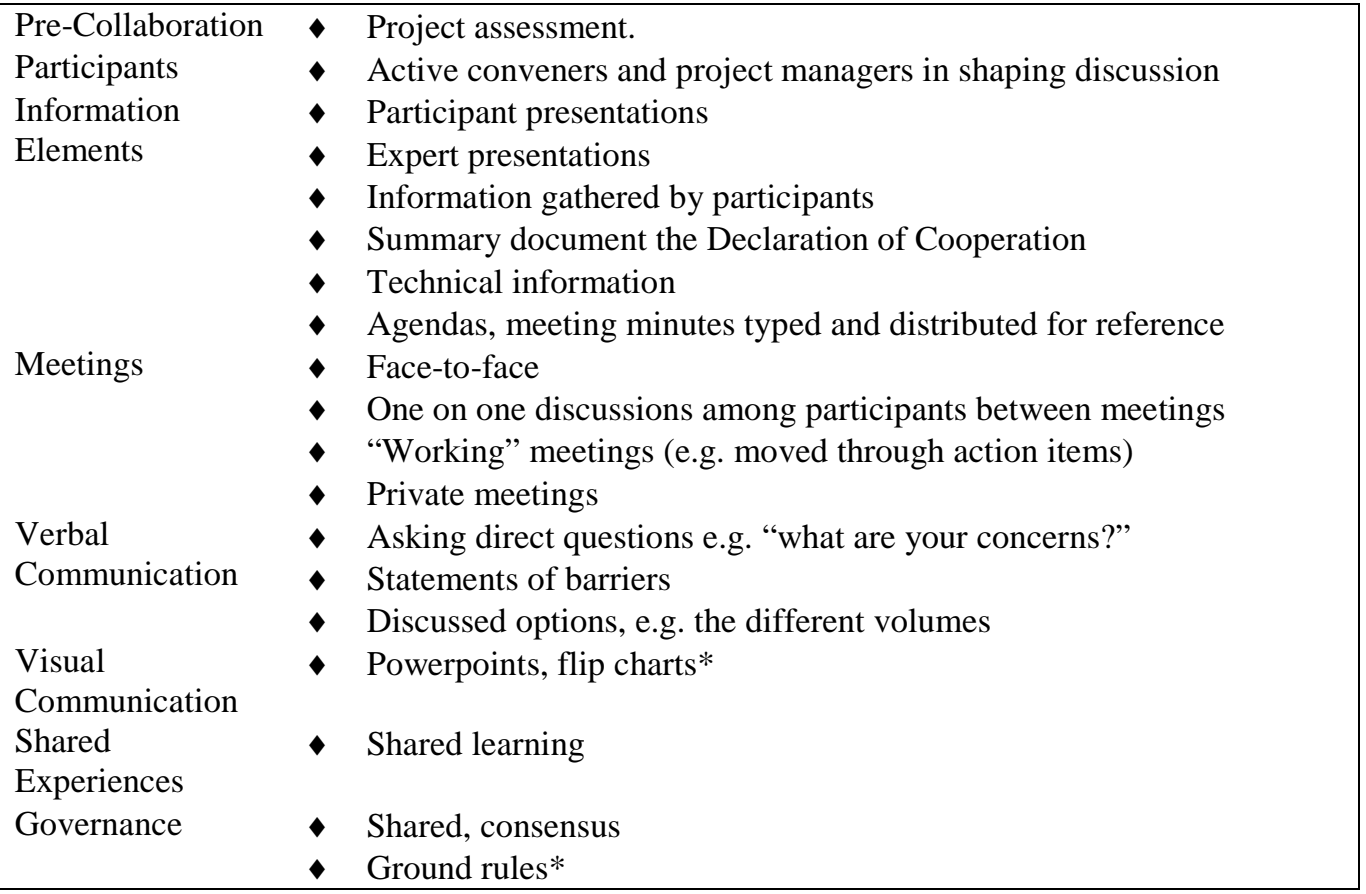

*Appears in documents, not emphasized in interviews.

\section{Participants}

Participants described the project sponsor, project managers and the

convener as active. All of them initiated discussions requesting people discuss

their interests, encouraged commitments, shaped discussions on options and

directed conversations about the substance of problems. Each of them had

knowledge related to diesel fuel and hurdles facing the differing participants.

In the example below, the author of the document (either a project manager or

convener) cautions participants to be realistic with their commitments to

ensure a feasible market for both buyers and suppliers.

Who will stick their neck out and state a guaranteed demand?

Distributors need commitments of X gallons per year/month

(Tyree and Brown will investigate). If Tyree sees development and people committing, they won't hesitate to bring ULSD 
down. Better be careful with that because we don't want to get ahead of refinery production (they're looking 12 months ahead). Brown or Tyree can handle the distribution side of it (Meeting Notes, Sept. 2004).

\section{Information Elements}

Presentations from both experts and participants helped shape the

discussion of relevant substantive information and how that related to people's

concerns.

..really the discussions surrounded getting familiar with the regulation, so what's coming, what is it you're going to have to do later on, and why later on is that going to cost you more money...just getting familiar with the facts (P46).

We did bring in people... [who] are working from the suppliers' standpoint, trying to increase their capacity to deliver this. A lot of it has to do with the distribution, you have a pipeline down here, you can't use the same pipeline for the different fuels. You have to figure out if you have enough critical mass... all those things he was able to describe... because you can't bring the direct distribution down here, you've got to truck it down...So we had people who could discuss why these costs were there, the barriers, how we might try to remove them... it helped everyone understand better, and it helped some people make some decisions that would be beneficial to them (P14).

Additionally, information in people's presentations helped address

some participant's interests.

...Our central problem was really in creating confidence in the market that our products would 1) do what we were claiming it would do as far as emissions reductions, and 2) that it wouldn't cause issues or problems for the fleet. So one of the advantages for us in being a collaborator in the project was that we were able to talk to a group of fleets all at once... some members of that group already have experience using our product, and so we were able to, in a group setting, have a dynamic situation where 
we could gain a lot of confidence in our product for those who hadn't started using it yet (P30).

The use of summary documents such as meeting minutes and

the Declaration of Cooperation, helped the group keep track of their

commitments.

Then it was each of the parties at the table talking about, and I guess round tabling about what could they bring to the table, what kind of commitment could they make, what kind of commitment were they willing to make, what can we sign on to, so there was a lot of that.... And yes, there was a draft resolution of some sort... Once everybody was in agreement, we all put our names on a piece of paper...(P46).

\section{Meetings}

Direct communication in multiple face-to-face group meetings helped

people understand the issues in relation to their interests. In the quotes below, a

project manager and the convener note participants' transparency.

They were just incredibly obvious [about their concerns and desires] because they would say the same things. So just those one-to-one discussions and the group discussions? Yeah, it was just really obvious they had the same interests, all you had to do was align the interests... it's a delicate task only in that you have to be respectful in communicating to each person in their own language...(P14).

Those who agreed to come and participate were already willing to be fairly forthcoming about their interests... I don't know if it was so much me asking as having the discussion as a group where everybody was asking questions and participating, but it gave us all a chance to better understand the perspectives of the different players and the different participants at the table and how these things affect them...(P17). 
A handful of private organizations required one-on-one meetings to

negotiate their buying commitments and prices, which was related to a concern

for protecting private business information.

... [Fuel seller business] started meeting with the folks that weren't comfortable talking about price openly in front of the group, and started working, okay, if you work with us this is what we can do, so it basically accelerated what needed to happen anyway, by probably a year or two. I think everybody would have got there eventually, but I don't think it would have happened all at once, which is part of what is helpful when you have to dedicate tanks, when you upgrade infrastructure, etc....

\section{Verbal Communication}

When prompted, participants emphasized direct communication about

their concerns. One project manager explained that in order to get people's

concerns and desires out into the group, "he just asked for it".

Once you got into a group meeting, did you share, did you tell everybody the concerns and desires you were hearing...? I asked them to share it, some of them shared it openly, some of them didn't, but what happened was enough folks shared it openly, and they were probably public sector buyers.

Do you remember what helped you understand differences and similarities in concerns among participants? Was it just people being straight up with each other? Yep, it totally was, you really didn't have anything to lose by sharing the truth. There were not a lot of risks (P14).

\section{Visual Communication}

Participants mentioned powerpoints and flip charts as a component of informative presentations. This element was not emphasized in interviews. 


\section{Shared Experiences}

It is evident from project notes that most participants asked for, gathered, and shared information to help support the project moving forward. Meeting summaries include detailed lists relevant to the research: potential costs of different fuel types, descriptions of various cost saving subsidies from different public grant sources, information related to fuel testing among all participants, and information about relative environmental and logistical benefits of different fuels.

\section{Governance}

Participants did not mention the role of ground rules in this process, however they used a template from Oregon Solutions. The group also worked to achieve broad agreement on their decisions to establish the market.

\section{Potential Disruptive Elements}

This case did not appear to suffer from disruptions based on social or problem complexity. Technical complexity could have disrupted the process. Recall participants were concerned about how fuels would impact different engines, and there were concerns about how to create the infrastructure to bring the fuel to Lane County. The group engaged in an information search through testing fuel types. The group also identified grant funding to help offset the cost of purchasing tanks to store the fuel. 


\subsection{5c Research Question Three: Role of Interests}

Interests shaped participant decisions most notably at the problem

setting and directions setting phases of the process. Table 23 shows the

participant actions affected by interests in relation to each collaborative

process stage.

Table 23 Lane Clean Diesel: Participant interests' impact on the process

\begin{tabular}{|c|c|}
\hline $\begin{array}{l}\text { Collaboration } \\
\text { Stage }\end{array}$ & Participants Interests Affected the Following: \\
\hline Problem Setting & $\begin{array}{l}\text { Participants deciding to enter the collaboration } \\
\text { Committing to the collaboration }\end{array}$ \\
\hline Direction Setting & $\begin{array}{l}\text { Perspectives on issues } \\
\text { Identifying sub-issues } \\
\text { Joint information search } \\
\text { Exploring options } \\
\text { Reaching agreement and closing the deal }\end{array}$ \\
\hline Implementation & $\begin{array}{l}\text { Commitment of resources } \\
\text { Program outputs: the market }\end{array}$ \\
\hline
\end{tabular}

\section{Problem Setting}

Participant interests helped motivate participants in becoming involved

in the collaborative process.

...Their concerns and desires were critical in motivating them to participate in a very real, concrete sense, rather than an abstract, intellectual exercise... It's very different when you're facing the federal mandates...there were some concerns and fears about that, it also presented opportunities. Everybody there was conscious about what's happening in the energy field, so those interests... drove the process and made it much more concrete and real than it would have otherwise been... they had a reason to better understand this, not as some sort of abstract intellectual idea, but as a concrete way that they can either operate their business, or do their job in the public sector, or just participate where they're going to have to live with the results....(P17). 
Participant interests helped ensure that people stayed committed to the process

and continue their involvement in the collaboration.

...the main thing is it [interests] kept people at the table. A lot of times you'll have these kind of things, the first meeting you'll have a lot of people, then the next time fewer people, the next time fewer people, so you winnow it down to the people who really cared and others thought 'oh nothing is going to come out of this'. We actually kept participation at a pretty high level... and I think it was because we were talking about real things that were going to affect people, they were looking for solutions, they were looking for things they could positively do, and even folks who weren't ready to make a commitment to go forward...[knew:] I need to express the concerns I have because they might have some impact... (P17).

\section{Direction Setting}

Participant interests shaped perspectives on issues. Participant interests were linked to organizational objectives, financial limitations, and business goals. This is part of what helped participants determine how much fuel they were willing to commit to purchasing in order to establish the market.

... from a municipal or government agency, the fact finding mission of being able to [substantiate] the reason for paying more for fuel... You needed to come up with reasons why that made sense... From a private sector side of thing, there are things somewhat intangible, branding and labeling, an opportunity to tell a story, that we took advantage of. From the city or government perspective, that's a harder sell...so they needed to gather facts about public health, environmental impacts, a few different mitigating factors that helped offset some or all of those additional facts on the fuel itself...(P46).

Participant interests helped form a basis for understanding the issues and related options. The group engaged in a learning exercise to help people better understand the logistics of using ULSD or bio-fuel, and setting up a 
market for the two. Once interests were on the table, the main emphasis was on aligning them, or seeing how they fit together in a way that would work for everyone. The only way to accomplish this was to seek further information.

A big part, it really is about aligning interests, and there are a number of folks that had to express 'this is what we're interested in, then this is what we're concerned about' just having that voiced, and having that all in one place where people could see it. It was a substitute for a whole lot of market research, or business development because then the suppliers could say okay, you guys are asking for this, we can give this to you if you can guarantee you'll buy this much from us over this amount of time...(P14).

Information then became a way of addressing the concerns. Notice in the quote below, each participant concern is labeled as an "issue" of its own. A representative of a private business describes three major concerns in buying biofuel or ULSD: 1) Will use of the fuel result in lower emissions? 2) Will use of the fuel harm my engine? 3) Can I afford it?

It's the fleets getting comfortable with 3 things... the first we've talked about is that the emissions claims are actually real, that's a fairly easy thing to resolve once you have $3^{\text {rd }}$ party testing and empirical evidence... The second would be is the product going to work well in their vehicles, or is it going to cause problems, again empirical evidence and testimonies take care of that. Third is a little more of a tenuous issue and that's the price, how much more am I going to have to pay to do this? And if I remember the project right, there had actually been some federal money in the form of grants to help alleviate the additional start up costs. All of those issues were largely taken care of, I think primarily in a very few group conversations.... (P30).

Participant interests shaped the development of strategies to address issues. This happened because interests shaped discussions of a bargaining 
range and a negotiation of incentives that would help different players come to an agreement. This was especially important for creating value in the negotiation.

When people say I'm willing to purchase this much of the cost of the tank, but really I will lose money on this deal unless somebody can come up with the balance of the tank, that spurs the request by [agencies] for some infrastructure development, but that broke it open, once that was there, it was easier and easier for people to play (P14).

Participant interests shaped agreement on the options. Following a discussion who could commit to what, the group decided that setting up a market was feasible. Beyond feasible, it would be profitable for the suppliers with some extra government assistance as described by an agency representative below.

The key thing was educating the suppliers on that yes, there really are huge buys for this kind of fuel... it was nice to have the extra money to help... because one of the tanks we put in, bio diesel tanks at [organization], that was probably a $\$ 100,000$ investment for them... And I think we gave them $\$ 15,000$ off the grant to help, also we educated them about the business energy tax credits, which a lot of the people don't know they can qualify for....for Bio fuels infrastructure, that was probably another $35 \%$ of their out of pocket (P19).

\section{Implementation}

Participant interests influenced the generation of options that influenced the commitment of resources. Following agreement on a set of options, the group committed necessary resources including grant dollars, infrastructure costs, and time in developing the market. 
Figure 12 below reveals example participant interests and elements of the collaborative process that helped address those concerns. This section summarizes how the group brought up and addressed participant interests.

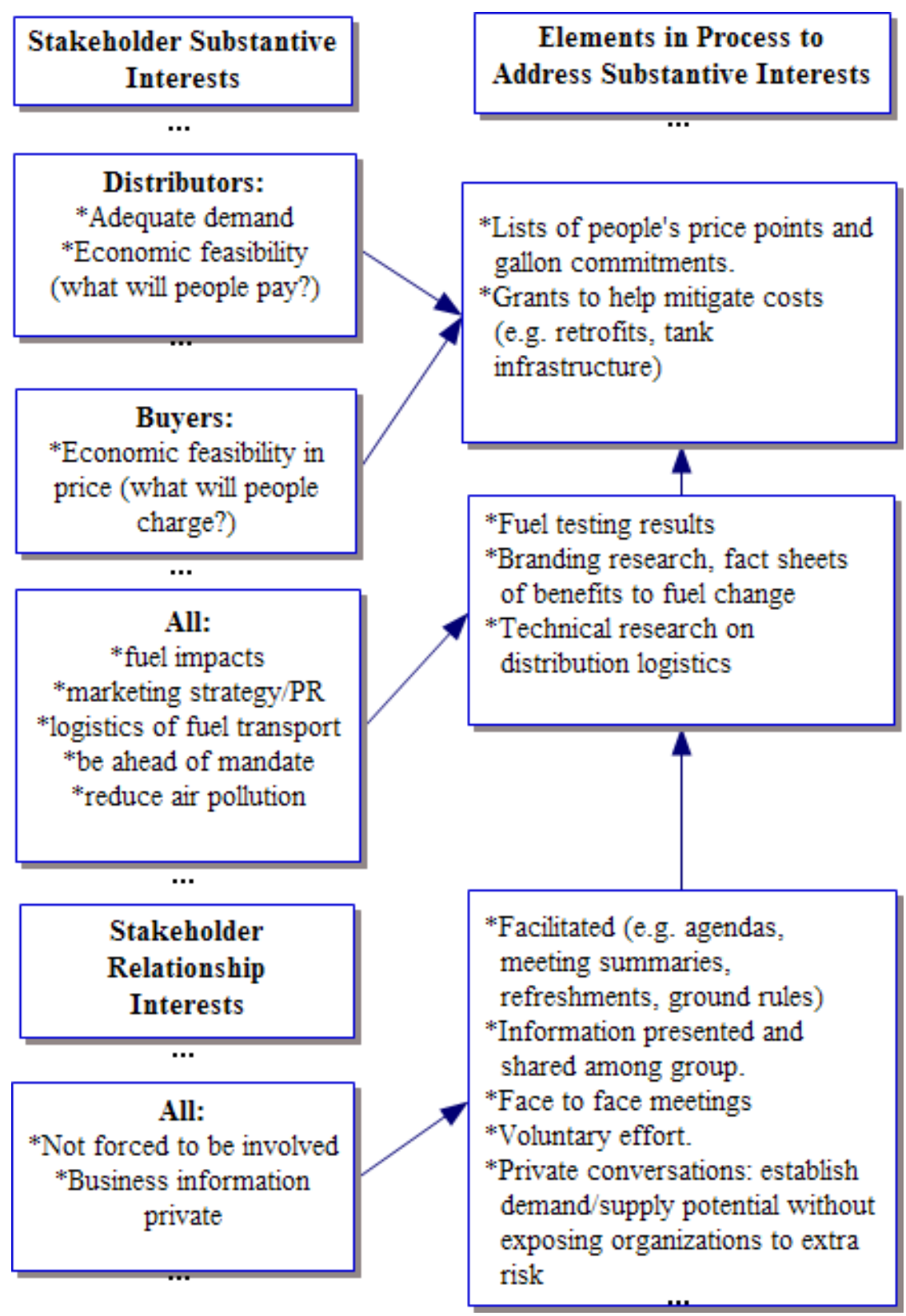

Figure12. Lane Clean Diesel Project: How interests were addressed. 
Participants in this collaborative process emphasized substantive, tangible interests. These interests were addressed largely through discussion of issues, fact finding and discussions of options. Participants mentioned intangible relationship and process interests as a means of support for addressing the tangible concerns. For example, private businesses needed to feel safe divulging confidential information in order to determine if a market was feasible.

The sponsor, convener and project managers were aware of participant interests prior to convening based on their experience and the project assessment. The facilitators brought up issues and asked participants to describe concerns in the first meeting. The group began framing the problem around an upcoming ULSD mandate that affects both public and private organizations. Following a review of ground rules, the group discussed air pollution and upcoming ULSD mandates as well as Business Energy Tax Credits that can help with infrastructure or retrofit costs. The group transitioned into a discussion of a logistical problem of establishing a market while taking advantage of government cost-saving programs - one way of addressing the upcoming mandate ahead of schedule. Sub-issues included the barriers to distributing ULSD in Lane County, the relationship of biodiesel to ULSD, and the use of a branding strategy to increase business. 
The group moved from the problem setting stage to the direction setting stage in that first meeting. The group also discussed who else to invite, identified needed resources, and identified information they would need to help make decisions.

The discussions and action items were centered on substantive issues; these elements addressed substantive participant concerns. Public agencies wanted to reduce air pollution but had limited budgets. Limited dollars meant the agencies needed thorough facts to rationalize spending tax dollars ahead of the mandate. Agency's relationship concern about public opinion was connected to their willingness to commit. This interest was a foundation for gathering fact sheets on the benefits of ULSD and biodiesel.

Private businesses were concerned about public image from the perspective of a marketing strategy: how could they benefit from spending money and extra effort by complying with a mandate ahead of time? The group agreed that a branding or public relations discussion would help both public agencies and private businesses achieve more benefits. The group focused on bumper stickers with everyone's logos, a trademark, and press coverage promoting a cross-sector partnership to help decrease harmful pollutants. The Lane Regional Air Pollution Authority paid for developing this trademark and disseminating the bumper stickers.

All sectors shared three substantive concerns: the economic feasibility of establishing this market (e.g. cost of fuel, cost of retrofits, costs of 
infrastructure), potential fuel use impacts (e.g. harm to engines, specific fuel usage requirements such as temperature or additives) and the logistics of fuel transport (e.g. trucking it from Tacoma, WA and storing it in tanks). The group collectively invested in several fact-finding missions to help gather information to help determine price points, government funding that could mitigate costs, and fuel testing results. Once the information was gathered, these initial concerns were addressed.

Interviewed participants consistently described the group's information sharing as being crucial to helping participants understand issues and concerns. Agency participants experimented with fuel products and returned to the group with results: what worked, what did not, what the circumstances were, etc. In this way, potential users could know more about what they might buy before purchasing it. They achieved a degree of common understanding about the products they might buy, and in turn counteracted potential uncertainty about using these products.

Participants identified intangible relationship and participant interests as being important to this collaboration. In interviews, participants described the voluntary nature of this collaborative, participant expertise, and the ability to hold private discussions as important to creating a feeling of mutual respect and trust in this process. Private discussions were held between distributors and potential buyers in order to establish the level of demand and range of prices people were willing to pay. This ability to talk in private helped these 
participants trust the process and be certain the demand levels were high enough to make the needed infrastructure investments. This was crucial given that public agencies had price premiums (e.g. $\$ .05$ or $\$ .10$ a gallon) over which they would not be able to participate - limiting their gallon commitment. The two distributors added bulk storage tanks based on the demand for ULSD in this project. The Environmental Protection Agency provided each company $\$ 15,000$ to offset the combined $\$ 160,000$ cost of this infrastructure.

Building support through involving other players was a key portion of the implementation phase. A core group of participants conducted much of the fact finding. The participants spread word of progress and attracted other participants, increasing the potential for success. By the second meeting there were individuals from 22 organizations (up from 16) and more than 30 organizations committed to the project by the time the Declaration of Cooperation was created. 


\subsection{Reduced Engine Idling at Truck Stops Narrative}

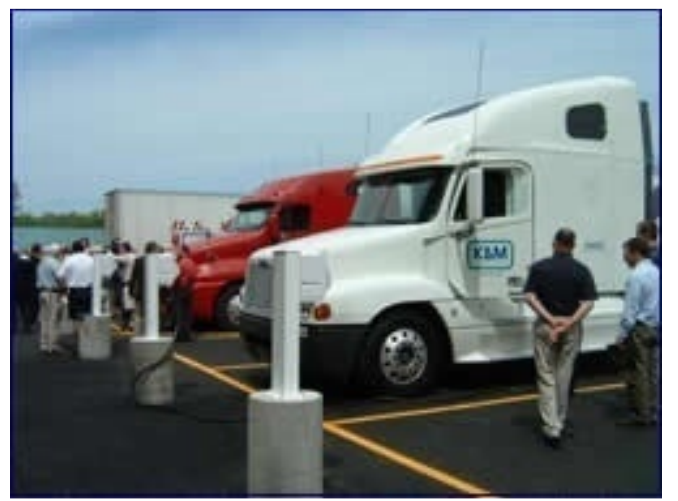

Figure 13. Reduced Engine Idling Image (Image from Shorepower Technologies)

\subsubsection{Problem Description}

Drivers of large diesel trucks often idle truck engines during mandated safety rest periods. There are more than 10,000 trucks that travel the I-5 corridor in Oregon every day (Downing, 2004). Truck drivers run their engines off battery power, releasing carbon dioxide, diesel particulate matter, and other potentially harmful emissions in the atmosphere. The practice adds wear and tear on the engines, is a quality of life issue for drivers, and adds to drivers' overall transportation costs. Prior to the collaborative effort, there had been a few incidences of communities neighboring truck stops in different cities along the I-5 corridor complaining about sound and pollution from truck idling.

Instead of running trucks off of battery power, drivers could link to a truck side service unit that is connected to the main power grid to power heating, cooling or personal appliances in the sleeper unit. This is known as truck stop electrification (TSE). TSE is a site-based approach to the idling problem requiring the installation of infrastructure in truck stop parking lots 
and minimal equipment for trucks. Other alternatives to reduce the need to idle include outfitting trucks with auxiliary power units (APU's) or other devices to provide onboard heat, air conditioning and power. Such devices can be used wherever the truck driver chooses to stop and do not require infrastructure at truck stops.

The main barrier to truck stop electrification is that the installation of the hook-ups requires action from truck stop owners, drivers and technology providers. Drivers need to purchase adapters in order to use the hook-ups but will not invest in this cost until there are a large number of places that have the technology available. Truck stop owners will not install the hook-ups until there is a market for them. Technology providers do not want to risk an economic loss by putting new technology in place without an established demand.

\subsubsection{Origins of the Collaborative Effort}

As the National Association of Truckstop Owners stated on idle reduction technologies "Ultimately, success in idle reduction will require a collaborative approach by travel plaza operators, after-market providers, utilities, original equipment providers, trucking fleets, and appropriate state and federal agencies" (D. o. C. Reduced Idling, 2005).

The Oregon Department of Environmental Quality (DEQ) established a Clean Diesel Initiative with a goal to reduce emissions from diesel engines for public health benefits. The initiative relies primarily on retrofitting exhaust 
controls on existing engines and using cleaner grades of fuel. Truck stop electrification, with reduced need for engine idling, is considered another technique to achieve that goal. Representatives at the Oregon DEQ thought bringing different parties together to discuss opportunities and barriers could help foster a system of emission-free truck stops in Oregon. In 2003, Kevin Downing of the Oregon DEQ hoped to open a dialogue on the chicken and egg issue of reducing truck idling through using either TSE or APU technology. He wanted to help different groups understand that there was a common problem, and see how they could each contribute to a solution.

The collaborative group developed a project plan that supported a grant application to the Environmental Protection Agency's (EPA) SmartWay Transport program. The project focused on commercial truck parking facilities because federal law prohibits providing services at public rest areas that compete with private operations. They also focused on TSE to ensure many of the benefits are accrued within the state of Oregon, and because it was less expensive than installing APU's. Oregon State University (OSU) and the Climate Trust administered a project that would "electrify" at least 600 commercial truck parking spaces (out of nearly 2000) primarily along the I-5 corridor. There are 5,700 commercial truck spaces in the state and 290,000 long haul trucks licensed to operate in Oregon as of 2005 (Downing, 2004). OSU researchers developed a site prioritization method with DEQ. They also implemented a monitoring, evaluation and assessment system to monitor user 
response. The Climate Trust solicited participation from truck stops, technology providers and drivers.

\subsubsection{The Collaborative Process}

This was a government-initiated short-term collaboration with a shortterm (less than five years) implementation phase of the TSE technology. One of the technology providers dropped out of the discussion after the Declaration of Cooperation was signed. Both providers signed the agreement to be a potential future partner and implement their technology. Thus the group used the remaining provider.

The project had two project managers, one for process and one for content. The convener, Dr. Gail Achterman of Oregon State University, consulted a text on collaborative learning for guidance in facilitating discussions. One participant, Bob Russell of the Oregon Trucking Association, acted in a bridge-building role helping to address concerns among government individuals, truck owners, and the truck stop owning participants. The group worked on a set of ground rules that included general principles for conduct and guidelines for how the group would commit to working together this is a standard template provided by Oregon Solutions.

The group formally met as a team four or five times between July 2004 and January of 2005. Participants met on their own to discuss concerns between meetings. The group used formal meeting time as a "working" session where objectives were set prior to each meeting, participants gathered research 
or information and presented in the group meetings. The group used meeting notes and summaries as references. A sub-set of the team worked on an EPA grant together, which helped those participants better understand the scope of the problem and potential benefits of idle reduction (Achterman \& Graetz interviews, 2009). The group developed an information element that was crucial to the project: an analysis of the valuation of benefits from truck stop electrification that incorporated financial, environmental and public health costs of idling versus installing idle reduction technology (D. o. C. Reduced Idling, 2005). This was in addition to a summary cost-benefits analysis of three different technologies (Shorepower TSE, IdleAire Technologies, and Auxiliary Power Units). The differences among the technologies are listed below.

- Shorepower TSE - truck connects to pedestal installed into parking spaces. Delivers electricity, internet and cable services.

- Idle Aire Technologies - truck has on-board equipment that connects to an overhead unit that provides services.

- Auxiliary Power Units- truck has on-board that use a small engine to provide heat, cooling and electricity.

Several funding sources helped the group successfully implement the project including money for carbon dioxide offsets from the Climate Trust, a grant from the Environmental Protection Agency, tax credits and loans from the Oregon Department of Energy. The technology provider also matched 
contributions to a certain level, while private businesses and other participants provided technical assistance.

\subsubsection{Current Status of the Collaborative}

Originally, Climate Trust (with input from the collaboration team) decided to use Idle Aire Technologies in the RFP process. Idle Aire removed themselves from consideration. The group moved away from APU's because they wanted to ensure that Oregon tax money would directly benefit Oregon communities. The APU technology goes with the truck and travels beyond Oregon's boundaries. The group used Shorepower Technologies.

During the last five years, members of the group are still working to install the first 200 of 600 proposed units. There were some unexpected logistic issues with implementation that arose, causing delay in the process.

\subsubsection{Reduced Engine Idling Within Case Analysis}

\subsection{5 a Research Question One: Identifying Interests}

This group identified concerns and desires early in their project.

Several business participants expressed that the intangible relationship interests related to their willingness to stay engaged. At the first meeting while drafting ground rules, the group discussed the need for and their commitment to open communication of concerns, resources, and ideas. The group also agreed on a need for building trust and respectful, active listening. 
Table 24 Reduced Engine Idling: Identified interests

\begin{tabular}{|c|c|}
\hline Tangible Interests & Intangible Interests \\
\hline On Substance of Issues: & On Substance of Issues: \\
\hline Save money. & Convenience. \\
\hline $\begin{array}{l}\text { Truckers want to have comforts during } \\
\text { mandated rest-stops (e.g. } \\
\text { electricity, air conditioning, heat) }\end{array}$ & $\begin{array}{c}\text { Concerns over truck-stop parking lot pedastal } \\
\text { infrastructure w/TSE (e.g. cost, } \\
\text { maintenance, interfere with parking }\end{array}$ \\
\hline $\begin{array}{l}\text { Concern electrified truck stops would } \\
\text { compete with other truck stop }\end{array}$ & $\begin{array}{l}\text { lots, truckers run them over in the } \\
\text { dark/rain, cause a loss of business) }\end{array}$ \\
\hline services $=$ loss of business. & Understand the potential demand from the \\
\hline $\begin{array}{c}\text { One company needed regulatory assistance } \\
\text { to be a technology provider. }\end{array}$ & $\begin{array}{l}\text { trucking community for this } \\
\text { technology. }\end{array}$ \\
\hline $\begin{array}{l}\text { Concern about ruining a truck's engine by } \\
\text { turning it off. }\end{array}$ & $\begin{array}{l}\text { Concern there wasn't a demand from truckers } \\
\text { for this. }\end{array}$ \\
\hline Driver retention. & \\
\hline Equal competition among idling reduction & Relationships: \\
\hline technologies (e.g. not have one & Respect. \\
\hline type pushed in this dialogue). & Openness. \\
\hline & Being heard/listened to. \\
\hline Opportunities: & A willingness to drop positions. \\
\hline $\begin{array}{l}\text { Use of idle reduction technology to reduce } \\
\text { carbon dioxide emissions. }\end{array}$ & $\begin{array}{l}\text { Truck stops and truckers improve relationship } \\
\text { with public. }\end{array}$ \\
\hline \multirow{7}{*}{$\begin{array}{l}\text { Have a source of } \mathrm{CO} 2 \text { emission reduction to } \\
\text { use in climate trading program. } \\
\text { Improve air quality for human health. }\end{array}$} & Protect other participants from negative \\
\hline & impacts (e.g. P.R. or financial burden) \\
\hline & Process. \\
\hline & Consensus \\
\hline & Voluntary \\
\hline & Opportunities: \\
\hline & $\begin{array}{l}\text { Help truckers have more cost-effective } \\
\text { amenities that improve their quality of life. }\end{array}$ \\
\hline
\end{tabular}

The conversations were focused on different stakeholder groups' concerns in relation to different barriers of idle reduction (M. A. Reduced Idling, 2004). As people teased apart the issues, their tangible and intangible interests became apparent (see table 24).

In a follow up survey, participants were asked whether or not they agreed that specific interests identified in the interviews were important, see table 25 below. The seven respondents, two staff and five participants, emphasized the importance of reducing air pollution. More than half of 
respondents agreed that substantive concerns were important including: desire for $\mathrm{CO} 2$ reduction, avoiding unnecessary costs with idling reduction technology, and a concern about trucker demand for this technology. Of relationship and process concerns, everyone agreed that honesty was desirable, more than half agreed that respecting individual's views was important, and more than two-thirds of the respondents wanted to improve trucker quality of life.

Table 25 Reduced Engine Idling: Follow-up survey responses of important interests

\begin{tabular}{lc} 
Desire to reduce air pollution & 100 \\
$\begin{array}{l}\text { Desire for CO2 reduction } \\
\text { Avoid unnecessary costs with idling reduction technology (e.g. installation, }\end{array}$ & 71.4 \\
maintenance) & 85.7 \\
$\begin{array}{l}\text { Concern that truck stops will lose revenue from competition } \\
\text { Concern with trucker demand for idling reduction technology (e.g. worry they won't }\end{array}$ & 14.3 \\
use it) & 57.1 \\
$\begin{array}{l}\text { Desire to improve trucker quality of life } \\
\text { Desire for honesty }\end{array}$ & 71.4 \\
Concern that everyone's view be respected & 100 \\
Desire to improve relationships & 57.1 \\
\hline
\end{tabular}

In interviews, participant brought up interests intertwined with issues.

“...Certainly the other groups, [Organization] wanted the offsets so they could sell them to the utilities, and the government folks were mostly interested in the environmental benefits" P22.

Well, I think from the public's perspective it was a health issue in reducing air pollutants, for us it's a global warming issue, so reducing greenhouse gases, I think from the trucking sector the key issues were cost, keeping cost down, not just how much is it going to cost to install the technology, to maintain the technology, who will bear those costs...(P10). 
The issues of global warming and the reduction of pollution were the broadscale rationale for being involved in the project. The deeper concerns, or tangible and intangible interests, were buried and became clear when people discussed barriers preventing them from adopting idle reduction technology.

.... On the trucker's side, maybe they weren't necessarily motivated with fuel prices at that level, they didn't know there were alternatives, and maybe they didn't care, or they thought it was not the right thing to do to the engine. On the truck stop side, it was the barrier they didn't see anybody demanding this type of service... [one operator's] opinion was that he can understand there was potentially a problem [idling], but he didn't see how he had any opportunity to provide a solution...(P28).

It is clear that some business participants were doubtful of the different technologies. One participant notes a business owner who had a negative experience in the past: "he had worked with a company once before that had come on to his lot and installed pedestals, then that company went bankrupt and he was stuck with these pedestals that drivers were knocking down in the dark, dragging behind their trucks, and it was a burden for him, it took up space in his lot...” P28.

Some participants were also skeptical about working with government. One participant explains that the typical way the trucking industry relates to public agencies is not collaborative; private business owners wondered if this would actually be different (P22).

There was a lot of skepticism and mistrust of government...I think that people may have been interested doing this may have understood there was an issue, that there was potentially a 
solution, but their skepticism level was fairly high, where by the end of the process their buy in about getting a solution that was real, and could be implemented, and would make business sense, they were much more on that side than they were in the beginning....(P28).

Participants had intangible concerns of being respected and feeling

heard. This may have not been obvious to them at the beginning of the process, however, when these concerns were addressed it helped contribute to a sense of trust in the collaborative process. This was deemed by at least two participants as a part of the group's success. "[Project managers and conveners] were very patient, they listened to the truck stop operators concerns, acknowledge their concerns and helped work through them....sort of explore what they were, and perhaps what they weren't, so they could get to an outcome...there was no agenda being pushed."

Right, part of it was just having a forum for everybody to express all their interests, all their needs acknowledged as being important, and that the concerns, they weren't necessarily a bad guy, they weren't evil, they were doing these because of fundamentally sound reasons (P28)

Interests were connected to people's roles and responsibilities. Each

person's responsibility shaped a perspective that in turn shaped concerns.

...Correct, that the truck stop industry's position was represented... and there was an understanding to the problems that are faced by the truck stop industry with the push for antiidling legislation and technology....Logistical concerns, logistical problems that need to be covered, the practicalities...everything looks good in theory, but there's a practical and an application side, real world does not always follow theory $(\mathrm{P} 3)$. 
... and the interest from the state's perspective in this is that it just seemed obvious from an outside observer that there was a problem and there was a solution... and that continuing with the problem has adverse impacts on the environment in terms of elevated diesel particulate and emissions from the engines, which not only affected local health issues, but it also affected livability for nearby residents from truck stops..(P28).

Participant interests were connected to individual's positions on different issues. Again, the group did not make distinctions among issues, positions and interests. One truck stop owner had a negative experience with a type of idle reduction technology in the past. This led to skepticism, reticence, and a position that these are not necessarily beneficial to either a business or the truckers.

...plus as [person] told me, it's that on a dark night when it's raining, truckers may not know what's going on at 50 feet behind their tractor, so when they're driving around the lot, around these pedestals, they may end up knocking them down and tearing them out, and destroying the infrastructure....(P28).

The technology participants had interests that were based on their business objectives.

[Technology provider] needed help, they needed technical assistance, regulatory assistance, funding, to begin to enter into this market and be a technology provider for reducing emissions at truck stops... while [other technology provider] had basically a Wall Street model for how to do this (P27).

Truck stop owner participants' business objectives (e.g. retaining customers) extended to meeting the needs of their customers.

... as we got deeper into it, we were able to get a joint statement from the truck owners and truck stop operators, and the trade association sort of jointly supporting this effort. What they 
didn't want to have happen is electrification going... into rest areas, they're very worried about competition...we don't have private service providers at truck stops in Oregon... we have state owned and operated rest areas...the truck stop owners wanted to implement the technology and wanted to try to find a way to do it with minimal risk financially, and they didn't want to see the pilot [projects] going to the rest areas, that would keep trucks that might come into their truck stops... (P27).

Each participating organization seemed to prioritize their interests based on their role. For example, truck stop businesses appeared to have had a primary concern of economic feasibility based on their business model. Economic feasibility was based on cost to implement it, potential negative impacts on the parking infrastructure, and potential business lost by its presence (if any). This complex cost-benefit concern was followed by:

- concerns about types of technology affecting the economics of their customers,

- concerns for quality of life for truckers,

- air pollution reduction, and

- desire for positive public relations.

The economic feasibility concern appears to be consistently re-evaluated, and at the forefront of participants' perspective based on different technology options.

Well for people like the truckers and the truck stops, the economics drive the issue for them, if it costs me money I don't want to do it. And from the public agency side, why is that a barrier, we can see this bigger picture [air pollution]...from the agency side we were able to find resources that allowed them to capitalize these initial projects to reduce their risks, so that allowed for the business side to engage in these behaviors without seeing it was going to damage bottom lines, or profitability...Then they were willing to take some risks in actually saying yeah, you can put this stuff on my lot (P28). 
In summary, participants brought up substantive, relationship and process concerns in both the interviews and during the process, see table 26 . A history of mistrust between agencies and private businesses contributed to the project managers and convener emphasizing the need for openness and respect. Participants focused on substantive interests. Substantive interests were intertwined with issues. Participant interests were also connected to participant roles and organizational objectives.

Table 26 Reduced Engine Idling Summary: Interest findings

\begin{tabular}{|c|c|}
\hline Interest Types & Identified tangible interests in substance and process \\
\hline & Identified intangible relationship and process interests* \\
\hline & Identified shared $*$ interest \\
\hline $\begin{array}{l}\text { Theory-related } \\
\text { Themes }\end{array}$ & $\begin{array}{l}\text { Interests discussed in relation to central problem and sub- } \\
\text { issues }\end{array}$ \\
\hline & Interests intertwined with issues and positions \\
\hline & History of conflict led to mistrust that had to be addressed \\
\hline & Integrative and positional behavior present \\
\hline
\end{tabular}

4.2.5b Research Question Two: Facilitation

The group discussed interests in relation to issues, in response to information searches and during group meetings. Side meetings between the convener and at least one business owner helped address fears and skepticism about using this technology. Participants identified key facilitative elements that helped this process, see table 27. 
Table 27 Reduced Engine Idling: Facilitation elements

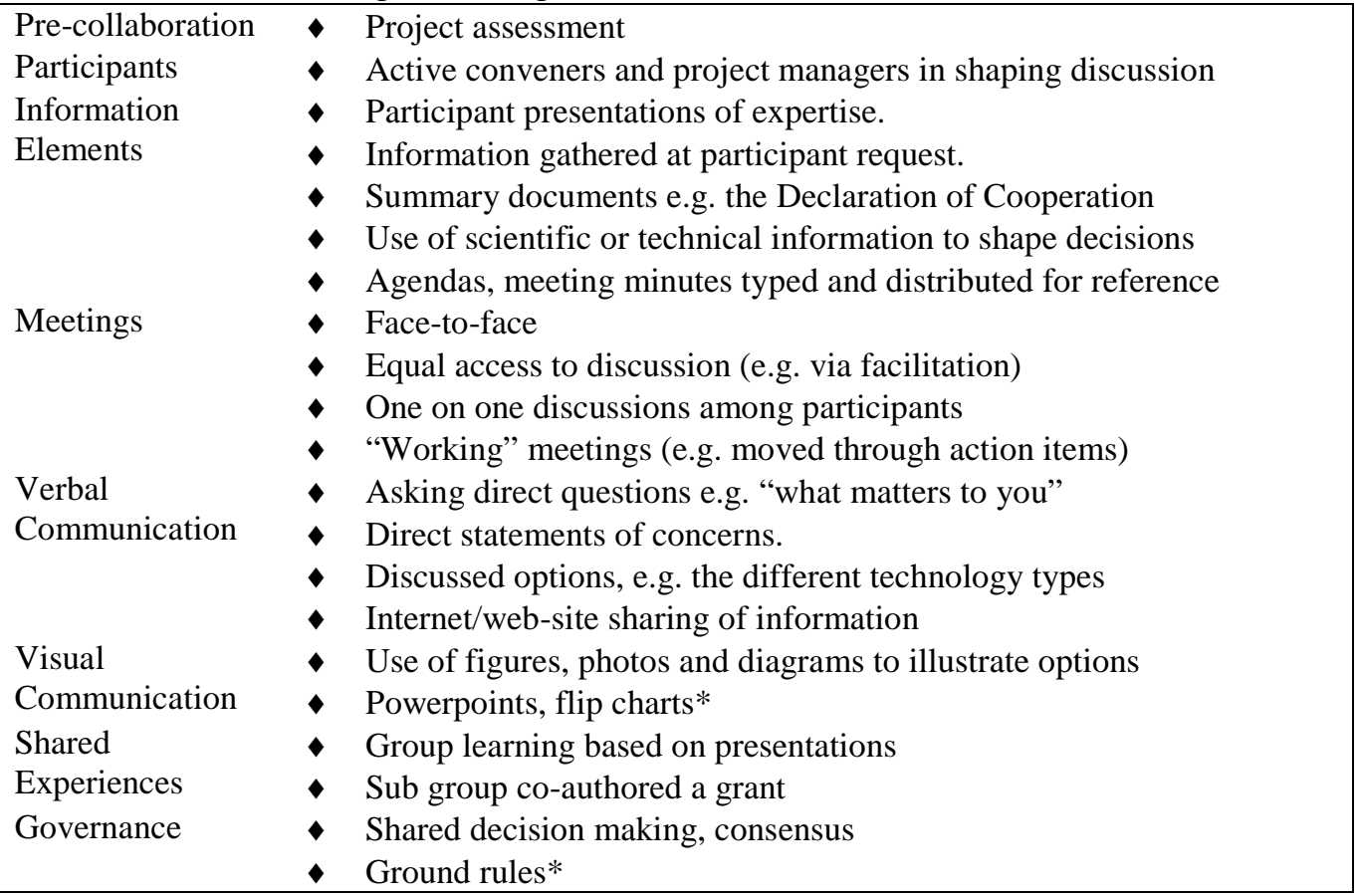

*Interviews did not emphasize

\section{Pre-collaboration}

The project managers completed a project assessment with help from

the convener before bringing people together. This helped the facilitators

identify different parties' concerns, issues, and what prevent parties from

participating. The information gave the project managers and conveners input

on how to frame discussions and who to invite to the table. The convener and

project manager focused on bringing a diverse group of players to the table.

This is described in the quote below.

...So the discussion with the stakeholders was are you interested in a discussion about what can we do on a volunteer basis, it might include reducing idling at truck stops, that doesn't mandate anything but shows a willingness on the trucking sector to find ways to address the problem...We had the makers of the trucks, we had the trade association for 
truckers, we had company owners, and we had truck stops. For the project to go forward we had to understand if they wanted to be at the table... we were trying to find out what they think the issue is, what they think the solutions are, what kind of outcomes might they want to see, who else should be invited... (P 27).

\section{Governance}

The group drafted ground rules in the first meeting on September 13, 2004. They included four general principles for conduct and process, and eight complex rules related to trust-building, cooperation, communication, concerns, and allocating resources. Below are two examples from this list:

We agree to approach problems with humility and adaptability. We will inevitably make mistakes and we will learn from these mistakes, make correlations, and not place blame.

We commit to openly communicate ideas, potential contributions, and concerns, and also commit to engage in respectful, active listening to each other.

The ground rules in this process follow the same template structure offered by project managers from Oregon Solutions. While only marginally referenced by participants, the conduct of participants reflected in meeting minutes match the guidelines set by the group. This indicates the group who participated in the on-going efforts took the commitments seriously, or followed a code of conduct that aligned with the ground rules. The group worked to achieve consensus and shared decision making to create the final agreement. 


\section{Participants}

Participants noted that the active convener and a participant leader

helped shape the course of the discussion.

[Person] was very good at directing a meeting and keeping people focused, and pushing people towards getting some type of resolution, so what I recall is she would always be pushing back, she'd always be thinking 3 steps ahead of what do we need to do... (P28).

[Name] did a fantastic job as a convener, and the folks from the [organization] and [convener] did an excellent job developing trust. They were very patient, they listened to the truck stop operators' concerns, acknowledged their concerns, and helped work through them... Sort of explore what they were, and perhaps what they weren't, so they could get to a point they could get to an outcome (P2).

Participants in this group were flexible and concerned with each other's interests. Several interviewees acknowledged that they wanted a solution that helped everyone. So while each person came in with his or her specific interests, they worked to create something that helped others at the table; this is reflected in the quote below.

...that's kind of how consensus was brought about, everyone wanted consensus, everybody wanted to find a solution, they just wanted to find a solution so nobody was hurt, that the trucking industry wasn't given this burden, or the truck stop industry given this burden to deal with themselves, so that all came from mostly discussions (P3).

\section{Information}

Summary documents, such as the Declaration of Cooperation helped people think about what they wanted prior to signing a commitment. The DoC 
has a brief description of the problem they are working on, their commitments, and an implementation plan for how the group will accomplish the content of the agreement (P28).

Presentations and research gathered by participants and experts helped expand people's understanding of different issues and options on the table. The participants used the information to help them understand how different options would affect their interests. This is the key element that helped people understand how their substantive interests could be addressed.

One of the issues right now in the trucking industry is driver retention, and so it was a concern for them to have to lose people, so they wanted to improve working conditions, they were concerned about the impacts of idling on drivers, of the exhaust emissions, so they installed cab fired heaters... So that does fine for the cold days, it doesn't do anything for the hot days ... [Organization] had commissioned some studies ... and were able to determine a truck hooked up to their system, the driver slept more, had a deeper and more restful sleep than the guy sitting in a truck that was idling all night long....(P28).

There were a few presentations by various groups that were involved, who they were, what they were, what they were trying to accomplish, what their goals were, or what their concerns were, it was kind of everyone educating everyone about [themselves]...(P3).

\section{Meetings}

Face-to-face group discussions at the beginning of this collaborative process helped participants describe their concerns and desires (P2, P22, P28, P27). 
The content of one-on-one conversations away from the table between

participants seemed to help address at least one party's concerns. Several

participants had conversations outside of the group meetings that allowed them

to caucus and return to the group ready to participate in the collaborative.

You know, it was when I think the truck stop owners came to the realization that it was inevitable that they would be installing this type of technology, it was a question of when, and the opportunity that was before them gave them significant financial benefits.... It was a combination of that and certainly the behind the scenes discussions.... I remember a particular conversation I had with one of the operators in their office, and when we got done with that things seemed to go better...(P22).

In the quote below, another participant describes a particular side-

conversation event but uses terms "position" and "interests" interchangeably.

The main idea is that there was a willingness to continue negotiating.

I suggested you talk with [name], and specifically talk with [him] about his outside the room conversations with both [name], and other truckers, as well as [names] at the truck stops...I know originally [he] was representing only the truckers' interest, so [he] came to a meeting saying I represent the truck stops' interests as well, and we have, among our own group, developed a position around this issue we wanted to present to the group...so I don't know how much of that might have influenced [another person's] decision ultimately to move from skeptical to interested...(P28).

\section{Verbal and Visual Communication}

Direct group discussions were the primary method of bringing up people's interests. While discussions were focused on issues, and logistics, this also surfaced what people cared about. People directly stated their concerns and asked clarifying questions (P28, P3, P27). As one participant notes, the 
group "needed to understand each other's issues, or each others hurdles they had to overcome to bring it to reality, and needed to understand that the cost to one industry versus another industry, if something is implemented or mandated, and being open minded about that, and respectful of that....." (P3).

Participants mentioned the helpfulness of visual elements of presentations in passing. These included powerpoints, descriptions of the various technologies, and scientific study results.

\section{Shared Experience}

In addition to the learning that resulted from presentations, a sub-set of the group worked together prior to convening on applying for a grant. The grant served as both a summary document and a shared learning experience. The grant process helped a subset of participants understand their stake in the project. When the sub-group met with the larger group to collaborate, a new issue emerged of how the objectives of this collaborative would address the grant's requirements. The grant provided key financial resources for participants choosing to install the idling technology, thus was a component in the cost-benefits analysis that addressed the private sector participant's bottom line financial concerns.

...So it was really a sharing information on what are the technologies available, what are the comparative costs, and the really complicated part of the whole thing became tying it to the EPA grant, the truck stop electrification grant, and using the collaborative group to help us put together the business deal that made the EPA grant successful. So the complex problem we were solving was how to put the business deal together for the 
research grant to work, so who is going to sign up their truck stops, what companies are going to be involved, how is the money going to flow, how much to the researchers at the university, how much to [organization], how much to the truck stop owner...(P1).

\section{Potential Disruptive Elements}

A history of skepticism and mistrust between private businesses and government organizations could have disrupted this process. The convener's understood concerns the truck stop owners had relating to hosting the infrastructure, and fearing a mandate. Although participants did not recall the content of meetings between the convener and truck stop owners, agency personnel noted that the apparent truck stop owner skepticism changed following these one-on-one meetings.

The project also had the potential to be disrupted from technical information. The group addressed confusion about different technology through information gathering and the costs-benefits figures. The challenge of funding the project was addressed through a sub-group who also gathered information to write the EPA grant. In sum, this group addressed social complexity and technical complexity to prevent disruption.

\subsection{5c Research Question Three: Role of Interests}

Interests were a component of each participant's motivation at several stages of this collaborative process. These are summarized in this section, see table 28; notice the impact on the direction setting phase. 
Table 28 Reduced Engine Idling: Participant interests' impact on the process

\begin{tabular}{|ll|}
\hline \multicolumn{1}{c|}{$\begin{array}{c}\text { Collaboration } \\
\text { Stage }\end{array}$} & \multicolumn{1}{c|}{ Participants Interests Affected the Following: } \\
\hline Problem Setting & $\begin{array}{l}\text { Participants deciding to enter the collaboration } \\
\text { Collective understanding on the problem } \\
\text { Pirection Setting }\end{array}$ \\
& $\begin{array}{l}\text { Perspectives on issues } \\
\text { Identifying sub-issues } \\
\text { Exploring options } \\
\text { Reaching agreement and closing the deal } \\
\text { Commitment of resources }\end{array}$ \\
\hline
\end{tabular}

\section{Problem Setting}

Participant interests shaped their willingness to come to the table. As one participant explains: "I think people's interests were the main reason they were all there" P10. Interests also helped participants develop a common understanding of one another in relation to the problem and potential solutions.

...I think it helped everyone understand where each party was coming from and what each party's interests were, and how it could all work together (P10).

...People were able to buy into seeing what the other person's perspective and point of view was, then they were able to accept that, then from there they could move, say they could move off their position to where they could see taking some action to address the other parties concerns (P28).

\section{Direction Setting}

Concerns and desires shaped participant perspectives on issues and their particular problem (or sub-issue) emphasis. Much of this was related to barriers that different stakeholder groups faced including the truck owners and the truck stop owners.

...I think everyone may not have understood the problems facing the truck driver wanting to idle his truck, they all 
recognize it's wasteful and we should try to find other solutions for him, but it's not as easy as just flipping a switch. There's education that has to go on, there's infrastructure that has to take place, and trucks have to be modified, so there was a lot of that kind of discussion going on to try to make all players involved understand all of the details and the problems that are out there, or the hurdles that needed to be overcome (P3).

Participant interests helped determine what information was needed

about the logistics of technology options in addressing the barriers to idling

reduction. Truck stop operator considerations are described in the quote below.

[name1] was the one who explained to all of us [about the mandated rest periods]... Most of us had no idea there are these hour restrictions on what truckers do... We had a discussion and we all said we can't address that [truck-based idling reduction, instead of site-based]. Or then [name2] would say this is really interesting, I'd like to be able to have the no idling at my truck stop, but... how I make my money is these people parking, and if I've got to dedicate some spaces to this new technology, and I don't know whether they're going to use it or not, that's a concern of mine. We never thought about it, I don't know the business model of a truck stop, and we thought okay, so what do we do to address that (P1).

In the quotes below, a project manager describes the truck operators'

perspective.

If they use the [tech1], they pull up and put this thing in the window, they have to pay for it, they decide that's a better deal than parking someplace else and just running the rig. To use the [tech2] they have to have electrical harnesses in their truck...So you have to have an infrastructure in your truck to use the electrical plugs...the truck owner has to decide is there a payback for me to buy this power unit? It gave a clear sense of what the truck owner's choices are, business as usual, pull off and plug in, pull off and stick a thing in my window, I have to pay for both of those, or buy my own central unit (P27). 
..For many in the trucking industry or those that hang around [inaudible] very much, there's a sense you never turn a diesel engine off. In fact I heard one story one time about a truck driver, long haul driver who would come home on the weekends, he would leave his truck running the entire time (P28).

Concerns and desires helped determine what information was necessary

in order to make decisions on options (P1, P28, P3, P27). The quotes below

show how discussions of interests and issues helped the group focus the

project. This focus pointed the direction toward the eventual agreement and

resource commitments.

The difference of perspectives and the different concerns they had, the different roles they play, they learned a lot from one another about their various perspectives and what they could contribute to solving the problem.... It tended to narrow the scope of the problem, because people would, we learned about the difference between onboard and onsite [technologies], so we said we're only going to do onsite, we're only going to do onsite at commercial truck stops...(P1).

...I think the trucking industry felt like they had an opportunity here to actively promote these alternatives, and any kind of tax credit, or subsidy they could, it was a win/win for the trucking community. At least those that owned the trucks would have more options, and the truck stops felt this is a good deal because they were getting pressure from their neighborhoods, each one of the communities was putting up with trucks running 24/7, and diesel fumes, and it was a good neighborly thing... I think it [interests] just solidified the direction of the discussion (P27).

\section{Implementation}

As described above, participant interests influenced how participants viewed different options. Participants' organizational objectives were linked to 
their interests. Participant interests shaped the agreement and the commitment of resources in the implementation phase of this project.

\subsection{5d Research Question Four: How Were Interests Addressed}

In this project, collaborative process elements helped participants understand one another and the barriers to reducing truck idling. Specific communication and meeting elements were used to establish a platform for problem setting (see figure 14).

The agency sponsor in this project spoke with nearly all parties prior to convening, in addition to the project assessment completed by the Oregon Solutions project manager. These pre-convening elements helped the sponsor, the convener, and the project manager understand different participant concerns before meeting as a group. The project assessment helped the convener determine what individuals and organizations could contribute to a solution. The convener included public agencies who could contribute funding and regulatory assistance, private trucking and truck-stop businesses who provided information and would be eventual users of the technology, reduced idling technology providers, and non-profits interested in pollution reduction.

Several elements in the process helped address relationship and process interests (see figure 15). In the first meeting, participants approved ground rules and discussed the issue of idling and air pollution. The ground rules set an explicit tone of valuing honesty, openness, and sharing of concerns. Project manager and convener conduct were noted by multiple parties as being crucial 
to contributing a feeling of trust in the process. Private conversations between group meetings among different parties about how substantive interests would be addressed also helped people feel comfortable with continuing their commitment to the process.

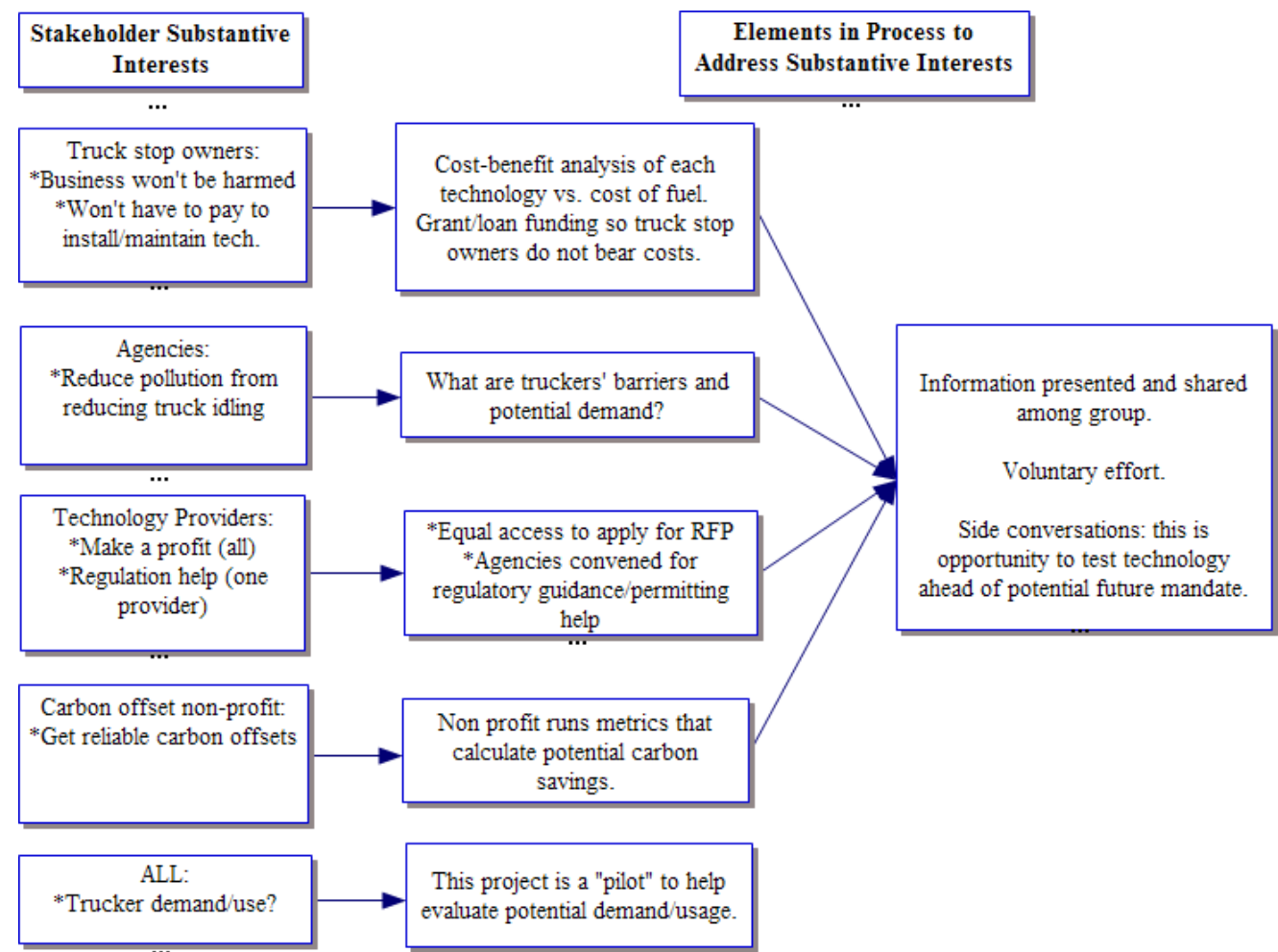

Figure 14. Reduced Engine Idling: How substantive interests were addressed.

The group meetings provided a forum for participants to state their concerns and ask clarifying questions. The convener and project manager acted in both coordinating and facilitating roles using active listening and thinking ahead for where the group was going. This was an agreement-seeking process, the Declaration of Cooperation acting as the end-point to the agreement. The 
implementation plan gave participants a road map for where they would go next when the official process ended.

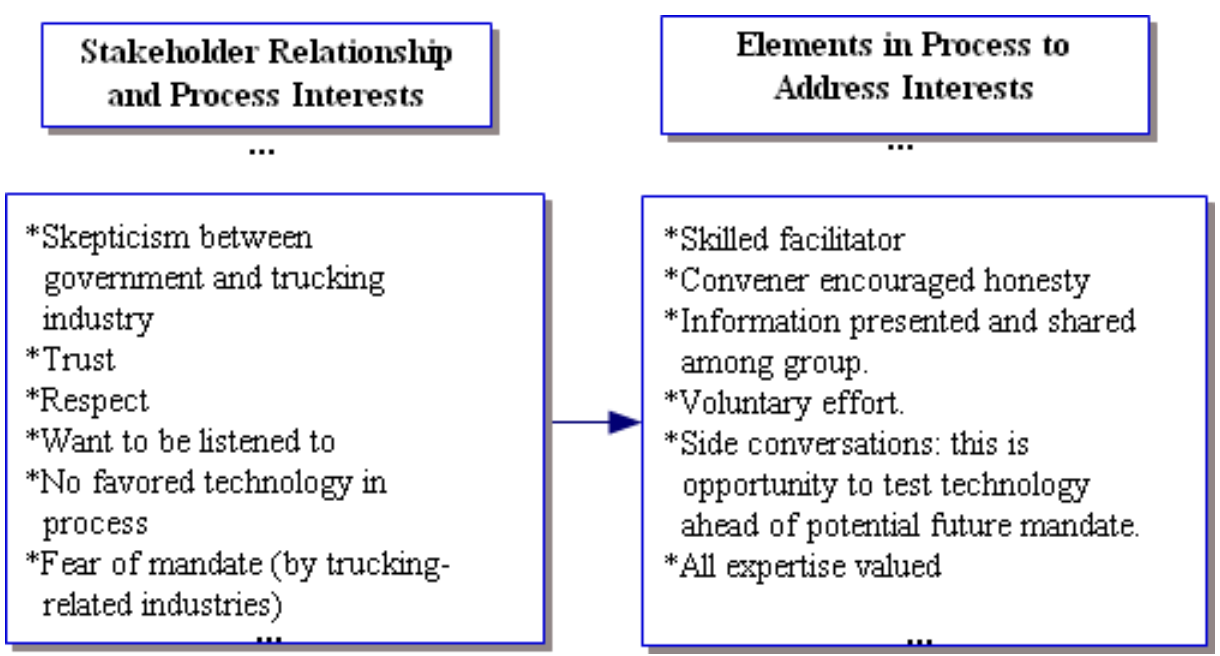

Figure 15. Reduced Engine Idling: How relationship interests were addressed.

Participant disclosed interests and issues in the first meeting. Public agencies wanted to reduce air pollution from truck idling. They had an idea to help truck stop owners assist truck drivers in a behavior change: using idle reduction technology. The truck-related business also wanted to reduce air pollution and to improve their relationships with neighboring residential communities. Truck stop owners did not want to have one technology advocated over others, e.g. they wanted the discussion to be "technology neutral" (P3). Truck stop owners also worried about the potential for negative economic impacts to their business based on competition for service use.

During the direction setting phase, the group sought specific information related to stakeholder interests. All parties were concerned about the potential use and demand by truck owners for this technology. A lack of 
clarity about truckers' barriers to using reduced idling technology led to research and presentations about trucker issues. This helped all participants better understand what could be done to help increase the demand and use of this type of technology. The number of actual truck drivers present in the discussion was relatively small so the ability to change perception among many truck drivers based on this information sharing was limited. It is not clear if the group did any outreach to involve truck drivers. For example, while the truck stop owners now know that turning off a diesel truck's engine will not harm it - truck owners may still hold onto this myth and perpetuate it among their peers. The group assumed that as fuel costs continue to rise, TSE would be better able to compete against truck idling, provided myths related to engine health were overcome.

The truck stop owner's concerns about costs for implementing the technology were addressed in a cost-comparison chart of different technologies. From the interviews and document review, it is unclear if and how the concerns of future costs to implementing the technology were directly addressed. The skepticism of one truck-stop owning participant about installing technology based on a previous experience may have been shifted by the fact that 1) some type of idling technology may be mandated in the future and this project was an opportunity to work out problems ahead of that mandate on a smaller scale, 2) the project would add positive public relation benefits that may help truck stop owners' relationships with neighboring 
communities, and 3) the presence of funding from the EPA, the Climate Trust and the DEQ removed the financial costs of installing and maintaining pedestals from truck stop owners. This last element addressed a key economic concern for truck stop owners: that their profits would be marginalized from paying to install the service.

Both Shorepower Technologies and Idle Aire Technologies could potentially have negative repercussions for truck stop owners. Shorepower involves installing pedestals that require space in a truck-stop parking lot. Idle Aire provides amenities that compete with truck stop offerings. However, neither technology is able to provide particular truck stop amenities including fresh food, human interaction, and live entertainment. Both types of technologies were given equal access to the RFP process, a concern of theirs. One technology provider needed regulatory assistance, which was addressed through convening relevant participants who provided help. 


\subsection{Lakeview Biomass Energy Facility Narrative}

The Lakeview Biomass Energy Facility Project (Biomass) is one project culminating from the long term collaborative, the Lakeview Stewardship Group (LSG or Stewardship Group). The LSG collaboration is case five and appears at the end of this chapter. While the Biomass project was based on the LSG's foundation and the on-going work of the Lake County Resource Initiative (LCRI), it is a discrete project with its own collaborative process and players.

\subsubsection{Problem Description}

The Lakeview Biomass project emerged out of struggles with three issues: economic decline of a rural community, ecosystem decline in Eastern Oregon forests and an increase of wildfires. The Biomass project addressed long-range strategic goals of the Stewardship Group on these three issues. Wildfires decreased the amount of potential timber available for the local economy; the fires destroyed residences and ranches; and fires threatened community members. Forest fires in Oregon also released carbon dioxide (CO2) emissions, thought to affect global climate change. Between 1992 and 2001 emissions from fires in Oregon were in a range from a low of 0.5 million metric tons of $\mathrm{CO} 2$ in 1993 and a high of 22.3 million metric tons of $\mathrm{CO} 2$ in 1997 (Project Summary, 2005).

Decades of fire suppression and over-story forest harvesting had led to a build-up of dry timber and plant material, unnaturally dense young forests, 
and a greater risk of severe fires on the forested land. Two other terms are used here to describe the dry material: "fuel loads" related to its potential to fuel forest fires, and "biomass" when referring to its potential as an alternative energy source. The number of forest fires in the Sustained Yield Unit (the Unit) in Lakeview had been on the increase. Sustained Yield Units were created in 1944 in an Act to stabilize communities and to assure a continuous supply of lumber products (58 Stat. 132; 16 U.S.C. 583-5831). The Unit is the primary focus of the LSG case. Over 200,000 acres of the Fremont National Forest had burned in wildfires in the late 90s (Project Summary, 2005). These fire hazard conditions were magnified by heightened forest mortality from insects, drought and disease. In 2002, the Lake County Resource Initiative partnered with the University of Washington to assess forest fire risk on the Fremont National Forest. The findings showed that $77 \%$ of the Fremont National Forests (FNF, 1.2 million total acreage) is in moderate to high fire hazard condition (Project Summary, 2005).

The Lakeview Stewardship Group prescribed efforts to address the fire risks through reducing fuel loads based on their goals and extensive research on the status of the forest (Executive Summary, 2005). They recommended an accelerated thinning and prescribed burning program, focused on the relatively dry, low-elevation ponderosa pine forests, which cover nearly half of the Stewardship Unit (Executive Summary, 2005). Supporting this plan, the Group also suggested that a biomass energy plant could 'improve the local economy 
and help accomplish ecologically beneficial thinning projects within the Unit" (Executive Summary, 2005). The Stewardship group and LCRI looked into options for using the biomass to reduce catastrophic fires and identified several options including building a biomass energy facility.

\subsubsection{Origins of the Collaborative Effort}

In 2003, LCRI contracted with $\mathrm{CH} 2 \mathrm{MHill}$ to complete a preliminary feasibility study for a 14MW biomass power plant (Project Summary, 2005). Up until the Lakeview Biomass Project, biomass plants were considered uneconomical in Oregon because the cost of producing power was nearly double the open market price for power (Project Summary, 2005). The project team investigated using carbon credit sales, federal 10-year stewardship contracts and Renewable Energy Production tax credits as a means of making the biomass plant profitable. The results showed that the proposed plant would provide a $7-17 \%$ internal rate of return on investment depending on which combinations of the potential factors are used (Project Summary, 2005). The 10-year stewardship contracts would be crucial, as they would enable $2 / 3$ of the proposed fuel source to be available.

A stewardship contract is a multi-year agreement issued by a government agency (e.g. the BLM or US Forest Service) that assigns responsibility for managing a particular tract of forested land to an organization or company (USFS webpage). Stewardship contracts may combine different activities or services, such as forest thinning and brush 
clearing, into one contract. Carbon credits are part of an emerging carbon trading market where organizations and individuals can purchase carbon credits that intend to "offset" environmental damage incurred from releasing carbon dioxide into the atmosphere (Trust, 2009).

The plant would support ecosystem health by garnering a portion of its fuel supply from biomass in local forests. The supply would be approximately 1/3 from a local mill (the Fremont), 1/3 forest thinnings, and 1/3 juniper from rangeland improvements (Project Summary, 2005). Juniper is an invasive species that has spread rapidly to the detriment of native grasses, aspen groves, meadows, and other important habitats (Executive Summary, 2005). The facility would create $12-15$ jobs at the plant and $75-100$ jobs in the woods through cutting and clearing forest biomass. LCRI and the Stewardship Group were in support of pursuing the biomass plant as a collaborative project as the project had the potential ability to address the environmental and economic interests of related parties.

The proposed plant would be located on the Collins Company's Fremont Sawmill. The Collins Co. was planning take their older boiler off-line and purchase steam from the biomass plant. The total installed capital cost was estimated (in 2003) at \$39.9 million. Based on assumptions that the biomass fuel has 50 percent moisture content and 24,000 pounds per hour (lbs/hour) of process steam load to the adjacent sawmill, the proposed power plant is estimated to generate a gross output of 14 megawatts (MW) and a net output of 
12.7 MW. The proposed power plant would burn 600 tons per day (tpd) of biomass fuel. It is unclear if these estimates were based on dry or wet biomass supply.

With funds left over from the feasibility study, LCRI requested CH2MHill contact energy companies to see if any were interested in the Lakeview Biomass Project. One company out of two decided to enter into a development contract with the Collins Companies and will be deciding if they want to move forward with construction. For any company to invest in a $\$ 39.9$ million plant, they would need a guaranteed supply of fuel.

A team of partners had already assembled to help move the Biomass project forward including LCRI, the Lakeview Stewardship Group, the Oregon Department of Forestry, the Collins Company, Sustainable Northwest and others. A similar effort for managing a forest ecosystem with biomass had been completed in a Memorandum of Understanding among tribes at Warm Springs, the BLM and the Forest Service, that LCRI could draw on as an example. The group determined that in order to ensure economic feasibility of the project, they would need assistance in developing 10-year stewardship contracts with the Forest Service and the BLM, information on permitting, political support for Renewable Energy Production tax credits Business Energy Tax Credits and Carbon Mitigation Credits, and support in validating carbon credit use. For each of these sub-issues in the overall problem of developing the Biomass plant, LCRI and partners would need additional input from other organizations 
and agencies across Oregon. LCRI proposed the project to Oregon Solutions as a way to receive this assistance and convene the diverse groups.

\subsubsection{The Collaborative Process}

This collaborative project is a longer term project and will require ongoing implementation in order to make sure the amount of biomass used by the plant fits with ecosystem management goals. Jim Walls of the Lake County Resource Initiative initiated this project with support from the private sector, other non-profits, the local community, and local governments. The history of collaboration among local government agency offices, the Collins Company, LCRI and the Stewardship Group helped provide momentum to this project. By 2005, the Forest Service had been working with the Stewardship Group's long range strategy, a regular monitoring system was in place to evaluate different forest treatments, and a private energy firm had already expressed interest in working to set up a plant.

Oregon Solutions staff member Pete Dalke helped move the project through its application and Oregon Solutions designation phases and launch the first meeting of the collaborative. Through OS, two project managers were hired from consulting firms. Two conveners, Hal Salwasser, Dean of the OSU's College of Forestry, and JR Stewart, a Lake County Commissioner, were identified by OS staff and then designated by the Governor's office. The first meeting in May, 2005 included introductions, an overview of the project, 
an overview of how Oregon Solutions processes work and ground rules for meeting conduct were established.

Much of the problem setting had been established prior to this collaborative group convening. The Stewardship Group had already set goals and objectives for forest restoration activities in the Unit. There was general agreement among the LSG participants about the utility of the biomass plant; the logistics of its development was the cause of some disagreement. The subissues of plant size and the amount of potential biomass for the plant based on Stewardship Contracts were key subjects of concerns and discussions. Additionally, environmental advocates who had not been involved in the LSG process had concerns about the Biomass facility.

During the direction setting stage of this process, the larger group (e.g. Project Team) met face-to-face, smaller sub-groups such as agency representatives met to work out specific sub-issues, and individuals had private conversations in person, by phone, or through email. Project managers performed both facilitative (e.g. clarifying interests, side meetings for sensitive discussions) and coordinating (e.g. meeting note preparation) tasks for managing people and substantive issues. The project sponsor also acted in a facilitation capacity. Jim Walls of LCRI supported the project managers and conveners through helping to arrange meeting locations and providing background information. One convener, early on, expressed that the group should aim to complete the project in a maximum of five large-group meetings. 
This limit was recalled by a number of participants as an impetus for getting things done quickly. Part of this rationale was to enable the group to take advantage of tax credit application deadlines.

A major concern during the implementation phase, even though the agreement was established, is the scale, or size, of the biomass plant. The plant is intended to be a tool for restoration work. However, in order to be feasible economically and make a profit, it has to be a certain size. If the plant is too large, some participants were concerned it would need a larger supply of forest biomass than was commensurate with forest management goals.

\subsubsection{Current Status of the Collaborative}

The Biomass group signed an agreement, the Declaration of Cooperation, on January 12, 2006. This project remains in its implementation phase. A sub-set of the Oregon Solutions group including LCRI representatives, representatives of the BLM and the Forest Service, the Collins Co., and members of the Lakeview Stewardship Group, continue to work on getting the plant built.

The collaborative process ended with DG Energy Solutions LLC agreeing to lead the planning, permitting, design, commercial contracting, financing, construction and long term operation of the Lakeview Biomass project, bringing the majority of the equity capital required to develop and construct the project (DoC, 2006). DG Energy a California company, was purchased by Marubeni Corporation based in Osaka, Japan in 2006. Early in 
2007 Marubeni announced it was committed to building a 10-15 MW biomass cogeneration plant in Lakeview, Oregon. The price of fuel also increased since the DoC was signed, impacting the costs of construction and the economic feasibility of the plant. "...the estimates on the cost of putting that thing up per kilowatt hour have almost doubled since we first met... Originally the estimates were coming in at $\$ 20$ - $\$ 25$ million, now the last estimate I heard was 40 million, you should ask [name] as this is all paraphrased...(P 55)."

Different elements of the collaborative agreement have been implemented. In 2007, Collins Company announced they would expand their Lakeview Fremont Sawmill to add a $\$ 6.6$ million small log mill to their existing facility. They have retooled their mill at the time of this writing. A 20year Memorandum of Understanding was finalized in 2008 by Lake County Resources Initiative, Lake County, Town of Lakeview, City of Paisely, Marubeni Sustainable Energy, Inc., The Collins Companies, Oregon Department of Forestry, U.S.D.A. Forest Service Fremont-Winema National Forests, and Bureau of Land Management-Lakeview District (MOU, 2008). The agreement provides a framework for planning and implementing forest and rangeland restoration and fuels reduction projects that address indentified resource needs while being supportive of the Lakeview Biomass Project (MOU, 2008). The MOU ensures that both the Forest Service and the BLM will offer woody biomass for utilization as a component of all applicable future potentially long-term stewardship contracts. Specifically, the Fremont-Winema 
National Forest offered a minimum of 3,000 treatment acres per year outside of the Lakeview Stewardship Unit. The Lakeview District of the BLM offered a minimum of 2,000 treatment acres per year District-wide.

LCRI and the Collins Co. are currently in a struggle with the Marubeni Company. When the project began they were working with a California company - DG Energy who intended to spread forest management benefits to Northern California forests. Marubeni bought DG Energy and continued to participate as the developer.

As of the summer of 2009, affected by the global economic crisis, Marubeni is for sale. The Biomass project has become a major asset of the company and despite four separate requests to purchase only the Lake County Biomass plant project Marubeni is refusing and wants a buyer for the whole company. Unfortunately, the collective benefits the collaborative group created to help the project earn a profit are timeline sensitive. The Oregon Legislature originally approved a 20 million dollar Business Energy Tax Credit to help launch the plant. In the 2009 session, the Legislature agreed to reduce this amount to 10 million - which took effect in late summer 2009. Collins Company extended their contract to July 15, 2009. Most likely, in the event that the energy company did not fulfill their end, Collins may have refused to work with them. This situation between the group and the Japan-based Marubeni has caused considerable frustration. 


\subsubsection{Lakeview Biomass Facility Within-Case Analysis}

\subsection{5a Research Question One: Identifying Interests}

Participants identified tangible and intangible interests at the beginning

of the collaborative process (see table 29). Both types related directly to the

Biomass project and to broader issues. Many of these concerns and desires

overlapped with those of the Lakeview Stewardship Group long-term

collaborative, however, as this project brought in new participants, new

interests emerged or had to be revisited.

Participants focused their concerns and desires on the problem

substance. The group could see connections among different stakeholder

interests. For example, forest management to harvest biomass contributed to

employment for the local community (P24, P15). The quote below articulates

different participants' concerns.

...If it was the investor, they probably wanted to see more energy development; if it was public groups they probably wanted to know how this could help support the management that needed to be done with the lands; for the whole local community, economic development was an issue. The environmental groups wanted to be sure the development wasn't doing anything damaging to the landscape... P15

Participants also raised additional concerns about responsibilities,

relationships, and process during the interviews. For example several agency

representatives noted that their involvement was partly to keep a positive

relationship with the Lakeview community in relation to their responsibility of

implementing forest management plans (P15, P3). One agency member notes 
Table 29 Lakeview Biomass: Identified interests

\begin{tabular}{|c|c|}
\hline Tangible Interests & Intangible Interests \\
\hline On Substantive Issues: & On Substantive Issues: \\
\hline Biomass supply: & Concern with habitat $\&$ biodiversity. \\
\hline Concern of ability to guarantee supply. & Desire to help with rural economic development. \\
\hline Cost $\&$ amount of supply & Fear of an economic "beast" that would burden \\
\hline Treat fuels at more rapid rate. & the forest ecosystem for economic benefit \\
\hline Ecosystems: & Desire that biomass be a tool to accomplish \\
\hline Increase or maintain ecosystem health. & ecosystem objectives, not economic \\
\hline Wildfires. & demand alone. \\
\hline $\begin{array}{l}\text { Juniper encroachment \& ability of biomass } \\
\text { plant to be a tool for managing this. }\end{array}$ & Complexity of biomass facility as a problem. \\
\hline Hydrologic system needs/improvement. & On Relationships: \\
\hline Restore acres of forested land. & Concern about outsiders telling us what to do. \\
\hline Economics & Feel respected $*$ \\
\hline Economic feasibility of the plant. & Feel listened to/heard* \\
\hline Develop community jobs/ecological & Have input valued* \\
\hline restoration workforce & Desire for political support. \\
\hline Leverage incentives from state programs. & Apply lessons learned to other communities. \\
\hline Commercial profit. & Potential for good neighbor business \\
\hline The Plant & relationship. \\
\hline Obtain biomass for energy. & \\
\hline Desire for adequate/sustainable plant & On Process: \\
\hline scale. & Need communication between this effort and \\
\hline Improve mill infrastructure. & regional/national agencies. \\
\hline Prevent loss of community infrastructure. & Need to synergize competing/divergent efforts \\
\hline Need to demonstrate non-energy benefits & regarding biomass power. \\
\hline How to balance investor timeline need & Is the project mature enough? \\
\hline $\begin{array}{l}\text { with local collaboration and policy } \\
\text { needs? }\end{array}$ & $\begin{array}{l}\text { Concern the biomass plant won't be built after } \\
\text { effort* }\end{array}$ \\
\hline Carbon Offsets & Move process along expeditiously. \\
\hline Desire to reduce $\mathrm{CO} 2$ emissions. & Demonstrate on-the-ground success. \\
\hline Learn how to measure avoided carbon & Desire for momentum and enthusiasm. \\
\hline $\begin{array}{l}\text { emission in relation to land } \\
\text { management. }\end{array}$ & Concern timeline is too ambitious. \\
\hline & On Principles: \\
\hline On Roles: & Honesty (of self, of others). \\
\hline Job duty or responsibility. & The project must benefit all (e.g. equity in gain). \\
\hline On Process: & In Opportunities: \\
\hline Like to provide staff and money to project. & Benefit national forest \\
\hline Get a good Declaration of Cooperation. & Desire to solve a problem. \\
\hline Concern about appeals. & $\begin{array}{l}\text { Project act as springboard for other communities. } \\
\text { Raise awareness of biomass for rural economies. } \\
\text { Create new model for branding Oregon } \\
\text { Build on rural initiatives on renewable energy. }\end{array}$ \\
\hline
\end{tabular}

* May not have been explicit during the collaborative process - expressed by individuals involved in the Stewardship Group and the Biomass project. 
"we are encouraged to collaborate. Our Secretary of the Interior at the time, Gail Norton, she had the 4 C's and one of them was collaboration."

In the initial Project Team meeting, the conveners and facilitators helped participants articulate their concerns and aspirations. The list highlights discrete process objectives such as "get a good Declaration of Cooperation", project resource objectives such as "providing staff and money", substantive issues including reducing $\mathrm{CO} 2$ emissions and conducting a biomass supply assessment, and concerns with the scale appropriateness of the eventual Biomass facility (Meeting minutes, 2005; see table 29).

Participants also raised interests related to relationships. Relationship concerns within the group included a concern with 'outsider' control over local decisions, the desire to create a good neighbor business relationship, and a desire for improved communication between this effort and regional/national agencies. Participants described interests about the relationship between the project and the larger forest management community. These included a desire to help biomass be recognized as an opportunity in the sustainability arena, wanting to apply lessons learned to other communities, and wanting to create a sense of perspective and awareness of biomass for rural economies. Since certain participant's interests were so disparate, the group benefited from having a degree of affiliation in order to unbundle differences.

Uncertainty was a component in the complexity of the central problem. For example, uncertainty surrounded the issue of biomass supply for the plant. 
Parties were about 1) the availability of a potential quantity of biomass, 2) the ability to provide that quantity based on policy changes affecting government agencies, 3) how biomass removal would impact fire management, 4) how biomass removal relates to invasive species removal (e.g. juniper), 5) concerns about stewardship contracts to obtain the biomass, and 6) a concern about the tension of using biomass to address an ecosystem management versus an economic development issue. One participant describes this scale issue based on interests below.

One was the scale of the plant, the size of the plant. The concern was the investor had to make money... too small a plant it didn't seem like the numbers worked out so that they would get a return on their investment. The size of the plant corresponded with the long term fuel supply needs: the bigger the plant, the more the agencies had to guarantee, or provide potentially a larger supply of fuel. Our [agency] concern is don't build the plant bigger than what you think the supply is going to be...So we went around and around on that...P3

These concerns had to be addressed in order to forge an agreement.

In the follow up survey, staff and participants were asked whether or not they agreed that specific interests identified in the interviews were important, see table 30. The thirteen respondents, two staff and eleven participants, emphasized the importance of protecting Lakeview's economic health (100\%), protecting/restoring forest health (100\%), and reducing wildfires $(92.3 \%)$. More than two thirds of participants were concerned that the Biomass facility be of an appropriate size for forest restoration not only for economic benefits $(69.2 \%)$. Respondents agreed that the process/relationship 
concerns that everyone's view be respected (84.6\%) and a desire to solve a problem $(84.6 \%)$ were important. Respondents were split regarding the importance of the desire to make a profit (46.2\%) and a desire for honesty $(53.8 \%)$.

Table 30 Biomass: Follow-up survey responses of important interests

\begin{tabular}{|ll|}
\hline \multicolumn{1}{|c|}{ Biomass Facility (n=13) } & \% \\
\hline Protect economic health to Lakeview community (e.g. protect the mill, protect jobs) & Yes \\
Protect/restore forest health (e.g. protect habitat, watersheds) & 100 \\
Concern Biomass plant size be a tool for restoration, not primarily for economic & 69.2 \\
benefit & \\
Desire to reduce wildfires & 92.3 \\
Desire to make a profit & 46.2 \\
Concern that everyone's view be respected & 84.6 \\
Desire to fulfill job duty/responsibility & 23.1 \\
Desire for honesty & 53.8 \\
Desire to solve a problem & 84.6 \\
Other text (one response: & \\
That the goal remain restoration not supplying the facility & \\
\hline
\end{tabular}

In summary, most of the participants described a shared interest: a desire to reduce wildfires. Many of the players also entered this agreement with a common interest of increasing the restoration activity of the forest. This interest was an emerged commonality from the Lakeview Stewardship Group's long-term collaborative effort and included public agencies, some environmental groups, private community businesses, and other Lake County community members. The Biomass Plant and supporting ecosystem restoration efforts were the means for reducing the severity of wildfires. Both concerns might seem at odds with a key private interest: earning a profit by running a Biomass plant. 
Table 31Biomass Summary: Interest findings

\begin{tabular}{|ll|}
\hline Interest Types & Identified tangible interests in substance and process \\
& $\begin{array}{l}\text { Identified intangible relationship and process interests* } \\
\text { Identified shared* interest }\end{array}$ \\
Theory-related & Interests discussed in relation to central problem and sub- \\
Themes & issue \\
& Interests intertwined with issues and positions \\
& Conflict/disruptions present \\
& Integrative and positional behavior present \\
\hline
\end{tabular}

\subsection{5b Research Question Two: Facilitation}

Project managers, participants and conveners used techniques that helped moved the process forward (see table 32). Many of the techniques focused on helping participants understand substantive information related to the biomass plant. Specific interventions helped make participant interests about substantive issues more explicit.

\section{Pre-collaboration}

The project managers completed a project assessment prior to convening. A member of the Lakeview Stewardship Process, Jim Walls, had already gathered much of the information related to issues and participants. Project managers emphasized Jim's experience and expertise, rather than the assessment itself, as helpful to the convening process.

This collaborative process was aided by the shared understanding generated in the Lakeview Stewardship Group. The LSG collaboration had discrete outcomes, such as a monitoring program, that showed other collaborators it was possible to complete forest restoration work that benefited the community. The quote below is from an individual involved in both 
processes describing how the monitoring process helps people understand

adaptive management.

...We brought these people up to speed on where we had been in our collaborative process... and to explain, this is our strategy, we're now arm in arm with the Forest Service in our prescriptions for these different projects.... Now, you guys are coming in to town and you're new kids on the block...this is how we perceive the thinnings are going to need to be done...Let's issue a Stewardship contract and let them go do some thinning, and let's see how they do that. Do we like how the equipment, what kind of footprint is it leaving on the ground, do we like the end result? Let's come back next year and look at it when it's all finished and they're through mulching and cleaning up... (P24).

Table 32 Lakeview Biomass: Techniques

$\begin{array}{ll}\text { Pre-collaboration } & \text { Project assessment* } \\ \text { Participants } & \end{array}$

*Project assessment and ground rules were not emphasized in interviews; not all participants attended field trips. 


\section{Participants}

As mentioned earlier, participants from the prior Lakeview Stewardship Group walked in with a shared understanding and a sense of possibility.

Interviewed participants mentioned both project managers and one convener as being active in identifying and helping to clarify participant interests.

\section{Information Elements}

The group captured information in summary documents. For example, at the first Project Team meeting on May 12, 2005, the co-conveners asked participants to list their aspirations and concerns for the project that project managers captured on flip charts. The conveners and project managers then sorted the concerns into those related directly to the Biomass project and those related to broader issues. The project managers disseminated the summary among the group as part of the meeting minutes.

The Declaration of Cooperation was another summary document. It captured issues, solution logistics, resources, and a few interests in one place and was reviewed by the group. In this project, the project managers developed different commitment language and helped each signing organization edit it. This was not a group-edited document.

\section{Meetings}

Participants emphasized the benefit of group discussions on substantive issues. In the quote below, participants describe that concerns were revisited as the group negotiated a scale for the Plant that would work for everyone. 
...I just think it [interests] continued to come up. We were trying to get to a situation where the energy investor was comfortable that he was going to get the supply of materials, that the mill owner was comfortable that if he invested in a small diameter processing line that there would be material for that, and get the agencies feeling comfortable that the environmentalists were going to support it. And that [interests] just continually comes up (P20).

The group also used sub-committees to help gather information and work through sub-issues. This project involved both technical and scientific complexity, requiring discussions among those who had the relevant expertise - especially if this information centered on a source of contention. One agency participant described three issues that had to be addressed. First, how will agencies pay for the restoration thinning? Second, what are the potential impacts of managing western juniper land through cutting and removing it? Third, the BLM already has a competitive market for its biomass - so it could not guarantee that the material from its 2000 acres a year would go directly to the Plant if someone else outbid them. As one participant notes, each of these issues were critical.

...I have called a number of existing biomass managers, some are frustrated because they built their plants too big and were based upon an anticipated fuel supply...I've interviewed biomass managers that the agency said yeah, there's a lot of biomass out there...then all of a sudden they can't operate that plant at full capacity because for numerous reasons, the agency and other potential fuel providers were not able to implement treatments and timber sales that included removing biomass. As a result, the biomass companies are not getting the return on their investment... So the size of the plant was important not only for a sustainable supply of biomass to supply it, but financing too $(\mathrm{P} 3)$. 


\section{Verbal and Visual Communication}

Project managers explicitly asked people to describe their interests at the beginning of the collaborative process. One facilitator explains, "I do a little definition of what an interest means and ask them to try and explain what their interests are. Too often they are unexamined, it's a start in getting people to shift to that thinking" (P2). Project managers used methods to uncover interests during the whole process.

When I see, for example, an environmental stakeholder sticking to a certain rule or regulation or that they just won't budge from... I might ask them what is it that this thing is protecting? And could it be achieved better in a different way? (P2)

Project managers repeatedly encouraged people to be honest and trusting in expressing their concerns. A project manager explains:

Really in order for a project like this to go forward and this is a term that I used during the process, "everyone has to learn to flex their trust muscles." It means that you have to be willing to put your real concerns, your skepticism, your good ideas out into the whole group so that everyone can begin to address them. And you have to trust that the other people in that process are going to meet you with the same sort of openness (P20).

Project managers and some participants drew people, or their issues, into the group conversation either in the moment or through a follow-up one-on-one conversation.

Beyond direct requests for information, project managers used other techniques to help people feel comfortable expressing themselves.

... I think when you're dealing with biomass... you tend to deal with...People who may not be comfortable speaking in front of big groups. So you have to make sure you draw them in as comfortably as possible when the time is right... good 
facilitator in a project like this needs to have done a little homework and kind of know who the people are that are at the table, the people that we're dealing with, and then just be very sensitive throughout the process when you see someone go back into a shell, or when you know that a particular speaker is touching on an issue that might be sensitive to another key stakeholder, making sure that you then bring them in and follow up. A lot of it is just reading people and making sure that they stay engaged (P20).

Participants also engaged in active listening using summative, or mirroring statements, in both written and verbal form. This information was captured in summary documents or flipcharts that the group could refer to, as described below.

It was in a number of group meetings where ...[participants] self-revealed, talked, educated the group. We team-taught each other, and the facilitator of course, was really good about pulling those together in a concise way, so then both in documented form and reiterated verbally, here are the groups' common interest, this is where I hear some individual interests, and so made sure the group could find some common ground to stay on task to get to a particular point, even though we weren't $100 \%$ matched on everything (P45).

\section{Shared Experience}

A few sub-groups of the large project team engaged in shared experiences. One sub-group worked on developing a Memorandum of Understanding. Participants in this process described it as helpful in strengthening understanding of issues, interests and positions. Another group visited a forest site to look at ecosystem conditions. Participants who attended regular meetings heard information from expert presentations. 


\section{Governance}

The group used Oregon Solutions' ground rules template and worked to reach broad agreement. Interviewed participants did not emphasize their role in the process. The group worked to generate broad agreement and make decisions based on consensus.

\section{Potential Disruptive Elements}

This project managed disruption from social complexity, problem complexity and technical complexity. At the beginning of the process, stakeholders representing environmental groups other than those involved in the Lakeview Stewardship Group opposed using the forest for economic benefits. Members of the LSG shared monitoring results, scientific information, and adaptive management goals from their collaborative process to help encourage a new perspective for the participants who were initially skeptical.

As mentioned earlier, the project dealt with a complex problem that combined multiple issues: forest management, ecosystem health, local economic development, and wildfires. The group had to tease apart each issue, and understand their connections. Scientific information also accompanied these sub-issues. The group used meetings and group discussions to help prevent this from being a source of disruption. 


\subsection{5c Research Question Three: Role of Interests}

Interests contributed to participant decisions most noticeably in the direction setting stage of this collaborative process (see table 33 below). While participants' decision to attend these meetings and commit to this project may have been partially based on their interests, this was not made clear during interviews.

Table 33 Biomass: Participant interests' impact on the process

\begin{tabular}{|c|c|}
\hline $\begin{array}{c}\text { Collaboration } \\
\text { Stage }\end{array}$ & Participants Interests Affected the Following: \\
\hline Problem Setting & Not emphasized in interviews or documents \\
\hline Direction Setting & Perspectives on issues \\
\hline & Positions on issues \\
\hline & Identifying sub-issues \\
\hline & Exploring options \\
\hline & Reaching agreement and closing the deal \\
\hline Implementation & Commitment of resources \\
\hline & Program outputs (e.g. MOU) \\
\hline
\end{tabular}

\section{Direction Setting}

Interests shaped perspectives on the problem, including the problem definition and sub-issues. Several participants explained that each stakeholder group had a perspective on the biomass plant's feasibility based on specific challenges (P22, P20, P3, P55, P45, P2). The investor was concerned with fuel supply. The agencies were concerned with being able to gather a level of supply over a certain number of years, both in terms of funding and physical resources.

.... So you've got to get all those agencies willing to work together to sign agreements with an energy investor on a level of supply over a number of years. And they had tended to not 
want to do that for all kinds of reasons, because they take heat from environmentalists for logging agreements, and they're concern of course is how is this going to be viewed, how is an energy agreement going to be different from a logging agreement?....(P20).

Interests also shaped some individual's and organization's positions on issues.

In the quote below, a participant describes one individual's position (described as an interest) change over time.

[environmental representative] he came to the very first meeting, he wasn't even going to come talk with us. He already knew we were just a bunch of liars, and watching his interest change from stopping us from doing anything, stopping salvage sales after catastrophic fire, to let the forest do it's own natural thing. And the change there was [his new understanding that] man's intervention over the last 100 years has stopped natural occurrences, now we have catastrophic fires, that's not natural (P55).

In the next quote, we hear how interests connected to understanding about a sub-issue, size of trees, and its relationship to positions (in this case, the amount of potential subsidization of the biomass cutting).

... can we still make this work and make it a commercial operation, a viable operation if we don't cut any large trees? Yeah, a key point is then what's a large tree? If you can harvest a 16 inch tree, or an 18 inch tree, it will help get some of that biomass out of the woods, if the environmental groups say we don't want you cutting anything over a 10 inch tree.... what we're going to have to do is subsidize the operation. What I mean by subsidize is we have to pay to cut, and yard, and transport that biomass out of the woods to the biomass plant. We would get in discussions of the more trees you're allowed to harvest of maybe the middle size class, the more viable an operation you can do, the more biomass you're going to generate, the less you have to subsidize... we need to have an operation that's not necessarily subsidized (P3). 
Interests shaped the development of strategies to address sub-issues. Interests helped people better understand the logistics for dealing with sub-issues. This influenced how people negotiated (P38, P2, P55). In the first quote below, a project manager explains how the change in position from the investor on megawatt size for the plant came more in line with what the community put forward. The second quote from a participant who acted in a leadership capacity reveals his perspective of how much interests contributed to learning the nuances of sub-issues.

Now, the other piece was as we moved through the project... they started lowering the megawatts that was their target and raising what they could pay per ton so when they got it to the place that fit with the community, and I say community meaning the strategic plan that had been put together by the community and all the stakeholders... (P2)

I think [interests] drove it completely, economics, environmental, scientific interests, community interests, it all drove it.... the group also helped to identify...we were able to flesh out complexities, or conflicts, issues of funding, legislative issues that needed legislative fixes in order to be beneficial, we were able to itemize a number of that...(P45)

Participants explained that interests and issues helped clarify what they wanted to commit to $(\mathrm{P} 45, \mathrm{P} 3)$.

...I'd say, because of the technology and the scale that was going to being used, because it was a biomass facility, similarities of interests among the different stakeholder enable them to ...I don't want to say embrace... but accept... a biomass facility as a solution to their common problems. So those interests shaped how they viewed the solution to the different problems? The solution, the way that it came out in the end, was something that wasn't going to...that fit within the 
realm of their common interest. It supported all their interests and didn't hurt anyone's interests if that makes any sense (P2).

\section{Implementation}

Program documents during the implementation phase contain language that reflects participant interests identified during the collaborative. The 2008 MOU document has a "Purpose and Objectives" section and a "Mutual Interests and Benefits" section. Different concerns and desires are included in this language - indicating that the implementation phase is retaining a set of core interests. The purposes and objectives frame the MOU around work to improve and protect the vitality and resiliency of forest and range ecosystems, water resources, wildlife and fish habitat, air quality and the commercial value of forest biomass for producing electric energy and other beneficial uses. The efforts will also reduce hazardous forest fires and the prevalence of noxious and exotic plants while promoting the reestablishment of native species. Further, the agreed efforts will facilitate a re-introduction of fire in firedependant ecosystems through a method that increases economic opportunities in the area while gathering information to improve forest and range management (MOU, 2008). The mutual benefits of the project included helping federal agencies reduce excess 'vegetative stocking' from forest land within Congressional appropriation levels while supporting the wood products industry in Lake County (MOU, 2008). 


\subsection{5d Research Question Four: How Were Interests Addressed}

Participants identified substantive, relationship and process interests. Facilitation techniques, especially in relation to fact-finding and exploring logistics, helped people understand sub-issues (see figures 16 and 17 on the following pages). Interests were connected to these issues, and to participant positions. Interests were notably a basis for negotiating and creating both private and public value in this project. Private value was created for the private business companies through financial incentives and potential profits. The public values in this project include forest restoration, reduced fires and economic development. On some issues, the group began with positions and then moved to sharing information, assessing tradeoffs and inventing options to create value (Lax \& Sebenius, 1986). On other issues, the group began with issues, moved to information sharing, and then developed approaches that dovetailed differences. 


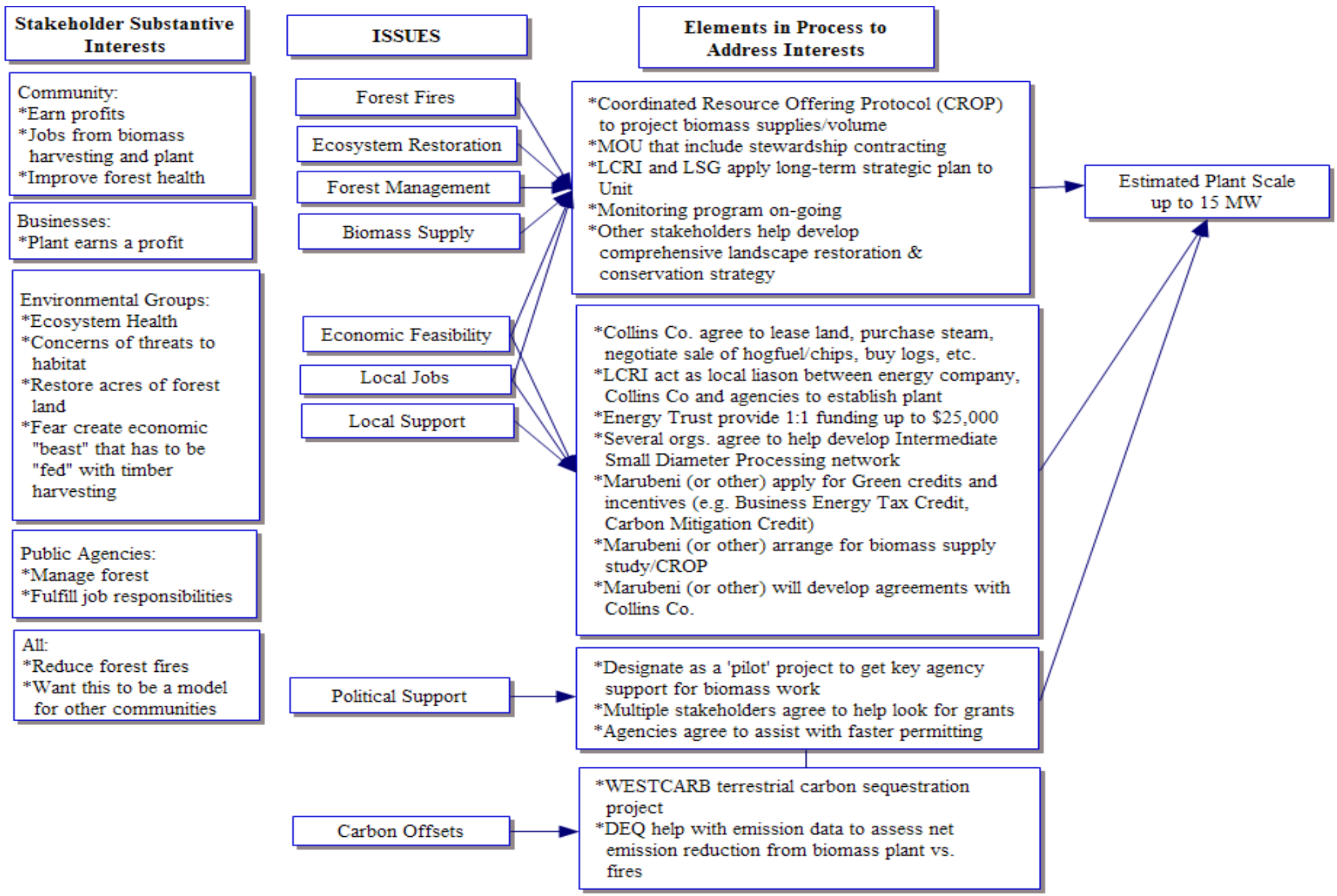




\begin{tabular}{|c|c|}
\hline $\begin{array}{c}\text { Stakeholder Relationship \& } \\
\text { Process } \\
\text { Interests }\end{array}$ & \\
\hline $\begin{array}{l}\text { *Communication with national } \\
\text { regional agencies } \\
\text { *Concern with outsider telling } \\
\text { us what to do } \\
\text { *Desire political support } \\
\text { *Raise awareness of biomass } \\
\text { *Take advantage of } \\
\text { opportunities } \\
\text { *Respect } \\
\text { *Honesty } \\
\text { *Have input valued } \\
\text { *Project benefits all } \\
\text { *Desire to solve problem }\end{array}$ & $\begin{array}{l}\text { *Convened diverse group including agencies } \\
\text { *Shared expertise } \\
\text { *Joint information gathering \& review of science } \\
\text { *Sub-group meetings } \\
\text { *At least one field visit } \\
\text { *Community-based meetings in Lakeview } \\
\text { *Shared meals } \\
\text { *Face to face meetings } \\
\text { *Open leadership } \\
\text { *Explicit request for honesty/trust } \\
\text { *Facilitation (e.g., scheduling, ground rules, meeting } \\
\text { agendas and summaries) } \\
\text { *Direct communication } \\
\text { *Open meetings } \\
\text { *One-on-one conversations }\end{array}$ \\
\hline $\begin{array}{l}\text { *... } \\
\text { * Demonstrate on the ground } \\
\text { success } \\
\text { *Expeditious process } \\
\text { *Is project mature? Timeline too } \\
\text { ambitious? } \\
\text { *Concern plant not be built after } \\
\text { so much effort }\end{array}$ & $\begin{array}{l}\text { *Limited number of group meetings } \\
\text { Concern about demonstrating on the ground success } \\
\text { and meeting deadlines for agency-based incentives } \\
\text { (e.g. energy tax credit) outweighed concern of } \\
\text { timeline/maturity of project }\end{array}$ \\
\hline
\end{tabular}

Figure 17. Biomass project: How relationship and process interests were addressed.

The group identified common interests. Much of the group was in agreement that many of the forested and rangeland areas in and around Lake County needed restoration efforts through underbrush thinning and invasive species removal. These management efforts would address the collective concern about reducing wildfires. The group agreed on a proposed exchange: The forest needed to have biomass removed; the Plant needed biomass. If agencies can give biomass to the Plant, and the Plant has enough to earn a profit - everyone is satisfied. It became increasingly complex based on differences within these two dimensions. 
After the interests were assessed, the group worked to gather information and complete tasks that would address the substantive ecosystem health and economic development concerns. The group created value based on joint gain strategies described by Lax and Sebenius (1986) in Chapter Two (see page 21). For example, differences in forest health and economic needs were unbundled to develop the stewardship contract option.

Some environmental group representatives did not want any form of resource harvesting for economic benefits; other participants persuaded them that the overarching benefit was for ecosystem restoration. Local community members looked for job creation opportunities centered on ecosystem restoration efforts. The Collins Company was concerned about having a volume of material that would help keep its last mill in the area running. The agencies were concerned about being able to obtain the necessary volume based on limited work forces and limited budgets. Information sharing and relationship building techniques helped address these issues and interests.

Biomass and its relationship to restoration efforts was a major focus. The Plant would have essentially two sources of fuel: 1) 1/3 from the Collins Company saw mill waste, and 2) 2/3 from forest and rangeland ecosystem management (e.g. from the BLM and US Forest Service land). The Collins Company's sawmill waste also partly depended on the ecosystem management efforts and they had re-tooled their mill to accommodate smaller log dimensions. In BLM, US Forest Service, and private land biomass removal requires money to pay for the work, people to do the work, and a 
prescribed level of work to restore forested areas rather than deplete them (e.g. level of work).

Discussing these issues through the Memorandum of Agreement helped the group think of creative approaches to address them, and provided realistic expectations for any participating energy company. For example, long-term stewardship agreements would help provide a labor force to do the thinning and create local jobs. However, they are still a relatively new practice because guaranteeing a certain volume of material is a challenge. Material is thinned or logged based on a public agency's ability to contract for the labor. If political agendas, leadership or objectives change, the budget shifts with them. None of the participants wanted to commit to something that was unrealistic or would put the project in jeopardy. The group created objective criteria (Fisher \& Ury, 1991) to help them establish feasible numbers. The potential biomass available for the energy company was based on a twenty year timeline, projected availability of biomass volume per acre, and projected volumes based on current budget allocations. The Stewardship Unit would provide material exclusively for this project. However, the energy company would have to bid on BLM-sourced biomass against other competitors.

The issue of plant scale was the centerpiece of the discussion on differences of interest. The group began with positions based on their concerns, reflected in the gradual lowering of MW offered by the energy company. "In the energy field companies that do this, it takes the same amount of staff and dollars to run a $30 \mathrm{MW}$ plant as it does a $10 \mathrm{MW}$ plant - it takes more material but the cost of personnel in the 
plant is the same... There were times when DG Energy and AES (previous energy companies) wanted to push this to a 25 or $30 \mathrm{MW}$ plant, for those reasons (P16)." The community, including agencies and environmental groups, started their negotiating range at a 10MW size for the plant. In face-to-face team meetings, the group used information about fuel supply projections and potential sources of financial support to build the plant to help inform negotiations about the plant size that would address both environmental and economic concerns.

In order to make this number more appealing, and increase the potential for the project to be a better profit-maker, the group explored funding supports through carbon mitigation credits, business energy tax credits (\$20 million), and other incentives. This helped carve a significant portion of funds from Marubeni's initial capital investment costs. From meeting notes and interviews it is unclear how open the energy company was with its financial bottom line, and how much information it kept secret to get a better deal. Rather than staying at either extreme, both sides moved toward each other's side in the zone of potential agreement. This did not occur in a distributive bargaining style where each side anchored their position, made counteroffers, made concessions and moved to a midpoint (Raiffa, 1982). Rather, the Plant size was shaped by information sharing from participants shaped by different party's concerns. The final proposed plant size, $15 \mathrm{MW}$ reflected information about projected supplies of biomass - and is much closer to the community's desires. As one participant notes "we do believe this [size] is sustainable but that's the outside edge that we're going to do. They [the energy companies] learned very quickly as they were 
doing, looking at building this plant, that they'd better stick within those guidelines because that's where the support is at." This statement was based on knowledge of projected biomass supply numbers as well as community support for financial tax incentives.

Information was crucial to addressing interests in this process. Some environmental advocates resisted the idea of removing trees for economic benefit. A few participants, who had not been part of the Lakeview Stewardship Group, did not originally agree that extraction of biomass, especially logging of mid-sized trees, was in alignment with ecosystem health conservation and restoration concerns. "[Environmental organizations] look at restoration thinning as getting the forest back to the original historical condition, commercial logging is out there trying to make money, two different objectives there...they were concerned, particularly in the juniper world, once we get these forests and range lands back into a historic condition, the biomass supply will drop, so don't expect this sustained biomass supply over 20 years (P3).” Members of the LSG including public agencies, environmental organizations, and one of the conveners helped skeptical participants see physical evidence and scientific information to convince them that restoration thinning, which included some logging, was a worthwhile, if involved, approach. A sub-group took at least one field trip at the beginning of the process to help participants understand what adaptive management involving thinning looked like on the ground in a juniper forest. LSG members also shared what they learned from developing and implementing their long-range strategy through small management projects on the Stewardship Unit. This 
included discussing areas of particular concern to environmental groups such as salvage logging and logging trees over 21" (see the Lakeview Stewardship narrative beginning page 250).

Particular social techniques helped people understand one another's perspectives, issues, and concerns. For example, face-to-face meetings concerning documents including the Memorandum of Agreement and the Declaration of Cooperation helped participants outline their issues, concerns, and commitments before crafting an agreement. One BLM participant explained that it was through this process of learning in relation to the US Forest Service that the agencies refined their biomass supply projections. The BLM first did an inventory of available fuels while the Forest Service did a projected fuel supply based on existing funding and staffing. The problem with a simple inventory is that, "when you give them strictly inventory data they see 'look at all the fuel out there!'” but the reality is that the staffing and funding level may not be able to removal it all. The on-going conversations among different participants helped each refine their concerns related to different issues.

Other process elements specifically helped people feel more comfortable with one another and the process. For example, participants and project managers used explicit statements to encourage openness and honesty, e.g. "flex your trust muscles." Shared meals and bus rides out to the site visit gave people time to get to know one another informally. Some process elements helped with both content and relationship concerns. The site visit helped a sub-group of participants get an on-the ground 
experiential understanding of restoration activity, gave participants a chance to share expertise, and help them better understand where each was coming from.

Both the Declaration of Cooperation and the Memorandum of Agreement are summary documents that capture interests, issues and implementation plans. The MOU was a critical piece of information that helped stakeholders understand how biomass supply - the main resource required for this plant beyond financial capital, would be negotiated in the future. Meetings were structured around moving the process forward by gathering elements for these two documents.

\section{After the Agreement}

During the collaborative process, the original energy company, DG Energy Solutions LLC agreed to take the lead in "planning, permitting, design, commercial contracting, financing, construction and long term operation of the Lakeview Biomass plant, bringing the majority of the equity capital to develop and constructing the project" (DoC, 2006). They agreed to work with other Team members to secure local and federal production or tax credits to facilitate the development and financing of the project. DG Energy would obtain a profit from the eventual Plant following its investment of time, money, and effort. Agencies and other organizations contributed extensive skill, technical assistance, and additional funding to help create the potential for new jobs, increase restoration activity on unhealthy forests (both privately and publicly owned), decrease forest fires, reduce carbon emissions from fires, and create a renewable energy source. 
The community partners, agencies and environmental organizations put a great deal of effort into increasing the potential value of a future Biomass plant. The amount of effort the final private power plant developer expended was not as high, although its predecessor had done sufficient work to contribute to an agreement in the Declaration of Cooperation. During implementation DG Energy was bought and Marubeni entered the picture; a new set of negotiations began that were less integrative than the original agreement.

The group has had to revisit their concerns based on new information. During the direction setting phase the group used supply analysis estimates from both the Collins Company (e.g. Fremont mill production) and biomass supply estimates from the Forest Service and BLM to determine an appropriate scale for the plant. The group had agreed that a plant generating up to $15 \mathrm{MW}$ of energy would be of an appropriate size to turn a profit and support forest restoration work. The Collins Company reassessed the earlier estimated supply analysis numbers with actual mill production levels and actual forest thinning volume from 2008. The new numbers worked out to accommodate a plant up to a size 18 MW. In a June 2009 conference call, members of the Biomass collaborative project, mostly from the Lakeview Stewardship Group, discussed the new plant size. The group agreed that if the estimates were wrong and it resulted in an increase in harvest volume per acre the group would sue whoever was deemed responsible for over-harvesting (developer or agency). However, the group would support the thinning of more acres at the same volume per acre to achieve the $18 \mathrm{MW}$ size - this would better support their restoration timelines in the Unit. 
Members of the Lakeview Stewardship Group are concerned that current thinning levels in the Unit are not helping them meet their 20 year timeline to help improve forest health and decrease forest fires.

\section{Agreement Disruption}

The current struggles LCRI and the Collins Company (as a representative of the collaborative effort) are having with Marubeni is an indication that Marubeni's interests, e.g. to gain the most amount of profit or to gain the most amount in a company sale, are not in alignment with the community's. Marubeni is negotiating as though it has several better alternatives than developing this plant in Lake County. The global economic crisis and Marubeni failed business deals (e.g. several unprofitable biomass plants) may be interfering with this particular negotiation. 


\subsection{Tillamook Basin Flooding Reduction Narrative}

This project was distinct from the other four cases in that facilitators managed persistent conflict and positional behavior among participants. The case required additional analyses crucial for understanding the interplay among interests, disruptions, and facilitation techniques.

Figure 18. Tillamook Bay (Tillamook Bay Watershed Council)

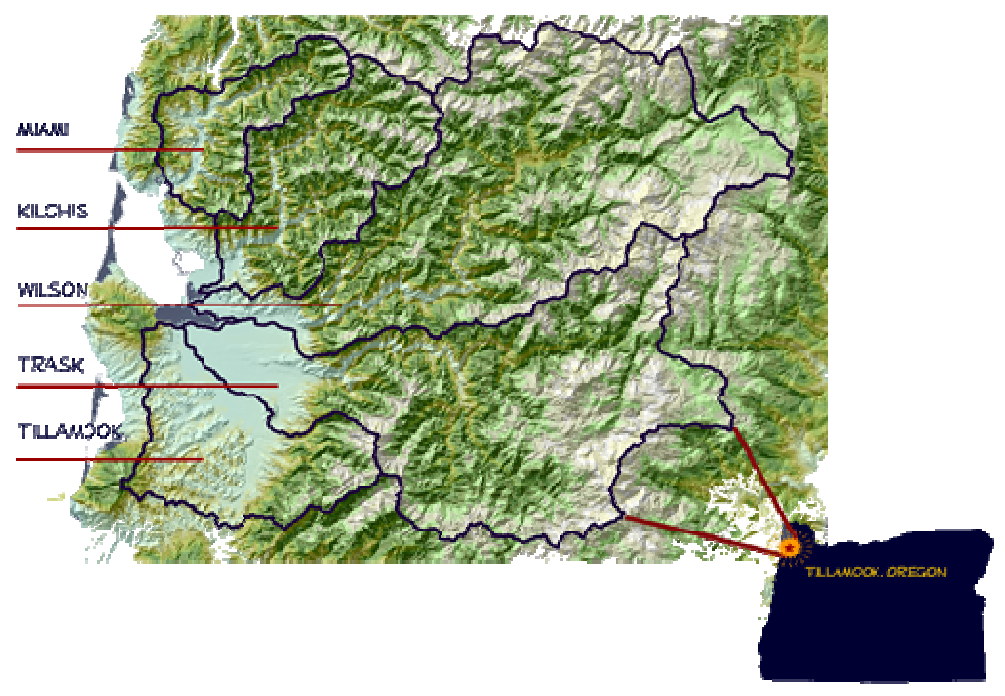

\subsubsection{Problem Description}

The Tillamook Basin is located on the north Oregon coast and is subject to seasonal flooding events during winter months. Community members, agency personnel and scientists agree floods have increased over time in frequency and magnitude (DoC, 2007). Most participants in this project agree that flooding is a problem for people who have homes, farms, or businesses in the middle of the water flow. There are two central problems the group worked on in this project: deciding how to reduce flooding damages, and building relationships in order to do so. 
The Basin is the home of the City of Tillamook with a population of nearly 4500 (U.S.Census, 2008). Flooding affects residents' homes, the agricultural community, and businesses along north Highway 101 in property damage and lost revenues. Tillamook is home to a sizeable dairy industry; as one individual notes, "Tillamook has more cows than people" (P 49). Cows represent business investments by farm owners and have died in floods. Tillamook County has had several federallydeclared flood disasters and was "declared a federal disaster area because of the February 1996 flood; Tillamook County suffered over $\$ 53$ million in damage, which is the equivalent of $148 \%$ of the county's annual budget"(USACE Feasibility Report, 2005). From 1996-2007, frequent flood damages have ranged from $\$ 5$ million to $\$ 53$ million per event (Appropriations Request, 2009).

The Tillamook Bay and its watershed are also components of the Oregon Coastal Salmon Restoration Initiative, The Oregon Plan, and is designated as a significant tidal estuary in the National Estuary Program. An estuary is where salt water from the ocean mixes with sources of freshwater; the area included in the estuary includes sections of rivers, the Bay, and wetlands. Estuaries are considered critical natural areas because birds, mammals, fish and other wildlife depend on their habitats as places to live, feed and reproduce (U.S. Environmental Protection Agency, 2009). Because the area is both economically and ecologically valuable to its citizens, different parties view flooding reduction efforts from two perspectives: impact on community and impact on ecosystems. 
Flooding results from a complex set of related factors: rain, storms, tides, natural land features, man-made development, river siltation, and water run-off from higher elevations. Rain during winter months, November through March, ranges from an annual average of $230 \mathrm{~cm}$ (90 inches) along the coast to a maximum of $380 \mathrm{~cm}$ (150 inches) in the elevated north-central portion of the watershed (Komar, 1997). Extreme rainfall events during storms occur within this range; for example, on February 2 of 1996 over 7 inches fell in one hour at the Lees Camp measuring station (OS video, 2009). The Bay receives water from changing tides, ocean storms, and inland storms that affect river water levels. Five major rivers (Miami, Kilchis, Wilson, Trask and Tillamook) drain into the Tillamook Bay and estuary.

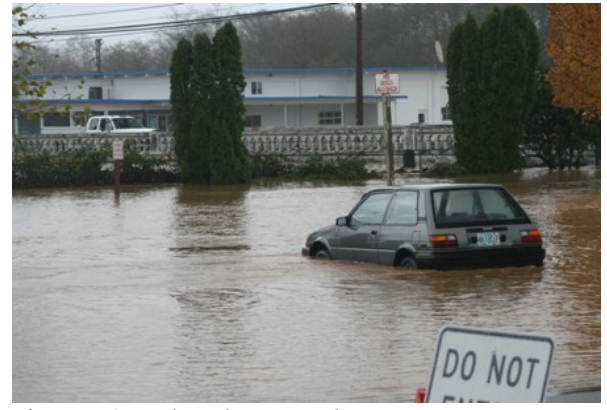

Figure 19 Flood example one (Tillamook County website)

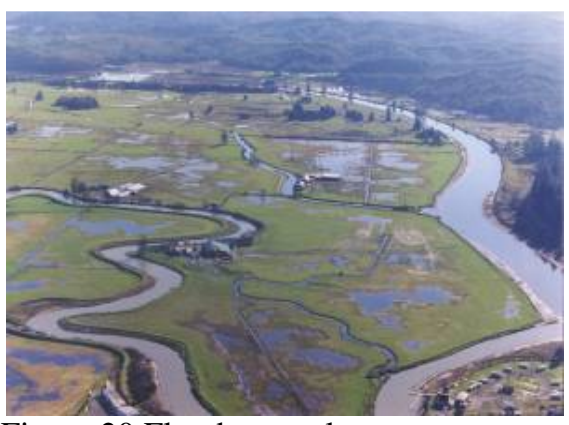

Figure 20 Flood example two (PIVOT website)

Natural land features and human development contribute to flooding (see images above). Natural land features such as braided rivers and floodplains encourage water to move across land as it flows toward the ocean (Bayley, 1995). This affects human developments and dairy farms built in the floodplains. Soil permeability, the size of the floodplain, and slope of the land also contribute to flooding. Development of impermeable surfaces such as parking lots and roads prevent the land from 
absorbing water as it would have historically (EPA, 2009; Follansbee \& Stark, 1998).

A levee is a type of dam built to reinforce riverbanks and prevent flooding by confining the water flow. In some places, like Tillamook County, levees also prevent floodwaters from spreading out over agricultural land - which can help save cows, but prevents the land from absorbing the water.

River flooding is related to river channel capacity, among other factors. Water volume, water velocity, soil permeability, slope, channel depth and channel width contribute to river channel capacity. Sedimentation affects channel depth and occurs from both natural processes and human activities. Natural and human sources of sediment include: sediment transport related to upland logging practices, a series of four fires called the Tillamook Burns, channel and river bank erosion, silt carried in from ocean tides, and building of levees and dikes which change water flow and drainage patterns (Bostrom \& Komar, 1997; Coulton, Williams, \& Benner, 1996; Komar, McManus, \& Styllas, 2004).

...The lower portions of the rivers overflow frequently because channel capacity is inadequate to handle heavy flows during severe rainstorms when combined with high tides. The resulting flooding cut off access to U.S. Highway 101, the major north-south arterial along the Pacific Coast, and inundated residential, commercial, and pasture areas...(USACE Feasibility Report, 2005).

Methods for addressing flooding are controversial. Flood reduction options are linked to how different participants understand the land and river systems. Participants select flood reduction methods based on concerns about impacts, funding requirements, perspective, and regulations. In this project, flood reduction to minimize negative impacts on community developments (e.g. businesses, homes) is 
interdependent with ecosystem management and environmental regulations because human development is in the middle of a natural flooding area.

Federal and state regulations affect flood reduction efforts in the Tillamook Basin, because of surface waters, the estuary, and endangered species (see table 34). In 1973, the U.S. Congress passed the Endangered Species Act (ESA), creating federal and state programs to conserve ecosystems of threatened and endangered species of fish, wildlife, and plants. Section 7 of this Act requires Federal agencies and state offices to make sure any action authorized, funded, or carried out does not jeopardize the existence of listed species, or modify critical habitat. In 1998 the Oregon coastal Coho salmon was listed as threatened under the ESA; any physical work in the Tillamook estuary and its five rivers is held under close scrutiny.

In 1977, the United States Congress also passed the Clean Water Act (CWA) that made it illegal to discharge any pollutant from a point source into navigable surface waters (e.g. rivers, lakes) unless a permit is obtained (EPA, 2009). Programs headed by the Environmental Protection Agency (EPA), United States Fish and Wildlife (USFW), Army Corps of Engineers (Corps), the National Oceanic and Atmospheric Administration (NOAA) and other federal agencies are required by law to uphold these regulations. Section 320 of the CWA also requires the EPA to develop plans for attaining and maintaining water quality in an estuary.

Oregon state agencies such as the Department of Environmental Quality (DEQ) uphold regulations that support the ESA and CWA. Oregon regulations also govern different potential flood reduction efforts such as wetland mitigation and 
sediment removal (see table 34). Many sources of federal and state funding are tied to ecosystem restoration efforts through these regulations.

Table 34 Regulations and agencies affecting Tillamook Basin

\begin{tabular}{|c|c|c|c|}
\hline Regulations & Federal Agencies & State Agencies & County Agencies \\
\hline Clean Water Act & US Army Corps of & Dept. of Fish and & Tillamook Soil \& \\
\hline Endangered Species Act & Engineers & Wildlife & Water \\
\hline Oregon Statute Columbia & NOAA National Marine & Dept. of Environmental & Conservation \\
\hline River Gorge; Oregon & Fisheries & Quality & District \\
\hline Ocean Resource & US Fish and Wildlife & Dept. Land & \\
\hline Planning; Wetlands & USDA Natural Resource & Conservation \& & Tillamook County \\
\hline Removal \& Fill (ORS & Conservation District & Development & \\
\hline 196.600-990, OAR & & Department of State & City of Tillamook \\
\hline 141-085-0121) & & Lands & \\
\hline Oregon Statute & & Bureau of Land & \\
\hline Corporations for & & Management & \\
\hline Irrigation, Drainage, & & & \\
\hline Water Supply or & & & \\
\hline Flood Control (ORS & & & \\
\hline 554) & & & \\
\hline
\end{tabular}

\subsubsection{Origins of the Collaborative Effort}

Several groups had worked independently to reduce flooding, or focused on ecosystem restoration, during the last two decades. The County had been working on a flood reduction plan after the 1996 flood. They used federal grant and county funds to repair dikes and tidegates and supported the Army Corps of Engineers in conducting a Feasibility Study on ecosystem restoration projects and flood damage reduction. The County also used federal grant money to raise citizen homes and hired an Emergency Management Director to be pro-active on flood issues, among other things (Tillamook County website, 2008). The Tillamook Estuaries Partnership formed in 1999 (TEP) and received funding for wetland and river restoration efforts from grants and the NOAA Community-Based Habitat Restoration Program. Many of these projects have flood reduction benefits. 
The Tillamook Bay Habitat \& Estuary Improvement District (TBHEID) is a group of local farmers and business owners who formed a flood control district in 2002. The group had applied for multiple permits from state agencies over the years to maintain infrastructure, conduct dredging and dike repair activities on rivers in support of flood damage reduction. The group experienced long application delays and denials of some permits with federal and state agencies, especially with the Department of State Lands and the U.S. Army Corps of Engineers. This led to tense relationships between permitting agencies and some local community members. Frustrated, the TBHEID group, with support from County Commissioners, approached state legislators for help. TBHEID members also drafted a House Bill in 2005 to target the flood reduction issue. It did not pass. However it is an example of the group's investment of time and resources. The group wanted to be able to reduce flood impacts quickly and believed they were delayed by government agencies.

Until the 1970s, Tillamook city and county government, diking districts, and farmers built levees, constructed dikes, and dredged rivers in an effort to reduce flooding. Dredging also had a financial benefit for local aggregate companies who used the gravel for commercial purposes. Community members' experience is that excess gravel, sand, and silt fill riverbeds contribute to flooding. Dredging removes excess material and allows the water to move through the river to the ocean. From their understanding, this sediment comes from upstream natural and human caused erosion; they believe gravel collection mechanisms could help retain the material (Interviews, 2009). This understanding was different from those of agency personnel 
with flood reduction experience in the area. Agency personnel such as members of the Corps understood that river bank soil erosion contributes to sedimentation problems and rivers need to be wider, not deeper, in order to hold volumes of water. Dredging is a short-term, expensive solution as rivers fill again (Interviews, 2009). State and federal agency personnel were concerned about bank erosion and upstream erosion (Interviews, 2009). Agency personnel were also concerned dredging negatively impacts fish habitat due to increased amounts of fine sediment suspended in the water.

In the 1970s, government agencies began requiring permits for dredging as a result of federal legislation and state regulations. The majority of dredging activity, especially for commercial use, has not been permitted because the activity is considered threatening to endangered fish habitat. According to the CWA, a "point" source is pollution coming from a direct conveyance; for example a business discharging water through a pipe or ditch. A "pollutant" is defined as any thing discharged into surface waters other than sewage from vessels, water, or gas injected into a well (40 CFR 122.2). Pollutants can include substances that change the physical, chemical or biological properties of surface waters including solid waste, heat, silt, rocks, sand, dredged spoil, and chemical wastes (40 CFR 122.2; ORS 468B.040-047). Silt and sediment floating in the water are considered harmful to fish. Silt and sediment suspended in the water can increase water temperature, decrease visibility and diminish oxygen levels for fish (EPA, 2009; Wood \& Armitage, 1997). Dredging could be considered a point source of pollutants. 
Based on the apparent conflict between flood reduction activities such as dredging and protecting fish habitat through federal and state regulation, community members, and agency personnel were at an impasse. Community members encountered repeated delays and denials in permitting dredging activities. Their preferred method of historical flood reduction has been blocked by permitting agencies. Additionally, as flood levels increased over time frustrations from being unable to address the problem based on permitting issues has grown. Agencies could not permit working in the river if fish habitat might be harmed. Tense relationships existed between private and public sectors. Community members felt desperate to reduce negative flood impacts.

A second layer in the relationships between community members and agency personnel is the past government emphasis on research and planning rather than implementation of projects. The Tillamook Basin, rivers, and Bay have been the subject of dozens of research studies and are part of City and County land use planning efforts. Some interviewed community members felt frustrated that limited dollars, time, and agency resources have been directed toward research and planning, and fish habitat restoration, instead of constructing projects that directly relieve negative flood impacts.

Following extensive flooding in November 2006, community leaders participated in a Flood Summit at the request of County Commissioner Mark Labhart to see if the community could find ways to work together to reduce flooding and mitigate its negative effects. One of the decisions from the Flood Summit was for 
three local government entities to petition the Oregon governor's office for flood mitigation as an Oregon Solutions project. These entities include the Tillamook County Commission, the City of Tillamook, and Senator Betsy Johnson.

A key element in flood reduction is funding. The group began with a modest (relative to potential project costs) amount of funds from various sources (see table 35). The largest sum of funding came from Senator Johnson's efforts in the state Legislature, a one million dollar allocation for flood reduction. The dollars have been used as core money or match for securing other funding.

Table 35 Tillamook Flood Reduction: Financial commitments and expenditures (May 23, 2007 meeting; Addendum to DoC, January, 2009).

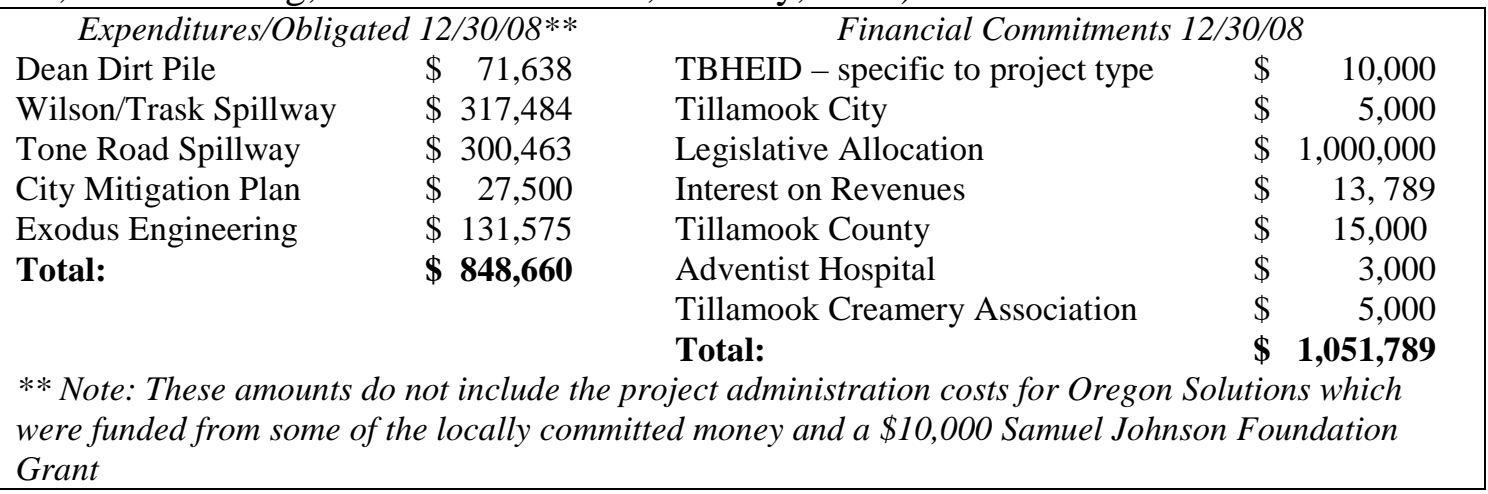

\subsubsection{The Collaborative Process}

The Oregon Solutions project manager and facilitator, Dick Townsend, conducted an extensive project assessment, interviewing 58 individuals, nearly half of whom were local non-government affiliated community members. Interviews led him to conclude that flood reduction required immediate attention, "considering the social, economic and political damage that occurs during major flood events in the Tillamook Basin, the option of doing nothing is an unacceptable alternative." He found that most 
individuals felt ready to work together although expectations were not high that Oregon Solutions would help resolve differences of opinion. The proposed flood reduction projects were so different there was a "strong likelihood that not all parties will have their needs met (Tillamook Project Assessment, p. 2, 2007).” Townsend recommended the governor designate the Oregon Solutions project; and that the project form smaller work groups, use site visits, and pursue technical studies to better understand flood reduction alternatives. A collaborative approach built on the success of smaller flood reduction projects might build a foundation for the group to move forward on larger-scale projects (Tillamook Project Assessment, 2007).

The project was approved based on the project assessment and was designated by the Governor in April 2007. The Governor's designation and Senator Johnson's involvement helped motivate state and federal agencies to work with community members to find projects they could all agree on to reduce flooding without diminishing ecosystem health.

The group began having monthly meetings in May of 2007 with Senator Johnson and County Commissioner Mark Labhart as Co-Conveners. Public meetings were located centrally in Tillamook and regularly attended by more than 40 participants. Group meetings involved participants sitting at an oval table facing each other with public seating along the perimeter. Members of the public could give input and feedback, but did not have a vote in either the Project Team or Design Committee. Participants of both teams represented a diverse group of government agencies and community members (table 36). Local government individuals are also citizens of 
Tillamook County. The facilitator and co-conveners had a background in flood issues from a policy, technical information, and experiential basis.

The Project Team created flood project sub-groups, and the Design Committee during the process. The Project Team made decisions using both consensus and simple majority voting styles. The Project Team began with 31 voting members, including the co-conveners in 2007, and added a DEQ representative and a member of the Tillamook Economic Development Council to make 33 members by 2009. The three congressional representative liaisons were non-voting participants in the Project Team. The project manager was a non-voting member of both the Design Committee and Project Team. The group retained the project manager to help facilitate the process through the beginning of the implementation phase until July of 2009.

The Project Team is the final decision-making body; the sub-groups explored details of different proposed flood reduction projects during the problem setting and direction setting phases. The Design Committee, a sub-set of Project Team members, was created during the implementation phase to work on flood reduction projects in more detail and advise the Project Team.

The Design Committee consists of members who represent diverse groups on the larger Project Team. Members were asked to serve by the two co-conveners based on leadership and knowledge. There are ten individuals on the Design Committee including seven government participants (federal, state, and local) and three local nongovernment representatives with ODF\&W manager Rick Klumph designated as Chair. Non-government representatives include one member of TBHEID, one member of the 
Oregon Farm Bureau and one individual from the Tillamook Estuary Program. Design

Committee meetings are also convened in public, face-to-face style in Tillamook.

Table 36 Tillamook Flood Reduction: Project Team membership

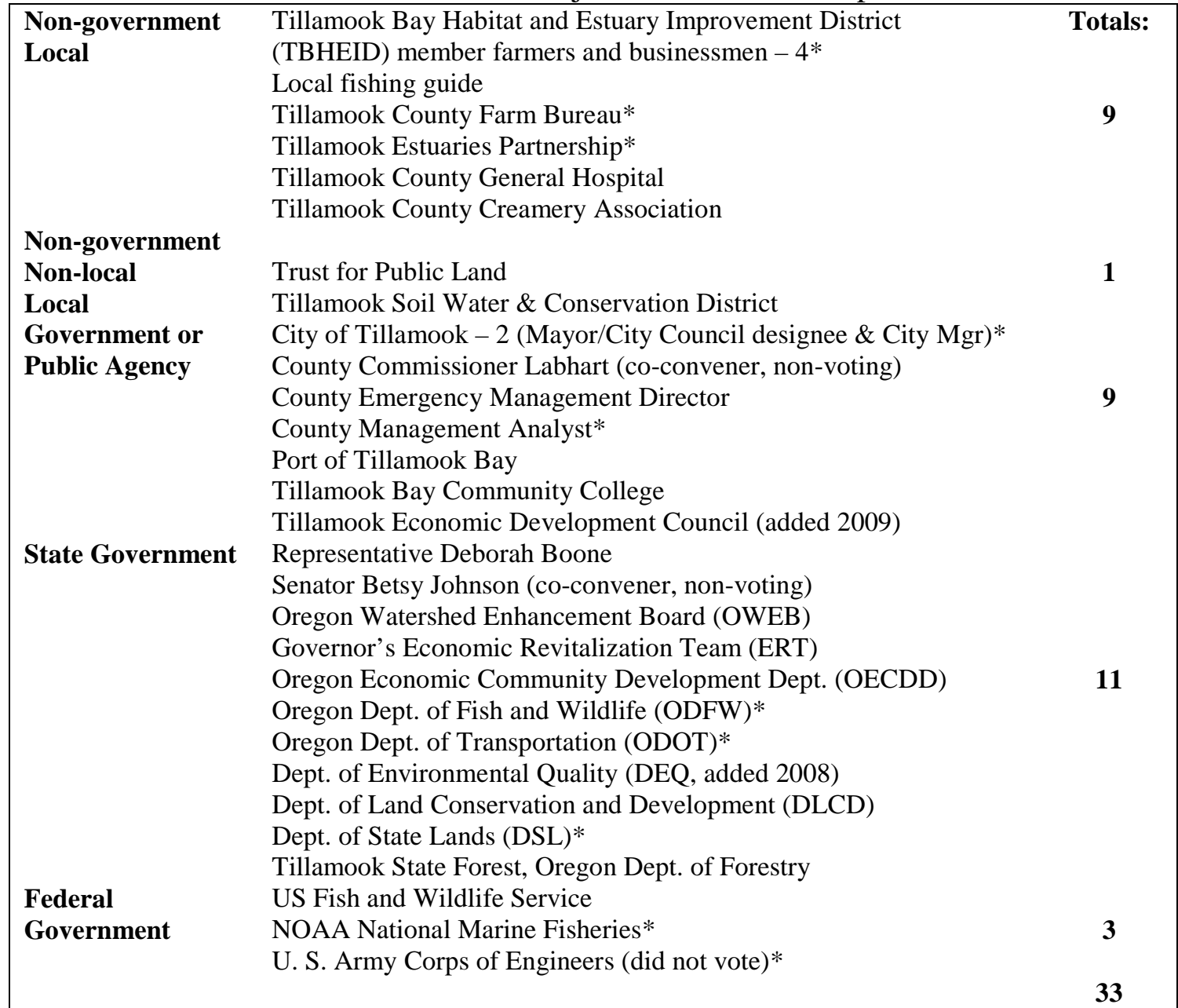

*Design Committee members (one member from the City and one from TBHEID). The three state representative liaison positions are not included.

The project manager began the problem setting phase at the first meeting with a discussion of "working principles for effective group interactions" that became the group's ground rules. Participant issues and concerns in the ground rule discussion were based on the project assessment. Included within the principles were 1) respecting the diversity of interests at the table, 2) sharing information to nurture trust 
and honesty, 3) agreeing by consensus, 4) focusing on flexibility, and 5) staying

committed to this one process. The project manager was concerned that groups pursuing more than one process would be confusing for participants and frustrating to the project.

Led by the two co-conveners and the facilitator, the Project Team discussed concerns in relation to flood reduction in order to develop a group goal statement and purpose for the project team. The goal statement went through several iterations ending at the following in July, 2007:

The goal of the Oregon Solutions Tillamook flooding reduction project is to reduce flooding and the adverse impacts of flooding while incorporating environmental, social and economic values in the development of short and long term solutions.

Footnote 1: While the geographic area for the project is the Tillamook Bay Drainage Basin, this project will hopefully create a template and process to address flooding in other coastal basins (watersheds).

Footnote 2: Long term definition: Ten (10) years or more.

Footnote 3: Environmental considerations may include: freshwater wetlands, estuarine areas, associated side channels, streams and rivers, forest lands and associated habitats and species. (June 27, 2007)

The group used consensus voting to adopt this goal statement. The co-conveners asked if anyone could not live with it, and as no one disagreed, the group adopted the goal.

In the Declaration of Cooperation, this goal includes the introductory words "develop and implement a plan to reduce flooding..." The project manager added this statement to clarify the project intent. The Project Team did not review the addition, and did not ask for it to be removed. 
The group brainstormed an initial list of potential projects for consideration in flood reduction. Following discussions, individuals volunteered to work in sub-groups to further explore the different suggestions. The sub groups focused on 1) Land use projects, 2) In-Stream projects and 3) review of prior US Army Corps of Engineers' recommended projects from the 2004 feasibility study.

The group identified financial commitments and potential funding sources for projects. Several participants described pre-existing research as a way of understanding the current situation and requested using the information rather than “getting bogged down” with more studies (OS Meeting, May 2007). The group primarily used the Corps' Tillamook Bay and Estuary, Oregon General Investigative Study [Corps Feasibility Study], community experience of past floods, and hydrological modeling from different consultants in the decision-making.

Project manager Townsend and co-convener Labhart drafted a criteria list the group used to evaluate flood reduction projects. The list included ten criteria such as 1) compliance with the team's goal, 2) potential funding sources and costs, 3) time frame, and 4) if the project had community and agency support (see list at end of narrative, Tillamook DoC, 2007). Consensus voting was used again to approve the criteria to evaluate flood reduction projects.

Following Project Team (PT) and sub-group discussions of the initial project list, each sub-group used the criteria to vote on potential projects. The evaluation criteria acted as a project description form. The sub-groups met about ten times to go 
through projects; using the criteria and group goal to narrow the list. Each sub-group brought supported projects to the Project Team for consideration.

At the September 12, 2007 meeting, each sub-group presented projects to the PT. Prior to voting, a convener asked for everyone's commitment to continue working together - regardless of the ranking of the projects. Each PT member had an evaluation sheet and ranked each project from one (the best) to five (the worst) on five categories. The categories used in voting were: 1) flood mitigation, 2) environmental impact, 3) community acceptance, 4) feasibility of completing the project, and 5) cost. This initial voting procedure resulted in a list of 19 projects ranked by number of votes where the lower numbers indicate a better ranking (table 37).

Table 37 Tillamook Flood Reduction project list

\section{Tillamook Flooding Reduction Projects \\ (Prioritized by Project Team 9/12/07)}

\footnotetext{
1. Wilson/Trask Spillway (223) - completed in $\mathbf{2 0 0 8}$

2. Tone Road Spillway (237) - completed in 2009

3. Dougherty Slough Permanent Structure (248) - part of Project Exodus

4. Comprehensive Community Vision and Strategic Plan (256) - Started 2009

5. Trask Hook (263) - tabled

6. Implement City/County Flood Mitigation Plans (274) - City plan started 2008

8. Hall Slough Project (274) - part of Project Exodus

9. Modified Wetland Restoration and Swale (279) - part of Project Exodus

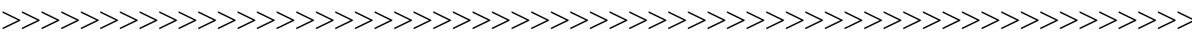

Other Projects for Possible Future Consideration

10. Tomlinson Slough Connection/Restoration (316)

11. Study of Drainage/Diking District Issues (321)

12. Old Trask Channel Restoration (340)

13. Drainage Maintenance and Flood Structure Improvements (349)

14. Wilson River Dredging - Mouth \& Bay Shoal (354)

15. Wilson River Restoration (358)

16. Upper Basin Storage (374)

17. Implement Storm Water Maintenance Plan (417)

18. Bay Dredging - multiple sites (426)

19. Bay Dredging - East channel (440)
}

7. Mediated Gravel Agreement/Stream Corridor Management Plan (368) - completed 2009

Numbers behind each project are the total number of "best on five categories" with lower numbers receiving the best rankings $(\mathrm{DoC}, 2007)$ 
Two months after the group voted on the project list, the Project Team signed an agreement, the Declaration of Cooperation, committing time, support, and resources to implement the top nine. Two of the projects were suggested by the Army Corps Feasibility Study as having both flood reduction and environmental restoration benefits: the Hall Slough Project and the Modified Wetland Restoration and Swale Project. The two were merged with the Dougherty Slough Permanent Structure project into "Project Exodus." Project Exodus is intended to reduce flooding while improving eco-system restoration. The Corps suggested, and the Project Team agreed, to model different alternatives of Project Exodus to determine what would have the greatest flood reduction impacts in the floodplain.

\subsubsection{Current Status of the Collaborative}

The group is in its third year and is mid-way through the implementation phase. Both the Project Team and Design Committee continue regular meetings either in-person or with email communication. The Project Manager finished his work with the group in July 2009. The co-conveners asked Paul Levesque, the County Chief of Staff to facilitate PT meetings. Rick Klumph continues to facilitate and lead the Design Committee as its chair.

Two of the priority short-term physical projects are complete (\#1, \#2). Two of the long-term projects have started. The Strategic Plan/Community visioning project (\#4) has begun with an inventory of available city-owned land for commercial purposes as well as a discussion of open space designs for vacant North Highway 101 public properties. The inventory helps provide land use alternatives for businesses 
wanting to relocate. Implementing the goals of an updated City Flood Mitigation Plan (Project \#6) has begun with the removal of the "Dean" dirt pile in the flood way, as well reducing flood plain insurance premiums through flood damage reduction.

Project \#5, the Trask Hook is a physical project the group envisioned as installing a culvert or other type of water by-pass to remove the hydraulic pressure created by the Trask River Hook Channel. Due to conflicting hydraulic analysis presented to the Design Committee and its relatively high cost, the group tabled it.

Project \#7, the Mediated Gravel Agreement is complete. Without detailing the agreement or the lengthy science studies that indicate how gravel removal negatively affects river ecosystems, the agreement allows some specific gravel bars to be "scalped" within specific limits (depth, final grade slope of the bar, etc.). The agreement cited the Corps 2004 Feasibility Study recognition that river channel capacity has been reduced from upstream soil erosion in combination with land use practices. Rivers are acting as "chutes" and are accumulating gravel in large sizes at their mouths (Mediated Gravel Agreement, 2009).

Priority projects \#3, \#8 and \#9 were combined into Project Exodus. It is a large-scale, expensive (\$7.2 million without land acquisition costs) construction project. The project reconnects Hall Slough, allowing high water flow from the Wilson River and water passage under Hwy 101. The project includes a southern and northern portion. The southern portion consists of creating a flow corridor by constructing spillways, setback levees and changing levees downstream of Hwy 101 between Hoquarten and Dougherty Sloughs and running westward to the Tillamook 
River (Consultants, July, 2009). In the northern half of the project, further levee removals are proposed in a public Wetlands Acquisition Area. The Wetlands Acquisition Area was an earlier ecosystem restoration project. Between 1999 and 2003 several partners used grants to purchase land to restore nearly 375 acres of intertidal habitat along the confluence of the Wilson and Trask Rivers (Tillamook Estuaries Partnership, 2009). The intention of Project Exodus is to get as much floodwater to the Bay as quickly as possible by way of a designated Flood Way.

During 2008 the Design Committee worked to put together a Scope of Work for modeling services from a consultant/engineering firm using different alternatives for Project Exodus. A Request for Proposals asked applicants to propose small projects to be implemented independently in the short or long term to mitigate flood conditions (Addendum, January, 2009). The Design Committee contracted with the firm Northwest Hydraulic Consultants - HBH Consulting Engineers. During June 2009, NHC/HBH completed modeling of various sub-projects and alternatives of Project Exodus. In August 2009 NHC/HBH presented modeling results to the Project Team and Design Committee, as well as other community groups such as TBHEID. Following modeling, the consultant found certain projects had negligible flood reduction benefits, leaving alternatives number "three" and "four" and several subprojects for the group to decide on. Following discussions of the model results, impacts, and the pros/cons of both alternatives in two meetings and side discussions, the Design Committee voted to recommend "Alternative Four" for further development and funding. The project has an estimated based on its $\$ 2$ million lower 
cost than the alternative, less levee construction, full restoration of 377 acres of wetland, full connectivity between the Trask River and historic sloughs, locating levees further from the river, and does not cause flood rise at the confluence of the Trask \& Tillamook Rivers. This alternative includes a berm built on the South Bank of the Wilson River and the grading of one privately owned field on the North Bank of the Wilson River (see Figure 21).

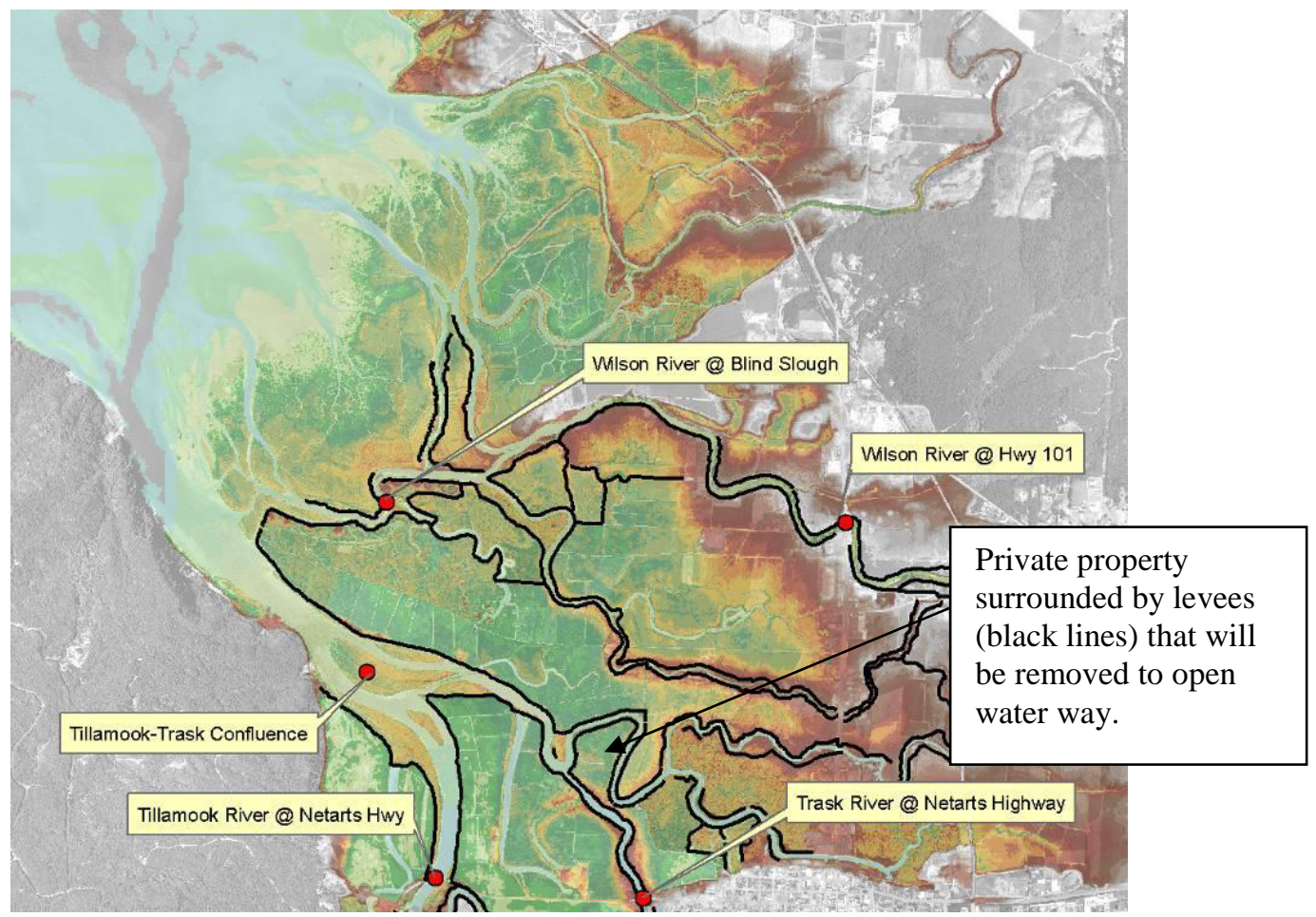

Figure 21.Project Exodus (NHC Duration Analysis, Sept. 1, 2009)

The Project Team used an email voting process to approve the "Alternative Four" recommendation. 32 members of the Project Team voted as follows: 6 no response, 1 no vote, 21 yes votes, and 4 abstentions. Both alternatives impact approximately 116 acres of privately owned grazing land. The Design Committee 
authorized the County to begin discussing the purchase of the required properties, flood easements, and temporary use of the privately-owned land.

The City and County applied for an additional legislative appropriation to fund further flood reduction projects. Other state and federal funds are being for application to Project Exodus. The Oregon Watershed Enhancement Board made a verbal commitment to provide $\$ 2$ million match. The project has a volume of support with local, state, and federal agencies who have agreed to expedite reviews, permits, and share agencies resources (e.g. time, technical assistance). This includes support from local special government groups such as the Port of Tillamook Bay.

Participants raised concerns about Project Exodus including 1) the impact it will have on private land-owners in, and bordering, the project area, 2) a concern of grazing land loss, and 3) a concern about the sources of money used to implement the project. During recent Project Team meetings the group explored use of FEMA funds available to repair the Port's flood damage on projects such as Project Exodus Alternative Four. These interests were addressed in meeting discussions and by gathering information from land owners, hydrologic modeling, and funding sources.

The Project Team recently re-committed to an amended, updated Declaration of Cooperation. Completed priority projects are described below in more detail (DoC Second Addendum, July, 2009):

\#1. Wilson/Trask Spillway: Flood water drainage is blocked when high water behind berms is not allowed to escape. For added flood drainage, this project allows the expeditious exit of flood waters into Tillamook Bay through a gated spillway next to the ten tide gates on the Tillamook Bay levee. The U.S. Corps of Engineers provided 
valuable information for optimal design criteria and the Oregon Department of State Lands waived permit fees and provided expedited permit application review. Funding for this project came from a legislative action in 2007. The Tillamook Bay Habitat and Estuary Improvement District provided some matching funds for this structure and for the Tone Road Spillway. Project construction was completed in September 2008.

\#2. Tone Road Spillway: This project shows a positive benefit for farm land where excessive loss of farm animals occurred in two floods over the last decade. The project has installed a second gate spillway north of Tone Road, to convey flood water into Tillamook River. The property owner and Drainage District endorsed this improvement. Project construction was completed in April 2009, using funds from the legislative allocation.

\#7. Mediated Gravel Agreement/Stream Corridor Management: Facilitation was needed to bring parties together with the goal of executing a final agreement and adoption of a Stream Channel Management Plan. The Plan addresses where and under what conditions gravel may be extracted in certain Tillamook County rivers. In 2000, a draft of an amended plan was completed, but an impasse was reached primarily due to concerns raised by DLCD. The Plan has now been rewritten and the new agreement signed. Oregon Solutions provided, through the PSU Oregon Consensus Program, mediation and facilitation services to work through Agreement issues. In February, 2009 the document was finalized. 


\section{Oregon Solutions Project Evaluation Criteria}

Criteria 1: Provide a brief description of the project, including the benefits derived from accomplishing the project.

Criteria 2: Does it comply with the Project Team's stated goal?

Reduce flooding and the adverse impacts of flooding while incorporating environmental, social and economic values in the development of short and long term solutions.

Criteria 3: What would happen if this project was not accomplished?

Criteria 4: Does the project have strong community and agency support?

Who are the responsible/lead parties?

Who are partners that need to be involved?

Criteria 5: List identified or potential funding sources to carry out the project.

What is a rough cost estimate to complete the project?

Will this project take additional funds to sustain the outcome and are there operating or maintenance costs associated with the project?

Criteria 6: Is this project characterized as a short or long term solution for the Team's stated goal?

Criteria 7: List the approximate time frame for implementation.

Criteria 8: Can the project be easily implemented? List the requirements for permits, logistics, EIS work, etc.

Criteria 9: Outside of permits and funding requirements, list any impediments/obstacles to accomplishing the project. List possible solutions to those obstacles.

Criteria 10: Is the project compatible with, or support recommended action items contained in, the Tillamook County and Tillamook City flood mitigation plans? 


\subsubsection{Tillamook Reduced Flooding Within Case Analysis}

This case is still active; selected participant quotes are unidentified and descriptive information is removed to retain anonymity. Note that the terms"concerns" and "desires" are used to clarify negative or positive interests. Bold-faced words are researcher prompts.

\subsection{5 a Research Question One : Identifying Interests}

Participants in the group emphasized numerous interests including flood reduction, funding, implementing projects, and ecosystem health in the problem setting and direction setting phases (see table 38). In fall 2009, mid-way into the implementation phase, community participants brought up interests about Project Exodus, as described in the last section.

Meeting notes and interviews indicate participants' positions were intertwined with positions during all three phases of the process. The quote below illustrates that beyond flood reduction people were concerned about land use, regulations, environmental habitat, past logging practices, future impacts of logging, and protecting community well-being.

Everyone had a common theme of wanting to see the community safe and wanting to find solutions to deal with the flooding. ...There was agricultural industry, dairy farmers especially, and business owners along 101, and I think they were concerned about security for their future... so they had specific interests associated with their use of the land. Natural resource agencies were also at the table... having to look at habitat protection, at the statutes, the regulatory process... I think the elected officials, county commissioners, city planners, and senators... they really desired community support and participation, and wanting to see success, and wanting to see everybody satisfied (P45). 
Table 38 Tillamook Flooding Reduction: Participant interests

\section{On Substance of Issues:}

Reduce negative impacts of flooding (e.g. property damage, loss of cattle)

Protect environmental resources (e.g. fish)

Concern agencies will not permit flood reduction projects

Concern of running out of funds to do flood reduction projects vs. plans/research

Concern with not having enough money for flood reduction projects

\section{Process:}

Desire for immediate work to reduce flooding (short-term projects).*

Desire for a fast timeline.*

Concern with too many meetings/talk.*

Desire for long-term flood reduction projects (e.g. can't fix all in six months)

Desire for ease/speed in agency permitting.

Concern that planning and research will slow down implementation of on-the-ground projects.

Concern with having time to evaluate and implement projects.
On Substance of Issues: Intangible Interests

Protect community safety

Protect business investment

Protect agricultural land

Protect community economy (e.g. businesses, agriculture)

Protect environmental habitat

Protect endangered species

Relationships:

Community and agencies work together to find a common agreement.

Desire for community support of projects.

Desire for agencies to help, instead of block, community efforts.

Desire that community's concerns be respected

Fulfill job duty/responsibility.

Desire for open-minded perspective.

Desire for people to communicate concerns.

Address institutional problems/issues.

\section{Process:}

Be candid about what will/won't work

Concern about all being dedicated to the process, e.g. not tear it apart.

Desperate for a change

One agency did not want to overly influence the process.

Wanted to help, provide assistance/understanding.

*Brought up by nearly three-quarters of participants in the June 2007 meeting.

Participant values were also connected to interests and positions. Values are

beliefs. As described in Chapter Two, conflict based on values involves a

disagreement about what should be. Several community members described a

position of wanting "no net loss" of agricultural land. This position was based on 1)

their desire to protect agricultural businesses, 2) a value of retaining private ownership

of land instead of government ownership, and 3) a fear of what Tillamook will become

if more land is publicly owned. One group of private citizens value the current mix of

businesses, they value having private land ownership in order to encourage economic 
development, and fear that this preferred mix will change. This sub-group had a strong feeling about what the City "should" look like; they value an ideal. Based on interviews, these values were at the core of disagreements about facts and interests. One individual also felt that the amount of money devoted to ecosystem recovery has been unfairly large in comparison to funds spent on flood reduction, or human-related, projects.

In the follow up survey, staff members and participants were asked whether or not they agreed that specific interests identified in the interviews were important, see table 39. The 18 respondents, two staff and sixteen participants, emphasized substantive interests in reducing the negative impacts of flooding (100\%), protecting environmental resources $(100 \%)$, and protecting the community economy $(83.3 \%)$. Table 39 Tillamook: Follow-up survey responses of "important" interests

\begin{tabular}{lc}
\multicolumn{1}{c}{ Tillamook Flooding Reduction (n=18) } & \% Yes \\
\hline Protect environmental resources (e.g. fish habitat, endangered species) & 100 \\
Reduce negative impacts of flooding (e.g. public safety, property damage, loss of cattle) & 100 \\
Protect community economy (e.g. businesses, agricultural land) & 83.3 \\
Concern of running out of funds to do flood reduction projects & 55.6 \\
Desire for short-term projects to get something done & 61.1 \\
Desire for long-term projects because cannot fix it all in the short term & 88.9 \\
Desire for agencies and community to work toward common agreement & 94.4 \\
Desire to fulfill job duty/responsibility (e.g. uphold mandates) & 44.4 \\
Desire that everyone's concerns be respected & 83.3 \\
Other text (4 separate responses): & \\
Desire not to see any fundamental change & \\
Desire to limit spending money on studies & \\
Many citizens felt disrespected/excluded & \\
The funding concern centered on where we were going to find the funding to pay for the work
\end{tabular}

Survey respondents were split regarding the concern that funds might run out to do flood reduction projects $(55.6 \%)$. Nearly two-thirds agreed that the desire to complete short-term projects was important $(61.1 \%)$ while more than three-quarters agreed that the desire for long-term projects was important (88.9\%). More than three-quarters of 
respondents agreed that the relationship/process interests of respecting everyone's concerns (83.3\%) and the desire for agencies and the community to work together (94.4\%) was important. Less than half of participants agreed that desire to fulfill a job duty (44.4\%) was important. These results show that the group agreed on a set of interests. The group encountered many difficulties in order to address the substantive interests.

Dredging was a contentious issue. Participants had positions connected to interests and value on this issue, see figures 18 and 19. Some community participants wanted to dredge the rivers and the Bay - a few of these individuals held a position "dredge." Agency personnel had been unwilling to permit dredging projects because of research findings that indicate dredging damages fish habitat. Agency participants took a firm "no dredging" position in an opposing stance. One participant from a national agency offered to allow community members to dredge as a short-term project if they conducted monitoring efforts to show that the work did not negatively impact fish habitat. This option was not brought up in other interviews. The group explored other flood reduction alternatives to avoid an impasse. Dredging projects and alternatives were included in an initial list the group voted on. Gravel bar scalping was part of priority project \# 7 the Mediated Gravel Agreement/Stream Corridor Management and was included in options for flood reduction during the beginning discussions. Although dredging projects did not make it to the top nine prioritized projects, the group agreed to consider them in the future. 
Based on interviews and documents, participants' relationship interests were as important as substantive interests throughout the process. In the first meeting, several individuals emphasized a desire to develop agreement, 'unify' citizens and agencies, and for all agencies to work together on a common goal. Other participants suggested that the group "recognize the community" and "tailor future projects to the community" to meet their needs (Minutes, May 23, 2007).

In interviews, both community members and agency personnel voiced concerns about relationships. Both agency and community members were concerned about participants having hidden agendas. One community participant also had concerns about the balance of private and public sector power based on the group composition during the process. This individual wanted a Project Team with a balance of government and non-government membership. One co-convener noted that all groups in this process had a great deal of power and any one of them could have derailed the process, regardless of the composition. “...It's all about relationships...you've got to continually address where people are, continually ask the quiet people are you okay with where we're going, are there any issues, any concerns, and try to address their issues and concerns..."

Some community members were distrustful of permitting resource agencies: they doubted the agencies would want to help reduce flooding given a historical difficulty in obtaining permits (P8, P9, P26, P28, P13). Other community members took a pragmatic stance: agencies may be sympathetic to home or business owners living in a flood plain, but had their own practical limitations regarding legislation and 
funding. One community member noted that some citizens "can't understand.....that you're not going to get any agencies to sign off on permits to reduce flooding if you don't take into account what you're doing for or against fish (P9)."

Some agency personnel were fearful of being yelled at; as in "we could dredge if you gave us permits (P43)." Other agency personnel were concerned with the weight of past issues impeding the group's progress. One agency representative was worried the group would listen to his views too much and not give the community's concerns attention (P13).

This process began with a history of tense relationships and disagreements. The atmosphere at stages of the discussion, especially around the voting process, was tense. While most participants did not think the discussion descended into pointed disrespect or public fighting, everyone acknowledged disagreements were part of the process. In interviews, a few participants labeled the situation as behind the scenes "warfare," while others referred to it as "difficult differences." This language could indicate a desire to minimize conflict, varying comfort levels with conflict, or both. Process interests were connected to relationship interests. Concerns about doing something immediately, not wasting time or money, and implementing real flood reduction relief was echoed by $75 \%$ of the individuals, across stakeholder groups, in the very first meeting (Minutes, May 23, 2007). One participant noted that in the beginning, engaging in a participatory process may have felt to some like a waste of time, energy, and may not have led to anything tangible: "“been there, done that' we're not going to get anything done (P28)." The fact that the entire group 
remained engaged and committed to the process speaks to participants' investment in the issues, the skillful staff members, and the skill of the leaders. Skill here means that staff members and leaders did not merely schedule and coordinate; they used focused efforts on building and managing relationships outside of the group meetings.

Focusing on interests did not stop people from adopting positional stances.

Some participants maintained demands because they were fearful, others maintained demands in order to get what they wanted. Although staff members were attempting to integrate interests, this objective may not have been clear to everyone.

Themes on interests appear in table 40 below. Meeting notes indicate individuals began the discussion explaining issues, stating positions, and broaching concerns. Individuals also communicated their interests in private to the co-conveners, the project manager, community leaders, and the chair of the Design Committee between group meetings.

Table 40 Tillamook: Summary interest themes

\begin{tabular}{|ll|}
\hline Interest & Identified tangible interests in substance and process \\
Types & Identified intangible relationship and process interests \\
Theory & Identified shared interest (e.g. flood reduction) \\
& Interests intertwined with values, issues and positions \\
& Interests discussed in relation to central problem and sub-issues \\
& Relationship and process concerns received equal emphasis as \\
& substantive concerns \\
& History of conflict led to mistrust that had to be addressed \\
& Conflict/disruptions present \\
& Integrative and positional behavior present \\
& Revisited interests during each stage. \\
\hline
\end{tabular}


Collaborators in this project used a number of elements to help the group understand each other's perspectives (see table 41). Note in table $\mathrm{x}$ the use of both verbal communication techniques and information. Some techniques were focused on substantive interests, some were focused on relationship and process interests, and a handful affected both.

\section{Pre-convening}

An extensive project assessment consisting of 53 interviews and a document review helped the project manager and co-conveners further understand the logistics of sub-issues and participants' interests. It also helped frame the relationship and process interests of different participants prior to convening the first meeting.

\section{Participants}

The presence of specific participants with needed expertise helped make sure projects could address individual and stakeholder group interests. The fact that this was also a project involving high-level political representatives helped motivate agency personnel. Governor Kulongoski sent a letter to the director of state agencies describing it as one of his programs and that he had an expectation that the director and state agency staff work to make it a success (P26, P28).

... so it went from a local group wanting to do flood restoration, that may not have had all the expertise it needed to get it permitted, to a much broader group that did include the expertise and commitment from state agencies, to find solutions to get the projects on the ground... and get them permitted. 
Table 41 Tillamook: Techniques that helped address interests

\begin{tabular}{|c|c|}
\hline Pre-Convening & - The project assessment (in-depth, 53 interviews) \\
\hline Participants & $\begin{array}{l}\text { - Active conveners and project managers in shaping discussions } \\
\text { Mix of needed parties, e.g. government personnel and community members }\end{array}$ \\
\hline Information & $\begin{array}{l}\text { - Participant presentations of expertise } \\
\text { - Use of scientific information (e.g. computer modeling) to shape decisions } \\
\text { - } \\
\text { - Aiscussed options } \\
\text { - Agendogies to illustrate ideas (e.g. funding sources tied to interests) } \\
\text { - }\end{array}$ \\
\hline Meetings & $\begin{array}{l}\text { Face-to-face } \\
\text { On-site in Tillamook } \\
\text { - One on one discussions among participants } \\
\text { Private meetings with conveners/project manager }\end{array}$ \\
\hline $\begin{array}{l}\text { Verbal } \\
\text { Communication }\end{array}$ & 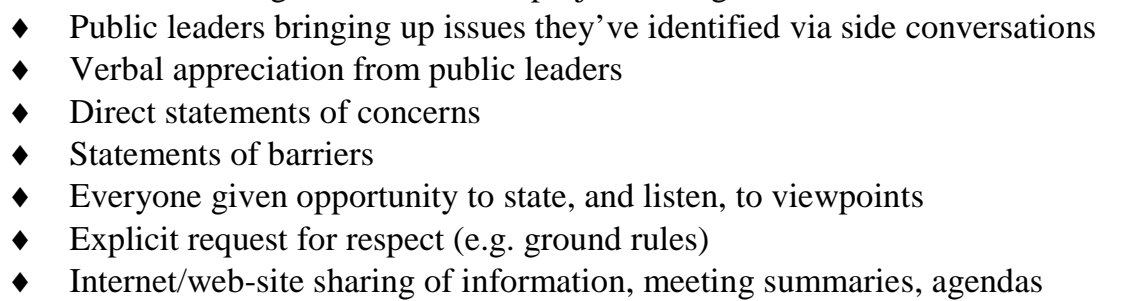 \\
\hline Visual & Use of figures, photos and diagrams to illustrate options \\
\hline Communicative & - Computer modeling in implementation phase \\
\hline $\begin{array}{l}\text { Shared } \\
\text { experiences }\end{array}$ & $\begin{array}{l}\text { Creating a goal statement } \\
\text { Re-commitment to the project } \\
\text { Reviewing computer modeling results } \\
\text { Site visits (sub-groups attended) } \\
\text { Celebrating successes }\end{array}$ \\
\hline Governance & $\begin{array}{l}\text { Ground rules } \\
\text { - Rimple voting on Project Exodus } \\
\text { - Consensus on goal statement, ground rules, and project criteria }\end{array}$ \\
\hline
\end{tabular}

Designing a project and writing an application to ensure a project's permit-ability was

a key element that had frustrated community members in the past.

The presence of community members in the sub-groups, Design Committee,

Project Team and in the audience helped the discussions stay focused on how different

decisions would impact the community. Agency personnel mentioned that it was 
helpful to hear personal stories and specific user groups' experience with flooding (P45, P13, P26). Community members felt responsible for making certain those who do not regularly deal with flooding see images, hear stories, and be given personal tours to make certain they understood the situation.

...when Oregon Solutions was started, nobody had anything, we had no maps, we had nothing, you were just appointed to a project team and you were supposed to do good things. So my first priority is to get whatever you need to know what you're talking about...I have a big case full of pictures and maps that I take with me, because many of the people, agency people, particularly, they don't have a clue what's in the back of some farmer's pasture that floods, they don't know where a slough goes, they don't know where there's a drainage ditch, they don't even know where the river goes, they only know where the rivers go as they drive along the highway if the river happens to be along the highway, so I can show them that...(P9).

Citizens were able to attend meetings and give input, which helped leaders understand the various perspectives within the community, beyond the sub-set of voting members. It should be noted that while agency personnel were on paid work-time, community members were not. Community member's volunteered their participation, taking time away from potential jobs or other activities.

An active project manager, two co-conveners, and the chair of the Design Committee encouraged discussion of interests. "Active" here means that the staff members went beyond scheduling meetings and writing meeting summaries. Staff members engaged in facilitation and mediation methods. Project staff requested agency and community participants discuss issues and concerns, encouraged commitments, validated different points of view, and brought up issues that were beneath the surface. Conveners continued to act in a facilitation role during the 
implementation phase after the project manager departed. Multiple participants

emphasized that the co-conveners and the facilitator were crucial to making sure different concerns were brought up, that focus on common goals was maintained , and that the group kept moving forward (P43, P26). The bulleted list below reveals other mediating actions from the project manager and co-conveners that improve $d$ relationships.

- Co-conveners and the project manager regularly asked if there were questions or disagreements before moving on in meetings.

- At least one co-convener regularly attended other community group meetings prior to the Oregon Solutions project and during. This included meetings of the Farm Bureau and of TBHEID.

- The co-conveners and project manager expressed their thanks and appreciation regularly in meetings to the group and through letters to public agency supervisors.

- The co-conveners and project manager directly named competitive tactical behavior in private. This occurred, for example, when individuals attempted to derail the process.

The co-conveners and project manager opened or pursued dialogue when others would not bring issues up. In the quote from meeting notes below, one coconvener continues acting in a facilitative role during the implementation phase:

"There's an elephant in the room that I think we need to bring up: why would we do this much work and spend this money to get this amount of flood reduction?" Co-convener, Sept. 2 meeting.

Staff members also closed lines of discussion when they felt individuals, or the group, had moved beyond airing concerns and venting into unproductive complaints. This second technique had a mixed effect as some participants felt it was needed in order to move forward (P13), and others felt it broke the ground rules by cutting off dialogue and seemed based in politics (P49). 


\section{Information}

The group used scientific and technical information in tandem with experience-based information to better understand issues. People brought up interests and positions in relation to this information. The hydrologist consultant built the model differently based on community concerns and issues. For example, community members noted that floods over the years behaved differently, e.g. the 2006 flood was different from 2001 and so on. As a result of this discussion, the consultant modeled alternatives based on three different flood events: 1.5 year, 5 year, and 100 year events. The consultant also revisited his model based on a community member's experience of duration of floodwaters in different rivers and made some suggestions to address it.

This is illustrated in the email exchange below.

Community member email (August 3, 2009):

"Alternative 4 has some problems that I believe will show up in advanced modeling. The modeling up to now has not addressed the interaction of the different durations in our waterways. High water lasts a very long time in the Wilson while is pretty short lived in the Trask, Kilchis and Tillamook. The system in place now is taking full advantage of this and we are now getting relief in the South part of the north 101 corridor in a matter of hours and the Tillamook and Trask fall quickly behind them. The Wilson however may stay up for days...."

Consultant response (September 1, 2009):

"Under current conditions, the Wilson River runs higher than the Tillamook very near to the bay and it has been observed that the Wilson River tends to flow at a higher level for longer durations than the Tillamook-Trask. Our modeling results agree with these observations.

If by removing the levees in Alt. 4 the higher water levels in the Wilson were propagated over to the Trask-Tillamook system adverse impacts could occur. The Tillamook River exhibits the greatest sensitivity to increased water levels due to its very flat slope - prior work shows backwater effects can extend miles up the system. We agreed to look at 
duration and volume issues for these alternatives as a result of these comments..."

Another community member requested that models be done with the existing infrastructure and development showing on maps.

... So my request for the modeler is that he also model it [the project] developed. We had a fight over that, an argument, the government doesn't want to do it [model] with infrastructure, we don't want to do it [model] without infrastructure....Do the whole (P49).

The model results with infrastructure present helped orient viewers to where Hwy 101 is and whose properties would be affected in what way. When the Design Committee and Project Team drew up pros and cons of the different Exodus alternatives, they had a common understanding of how flooding might impact different landowners based on these information reviews. Some participants also benefited from on-the-ground experience.

Experiencing on-the-ground success helped some participants feel their interests were addressed more than exposure to a scientific model. An illustration of both the utility of technical information and of experiential learning is the group's changing opinion about the spillway projects. Several participants note that the group was not in full agreement that the spillways would really be effective at reducing flooding before they were built (P28, P45, P43, P26). The hydrologic model revealed that a certain number of cubic feet of water would be moved out of flood cells during an emergency flood situation. Once the spillways were built, there was a flood and the spillways reduced both the duration and height of the flood - gathering commendations from community members. As one individual notes, “...the modeling 
showed it would work, what really changed the [community's] perceptions is when it did work..."

\section{Meetings}

All group meetings were held face-to-face on site in Tillamook and were open to the public. This arrangement supported relationship, process, and substantive interests. Participants in Project Team, Design Committee, or in sub-groups were seated around a rectangular table and members of the public sat outside the table.

Sub-groups helped the project team gain a better understanding of why people preferred specific options. Several participants noted that these sub-committees helped bring people's passion and knowledge about project ideas into the group (P13, P28, P26).

I think it was a great opportunity for the regulatory community, environmental community, the business community, to hear each other, and listen, and one of the rules is respecting others, and that was very effective...

The project manager and the co-conveners asked participants to come to them in private if needed. Both community and agency members had private meetings with the project manager and co-conveners. This allowed the leaders to bring up issues in meetings when participants were uncomfortable.

\section{Verbal and Visual Communication}

People directly communicated issues and concerns either in meetings, or in private. Participants were active about stating their concerns in this process, either at the table in the public setting, over email, on the phone, or in person between meetings. 
Project staff also used verbal examples to explain information as indicated in the next quote.

The other thing I think really helped people is through the process coming back to this fundamental issue of where is the money coming from. That helped people, and there are analogies; like you're giving to a charity, you pick the charity that has meaning to you, then the charity has to follow what their charter is about how they use the money, they're not going to go 180 degrees off. So those metaphors were used to explain? Right, people would talk to that, and then a very good discussion of we've talked to Fred Meyer Trust, and their interest is $X$, so we need to tailor or projects to $X, \ldots$ their due date for grant applications is Y, here's the type of projects they want... (P13).

The group used visual aids including figures and photos to illustrate options

during the implementation phase. This helped some members understand how different interests would be addressed.

Something that was really helpful to understand the issue was visual aides. At one of the last meetings we were able to have some hydrological modeling that showed some of the results of the project we want to implement... and how much relief it would actually bring the community, and I think seeing that, as opposed to just talking about it, was really helpful ... Seeing the model, and seeing that if you put these tide gates in, or you restore this wetland, that's going to bring this much more flood storage. Having the anticipated results of some of the projects we want to move forward was a little encouraging for people, and maybe not seen as scary to really think okay, we don't have to implement everything to get some results, and it's not going to take away future growth or things like that, that there's options (P45).

\section{Shared Experience}

The group crafted a goal statement that helped bring issues and interests into the discussion. Participants had mixed opinions about the final version, but the documented discussions leading up to it show different participants helped shape it. 
..... So the only thing we could do was agree okay, given everybody has different interests here, and the regulators, their policies, state statutes don't change, environmentalists, fishermen... businessmen on hwy $101 \ldots$ all of those things don't change, what we do is agree upon we're here to minimize the impact of flooding, while at the same time looking for ways we can improve the environment and economy (P43).

After the formal statement was adopted, the project manager put it at the top of all meeting agendas and reminded the group to think about how the projects addressed the goal. Participants continued to work with their own interests in mind; however the goal discussion helped the Project Team consider other issues and interests. One community member did not like the final goal statement but was willing to work with it (P49).

Establishing and re-visiting the group commitment to work together helped the group identify and stick to a group concern. This happened during the drafting of ground rules, again prior to voting, during the signing of the Declaration, a year into implementing three projects, and again during the summer of 2009 before the group decided on Project Exodus options. This re-committing was part of addressing process interests of helping the group stay focused on one process rather than being fragmented by several.

"Today she is asking for consideration of an affirmation of everyone's willingness to work together and prioritize. There is a temptation to say 'my project ranked 5 and I don't want to play anymore"' (September 12, 2007).

The group celebrated successes. The group's successful completion of earlier projects helped re-affirm the group commitment and establish trust in the process. All interviewed participants agreed that this project has been a success in meeting major 
concerns e.g. implementing short-term on the ground projects, getting things done, and working together to reduce flooding without negatively impacting the environment. Leaders emphasized that this has been and continues to be a group success: it required land owner support, the support of federal agencies, businesses and non-profits (P26). Leaders emphasized this group effort in all outreach efforts including a brief film for Oregon Solutions and press releases.

\section{Governance}

The group created ground rules and actively used them during the problem setting and direction setting phases of the process. The ground rules addressed relationship and process concerns, specifically honoring diverse interests and working to further a common goal.

The group reached consensus on the goal statement, criteria for selecting projects, and ground rules. The consensus was achieved based on having people determine if they "could live with" a final proposed draft of the goal statement, case selection criteria, and ground rules. While participants brought up interests during the discussion of each of these decision-making aids and not everyone fully liked the final products, people agreed to move forward with the resulting versions (P43, P28, P49, P8, P9).To project staff members, agreement on the goal and criteria implied that consensus guided the voting process.

Consensus, as it is understood in the conflict resolution literature, was not used in decision making. The group used weighted ranking, multiple criteria voting to determine which projects would receive priority. They also used simple majoring 
voting when deciding on Project Exodus alternatives. Weighted ranking on multiple criteria voting requires participants weight each option from 1 (the best) to 5 (the worst) based on a set of objective criteria - giving each option a final set of points. The criteria included 1) the cost, 2) flood mitigation 3) community acceptance 4) environmental impact 5) feasibility of completing the project (this related to permitting). This voting method required thoughtful consideration of a handful of factors that contribute to how easily a project could be implemented.

The benefit to the weighted ranking vote is that participants could not as easily use pressure tactics or personal influence to sway individual's votes toward one project or another. The criteria addressed agency and community participant's interests. Community members were concerned that agency participants might select projects that involved environmental restoration and were not supported by the community or had minimal flood reduction benefits. Agency members were concerned the community would select projects with potential negative environmental impacts and not feasible to permit. Feasibility was connected to the ability of a project to be both permitted and implemented. The criteria were developed by project staff members to address participant interests including concerns about funding, implementation potential, permitting potential, flood reduction potential, minimizing negative environmental impacts, and the desire for both short term and long term projects.

The downside to this voting process is that a few community participants felt that the number of agency affiliated voting members on the Project Team 
outnumbering the non-agency affiliated voting members. Agency participants felt the membership was balanced because the number of individuals from Tillamook was even with the number from outside. Community participants felt agency members voted on agency preferred projects despite the criteria. The vote was also binding in this instance. A binding arrangement can involve the will of the majority being imposed on the minority, a win-lose scenario (Moore and Woodrow in Susskind et al, 1999). A binding vote can stop participants from developing a proposal that integrates more interests for the widest support. In this case, the criteria-based vote helped the group generate support for some of the projects. Depending on which participant you speak with, some individuals think the group reached broad agreement, some did not like the voting process, and others simply felt outvoted (e.g. their favored project 'lost').

Had there been more trust and common agreement about flood sources, the group could have used a straw vote as a sorting mechanism for initial preferences. If the resulting vote tally did not adequately represent the strength of a given project, or the group's interests- the group could have re-visited the criteria and projects, discussed issues and used consensus to select the final prioritized projects. This method was contra-indicated due to a small number of participants maintaining positional stances, differences of opinion about how to best address flood sources, and the collective desire of the group to move forward. Consensus was not possible in this group's decision-making process due to fears that one stakeholder group or another might dominate the process. The fact that the group was willing to move forward on 
tackling the first nine projects indicates they successfully established sufficient, broad support, although it was not unanimous.

\section{Potential Disruptive Elements}

This process suffered disruption from social complexity, technical complexity, and problem complexity, see table 42. All stakeholder groups were not on the same page in terms of understanding how different interests could inform common gains. The agreement suffered disruptions during the implementation phase despite extensive efforts to support relationships and attend to participant process needs. The group was able to move through these disruptive elements based on skilled project staff members, participant leaders in the Design Committee, the use of information gathering during the implementation phase, the inclusiveness of the process, and flexible individuals on the Project Team and Design Committee.

Table 42 Tillamook: Disruptive elements

\begin{tabular}{|ll} 
Social complexity (Participants) & - Positional stances \\
& $\bullet$ Community members mistrust of representation ratio on \\
& Project Team \\
Problem Complexity & Difficulty maintaining trust in the process \\
Technical Complexity & Disagreement about information \\
Decision-Making & - Differences in perspective about the problem \\
\hline
\end{tabular}

\section{$\underline{\text { Social Complexity }}$}

Some participants used distributive tactics instead of creative problem-solving. Participants' maintaining demands reduced the ability of the group to develop creative options. Community actions were motivated by a desire to get as much for the community as possible; an understandable behavior. Agency representatives were motivated to prevent environmental harm, also understandable. The project staff 
responded to positional tactics, and the underlying interests, by meeting regularly with community member groups and agency representatives, bringing up community concerns during meetings, inviting input from community participants, and educating participants about how their interests would be addressed from different projects.

The history of the project made it difficult for all participants to trust each other and the process. Some community participants viewed the project as government-centered and government-driven. The history of government-community mistrust and positional behavior made it challenging for individuals to trust that everyone would act in good faith. One individual felt that the partnering did not fully involve equal decision making, "it's very measured and controlled." Despite this impression, documents from the process indicated meetings were open and participant input was welcomed, even encouraged. For example, the list of email recipients who were kept informed is nearly twice as long as the number of participants in the Project Team. Community members and agency members both worked to sort out elements of Project Exodus alternatives.

\section{Problem and Technical Complexity}

Participants had different ways of understanding sources of flooding: faith in scientific models and faith in experience. The group did not unanimously agree on the parameters of flood sources. A few areas of disagreement included how to address logging's impact on soil, channel width versus depth's contribution to river capacity, amount of land needed for floodways, and the ability of a swale to absorb water for flood reduction. 
Some participants did not believe model predictions or scientific information. For these few members, experience and on-the-ground results were easier to believe than a model. The spillway project example indicates that community members were skeptical that using hydrologic modeling as a basis for decisions would result in tangible flood reduction benefits. They were surprised, and appreciative, when the spillways resulted in a reduction in flooding. For other participants, the model was especially helpful in decision-making because it helped them understand potential onthe-ground impacts of different projects and allowed them to support them based on agency mandates. This helped the majority reach common understanding.

During the implementation phase, a small number of individuals in the Project Team did not agree about the best way to address those sources of flooding - and therefore which projects would be implemented. Not all projects could be tried out before launching them due to their scale and cost. Accepting how the model was created, who ran the model, and the implication of model results was fundamental for everyone to feel that their concerns were addressed. Comfort with technical information was tied to relationship trust. One community participant notes that it's not about the science, or the engineering - it's about what people believe. This relates to participant values.

Dredging the bay isn't going to solve our flooding problem. What's the other camp that says dredging the bay... That's an example of where people have their beliefs, and you can show them again and again different perspectives, different ways, and they still have their belief. What's underneath the belief dredge, not dredge, what's the source of that? Yes, it has to do with science, facts, education, what you believe and what you don't....so you pick the 
science you want that matches your belief system. It goes back to we're made up of belief systems (P49).

\section{Decision Making Complexity}

This element is listed as a disruption element because it relates to the other three fragmentation forces. One interviewed participant felt the composition of the Project Team was unequal and that this affected voting in favor of agency preferences. Two-thirds of the participants on the Project Team and Design Team were representatives of local, state, or federal government agencies. While the weighted ranking method used objective criteria to select projects, Project Exodus alternatives were voted on through simple majority. Thus, consensus was not used for decision making in Project Exodus.

Government leaders initiated this collaboration and some of the prioritized projects included city and county planning processes. This was necessary because governments issue permits; they have public contracting methods that community groups do not; and they are the legal recipient, repository, and provide public accounting for legislative funds and grants. The nature of flood issues required that the project be government centered. The group could have added two community representatives on the Project Team to address the power balance concern. However, if the group still voted for non-dredging projects, this may not have helped the underlying value conflict related to dredging. The value contention in the dredging issue is related to a small number of passionate community individual's belief that 
government should not take away the ability of land owners to take care of their land, via dredging.

Most voting Project Team members had developed common agreement on science and flood experiences in the implementation phase of the collaborative process. The final vote on Project Exodus resulted in a two-thirds majority approving the fourth alternative. Enough agency personnel abstained to make the ratio between government and non-government even - however, not everyone knew this.

\subsection{5c Research Question Three: Role of Interests}

Participant interests shaped participant decisions during this process (see table 43). This section details the way participant interests motivated different stakeholders and groups. Note that this process involved the group moving between the direction setting and implementation setting phases iteratively as the group made decisions, gathered scientific information or implemented projects, and made further decisions.

Table 43 Tillamook: Participant interests' impact on process

\begin{tabular}{|l|l|}
\hline \multicolumn{1}{|c|}{ Collaboration Stage } & \multicolumn{1}{c|}{ Participants Interests Affected the Following: } \\
\hline Problem Setting & $\begin{array}{l}\text { Group goal development } \\
\text { Problem conception }\end{array}$ \\
\hline Direction Setting & $\begin{array}{l}\text { Perspectives on the problem and sub-issues } \\
\text { Exploring options } \\
\text { Project priorities } \\
\text { Reaching agreement and closing the deal }\end{array}$ \\
\hline Implementation & $\begin{array}{l}\text { Commitment of resources } \\
\text { Program outputs }\end{array}$ \\
\hline
\end{tabular}

\section{Problem Setting}

Participant interests informed the development of group goals. The discussion for the group goal was active; various individuals from different stakeholder groups 
brought up their concerns and asked that the statement be adjusted for their interests.

From the meeting minutes of May 23, 2007 and June 27, 2007:

...There was consensus that reduction of unacceptable flooding is a good thing to address. Bruce Apple asked what was classified as "unacceptable"; to who or what circumstances define the depth of water that is acceptable or unacceptable [the group discussed subjective definitions of "unacceptable" based on home, business and land flooding]. Mr. Labhart said we need to pursue some sort of approach or method, that doesn't alter systems already in the community and to recognize other values such as eco-systems, economic and community livability that impact any one of those. Mr. Manning said we need to recognize short and long term solutions...[Following suggestions of different goal statements...More discussion and variations of the statement were brought up]....Mr. Holloway said [members and versions] have good ideas but get rid of "unacceptable" [more discussion].

\section{Direction Setting}

Participant interests shaped perspectives on the problem and its sub-issues.

While everyone agreed that flooding is a problem, the sources of flooding and how to best address its magnitude, intensity, duration, and frequency was a source of disagreement. Participant interests were a foundation for their perspectives. For some community members, economic livelihood was linked to flooding and this livelihood was related to land ownership. Any project that would reduce the amount of land available for either grazing or business activities was not a preferred option. Many community members were also frustrated with a history of planning for flood mitigation without implementing physical infrastructure projects to reduce negative flood impacts. This concern drove them to emphasize on-the-ground, short-term projects. 
For agency personnel, flood reduction requires more than a few smaller scale physical projects. They also want to reduce flood duration and magnitude in order to protect home owners and businesses. One-third of the agencyProject Team members were residents of Tillamook; as local public agency representatives they were concerned about reducing flood frequency and magnitude over the long-term. Longterm flood reduction requires a planning effort that takes into account how flooding happens and treats the river as a system of connected waterways. Any project could have a negative impact on environmental ecosystems. Agencies were also working to address a public (beyond Tillamook) concern for restoring watersheds to support salmon. This drove funding sources and project priorities.

...Oregon Watershed Enhancement Board, Oregon Department of Fish and Wildlife, those people have funds, but they're not going to give them to you if you can't show some benefit to fish and the environment. That's what their funding sources are set up for, unless you're willing to do that, you're just not going to get any money, period.

Participant interests were associated with how the group prioritized the projects. Interests were built into the criteria the group used to rank the projects. The group did not agree unanimously on all projects despite the vote. As noted above, participant concerns shaped how projects were funded. At this juncture, two shortterm physical projects have been completed which one representative of TBHEID felt addressed their concerns and helps the collaboration feel like a 75\% "success." The 75\% designation is related to the amount of legislative funds used for short-term, on the 
ground projects. For this individual, the issue of flood reduction projects was connected to obtaining as many resources for flood reduction as possible.

Not all community members support long-term plans and long-term strategies that incorporate environmental improvements to help reduce flooding. Participant values were a component of project preferences. Government agencies support longterm projects because they have the most potential for flood reduction impact, the most positive impacts on environmental ecosystems, and they address $1.5,5$ year and 100 year flood events.

Participant interests in understanding how projects would impact flood events contributed to the group exploring different options on Project Exodus. Information from the modeling results helped the group re-evaluate their concerns.

Interests shaped participant agreements. Participants used consensus in agreeing on the goal statement and they signed off on the project criteria as well as the Declaration of Cooperation. From interviews, agency personnel were in agreement based on how different projects affected their concerns. Some community members were also in agreement for these reasons. A small number of community members agreed to the process as a means that they hoped would get them to their preferred ends: money to fund short-term, on-the-ground. Their interests were about having access to funding, resources and permitting agencies in order to complete flood reduction. For these few, their agreement on the DoC may not have been about the structure of the process. 


\section{Implementation}

Participant interests shaped individual commitment to the project. Participants wanted to contribute to this project. One co-convener mentioned feeling motivated to contribute so as to not let down other leaders in the group. Agency personnel committed extra time beyond fulfilling their job responsibility to make this project a success. They also provided technical assistance to ensure different projects would make it through permit timelines quickly. Community members brought finances, time, resources, experience and passion (including images, photos) to the project.

\subsection{5d Research Question Four: How Were Interests Addressed}

This section summarizes how different types of interests are addressed in this process (see figures 22 through 25). The reader should note that "community" is not a whole group, nor are "agencies." The community is comprised of business owners along Highway 101 whose concerns about property damage resulted in projects with a different water reduction potential than those who owned grazing land outside the Hwy 101 corridor. Agency personnel represented different mandates and protected different resources e.g. land, fisheries. Generalities are used here as a simplification.

\section{Substantive Interests}

The top nine prioritized projects address core group substantive interests, see figure 16. Each project the group included in the top nine priorities reduces the negative impacts of flooding. Projects relate directly to substantive interests; figures 22 and 23 reveal how specific outputs address substantive interests. The central concerns were reducing negative impacts of flooding in order to protect people's 
safety, homes, and businesses. Most of the group wanted to protect endangered species and economic interests. Salmon are a common economic good as well as a common Pacific Northwest cultural heritage. The diversity of priority projects reveals how different interests were addressed.

Most parties agreed on-the-ground, short-term efforts were needed. The two spillway projects were paid for with legislative funds, the permits were sped through relevant state and federal agencies, and the structural work was completed within the first two years. This progress addressed substantive, process and relationship concerns: a) completing physical work in the short-term, b) using legislative money for on-theground efforts, b) agencies supporting the effort, c) the group established success right away and celebrated it and d) the two projects did no negative impact to environmental areas. These two projects are now an area of common agreement.

The mediated gravel agreement re-visited the dredging issue and addressed economic concerns. The gravel agreement was stalled for years until resolved in this process. Gravel bar scalping is now occurring and is intended to let some amount of gravel extraction support local industry. The project does not deal with the on-going, long-term issue of rivers filling with gravel. It also does not allow for extensive dredging as some community members would like. However, these issues were not the primary focus of the project - they are related and could be worked on in the future building on the project's strength. 


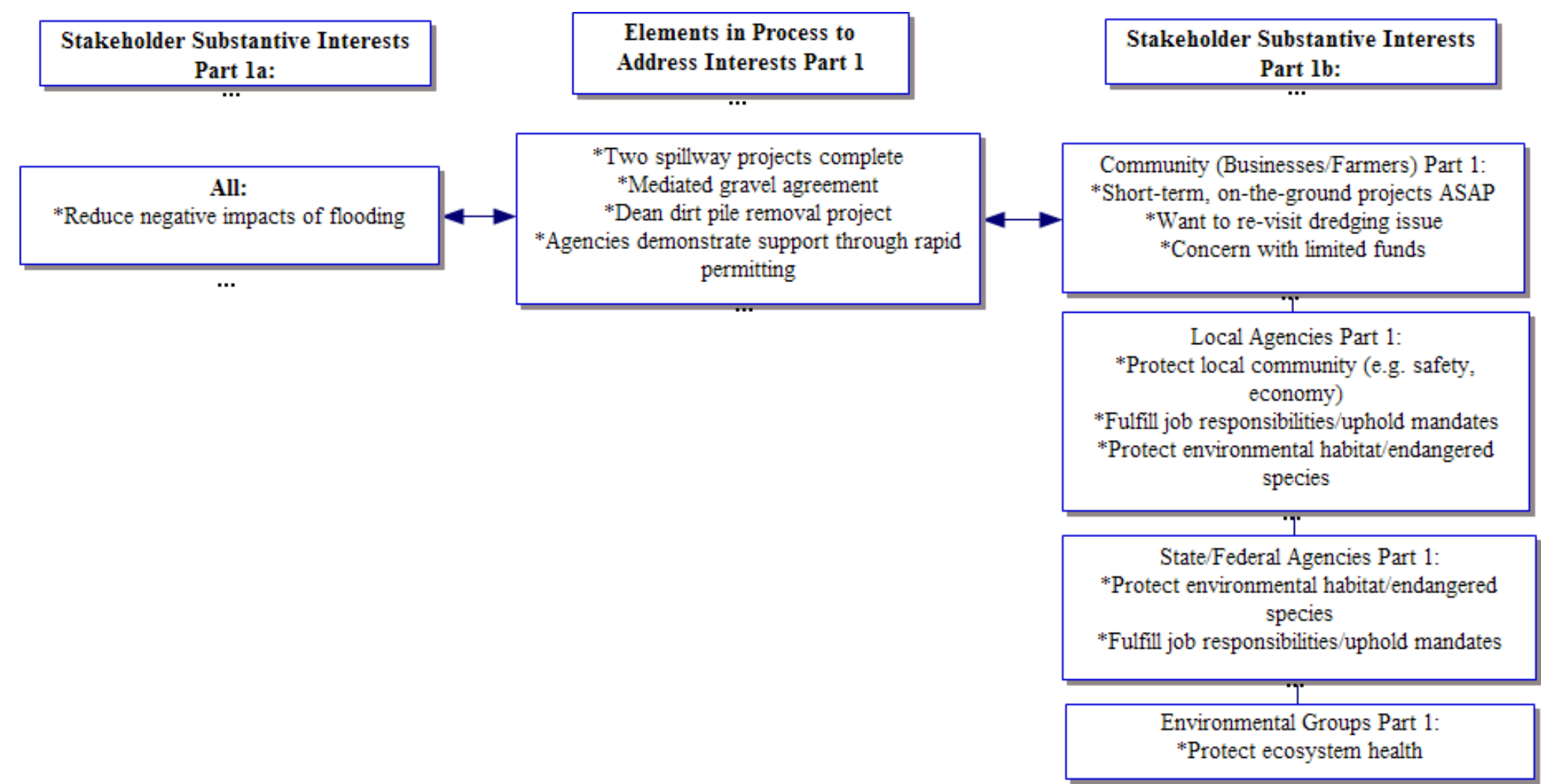

Figure 22. Tillamook: Substantive stakeholder interests addressed by priority projects. 


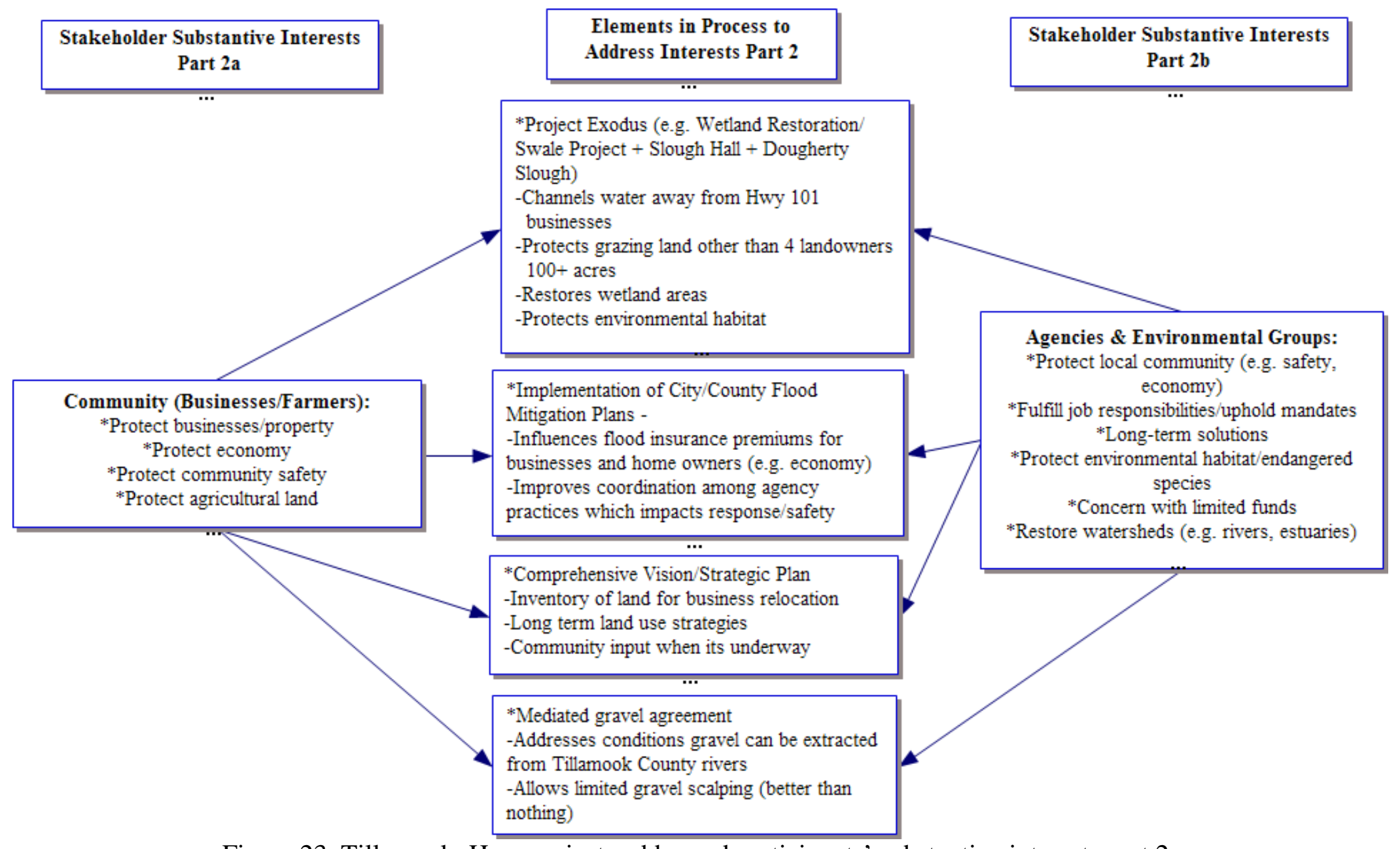

Figure 23. Tillamook: How projects addressed participants' substantive interests part 2. 
Issues:

*Flooding will continue to happen every year

long into the future

Funding for flood reduction projects comes

from environmental sources

Opportunity

Ecosystem restoration helps make flood

events less extreme (e.g. modifies water flow)
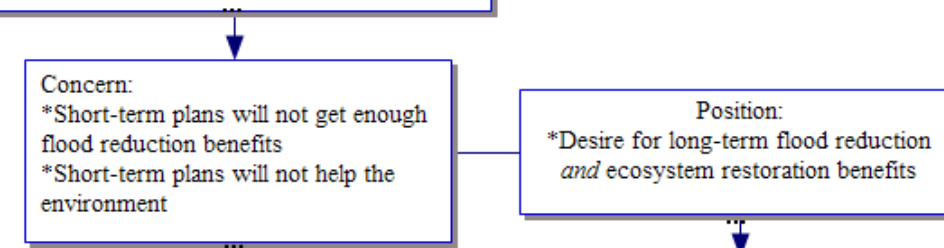

\section{$\overline{7}$}

$\left.\begin{array}{c}\text { Agency preferred Projects: } \\ \text { *Implementing City Flood Mitigation } \\ \text { Plan } \\ \text { *Comprehensive Vision/Strategic Plan } \\ \text { *Project Exodus (affects over } 100 \\ \text { acres of grazing land) }\end{array}\right)$

$\mathbf{4}$

\begin{tabular}{|l|c|}
\hline $\begin{array}{l}\text { Concerns: } \\
\text { *Protect environmental habitat } \\
\text { *Protect endangered species }\end{array}$ & $\begin{array}{c}\text { Positions: } \\
\text { *Clean Water Act } \\
\text { *Endangered Species Act } \\
\text { *No dredging }\end{array}$ \\
\hline \hline
\end{tabular}

Issues:

*Wetlands, estuaries and river system health

are diminished from human development, soil

erosion and human activities

meratures have increased, water is

cloudy, upstream fish habitat is depleted

downstream fish habitat is depleted.

*Salmon and other creatures are endangered.

Figure 24. Tillamook: Selected public agency interests, positions and preferred projects. 

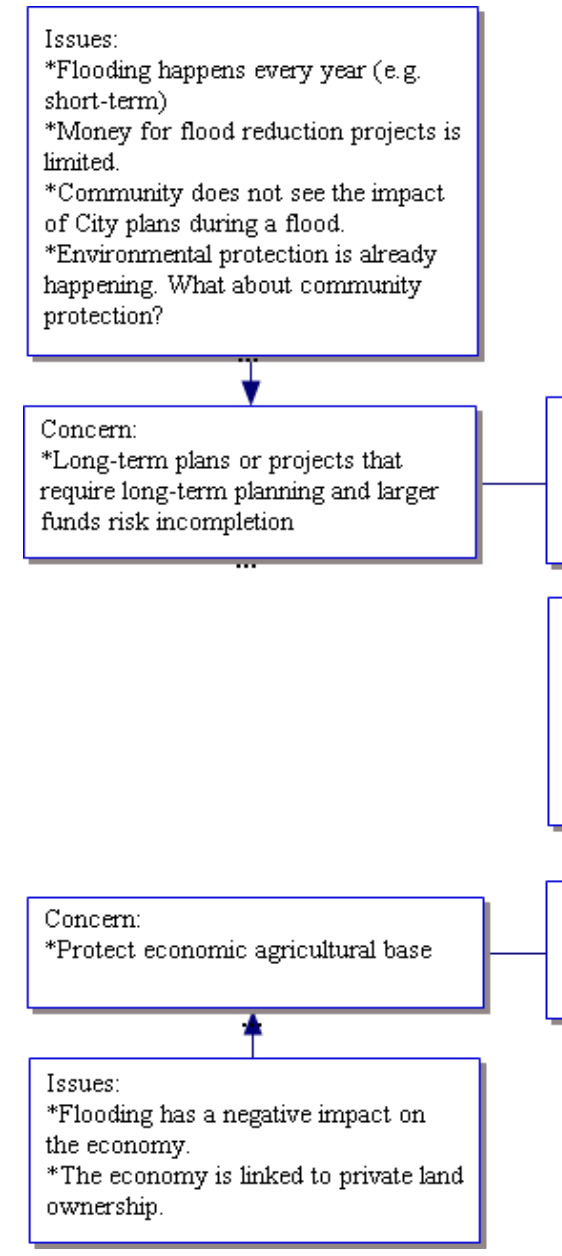
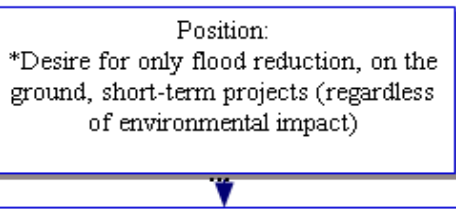

Community preferred Projects: *Dredging the Wilson River \#14, Drainage Maintenance/Flood Structure Improvements \#13,

*Dougherty Slough element of Project Exodus \#3

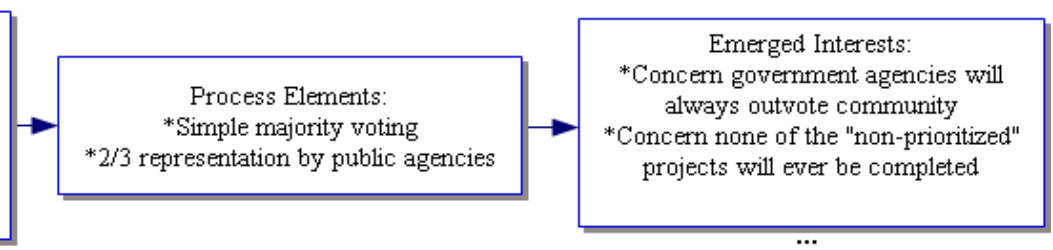

4

Do not want loss of acres of farm/ grazing land

Figure 25. Tillamook Flood Reduction: Selected community interests, issues, positions and preferred projects. 
Two projects, implementing the City Flood Mitigation Plan and the Comprehensive Community Vision/Strategic Plan are aimed at long-term planning strategies to address the economic health, public safety, and physical impacts of flooding. These were of little interest to some community members because they are not immediate on-the-ground flood reduction efforts. From an agency perspective, the City Flood Mitigation Plan affects the economy because it determines how flood insurance premiums are set in the future and will help decide who gets to build where. The goals of the City Flood Mitigation Plan also include repairing physical structures that addresses community concerns (see below).

A. Protect life and property.

B. Preserve natural areas related to flooding.

C. Coordinate and enhance emergency services related to flooding.

D. Improve structures aimed at controlling or mitigating flooding.

E. Enhance and promote public education about flooding.

F. Improve and promote partnerships, coordinate and implementation of short- and long-term actions in the plan (City Flood Mitigation Plan)

The Community Vision and Strategic Plan is aimed at having the community find long-term strategies if citizens want to relocate their businesses. It is intended to be a community planning land-use process. Some participants' do not see how their concerns are addressed by this project. It is also not clear to some citizens how either Plan will directly reduce the negative impact of flooding. This is an area lacking common understanding that could be mitigated by the City and Council's community engagement.

Project Exodus is a physical project intended to address both short-term and long-term flood reduction strategies while also protecting environmental habitat. It 
creates a channel for water to flow from Hwy 101 to the Bay by constructing new setback levees, removing existing levees, restoring tidal wetlands, removing old tide gates and constructing new gates. It addresses concerns for flood reduction, protecting community safety and property, and reducing the negative impacts of floods, as well as fulfilling a need for long-term methods. Engineers and agency personnel were surprised and pleased at the flood reduction levels attained especially in the 100 year model results as well as in the 1.5 and 5 year models. Agency personnel also appreciated the project's ability to restore ecosystem health.

Project Exodus has suffered from disruption. The management of that disruption helped the group craft better projects. In the August Project Team and Design Team meetings, there was disagreement among community members about the level of flood reduction being enough for the cost. The group would have been aided by some clear discussion of how Project Exodus and the different City Plans address substantive concerns of community members. For example, how many acres of farm land and business properties are having their flood levels reduced and by how much (see figures 24 and 25)? The group would also benefit from a list of different projects and relevant differing modeling results. In interviews people would refer to their memories "project X was better than projects A, C, D or M" but until this information is compared publicly it remains an opinion or contained in the mind of the modeler. Revisiting "acceptable" flood levels in tandem with "acceptable" ecosystem restoration levels could help the group develop a more refined set of criteria for consensus-voting on Project Exodus alternatives. These each take time and personnel 
resources, however, and as the group lost their facilitator in the implementation phase, there may have been limited funds to accomplish these efforts.

\section{Relationship and Process Interests}

This process was able to address most participant relationship and process interests due to 1) the mix of participants, 2) direct communication about issues and concerns, 2) strong leadership from project staff and key participant leaders, 3) the use of facilitation techniques, and 4) the merging of different forms of knowledge. The elements that addressed participant relationship and process interests are depicted in figure 20 .

The challenges this group faced addressing participant relationship and process interests were: 1) a history of mistrust among the participants, 2) a small number of participants who maintained positions rather than focusing on interests, 3) a lack of agreement among stakeholder groups about flood reduction efforts needing to both reduce flooding and protect the environment, 4) different beliefs about how different projects affect the environment, and 5) disagreement about the sources of floods. Active leadership from members of the Design Committee and project staff helped manage these disruptions and address participant interests.

Participants' direct communication with project staff helped the co-conveners and the project manager address participant relationship and process interests. The challenge is that the collective group was not always aware of individual participant's discomfort and therefore did not, as a team, address specific interests. The leaders and project staff worked to manage disruptions behind the scenes to help keep the 
meetings moving forward. This method was successful as it prevented pre-existing

mistrust from growing into an unmanageable dispute.

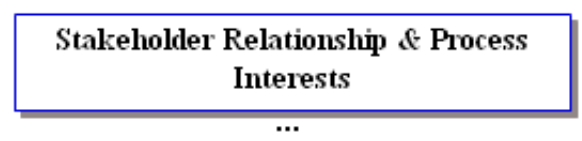

Community:

*Desperate for a change

* Desire for agencies to help community

*Respect community concerns

*Concern with power imbalance in Project

Team impact voting

*Short-term on-the-ground projects ASAP

related to trust

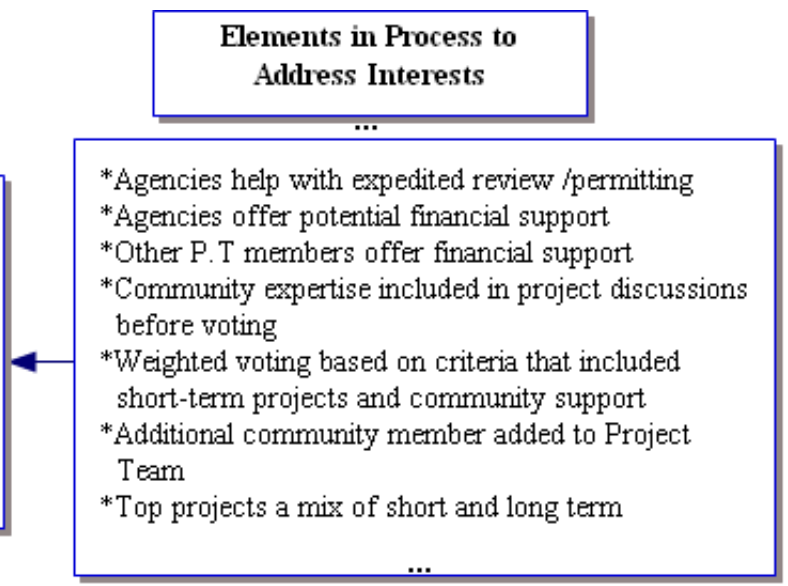

Public Agencies \& Environmental Advocates: *Desire for community support of projects *Uphold mandates

*Desire to maintain collaboration

*Long-term projects

*Fear of harming the environment

$\cdots$

\section{All:}

*Desire for open-minded perspective

*All communicate their concerns

*Have input valued

*Help create a success

*Desire for a change from history

*Do something ASAP
*Community presence on P. T. and in meetings

*Community offer financial support and expertise

*Hydrologic modeling and past Army Corps research

included in project discussions before voting

*Permit feasibility included in vote criteria

*Community-based meetings

*Regular face to face meetings

*Active leadership

*Clarifying, prompting questions

*Group goal statement

*Verbal appreciation of input from all

* Open meetings

* Group review of technical information

*Group review of expertise (community, permits)

*Group formal re-commitments to process

${ }^{*}$ Consensus on goal/criteria

*Completion of spillways in first year

Figure 26. Tillamook: Interests addressed by facilitation elements.

\section{Positional mentalities were a detriment to relationship building and}

maintaining trust. Both public agencies and community participants felt the other side

was not always acting in good faith. The project manager and co-conveners

successfully engaged community and agency participants to ensure no one would 
derail the process. This was critical outside of the public meetings. Mistrust in how the process was being conducted also prevented some participants from feeling their interests were not being addressed. Public agencies did not feel safe in talking about ecosystem concerns because some community members refused to agree they were valid. Some community members did not trust agency personnel because they felt the in the end the agency representatives were only looking after their jobs - which are "to protect fish." Again, project staff members worked to address these concerns in oneon-one meetings.

The presence of community members in tandem with agency personnel made for better projects - especially in discussions of technical information. As a collective (e.g. not in sub-groups or in one on one discussions) they waited until the implementation phase to co-learn new information about how flooding occurs based on the hydrologic model, and how to best address it. Most community members and agency personnel were willing to put aside their personal biases and work with one another to address flood issues. However, when feelings were high, the facilitation techniques helped address conflicts and keep the group moving forward.. Agency personnel were necessary for expertise and permitting knowledge. Community members were needed for their experience.

Trust was built when agency personnel extended themselves in their willingness to speed up permit timelines, were willing to consider alternatives, and worked with community members to address flood issues - while doing so within 
their legal boundaries. Community members committed sizeable time and financial resources to make sure agency personnel understood different decisions' impacts.

Information gathering and the voting criteria helped address relationship and process interests in addition to substantive interests. The project voting method helped participants use objective criteria to create a priority list of projects. The vote is the result of information, not purely subjective preferences. This process was not only about flood reduction; it was about helping the community without harming the environment. Agency personnel had to contend with was the Clean Water Act and the Endangered Species Act in addition to supporting state mandates. As depicted in figure 24 on page 240 , legislative mandates can generate positional stances. One community member noted "this isn't about individuals it's about the CWA and the ESA.” The laws were crafted to protect common pool resources such as fish, and common goods such as clean water - interests shared by the general public. The voting criteria helped protect agency personnel's interests in upholding mandates.

\subsubsection{Summary}

This process has been successful in completing work that meets different group's core interests. It has also been successful in fostering tenuous threads of trust across public agency jurisdictions and between community members and agency personnel. Some participants would not speak to one another at the beginning of this project. Most were skeptical that the group would achieve flood reduction benefits by working together because past practices had not resulted in on the ground projects. This conception changed. Some participants began with a competitive, us versus them 
mindset - and not all of that disappeared. Not all stakeholders were getting exactly what they want, the way they wanted it - and some used stalling tactics to prevent progress from being made. Most stakeholders were flexible and worked to address each other's interests. It is not apparent if all participants are aware how their general concerns are being addressed by the top nine priority projects.

The interplay between competitive and collaborative behavior improved the process. These passionate individuals are invested in Tillamook and want to protect its citizens and the surrounding ecosystems. Participants engaged in a dance between fixating on positions, and revisiting interests. Particular community member actions such as imposing time pressure (e.g. we need to do this now) and threats to pursue an alternative flood reduction process motivated leaders and agency personnel to use mediation techniques. Methods such as promising to give all flood reduction efforts consideration and arguing persuasively about how different projects will affect farmer and business' bottom line helped some members of the community be more willing to consider projects other than their favorites.

At the core of this project is a disagreement about how and why flooding happens. The group did not establish agreement of what amount of flood reduction would be sufficient for everyone. The group debated "unacceptable" flooding in the first meeting - but dropped the conversation when the term was removed from the goal statement. This may have been unattainable given everyone's different expectations and understanding of flood sources. If the group didn't move forward with the priority proposals the following is plausible: 1) a continuation of everyone 
feeling frustrated because of an impasse in flood reduction, 2) the potential loss of property and grazing capacity on a larger scale due to future flooding, and 3) worsening relationships reducing the potential of collaboration in the future.

Based on the interviews, participants did not have shared understanding of the term "consensus." Voting is not a consensus method; it is unclear why some participants felt they reached consensus in this process. The few participants who felt "locked into a process" they did not design may have given consent to the group goal and the criteria (the two elements where consensus decision making was used) in order to attain legislative funds for flood reduction. They gave consent as a means to an end.

All participants have remained engaged throughout the process - an indication of the process' strength. Since the process was designed for project development and implementation only key representatives were involved. The lack of a larger public process was a struggle for some community members. One citizen who was not a Project Team member felt like s/he was only being informed, not actually a partner in the decision making. Involving and informing the public remains a challenge for government-centered collaborations that involve planning projects.To their credit, public agencies collaborated and shared the decision-making power with community members. This is a challenging, rarely-tried process that not many agency personnel are trained in. Rather than telling the public "this is what we will be doing" they actively engaged representatives of civic groups, and various public agencies, in the design and decision making phases of project development. Despite its difficulties, this project was enormously successful in addressing core interests for the entire group. 


\subsection{Lakeview Stewardship Group Narrative}

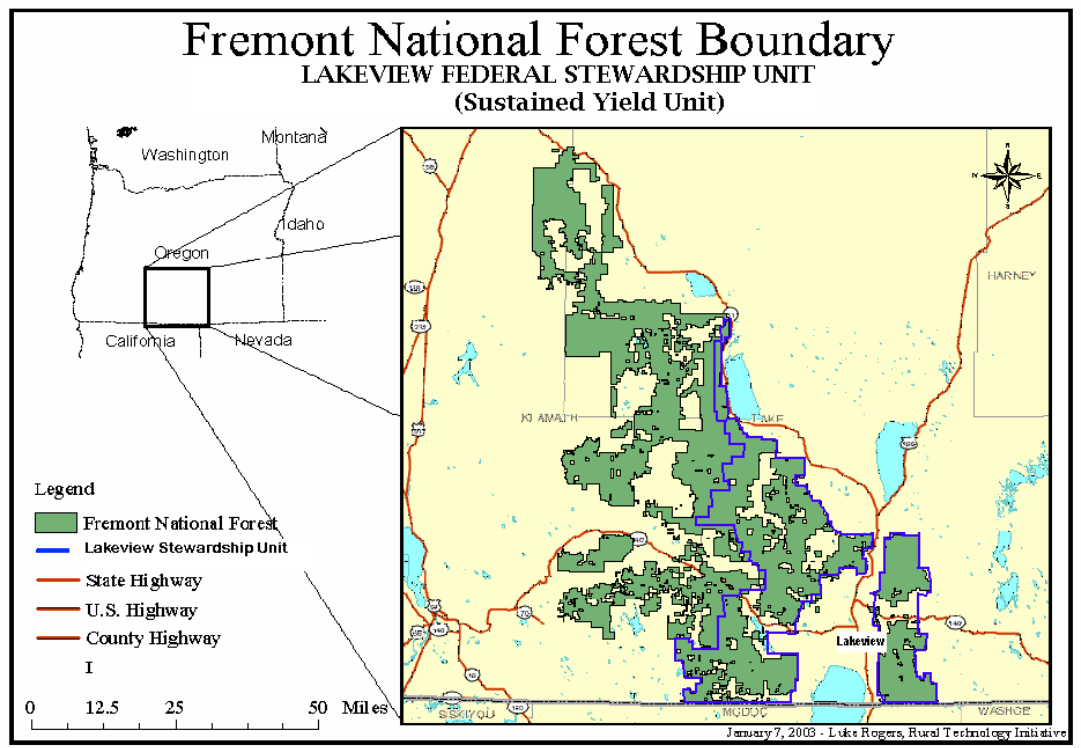

Figure 27. Image of Lakeview Stewardship Unit (LCRI)

\subsubsection{Problem Description}

The Lakeview Stewardship Group is a collaboration that emerged out of two issues: economic decline of a rural community and ecosystem decline in Eastern Oregon forests. The town of Lakeview is the county seat of rural Lake County with a population of just over 2400 in Southern Oregon. The town historically had an economy based on natural resources including timber, mining, and agriculture. Lakeview is adjacent to a Federal Sustained Yield Unit (450,000 acres), managed by the United States Department of Agriculture's Forest Service, within the FremontWinema National Forest.

Historically, a clash of perspectives has existed about how to manage forested land. For decades, forested land was valued by public agencies and private forest companies as a natural resource used for economic benefits. This perspective led to 
forest management behavior similar to that of industrial scale agriculture where a single crop is planted at one time, managed accordingly, and then harvested. The focus was primarily on "getting the cut out" resulting in clear-cutting land, cutting largesized old growth trees, and requiring logging roads and other infrastructure in the forests. All activities were intended to provide high-quality lumber that in turn supported community economies.

Environmental and conservation groups value forests as ecosystems. Their perspective is that forested land should be managed to ensure the maintenance of habitat for wildlife and ecological services such as water storage and filtration. Environmental groups viewed traditional forest harvest practices as destructive to ecosystems. Wildlife and environmental resources, without a voice, were viewed as being in need of protection by environmental organizations. The resulting clash of views resulted in legal actions and a host of aggressive political campaigns from the environmental groups against the other side.

Job losses based on timber harvest declines during the 1980s and 1990s had contributed to an overall economic downturn in Lakeview where families were living on low-incomes or leaving the community. Reduced incomes also meant declining support for city infrastructure including schools, hospitals and businesses. The community was hurting. 


\subsubsection{Origins of the Collaborative Effort}

In 1996 the Collins Company, a forest products company with mills in the town of Lakeview, closed the Fremont Saw Mill in the nearby town of Paisely. This closure was the fifth mill out of the six original mills in operation in Lake County. The Collins Company closed the fifth mill as a result of a decline of harvest levels in the federal timber program. The mill was operating at about $8 \%$ of its capacity with the reduced levels of timber. The Collins Company wanted to find a way to sustain its remaining operation in Lakeview. Beyond an economic imperative, management at Collins was also concerned about the social welfare of Lakeview citizens.

On previous occasions when the mill was hurting, the community had rallied around methods to obtain trees from the forest and boost timber harvest levels. One method is a salvage sale, where dead, or dying, trees are removed from a forest. Section 14(h) of the National Forest Management Act of 1976 (NFMA) authorized the creation and use of a special fund "in situations involving salvage of insect-infested, dead, damaged, or down timber, and to remove associated trees for stand improvement...."

Salvage sales have been historically unpopular with environmental advocates because scientists have found that dead standing trees (snags) act as homes for wildlife such as woodpeckers, standing snags provide shade for wildlife and regenerating trees, and fallen trees contribute to soil health as they degrade (Brown, personal communication, 4/17/09). When salvage sales were proposed, environmental advocates would attempt to hold up, or stop, the salvage process through litigation under different laws, such as the Endangered Species Act. In response, Lakeview 
community members would write hundreds of letters, attend meetings, and testify for approval of the proposed sale. The environmental non-profit groups and advocates would do their share of the same, from the opposite position.

Repeated, failed timber sales for the Lakeview mill, compounded by a continual decline in the local economy, led to a community sense of defeat, a feeling that citizens lacked control over their destiny. As one local leader put it,

they get doe eyed...we're being run over and we don't have any control over what's happening to us...People start clearly to feel they are not empowered, that what they think or mean does not matter, and they get concerned about their future.... When mom and dad come home upset and they're not sure about their jobs, that has direct impacts on the children, the dog, the cat, it has direct impact on the things that are involved in the community... I take it pretty seriously, and literally you can see incidences in depressed economic communities, the child abuse, sexual abuse, crime...(P62).

Conservationists felt they had to be pro-active in order to protect forest ecosystems and their wildlife denizens. One environmental advocate recognizes a downside to this position.

There's been an unfortunate rift and poor relationships that's developed between the environmental community in general and many rural communities over the issues of primarily in this region logging of the national forests including the spotted owl controversy, old growth logging, building in wilderness areas. And that's been an unfortunate controversy ... we thought this was a good opportunity, there was receptivity in the community to make a good faith effort to work with the community to try and find common ground over national forest management (P5).

The Collins Company has sole access to timber obtained from the Federal Sustained Yield Unit as they had received the bid from the Forest Service. The closure of the mill in Paisely, and the Unit coming up for re-authorization in 1998 initiated a 
community discussion about the future of the Federal Unit and how to protect the communities relying on the last mill in Lakeview. Paul Harlan, at the time the general manager at Collins, met with Jane O'Keeffe, then county commissioner in Lakeview, and a group of other community members to discuss options.

Community members had the idea that the Federal Unit could be certified through the Forest Stewardship Council. The Forest Stewardship Council (FSC) accredits third party certification bodies that evaluate forest management practices based on sustainable harvest, ecosystem health, and community benefits criteria. In the 90's the Collins Company had gone through FSC certification for its privately owned forested land and had been managing their land according to these principles.

Community members approached Sustainable Northwest, an environmental organization based in Portland, for aid in involving other groups in the discussion about reauthorizing the Unit and the possibility of certifying the public lands. This non-profit served a variety of functions during the length of the collaborative process. "Our role evolves over time; we serve very much a convening, coordinating, facilitating role in the early stages, then in the mid stages we serve as a capacity builder, build that [non-profit] entity at the local level...(P67)". Sustainable Northwest viewed this as a viable project for building a unique collaborative process because 1) the area did not have any endangered species issues making the issues potentially less reactionary, and 2) the community had "open, progressive-thinking leaders (P67)" including Paul Harlan and Jane O'Keeffe. Collins Company was considered the most progressive of all timber companies in the US at the time (P67). 
Sustainable NW met with community members and had leaders take a few site visits and an aerial flight of the Sustained Yield Unit prior to discussing the idea of certification and inviting other participants into the discussion. The project manager explains.

...They [community members] didn't know the Unit very well. Sure Collin's Pine knows the unit because they have land dispersed inside it, but [other community members] didn't... so I said how about if we just go visit the Unit, let's just go out and look at it, let's see what we think ...So I got a Flight Hawk pilot to come over and fly over the Unit, and that was a big moment for everybody, it's the epiphany moment for [a participant], [who] realized the Unit was potentially in bad shape, and maybe the environmentalists weren't so wrong, maybe...but we did need to invite the environmental community, and that the vision might have to be a little different than in the past... and others, said yeah, we have to get advice from the outside, this is a new world (P67).

Sustainable Northwest coached community members and leaders to invite agencies and environmental organizations to contribute to the discussion. However, when word got out to environmental organizations that the Lake County community was considering certifying public lands, the group found themselves in the middle of a controversy. As the group began inviting organizations to a community meeting in Lake View, different environmental organizations around the country wrote to Sustainable Northwest against the idea.

In one day I got 400 emails...from different environmental groups around the country.... One of them came to see me [this person] came into my office... and said what are you trying to do? I said I'm trying to work in this wonderful place called Lakeview where we have a timber company that's super responsible, and we have a responsible and responsive county commissioner, we have leadership, they want to do the right thing ... why wouldn't you want to do this? [This person] said if you do this we will declare war on you... I said why would you want to do that, why wouldn't you want to support a rural conservative 
community that wants to do the right thing? The answer was we don't want any harvesting of wood on public land, period... [the person] said, well maybe it won't be war, it will be a good pissing match, ... I said that's okay, we need to get through some pissing matches to get through the collaboration, [this person] said okay. That's when we turned around and invited them (P67).

Based on this response, Sustainable NW hired other trained facilitators with knowledge of forest ecosystem issues and the forest certification process to help support exploring options related to the future of the Unit during the first three years of the collaborative. At this stage, the Lakeview community was desperate and close to being economically destitute and would not be able to make any decisions on the Unit without input from both environmental organizations and public agencies. The group held a three-day event attended by 90 different individuals to discuss Unit reauthorization and the idea of applying FSC to the Unit.

Different parties came to the initial meeting based on different concerns.

[My primary purpose was to] try to ensure better provision of wildlife habitat on the associated national forest lands down there... When all this started in 1998 there were a lot fewer collaborations and proportionally fewer successful collaborations out there... I said the primary objective and purpose [for attending the Lakeview meeting] is kind of a mission statement related to wildlife and wildlife habitat. But then there's this subtext of well, let's explore this idea of collaboration, maybe it can work, we've got some concerns, but maybe this is a place where we can work that out, this concern about certification of federal lands, so there were multiple reasons for going to the meeting (P1).

Representatives from the Collins Company wanted to show the environmental

community that the past regime and past forest management had changed.

Because we felt like if they saw it had changed, they would be less inclined to fight the agency and their vegetation management plans and the projects, because the projects were probably a lot closer to what 
they [environmental groups] were thinking, it's not what they were portraying, it was better than that... I think we're closer to where you want to get to than I think you actually know; you're still hung up on the past. So we looked at wanting to try to highlight that and bring that up (P62).

Community members wanted to represent "the best interests of the Lake County people" (P63) and ..."to talk about how the community has a history here, it's a tradition, it's part of our heritage to go into the forest, to use it for hunting and fishing, [it's] what we use for our income, our families" (P21). The community wanted to be able to "use resources" again to support the local community - and they wanted to do it in a different way than in the past. "Our community was on our knees, we were at the bottom (P21)."

\subsubsection{The Collaborative Process}

This project is a community-generated, on-going collaborative process with a long (more than five year) time on-going implementation time frame. At the beginning of the collaboration, the central issue was whether or not the Unit should be certified by the FSC; beyond that was a secondary issue of re-authorizing the Unit. Forest certification was a source of conflict, with some environmental advocates taking strong positions that this should not happen. The central problem in this project evolved over time to a focus on adaptive forest management.

In the summer of 1998, environmental advocates from as far away as Seattle drove to Lakeview to attend a community meeting about the future of the Unit and the forest certification proposition. More than ninety people attended the first face-to-face multiple day meeting in Lakeview, including Lakeview citizens, environmental 
organization representatives, and representatives of public agencies (e.g. the Bureau of Land Management and the USDA Forest Service). Sustainable Northwest brought in additional facilitators beyond the staff that had been working with Lakeview leaders on the idea of forest certification. This initial meeting was not intended to necessarily spark a long collaborative process; it was to deal with two central issues: should the Unit be reauthorized and should the acreage be certified?

At this first meeting, community members spoke openly about their concerns and desires with regard to the health of the forests, local communities, the Unit and forest certification. Forest certification remained a point of contention - something the environmental community was not willing to support at that time....

What we didn't know, being naïve...the environmental community was absolutely, positively, deathly against any certification of any federal lands, 1) because they're looking at past practices, 2) it legitimizes, it could legitimatize, harvesting on federal timber lands, and a lot of those organizations had fought their whole existence for years at ending the exploitation and use of public resources for economic gain, or for anything... we naively had no idea we had stepped on a hornet's nest. It just seemed like common sense, we're common sense kind of people (P62).

Despite the point of contention on certifying the Unit, the environmental community was open to having a dialogue on new ways of managing the forest. Environmental groups were willing to work with historical adversaries for the good of the forest. Lakeview community members willingly dropped their position of certifying the national forest based on the receptivity of the environmental advocates who attended that initial meeting. Community leaders were willing to work with historical adversaries for the good of their community. 
A collaborative process evolved from this initial discussion centered on the group sorting through finding common ground between what initially looked like competing problems: forest ecosystem health and Lakeview's declining economic health. A core group of about fifteen individuals met between 1998 and 2001, referred to here as the Lakeview Stewardship Group (LSG). The group met in-person, in the town of Lakeview, at least once every two months supported by additional emails and phone call discussions. Sustainable Northwest provided trained facilitators to help the group through the initial three years.

A central aspect of this collaborative process was the regular use of site visits and field trips to the Unit to create a shared learning experience. In meetings, the discussion centered not on abstractions, but on actual circumstances the group had witnessed first-hand. Discussions included how different parties understood the related problems of forest health and the decline of harvestable timber. Despite participants coming from different perspectives on a given problem, and the many participants involved, the group determined that the problems were related.

In the summer of 2000, another multiple-day meeting was held in Summer Lake, attended by high school students, teachers, and local residents in addition to the group that had been meeting regularly. This meeting was intended to help the group establish a common vision. In this setting, a high school student mirrored back what she was hearing. Her encapsulation of people's desires led to the group's vision statement. The vision statement led the group to develop long-range goals for the forest and the community, see below. 
The Lakeview Stewardship Group envisions a sustainable forest ecosystem that, through a new understanding of the interrelationships between the people and the land, will ensure quality of life for present and future generations (Executive Summary, 2000).

The collaborative process contributed to multiple outcomes that helped sustain this vision. In 2001, the group successfully helped Lake County reauthorize the Sustained Yield Unit and renamed it the Lakeview Federal Stewardship Unit. This involved meetings in Washington D.C. and on-going efforts from core members of the Stewardship Group. In 2002, the Lake County Resource Initiative (LCRI), a nonprofit, was created to assist the County with workforce training and sustainable economic development, and to help with forest issues. This formal entity enabled the Stewardship Group to apply for funding for future efforts, and take the impetus off of Sustainable Northwest as a fiscal agent.

Between 2002 and 2005, a sub-set of the Stewardship Group collaborated on a long-range strategy for the Unit that would help realize the LSG vision. The vision and long-range goals shaped the development of this strategy. The Forest Service uses the strategy as part of their Forest Management Plan for the Unit.

\subsubsection{Current Status of the Collaborative}

The Lake Country Resource Initiative (LCRI) organization was created to support implementing the collaborative vision and goals set out by the Lakeview Stewardship Group in 2002. Since it is an independent entity, based locally in Lake County, it has its own mission that relates to promoting both forest and community health. LCRI's board of directors has members of the Lakeview Stewardship Group, 
as well as others from the community; thus LCRI does not answer directly to the Stewardship Group. The LCRI Board meets monthly and many of receives input from the Lakeview Stewardship Group. LCRI created an extensive monitoring program in partnership with a local high school, teachers, and students. They worked with government agencies to develop stewardship contracts that bring jobs to Lake County and needed forest management activities.

The Lakeview Stewardship Group meets quarterly, and many members who have retired from their official job remain involved on a voluntary basis. LCRI staff coordinates LSG meetings, help provide relevant information, and coordinate monitoring efforts on different projects being piloted in the Unit. The LSG continues to support the efforts of LCRI.

\subsubsection{Lakeview Stewardship Group Within Case Analysis}

Bold faced words are researcher prompts or responses in quotations from interviews.

\subsection{5a Research Question One: Identifying Interests}

This process began as a dispute over forest certification of public land. Prior to and during the initial three day meeting convening agencies, non-profits and Lake View community member representatives, there were two positions on the table: for (Lake View community) or against (environmental groups) forest certification. All participants during this meeting shared their substantive fears. It was this open, honest dialogue of sharing concerns and desires that created a platform for the collaborative process, see table 44 for a summary of interests. 
Table 44 LSG: Identified interests

\begin{tabular}{|c|c|}
\hline Tangible Interests & Intangible Interests \\
\hline Substance of Issues: & Substance of Issues: \\
\hline Maintain community jobs & Concern with threat to species, habitat $\&$ biodiversity \\
\hline Obtain trees for harvest & Concern with community disempowerment \\
\hline Keep the mill open & \\
\hline Develop community infrastructure & Relationships: \\
\hline Restore acres of forested land & Feel respected \\
\hline Increase or maintain ecosystem health & Feel listened to/heard \\
\hline \multirow[t]{13}{*}{ Complete job duty or responsibility } & Honesty (of self, of others) \\
\hline & Tired of fighting \\
\hline & Desperate for a change \\
\hline & Process: \\
\hline & Desire to try/understand a collaborative process \\
\hline & Have input valued $*$ \\
\hline & Reduce controversy* \\
\hline & Create something innovative \\
\hline & Help a cause (e.g. forest or community health) \\
\hline & Desire to solve a problem \\
\hline & Have good work recognized \\
\hline & Personal: \\
\hline & To be an honest broker of scientific information \\
\hline
\end{tabular}

* May not have been identified during the collaborative process.

Participants identified substantive, relationship and process interests.

Participants consistently articulated the overarching substantive interests of other

parties at the table.

I think that forest health probably brought the environmental community to the table, community economic health brought people like me to the table, but those things melded rather quickly (P63).

Relationship interests included being respected, honesty, feeling heard, recognition for good work, a desire to create innovative forest management, having input valued, and feeling like they were doing something to address their substantive concerns. Some of these may not have been expressed by all, or to all members of the 
collaboration. Another example is the Collins Company wanting to show

environmental groups that they were doing things differently:

A lot of the environmental side were harboring ill thoughts and feelings about a past regime and past management, but where we're at today, I think we're closer to where they want to get to than I think they actually know, they're still hung up on the past. So we looked at wanting to try to highlight that and bring that up (P62).

An environmental organization representative expressed relationship interests as part of his decision to collaborate, as recounted by a Lakeview leader:

I think we got very honest .... and they said when we wrapped it up, the environmentalists there said you know, 'I've always had a tough view of Lakeview, I've always been opposed to this and everything else, but I heard something that you guys really, seriously want to look at this from an objective point of view, and I heard a community, and I also saw a very special community, and I heard the legitimate change, that you guys want to seek. I want to explore that and be a part of that.' That's what I heard environmentalists say, which would not have happened if we had not gotten brutally honest, and had a real discussion about things (P62).

Interests were connected to participant roles in their organizations. Participants did not differentiate between personal concerns and those of the participant's organization; they overlapped for each participant. Substantive tangible interests that were connected to different participant's objectives included jobs maintained for the community, building community infrastructure, obtaining timber, and restoring acres of forestland.

It is unclear if the whole group discussed process interests. However the facilitators and community leaders explicitly had them in mind. They intentionally thought about who to invite, how meetings were run, and what types of information 
needed to be included. The quote below involves several interrelated elements for the

first three-day meeting that launched the formal group 1) face to face on-site meetings,

2) field trips, and 3) explicit requests for honesty.

We spent hours organizing this thing, we made sure we had lots of stops during the tour, we stopped for long periods of time, we went to different sites in the Unit, good, bad, and indifferent....We did one more aerial tour, site selections, so we made sure we weren't hiding anything in the unit, that we really saw all of the commissions of the Unit, and that the outside interest groups saw there was nothing here that was going to be off the table in terms of openness, discussion, conditions, anything, and that we could have an open, honest, transparent dialog. That's what we strived to do... (P67).

Substantive interests were linked to measureable outcomes. Participants

focused on desired, or feared, substantive interests. These measureable outcomes

related to sub-issues in forest management, as described by a participant in the quote

below.

The environmentalist perspective... was the poor environmental health of the forest that had resulted from the decades of too much fire suppression and too much logging of the large trees and there being a severe excess of these small trees that could cause intense forest fires and burn up the old growth and the streams...And from the timber industry's standpoint they wanted restoration in terms of the wood volume as the merchantable trees that they could use in the mill. From the community standpoint there was mixed interests, probably the main was maintaining the 100 jobs at the Fremont mill but also to reduce the threat of fires in the area.... Oh, yeah, the forest service. Well, their interest was to reduce controversy and get work done that serves the public interest. Interest of the public and the forest. Their mission is to serve people and care for the land or something like that (P5).

Interests were linked to issues and positions. For example, one participant describes that forest understory, as an issue, is both a problem and solution related to economic and environmental interests. 
Our problem is vegetation grows, that's kind of strange, but that's a good thing... we wouldn't have problems if this stuff wouldn't keep growing because it wouldn't choke itself, it wouldn't become fire prone, it wouldn't change its ecological structure. That realization that [this] was an issue, we said how can we do something about that to deal with the forest that also has an economic value to the community?

Integration. Yes, and they're not that diametrically opposed, how can we get the two to come together (P24)?

Positions on specific issues were dropped during this collaborative process

based on a common interest. Note that in the quote below, the participant acknowledges the other side's resistance based on reading visual and non-verbal cues:

"you get blood in your eyes". Also note that the issue of certification is linked to the speaker's position, and environmental group's opposing stance.

...we were out at the north end of Cox Flats sitting there looking at a Forest Service project and everything else, and we were still talking about federal lands and Forest Stewardship Counsel Certification, and I finally got up and I said it's still the right thing, we ought to be able to have an honest and open conversation about it, but obviously it gets in the way of having an objective discussion about what we ought to be doing out in the woods, because when it comes down to that, you get blood in your eyes, so I said I'll drop it. I'll drop the issue of certification, but we've got to keep talking about the issues that are on the ground. I think that helped, I don't think that was everything but I think that was part of the honesty thing about saying okay, if we drop it then we are here to talk about objective things, and that's, I can stay here for that. I think that helped set the tone as we went...P62

This dialogue, based on people's interests is what helped launch the collaborative process.

In the follow-up survey, eleven respondents, one staff and ten participants, emphasized substantive and relationship concerns, see table 45 . Respondents agreed the desire to restore economic health to the Lakeview 
community (100\%) and the majority of respondents agreed that desire to restore forest health $(90.9 \%)$ were important, see table 45 . The majority of respondents agreed that respecting everyone's view (90.9\%), the desire to help $(90.9 \%)$, and the desire for honesty $(81.8 \%)$ were important in this collaborative process. A little more than half of respondents agreed that the group's being tired of fighting $(54.5 \%)$ was important.

Table 45 LSG: Follow-up survey responses of important interests

\begin{tabular}{lc}
\multicolumn{1}{c}{ Lakeview Stewardship Group (n=11) } & \% Yes \\
Desire to restore forest health (e.g. protect habitat, watersheds) & 90.9 \\
Desire to restore economic health to Lakeview community (e.g. protect the mill, protect jobs) & 100 \\
Tired of fighting & 54.5 \\
Desire for honesty & 81.8 \\
Concern with being sued & 9.1 \\
Desire to fulfill job duty/responsibility & 27.3 \\
Concern that everyone's view be respected & 90.9 \\
Desire to help & 90.9 \\
Other text (two responses): & \\
Commitment to science & \\
The non-authentic disappeared &
\end{tabular}

Collaborators returned to discussing interests at different times throughout the length of the project in relation to new understanding of monitoring results, science, and observations of changes in the Unit. Participants discussed interests in relation to the substance of the central problem and its sub-issues. Interests were re-visited when new scientific information or technical understanding influenced perspectives on subissues or proposed solutions. This will be described further in the next two sections as the discussions were linked to specific techniques. 
Table 46 LSG: Themes on interests

\begin{tabular}{|ll|}
\hline Interest Types & Identified tangible interests in substance \\
& Identified intangible relationship and process interests \\
Theory-related & Identified shared interest \\
themes & Interests discussed in relation to central problem and sub-issues \\
& Interests intertwined with issues and positions and values \\
& Integrative and positional behavior present \\
& History of conflict led to mistrust that had to be addressed \\
& Open, honest language created climate of trust \\
& Position dropped in favor of integrative options \\
& Interests revisited at each stage \\
\hline
\end{tabular}

A common, shared, interest was generated in this process (P5, P66, P63, P67,

P5, P1). This common interest became something participants of the Stewardship

group would support in future collaborative projects with new partners, including the

Biomass facility project (page 149). An environmental advocate explains below.

What we were able to come to was an understanding that the conservation vision ecologically for the forest could be very compatible with what the local community wanted in terms of their cultural relationship with it. And it required some adjustment on both sides in terms of acknowledging the legitimacy of the other individual's and groups' perspectives.... The key interest that we all had, our common interest, was to increase the restoration activity of the forest... (P5).

In summary, the group identified different types of interests. A summary of interests-related themes are in table $\mathrm{x}$ below. They discussed issues, and information related to these issues intertwined with interests. Several leaders' willingness to speak openly, honestly and drop their position in the public venue helped foster a climate of trust. Together, these elements helped the group move forward in the collaboration.

\subsection{5b Research Question Two: Facilitation}

Facilitators, participants and the convener used techniques to move this

collaborative process from problem setting, through direction setting into

implementation. A summary of meetings, techniques and learning tools is in table 47 . A 
facilitator from the first two years of the project described several other social tools including establishing ground rules, setting agendas, meeting summaries, and the use of flip charts to capture issues or options. Recollection on details for each of these was fuzzy and participants did not have records from the first few years of the process.

\section{Pre-Convening}

The Stewardship Group did not conduct a formal project or conflict assessment. The convener and co-facilitator from Sustainable Northwest, Martin Goebel, had knowledge of forestry issues and relevant participants who might collaborate. He included as many people in the invitation as possible to help generate interest. Involving a diverse set of participants helped ensure more than one group would describe their concerns and desires.

\section{Participants}

Trained facilitators asked direct or prompting questions to help participants describe their concerns and desires. Participants also volunteered this information and encouraged others. A participant describes one of the facilitators in the quote below.

[person] had a knack of effectively but in a low-key way keeping everybody knit together, keeping us coming back for another meeting. Facilitating the meetings and discussion in an unobtrusive, low-key way that wasn't putting himself too much in the forefront but was getting the job done.... when I say low-key unobtrusive, when someone tries to sell me something, the harder they sell, the harder I push back. He's not a hard seller. He's very... understanding of the other commitments that people have and the difficulties of scheduling things...(P1). 
The participants were also active, passionate and committed. Each interviewed participant spoke highly of the others, remarking on one another's leadership, knowledge, and flexible mind-set. Multiple participants emphasized the role of open, honest leaders to fostering trust and ensuring this behavior was adopted by other participants. These leaders were from the local community, environmental groups and public agencies. The fact that Lake View leaders helped initiate this project and then maintain it, is an indicator of their commitment to their community.

Table 47 LSG: Key facilitation elements

\begin{tabular}{|c|c|}
\hline Pre-collaboration & Convener meeting with community leaders \\
\hline Participants & - Active community leaders and facilitators \\
\hline Information & $\begin{array}{l}\text { Pilot project assessment results that feed into the ongoing management } \\
\text { strategy } \\
\text { Participant presentations of expertise } \\
\text { Use of scientific information (e.g. computer modeling of forest stands } \\
\text { projected into the future) to shape decisions } \\
\text { Agendas, meeting minutes typed and distributed for reference }\end{array}$ \\
\hline Meetings & $\begin{array}{l}\text { Face-to-face } \\
\text { Onall groups sub-committees for specific issues } \\
\text { Equal access to discussion via facilitation } \\
\text { Phone call meetings from facilitators }\end{array}$ \\
\hline Verbal & - Asking direct questions e.g. "what matters to you" \\
\hline Communication & $\begin{array}{l}\text { Asking probing, or follow-up, questions e.g. "why?" } \\
\text { Asked for specifics behind positions, e.g. "why are you adverse to cutting any } \\
\text { trees over } 21 \text { inches?" } \\
\text { Discussed options, e.g. "What about this particular situation involving this } \\
\text { specific tree?" } \\
\text { Active listening }\end{array}$ \\
\hline $\begin{array}{l}\text { Visual } \\
\text { Communication }\end{array}$ & Use of figures, photos and diagrams to illustrate options \\
\hline Shared & - Developing long-term strategy for forest management in the Unit \\
\hline Experience & $\begin{array}{l}\text { Visioning at the beginning of the process } \\
\text { Shared meals, van-rides } \\
\text { Aerial flights } \\
\text { - Field trips to forested sites to examine treatments, "kicking the dirt" together }\end{array}$ \\
\hline Governance & - Shared, consensus \\
\hline Other & $\begin{array}{l}\text { Non-profit created to help apply for funding, coordinate meetings, support } \\
\text { forest efforts in Lakeview generally and specifically support Stewardship } \\
\text { Group efforts }\end{array}$ \\
\hline
\end{tabular}


...so yes, funding was important but funding was much less important than leadership, the funders would have never given us funding if we didn't have local leadership, combined with the process. When I say leadership I mean consistent, [Lake View leader] stuck through it almost the entire way, everybody who was part of the original collaborative stuck with it for a long period of time, there was not a lot of absenteeism or a lot of turn over, so trust-based relationships formed among the people in the collaborative (P67).

The leaders worked to establish honesty, trust and respect in the dialogue. Further,

understanding one another's interests was fundamental for the group moving forward.

This involved a team mind-set with an understanding of interdependence. This is

reflected in a community member's sentiment below.

I think that's part of strong teams and group dynamics is respect, it doesn't mean you need to agree with people, but you do need to respect what other people feel and see. If I knew what drove you and we're in a process together, and you didn't show up at one of the meetings, does that mean it's like 'fine, Tia is not here, we can finally move on'? No, that's disrespectful to the group and the organization. The group that operates well should reach the same conclusion whether you're there to pitch your point or not (P22).

\section{Information}

The group used scientific information to create the initial long-range strategy.

During the succeeding years, they established a monitoring program and used results

from it to update their management protocol.

Then another part that was a big play for moving everyone forward is this idea of learning, collective learning through monitoring, and that, I think the group was extraordinary in their investment in monitoring, which was, the first monitoring project was $\$ 100,000$, it was really significant. So that was one way about suspending disbelief, we don't know if it's the right thing but we'll try it, we'll monitor it. So they got some feedback for their efforts (P66). 
..So we provide that feedback, sort of like visual monitoring or whatever. Also we have a regular monitoring crew. That's the other thing LCRI did. The Stewardship Group said, when LCRI was created, we don't have all the answers of what we're going to do is correct out in this forest, we need to have a monitoring program so we can change as we learn, as we go along... So we got the grants to set up the monitoring group and run it under LCRI because we're an entity and they [the Stewardship Group] weren't (P55).

\section{Meetings}

Having face-to-face meetings in Lakeview helped environmental participants understand the concerns of Lakeview citizens in a more intimate way. Facilitation techniques were used to shape discussion of the central problem, sub-issues or related technical information. The content of meetings was always used to help move the group forward. In the beginning, the focus was on re-authorization of the Unit. As the different sub-issues evolved the group's tasks and action plans changed. The visioning discussion was used as a platform for developing a long-range strategy. Conversations to increase understanding were always linked to on-the-ground projects including grant applications, legislation or forest treatments.

This information contributed to a community meeting to discuss the primary issue of forest certification. After this three day meeting, the group agreed that more work was needed including a discussion of a shared vision. This visioning meeting incorporated a discussion of interests, which are embedded in the vision statement and group goals:

"The Lakeview Stewardship Group envisions a sustainable forest ecosystem that, through a new understanding of the interrelationships between the people and the land, will ensure quality of life for present and future generations (Executive Summary, 2000)." 


\section{Verbal and Visual Communication}

The most cited method of exploring interests was through direct communication; for example asking direct questions, probing questions, and follow-up questions. In this project, participants and facilitators asked these questions and encouraged others to speak up. Participants mentioned that in order for them to feel comfortable discussing their concerns and desires, they had to feel they were being listened to and their viewpoints were respected. Additionally, some participants volunteered to put their interests on the table to encourage others to do the same. One Lakeview leader encouraged others to listen and be honest with one another, using phrases such as "check your guns at the door" and "get naked in the sandbox" to nudge people beyond their comfortable positions into the uncomfortable substance of the different issues. These phrases, and the explicit honest tone set by different Lake View community leaders helped encouraged others to share their concerns.

Leaders and community members modeled statements like the following: "I really want to support what you're doing here...here are my constraints." Such statements help clarify interests while sharing information about barriers.

Participants actively communicated with the organizations, or stakeholder groups they were representing. The different stakeholder groups were limited by the concerns of their peers. In this project, each individual returned to his or her different constituencies and brought new perspectives back to the Stewardship Group - while simultaneously keeping their constituencies informed. 
..the agencies would say we really support this, we really want to make this happen, but listen, here is our planning, here's our timeline, here's our process. They have very limited ability to deviate from their process, so they would do that on a regular basis, and [environmental representative], was like I support this here locally, I have to go advocate with my higher ups in DC. So he would do that check in process, and the local community folks didn't have to do that generally, but they would, like [two community leaders], they were essentially representing in a non-elected manner, they would do that kind of thing as well. But they were really in touch with their limits, they knew how far they could go and how far they couldn't, so they did a lot of politicking behind the scenes, so I think that was part of the conversation (P66).

Participants made explicit requests for honesty and openness during every phase of meeting - around a table, out in the field, and over substantive information.

The 'get naked in the sandbox' thing became a core value, and it still is a core value of the ...working group, and what it means is let's stick out our arms, let's get in the sandpit and duke it out, or talk it out and come up with the best collaborative collective....we also told the facilitators of that big meeting, (inaudible), and they insisted, they would have insisted anyway, that it had to be a frank, open, honest, leave your guns at the door sort of dialog, you had to get the issues out in the open (P67).

The visual elements that were frequently mentioned by participants are covered in the next sections, shared experiences.

\section{Shared Experiences}

This collaborative process involved experiences that required shared learning of issues and of other participants. Field trips and site visits were crucial in this collaborative in shaping a common understanding of the problem. During field trips, discussion would return to interests, tied to issues. It is unclear how much of this was explicitly stated in discussions. Shared learning about issues created the potential for 
reflection on both participant interests and positions. For example, environmentalists

have historically supported the position of not logging trees 21 " in diameter or over in

order to protect old growth (e.g. larger) trees, during this process several

environmental advocates learned new information that caused them to rethink their

position.

I can remember several years ago going out onto .... a site, where there was a 22-23-24 inch white fir growing in a mixed conifer stand.

Carrying my increment borer and taking an increment from that and saying, huh, this tree is only 90 years old. And showing it to [person]...I remember him being reluctant to cut these larger than 21" trees. Based on our conceptual model of these forests changing with fire exclusion and grazing in the late 1800 s and wanting to return to the stand structure prior to that - this tree hadn't been there. It fits the model of being a post fire exclusion tree that is causing problems... in some ways what I was doing was presenting a cognitive dissonance for [person] in terms of his saying we want to generally restore to presettlement conditions, we want to deal with these overly dense stands, and I don't want to cut trees over 21"... he was still kind of resistant to that evidence. But in the succeeding few years he's become much more open to that, so he's been able to -- and I give him credit for that - to resolve that dissonance in terms of the new evidence rather than his pre-established position (P1).

The aerial flights at the very beginning of the process helped

community leaders from Lakeview develop a new perspective. Although this element could be included as a "field trip" it was remarked on by several participants as standing out in their mind.

...let's all go take a look and see what we're talking about so we're all on the same page when we start this conversation. I had just moved back to Lakeview after being gone for [20] years, my father worked in the timber industry, that's what clothed us, fed us, and educated us. I had a big chip on my shoulder about these people who, these environmentalists who made us stop working and make these people lose their jobs, my community, closed down all the mills. I flew over 
the forest and I saw what they were talking about, I saw the clear cuts, the roads, and I came down on the ground with a whole new paradigm (P24).

This collaborative process involved a sub-group of the Stewardship Group developing and writing a long-range strategy for the Unit four years into the process. This co-laboring to put the Stewardship Group's vision and goals into a plan helped the group wrestle with their concerns and desires.

One of the things that working on a document like that does is it forces you again, to take it to another level from the somewhat abstract, we had gone around and talked about specific trees, but the principles that inform ecosystem health and what does that mean. It takes it to another level of trying to specify that and come up with language describing what do we want to see on the ground, and how to do it that we all agree on. I think that was a helpful process. And the forest service was observing and commenting on drafts of that as well, so that helped us create something that was appropriate to their subsequent planning process $(\mathrm{P} 1)$.

Interviewed participants helped author chapters of the Plan. The document helped the group record the substance of the issues within the framework of their vision. Text below is from the Executive Summary of this strategy.

The goals of the Stewardship Unit are as follows:

- Sustain and restore a healthy, diverse, and resilient forest ecosystem that can accommodate human and natural disturbances.

- Sustain and restore the land's capacity to absorb, store, and distribute quality water.

- Provide opportunities for people to realize their material, spiritual, and recreational values and relationships with the forest.

The strategy focuses on eight main issues 1) forest and rangeland health, 2) soils and water, 3) fish and wildlife, 4) roads, 5) roadless areas and wilderness, 6) recreation, 7) community benefits and 8) implementation and economics. 
The shared experience also ensured that the group's understanding of the different issues would evolve as they read each others' drafts. Much of this effort took place through emails and conference calls.

Absolutely, once people understood what other people were concerned about,...like when you'd go out on a field trip they'd say I see that here we're seeing some signs of degradation, which all of a sudden was important to everybody instead of one segment of the group. So you started to see that understanding of other people's concerns, and willingness to address them as they came up as opposed to I need to get my issue out on the table right now and we'll come to yours later. We just started working as a unit, or a team, rather than a group of individuals with individual concerns (P63).

\section{Potential Disruptive Elements}

Participant positions threatened to prevent this process from happening. Environmentalists opposed forest certification. When the Collins Co. manager dropped forest certification from the table and explained he wanted to work to help solve the general forest problem - this helped several environmental advocates commit to collaborating.

As in the Biomass project, this project involved a complex problem that required extensive scientific information to understand. The group contained experts on forest management and ecosystem health who were able to help other participants learn relevant information. The group's shared learning experiences were crucial in building cohesion and managing the potential disruption problem complexity and technical complexity can cause. 


\subsection{5c Research Question Three: Role of Interests}

Interests helped participants develop a common understanding of one another in relation to the problem and potential solutions. This influenced different stages of the collaborative process. The different roles of interests in this project are in table 48 .

Notice participants' interests influenced stakeholder decisions in all phases.

Table 48 LSG: Participant interests' impact on the collaborative process

\begin{tabular}{|c|c|}
\hline Collaboration Stage & Participants Interests Affected \\
\hline \multirow[t]{4}{*}{ Problem Setting } & Participants deciding to enter the collaboration \\
\hline & Commitment to collaborate \\
\hline & Collective understanding on the problem \\
\hline & Developing group goals \\
\hline \multirow[t]{4}{*}{ Direction Setting } & Perspectives on issues \\
\hline & Exploring options \\
\hline & Developing a strategy to address issues. \\
\hline & Reaching agreement and closing the deal \\
\hline \multirow[t]{2}{*}{ Implementation } & Commitment of resources \\
\hline & Program outputs \\
\hline
\end{tabular}

\section{Problem Setting}

Participant interests are part of the perceptual lens for viewing incoming technical, scientific, or social information. In the quote below, the participant reveals the link between substantive interests and relationship interests.

Let's use [an environmental organization's representative] for an example, their interests first of all was to come down and see what in the heck we were up to, what are you guys trying to pull, and we want to watch you. That changed over time from the interest was to keep us from doing bad things to the forest to helping us do good things to the forest, and recognizing we're not just a bunch of bad people here...So the interest changed, and ours changed from you won't let us do any work in the woods to how can we do our work better...( P24).

In this quote, the participant refers to technical information Collins Company shared over time about how it manages forest harvests. When combined with direct experience of the land, this contributed to a perceptual shift from "doing 
bad things to the forest" to "doing good things to the forest." Additionally, this relates to each individual's perspective of "us" versus "them" i.e. "we're not just a bunch of bad people here" and "you won't let us do any work in the woods." This perceptual shift, and the interests, contributed to participants deciding to commit to the collaborative process.

Interests shaped participant perspectives on the problem and sub-issues. This includes the problem definition and each participant's problem emphasis. In the quote below, a community member describes the perspective shifting to include the concerns of other participants. This is because the other participant's concerns were dependent on hers.

I changed my focus from looking just at my little piece of the worry, which was we don't have jobs, we need jobs, the businesses are failing, I needed to change my focus from that part of the problem to the solution, and the solution was we need to change the health of the forest (P24).

Interests were associated with participant priorities on sub-issues. Some participants' interest priorities changed during the collaborative process. This change is based on a complex variety of factors. It is unclear how they relate and to what degree. The factors include: learning of other party's interests, having positive experiences of having one's interests acknowledged and addressed, learning new substantive information about the primary issue, and having an open mind-set.

\section{Direction Setting}

Interests shaped the development of group goals, as may be clear from the Long Range Strategy described in the previous section. From one participant's 
perspectives, interests were the raw material for developing a group goal centered on a common problem. For one participant, how interests are discussed is as important as discussing them. In the quote below, shared interests are related to shared goals and a collective group effort to attain them.

I think it was everything. I think we all bring concerns and desires to the table, and I think when you honor, listen and honor, and can legitimately consider other people's, I think it changes your concerns, and it should modify you as a group or as a team, other people should influence how you feel about things, and your concerns, and the rest of the stuff, because you' re going at it as a team, not as an individual. We show up with individual concerns, and you develop a group goal or concern, and a group solution to those concerns. If [interests are]

listened to and respected, and addressed. Correct, if they're not - If they're not, then what happens? If not you've got a pretty rough submarine ride, you can't operate as a group and you're not going to go as far if you don't have common goals (P62).

Interests shaped a strategy to address the problem in this case. The interests

were also the basis for creating an option that addresses that common problem.

The group's objectives evolved as their understanding of the problem shifted. Recall

that group collected substantive information throughout this process. In the quote

below a community member describes the feedback the group regularly gathers from the implementation of forest interventions.

We say all right, let's issue a Stewardship contract, let's get a contractor out there and let them go do some thinking, and let's go watch, go see how they do that. Do we like how the equipment, what kind of footprint is it leaving on the ground, do we like the end result? Let's come back next year and look at it when it's finished and they're through mulching and cleaning up. We like that, that looks good (P21).

This process is marked by a consistent, long-term implementation of goals backed by shared interests. The group worked on getting the Unit reauthorized first, 
then developed a vision for the Unit, then a long-range strategy that would embody

that vision, then multiple projects to help implement that vision, etc. The long-term strategy the Stewardship Group developed was based on shared understanding of forest health and its relationship to economic health in the surrounding communities. The goals the group developed were a context for different projects that would realize those goals. The goals are based on stakeholder concerns.

\section{Implementation}

Participant interests contributed to the options the group selected for the agreement. The shared interest of the group formed the motivation to pursue multiple projects, resources, and further partnerships in order to achieve the group's desired goals. Participant interests were therefore carried into program outputs. In the quote below the participant explains how their efforts are now incorporated into the Forest Service's activities.

I tell you they follow it [the long term strategy], within the NEPA documents and everything, they will have the goals of the Unit outlined and how the project they are proposing meets the goals of the Stewardship Group. In fact they come to the Stewardship Group up front and said 'how would you like to help us design this treatment we' re going to do?' Then we go back out in the forest on our field trips and look the treatment's done and say, 'whoops, I wished we would have done this, or this, we need to adapt the next one to look at this, if we want this, this is great this is exactly what we're after' ( P55).

Recall that elements of the long-term strategy, including its language, are being used by the Forest Service to manage the Unit. 
4.5.5d Research Question Four: How Were Interests Addressed

Participants identified tangible and intangible interests throughout this collaborative process. Explicit discussions including interests were part of problem setting and direction setting phases of the process (see Figure 28). Some negotiation of interests continues to be part of implementation as the Lakeview Stewardship Group contributes to on-the-ground projects through the Lake County Resources Initiative. LCRI stays in conversation with LSG participants to make sure efforts align.

Participant concerns were intertwined with forest management and economic development issues. Interests framed how participants understood the central problem, were a foundation for developing a group goal, shaped the selection of options, were part of why participants maintained their commitment, and contributed to the allocation of resources in this process. People communicated directly about their concerns within the context of leaders and facilitators encouraging one another to be honest and open. Shared learning experiences were a central part of this collaborative process. Discussions developed from field trips, examining scientific information, developing a long-range strategy and understanding results from monitoring programs. The monitoring program especially provided on-going information that helped environmental groups understand how the forest was progressing in relation to different treatments and helped address community members' economic development concerns. 


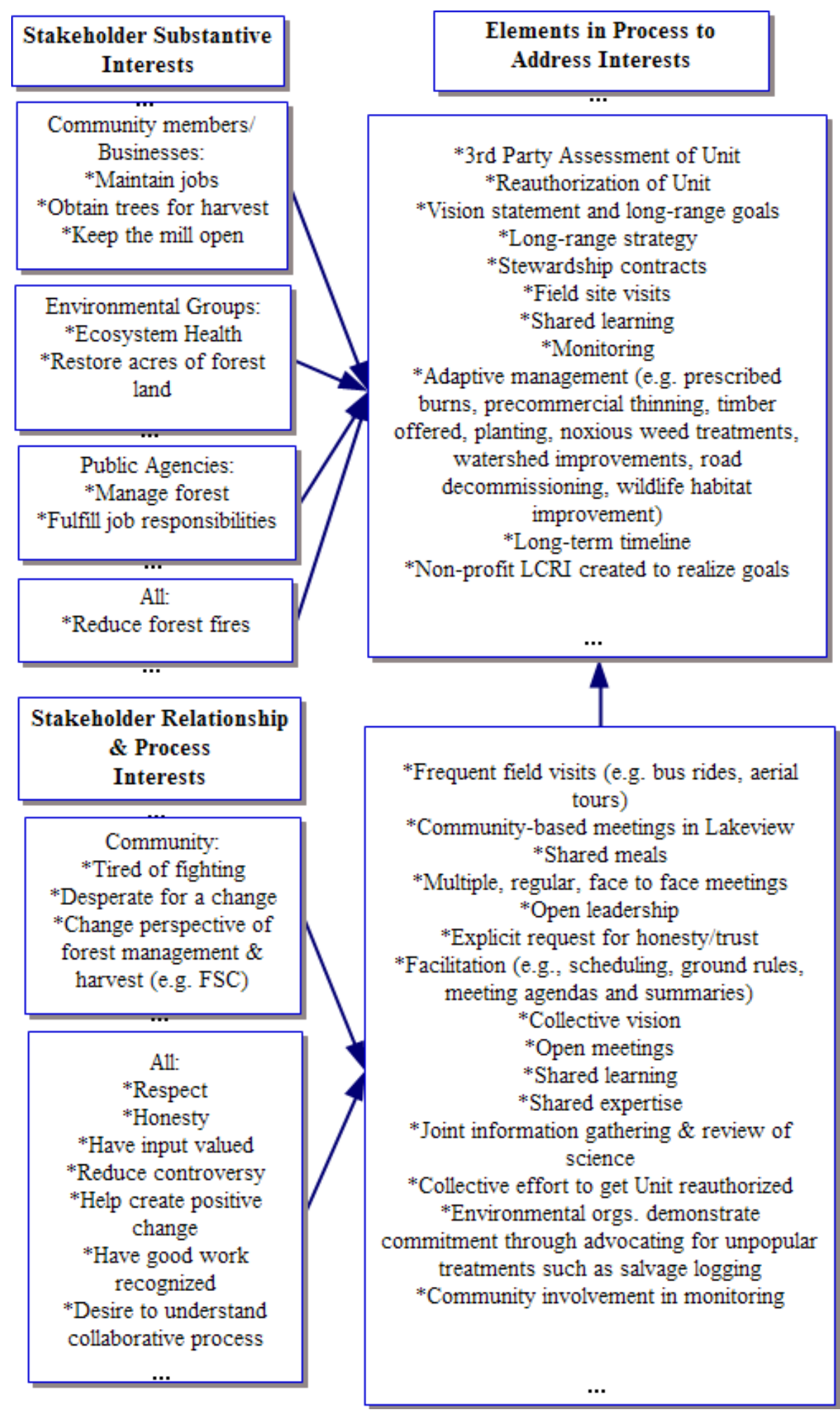

Figure 28 Lakeview Stewardship Group: How interests were addressed 
The participant describes this in the quote below.

Yeah, and that [monitoring] was really one of the attributes of the group which allowed it to operate at this high conceptual level without everyone being completely on the same page about what everything was going to look like. One of the ways it helped was that the substantive aspects for community folks was doing the restoration on such a scale it impacted the land and provided a steady stream of forest restoration byproducts, both thin material and biomass....so monitoring from the community's perspective was a way to grow the base of common ground and acceptable practices so that the land management projects could expand, so the restoration project for thinning could expand and have some predictable, stable supply of work...(P66) Discussions aided people in understanding the breadth and depth of different

issues. Discussing scientific information in relation to on-the-ground experiences helped re-frame people's perceptions of what was going on in the forest beyond solely the abstract (from research) or observations (from experience). This is a case where negotiations were iterative and continual. Discussions helped address people's concerns about people, problem and process. While the group may not have stated a concern for a fair process at the outset, people emphasized a desire for honesty and respect.

The long-range strategy is an output example that is informed by, and seeks to address, the different groups' interests. The document language wrestles with scientific information that informs habitat restoration, soil nutrient cycling and water protection. The document also describes the considerations necessary for using different harvesting (e.g. logging) practices to attain habitat restoration while at the same time supporting economic growth in Lake County. The quotes below are 
examples of how these concerns became embedded in a governing document that is

now being used to guide Forest Service adaptive management practice in the Unit.

There is a huge disparity in actual soil impacts with different groundbased timber harvesting and wood extraction systems and equipment. Consideration of how the particular equipment systems are to be used and the level of operator skill, care, and attention to detail are critical factors in limiting adverse impacts. Different operators on the same machine can have disparate levels of impacts. This issue can be addressed with training and education workshops for forest operators (Executive Summary, p. 42).

Local processing of derived raw materials and the use of local employment for forest management services will be strongly encouraged to foster the development of new, local, economic opportunities for wood products manufacturing and other businesses associated with forest restoration (Executive summary p. 41).

The time-frame of this project was notably long. The implementation phase of this project thus requires on-going efforts. LCRI established a monitoring program to inform future intervention options in the Unit. The information also helps private landowning stakeholders understand how different forest management practices impact forest health. 


\section{CHAPTER FIVE}

\section{Cross Case Analyses}

The previous chapter reviews individual findings based on document and interview data for each case. This section shifts to a cross-case perspective and describes findings for each research question from all data sources. Individual cases, or groups of cases, are highlighted when findings among the five were significantly different.

\subsection{Survey Results}

The follow-up survey was deployed to confirm findings from the qualitative stage of the study; they should be considered from this context. Findings are presented in aggregate and by case where there are differences. Inferential statistic results are presented here to reveal case differences; additional inferential tests are located in Appendix F. Note that the term "participants" are all individuals participating in a collaborative project. The term "respondents" is specific to those participants who also responded to the survey. Cases are numbered or abbreviated for the sake of brevity:

Lane Clean Diesel is Case 1 (Lane), Reduced Engine Idling is Case 2 (Idle), Biomass Facility is Case 3 (Bio), Tillamook Flood Reduction is Case 4 (Tlmk), and Lakeview Stewardship Group is Case 5 (LSG). Section 4.7 summarizes cross-case findings.

\subsubsection{Research Question One: Identifying Interests}

Interviews and documents revealed that the collaborative processes did not explicitly have participants define and track interests. This is confirmed by a moderate number of individuals indicating the process helped them understand their interests in 
the follow up survey (see the first line of table 49). However, individuals discussed interests in connection to the central issues due to staff members' and community leaders' use of facilitation techniques. Survey results confirm that participants identified, discussed, and understood one another's interests to some degree (see second line of table 49).

Table 49 Survey results of participant understanding each other's interests

\begin{tabular}{|lccccc|}
\hline & $\begin{array}{c}\text { Strongly } \\
\text { Disagree } \\
(0)\end{array}$ & $\begin{array}{c}\text { Disagree } \\
(1)\end{array}$ & $\begin{array}{c}\text { Agree } \\
(2)\end{array}$ & $\begin{array}{c}\text { Strongly } \\
\text { Agree } \\
(3)\end{array}$ & $\begin{array}{c}\text { Mean } \\
\text { (SD) }\end{array}$ \\
\hline $\begin{array}{l}\text { "The collaborative process in this project } \\
\text { helped me better understand my interests." }\end{array}$ & $4.5 \%$ & $20.5 \%$ & $50 \%$ & $25 \%$ & 1.95 \\
$\begin{array}{l}\text { "The collaborative process in this project } \\
\text { helped me better understand other } \\
\text { participants' interests." }\end{array}$ & 0 & 4.5 & 56.8 & 38.6 & 2.34 \\
\end{tabular}

$(\mathrm{N}=44$, all cases, staff responses not included)

The response rates from Lane Clean Diesel and Reduced Engine Idling were too low to accurately represent these groups, although interviewed participants consistently identified the same participant concerns. This finding indicates that when participants agreed to implement projects and programs, it was with some understanding of stakeholder interests.

Respondents in each case were asked to confirm if a list of primary interests identified from interviews were important. These interests appeared earlier in the chapter in the individual case analyses (see pages 105, 127, 164, 210, and 262). Each list of interests on the survey was not all-inclusive; it included at least two substantive interests, one relationship interest and one process interest, with others (see Appendix C1 for specific survey lists). Survey results indicate that respondents agreed at least one substantive interest was important (see table 50). This finding and the specific 
substantive interests survey respondents agreed on, indicate that participants'

substantive interests were connected to the central issues in each case.

Table 50 Important substantive interests by case confirmed in the survey

\begin{tabular}{|lc|}
\hline \multicolumn{1}{|c|}{ Substantive Interests } & \% Yes \\
\hline Case 1 Lane Clean Diesel (n=4) & 100 \\
Reduce air pollution & 100 \\
Case 2 Reduced Engine Idling (n=7) & 85.7 \\
Desire to reduce air pollution & 100 \\
Avoid unnecessary costs with idling reduction technology (e.g. installation, maintenance) & 100 \\
Case $\mathbf{3}$ Biomass Facility (n=13) & 92.3 \\
Protect economic health of Lakeview community (e.g. protect the mill, protect jobs) & 100 \\
Protect/restore forest health (e.g. protect habitat, watersheds) & 100 \\
Desire to reduce wildfires & 83.3 \\
Case 4 Tillamook Flooding Reduction (n=18) & 88.9 \\
Protect environmental resources (e.g. fish habitat, endangered species) & \\
Reduce negative impacts of flooding (e.g. public safety, property damage, loss of cattle) & 100 \\
Protect community economy (e.g. businesses, agricultural land) & 90.9 \\
Case 5 Lakeview Stewardship Group (n=11) & \\
Desire to restore economic health to Lakeview community (e.g. protect the mill, protect jobs) & \\
Desire to restore forest health (e.g. protect habitat, watersheds) &
\end{tabular}

Survey respondents from three of the cases also felt relationship and process

interests were important. Note that more than three-quarters of respondents from the

Biomass, Tillamook, and LSG project agreed that everyone's view being respected

was important in the collaborative process (see table 51). LSG participants also

emphasized honesty. Respondents revealed a personal interest in helping to address a

problem in the Biomass and LSG projects. This is important because it shows that the

substantive interests were not the only concerns the group had to address in order to

move forward in the collaborative process. It also confirms findings from the

interview and documents that these interests were important to participants. The low

response rate in the Lane Clean Diesel and Reduced Engine Idling projects means the 
survey was inconclusive in confirming relationship and process interests in these two cases.

Table 51 Important relationship and process interests confirmed in the survey

Case 3 Biomass Facility $(n=13)$

Relationship and Process Interests

$\%$ Yes

Concern that everyone's view be respected

84.6

Desire to solve a problem

84.6

Case 4 Tillamook Flooding Reduction $(n=18)$

Desire for agencies and community to work toward common agreement $\quad 94.4$

Desire that everyone's concerns be respected

Case 5 Lakeview Stewardship Group $(\mathbf{n}=11)$

Concern that everyone's view be respected

90.9

Desire to help

90.9

Desire for honesty 81.8

The common relationship interests participants emphasized in interviews across all projects were honesty, feeling respected, feeling heard or listened to, and feeling each individual's perspective had merit. Notice the last two overlap with how a process is conducted; for example the collaborative environment supports open communication and listening. Another process concern was emphasized in the Tillamook project when participants did not want "just a bunch of meetings;" they were focused on physically implementing projects. Individuals in different projects articulated a personal desire to be a benefit to the process through being an "honest broker of scientific information" (LSG and Biomass), by providing resources to help reduce air pollution (Lane Clean Diesel), by providing key skills such as facilitation or negotiation (all), or by providing important information (all).

\subsubsection{Research Question Two: Facilitation}

Documents and interviews indicated all participants in all projects used social techniques to manage issues, people, and the process. See Appendix E for the 
summary list of all techniques brought up in these projects. A sub-set of elements that were either common to all groups, or were emphasized by participants as being helpful in understanding substantive interests, was validated in the follow-up survey.

Participants indicated whether or not six categories of elements most helped them understand issues and/or interests. Issues were defined as the details of the subject the group worked on, e.g. flooding reduction, air pollution, forest health, jobs. Participants were asked about issue understanding in relation to participants and information type, as most substantive interests were discussed linked to issues and not all participants were clear on the distinction between issues and interests. Participant interests were defined as what people really cared about under the issues. The other four categories included types of meetings, types of visual communication, types of verbal communication, and types of shared experiences.

\section{Helpfulness of Participants}

Survey findings indicate that participant leaders, participants with different perspectives, and participants with valuable resources were important in shaping understanding of issues in each of these collaborative processes. People with important resources such as money or scientific information were helpful for understanding issues for 77 percent of respondents (see figure 29). Leaders other than the project facilitator or convener(s) were important for understanding issues for 58 percent of respondents. A moderate number of participants agreed participants who 'see things differently than I do' helped understand issues (47\%). There were no significant differences among the five cases in relation to what participants were 
considered helpful in understanding issues (see Appendix F). These findings indicate that collaborative groups benefit from a mix of stakeholders, and participants are influenced by leaders beyond project staff members. Conveners may benefit from finding stakeholder representatives who are respected and listened to by their constituency.

Figure 29. Types of helpful participants

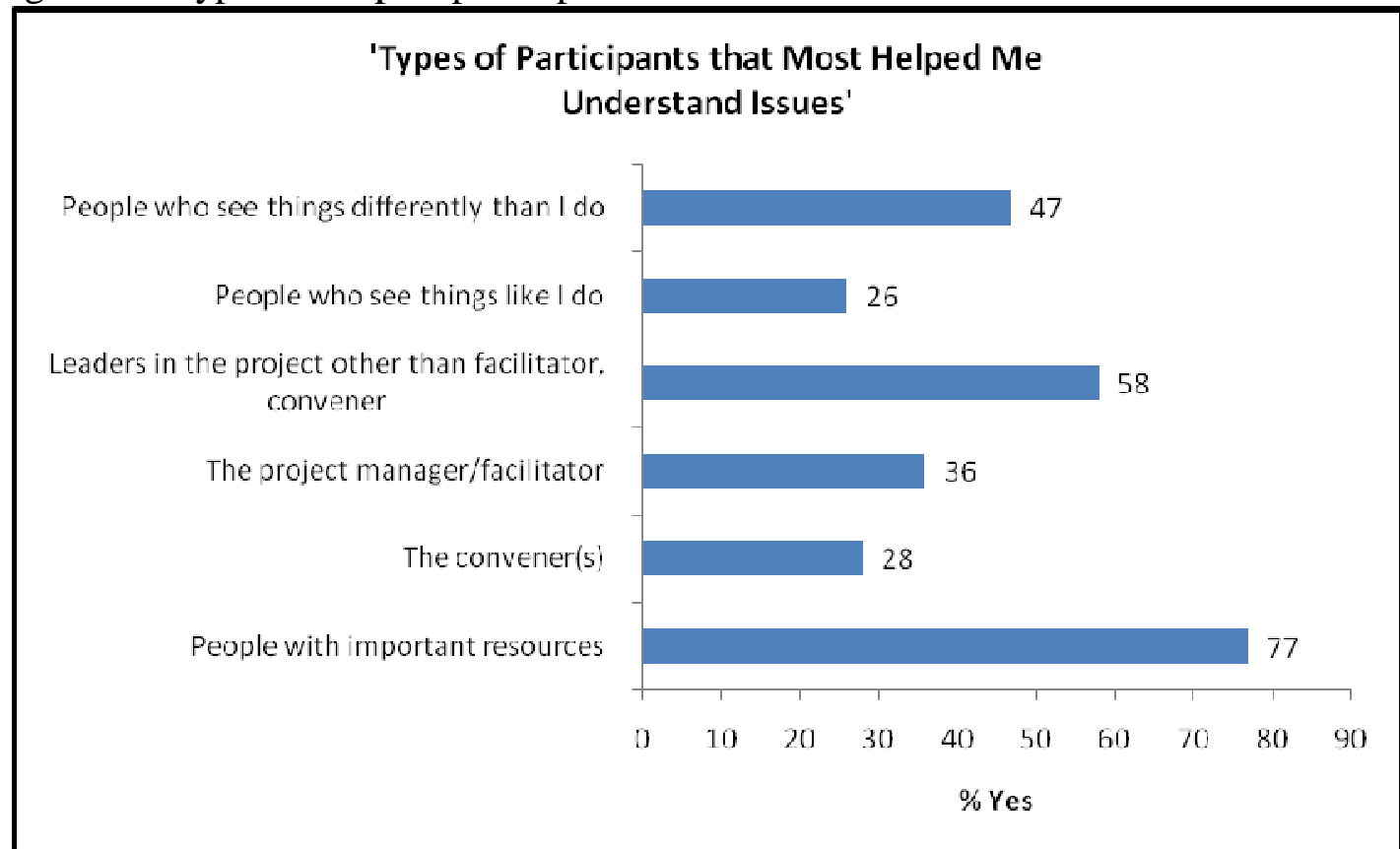

Survey respondents from all five cases $(n=53)$ indicating the types of participants that most helped them understand issues. Percentages rounded to nearest whole number

\section{Helpfulness of Information}

Survey results indicate that for all five cases, visiting expert presentations $(60 \%)$ and participant presentations $(81 \%)$ were most helpful in helping participants understand the issues (see figure 30). These results clarify results from the interviews

Figure 30. Survey results: information that helped participants understand issues 


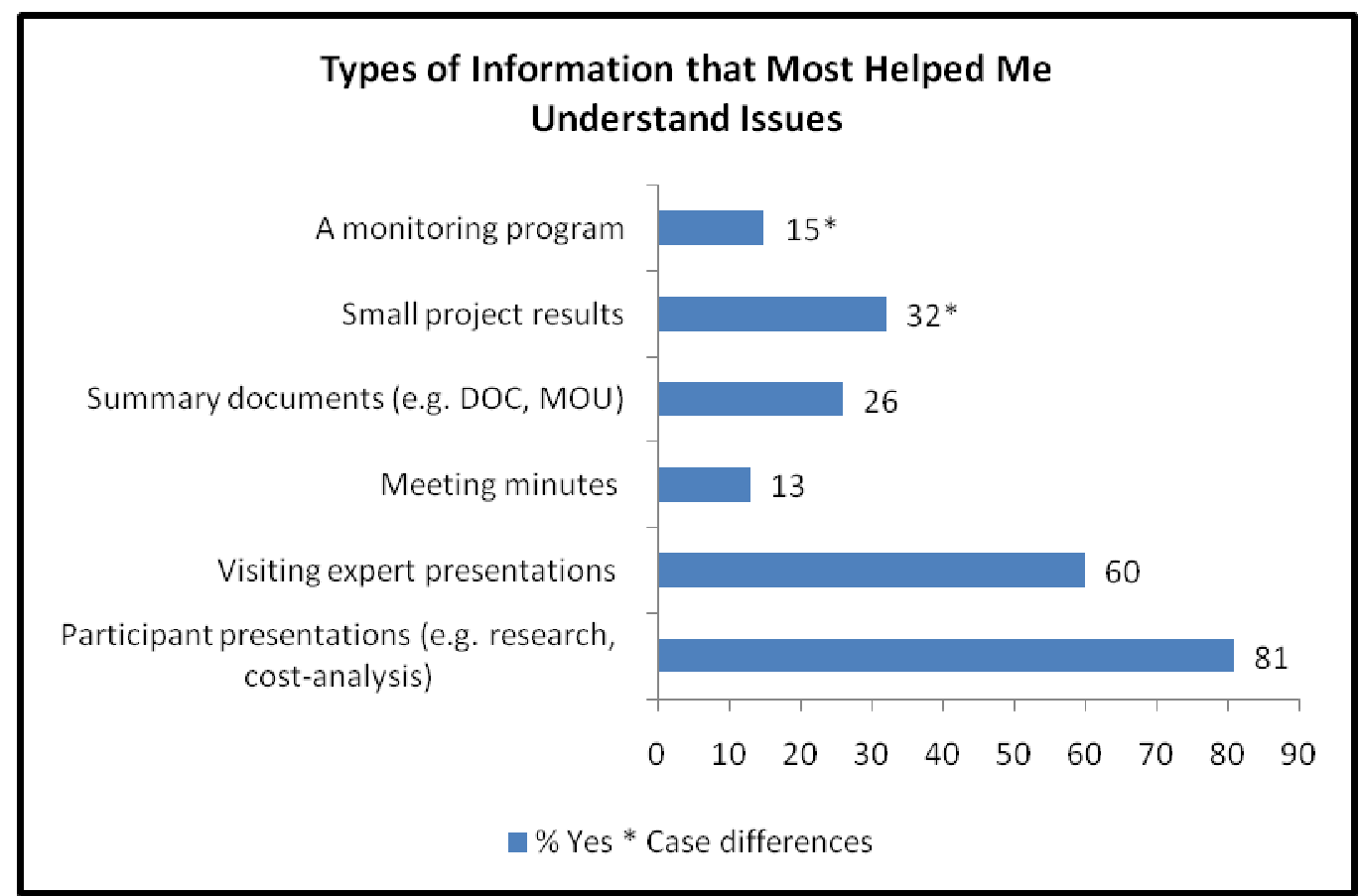

All cases, $\mathrm{N}=53$. All percentages rounded to nearest whole number.

Interview results indicated that Lakeview Stewardship Group, Tillamook Flooding Reduction, and Biomass projects used small project results during the agreement and implementation phases more than the other two cases. The survey results also confirm this. Chi-square results indicate that the proportion of yes and no responses were significantly different among the five cases on two issues: the use of small project results and the use of a monitoring program. Pearson Chi-square tests showed that cases one through four were not different from one another on either the monitoring program or small project results item (see Appendix F). Individual case responses for each element are in table 52; notice the difference between LSG and the other cases. 
Table 52 Information sub-types: case specific results

\begin{tabular}{|llllll|}
\hline & $\begin{array}{l}\text { Lane } \\
(\mathrm{n}=4)\end{array}$ & $\begin{array}{l}\text { Idling } \\
(\mathrm{n}=7)\end{array}$ & $\begin{array}{l}\text { Biomass } \\
(\mathrm{n}=13)\end{array}$ & $\begin{array}{l}\text { Tillamook } \\
(\mathrm{n}=18)\end{array}$ & $\begin{array}{l}\text { LSG } \\
(\mathrm{n}=11)\end{array}$ \\
\hline A monitoring program & $0 \%$ & $0 \%$ & $15 \%$ & $6 \%$ & $45 \%$ \\
Small project results & 0 & 14 & 38 & 17 & 73 \\
\hline
\end{tabular}

Percent affirmative, all numbers rounded to nearest whole number

The Lakeview Stewardship Group used an on-going monitoring program; it is unclear how much the Biomass participants reviewed this monitoring data. The Stewardship Group and the Biomass case were not significantly different from one another on either item: $\chi^{2}(1)=2.81, p=.09$ for small project results; $\chi^{2}(1)=2.6, p=.10$ for a monitoring program. These findings indicate that participants in all projects benefitted from presentations by community or visiting experts. Projects involving adaptive resource management such as the Lakeview Stewardship Group, may benefit from small project results and a monitoring program.

\section{Helpfulness of Meetings}

More than two thirds of respondents agreed that regular meetings (70\%), meeting face to face (64\%) and whole group or Project Team meetings (74\%) most helped them understand the issues (see figure 31). A moderate number of participants agreed that sub-committee meetings (42\%) and on-site meetings (53\%) were important for understanding issues. These findings indicate that regular discussions, in person, are most helpful for participants to understand issues. Meeting on-site in the community may relate to being able to connect with the context of different stakeholder groups, for example where they live, eat, work, and play. Interviewed participants indicated that sub-committee meetings helped participants move more quickly through information and allowed individuals to caucus. 
Figure 31. Helpful meeting types

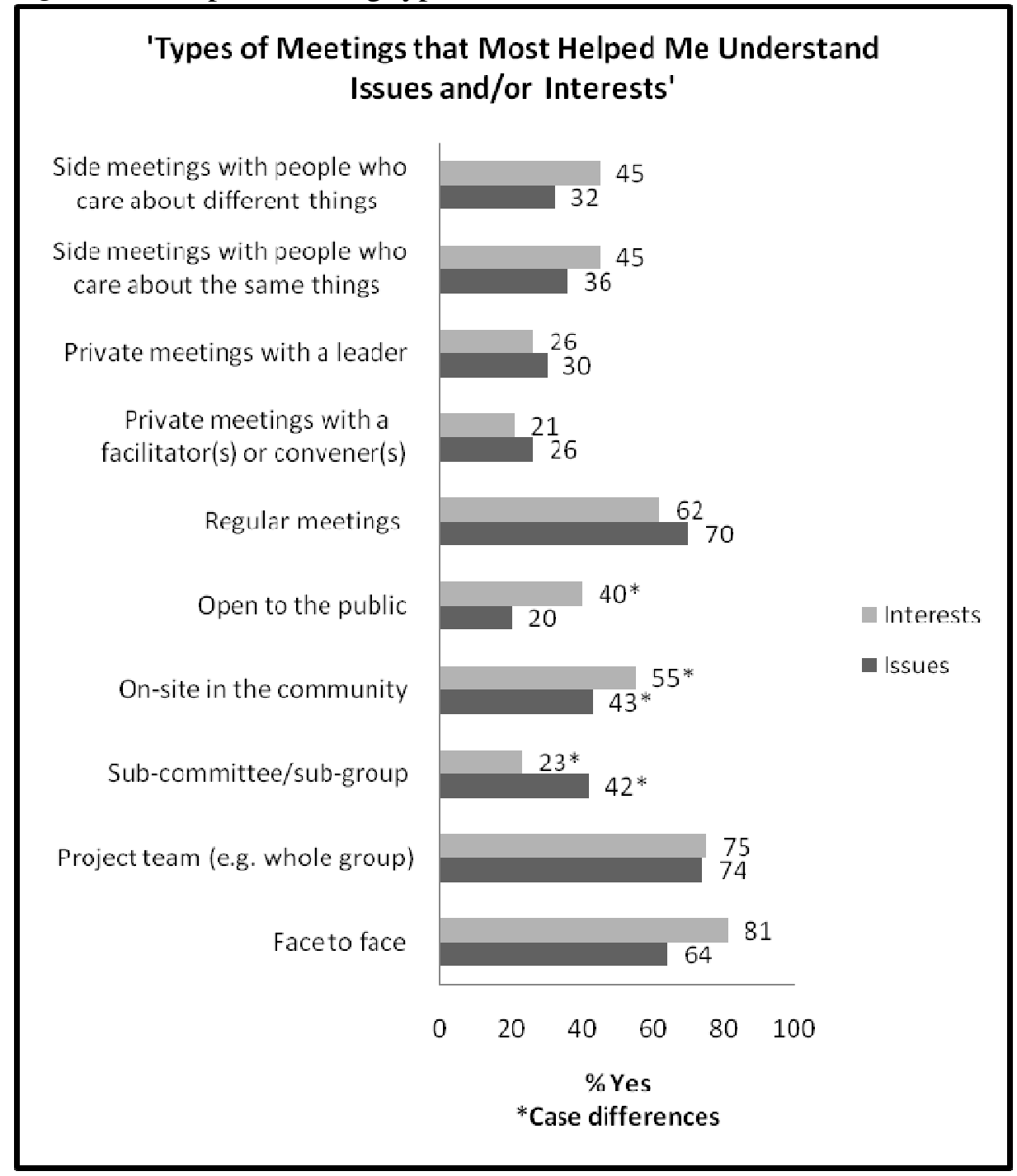

Survey responses for all cases, $n=53$

A higher proportion of respondents in the Tillamook case responded

affirmatively that sub-committees were most important in helping them understand issues (see table 53). These findings reflect Tillamook interview feedback that subcommittees helped participants explore ideas and gain a better understanding of issues because there were fewer individuals competing for discussion time. Participants in both the Lane Clean Diesel and the Reduced Truck Idling project did not work in sub- 
groups and thus did not answer affirmatively. A higher proportion of Tillamook respondents agreed that sub-committee meetings were helpful as compared to the Biomass case, but not to the Lakeview Stewardship Group (see chart 3).

Table 53 Meeting sub-types: case specific results

\begin{tabular}{|lllllll|}
\hline & 1 & 2 & 3 & 4 & 5 & $3-5$ \\
& $\begin{array}{l}\text { Lane } \\
(\mathrm{n}=4)\end{array}$ & $\begin{array}{l}\text { Idling } \\
(\mathrm{n}=7)\end{array}$ & $\begin{array}{l}\text { Biomass } \\
(\mathrm{n}=13)\end{array}$ & $\begin{array}{l}\text { Tillamook } \\
(\mathrm{n}=18)\end{array}$ & $\begin{array}{l}\text { LSG } \\
(\mathrm{n}=11)\end{array}$ & $\begin{array}{l}\text { Mean } \\
\text { Open to the public Issues }\end{array}$ \\
$0 \%$ & $0 \%$ & $15 \%$ & $28 \%$ & $36 \%$ & $26 \%$ \\
Open to the public Interests & 0 & 17 & 23 & 67 & 46 & 45 \\
On-site in the community Issues & 50 & 0 & 46 & 44 & 63 & 51 \\
On-site in the community Interests & 50 & 0 & 69 & 50 & 82 & 67 \\
Sub-committee/sub-group Issues & 0 & 0 & 38 & 78 & 27 & 48 \\
Sub-committee/sub-group Interests & 0 & 0 & 8 & 50 & 18 & -- \\
\hline
\end{tabular}

Percent affirmative, all numbers rounded to nearest whole number

Chi-square results indicate that there were differences in the proportions of responses among the five cases for three meeting sub-categories on interests: public meetings, meeting on-site in the community, and sub-committee meetings. Casespecific numbers are in table 53. The reduced engine idling case did not work in subgroups, thus had no affirmative responses. In Tillamook, 77\% of participants agreed that sub-group meetings were important to understanding issues and 50\% agreed these meetings were important for understanding interests (see appendix F for more detail). All cases met on-site in the community and were open to the public; however, the Tillamook case meetings involved more regular attendance from the public.

\section{Helpful Verbal Communication}

Nearly two-thirds of survey respondents agreed that four types of verbal communication were most helpful in understanding issues (see chart 4). These include discussion during meetings (81\%), discussions between meetings (64\%), talking about an issue after receiving information (64\%), and when someone brought things up such 
as, "I think we have to look at..." (60\%). A moderate number of participants agreed that regular discussions (45\%), statements of barriers (43\%), and requests for people to explain what they care about $(47 \%)$ were helpful for understanding issues. Pearson Chi-square results indicate that there were no statistically significant differences in the proportion of affirmative responses among the five cases, see Appendix F.

Respondents felt many of the same verbal elements were most helpful in understanding interests, with a few additions. Survey participants agreed that discussion during meetings $(81 \%)$, discussions between meetings $(66 \%)$, statements of interests such as "I am concerned about..." (66\%), and explicit requests for people to explain what they care about $(68 \%)$ were most helpful in understanding interests. Nearly all of the other items received moderate agreement (40\%) from respondents. Frequent discussion received the lowest amount of agreement from survey respondents (34\%). See figure 32 for details. 


\section{'The Types of Verbal Communication That Most Helped Me}

Understand Issues and/or Interests'

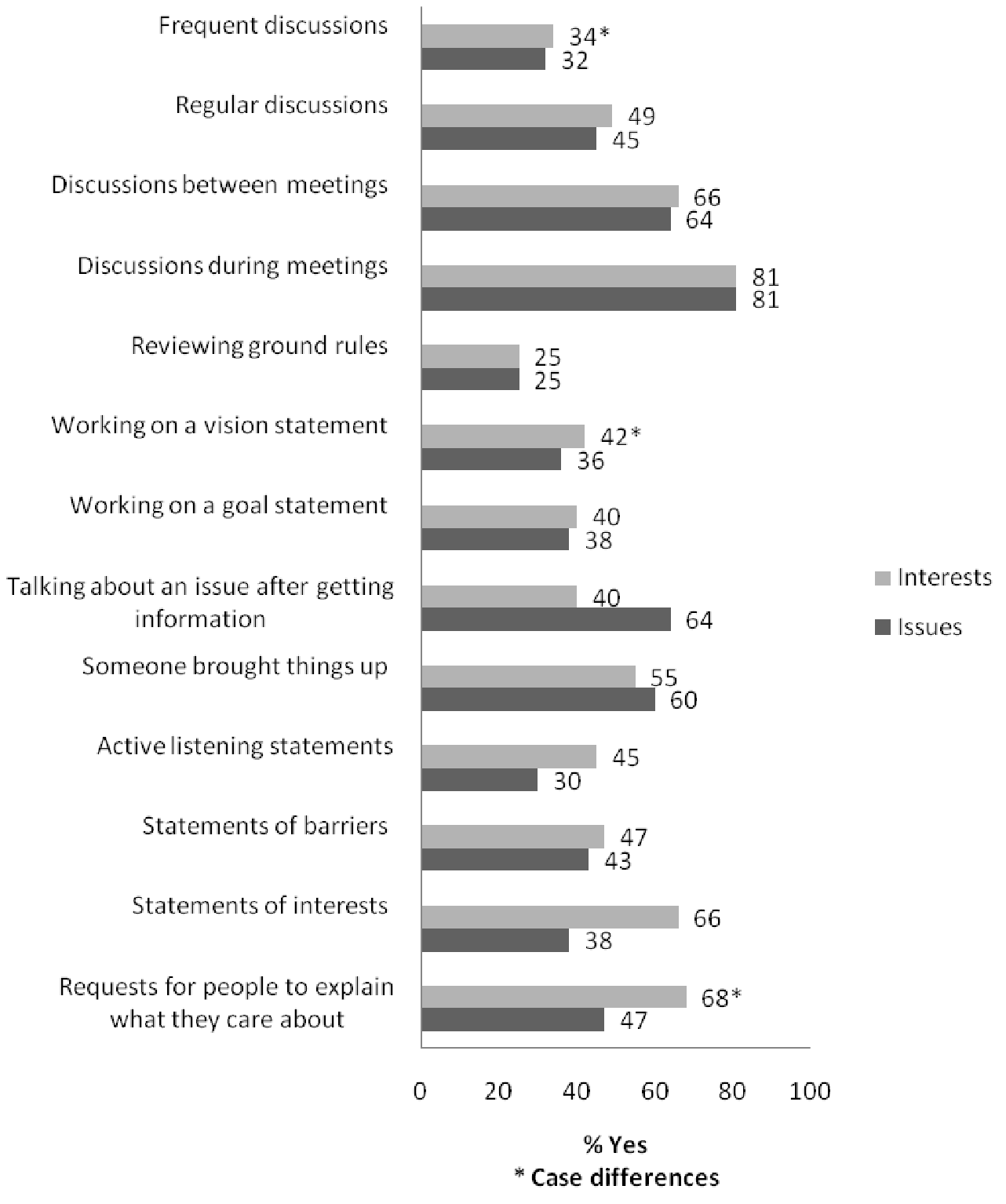

Figure 32. Helpful verbal communication types, survey responses for all cases

Pearson chi-square tests revealed that three items were significantly different among the five cases in relation to understanding interests: frequent discussions $\left(\chi^{2}(4)\right.$ $=10.49, \mathrm{p}=.03)$, working on a vision statement $\left(\chi^{2}(4)=11.54, \mathrm{p}=.02\right)$ and requests 
for people to explain what they care about $\left(\chi^{2}(4)=9.3, p=.05\right)$. A chi-square test showed that there were no differences among the Biomass, Tillamook, and LSG cases on these three items. On these three items, the Lane Clean Diesel and Reduced Engine Idling cases were more similar to one another, and different from the other three cases (see table 54).

Table 54 Verbal communication sub-types: case specific results

\begin{tabular}{|c|c|c|c|c|c|c|}
\hline & $\begin{array}{l}1 \\
\text { Lane } \\
(n=4)\end{array}$ & $\begin{array}{l}2 \\
\text { Idling } \\
(n=7)\end{array}$ & $\begin{array}{l}3 \\
\text { Biomass } \\
(n=13)\end{array}$ & $\begin{array}{l}4 \\
\text { Tillamook } \\
(n=18)\end{array}$ & $\begin{array}{l}5 \\
\mathrm{LSG} \\
(\mathrm{n}=11)\end{array}$ & $\begin{array}{l}4,5 \\
\text { Mean }\end{array}$ \\
\hline Frequent discussions Issues & $0 \%$ & $14 \%$ & $15 \%$ & $44 \%$ & $55 \%$ & $50 \%$ \\
\hline Frequent discussions Interests & 0 & 0 & 23 & 50 & 55 & 53 \\
\hline $\begin{array}{l}\text { Working on a vision statement } \\
\text { Issues }\end{array}$ & 0 & 57 & 23 & 39 & 45 & 42 \\
\hline $\begin{array}{l}\text { Working on a vision statement } \\
\text { Interests }\end{array}$ & 0 & 0 & 38 & 56 & 64 & 60 \\
\hline $\begin{array}{l}\text { Requests for people to explain what } \\
\text { they care about Issues }\end{array}$ & 50 & 43 & 31 & 56 & 55 & 56 \\
\hline $\begin{array}{l}\text { Requests for people to explain what } \\
\text { they care about Interests }\end{array}$ & 50 & 29 & 69 & 89 & 64 & $74 *$ \\
\hline
\end{tabular}

Percent affirmative, all numbers rounded to nearest whole number

*This mean represents cases 3-5

These findings confirm and clarify interview findings. Participants emphasized that prompting questions, clarifying questions, active listening, and talking with other participants most helped them understand issues and interests. Here we see that discussing issues during and between meetings helped participants better understand both the content of issues, and participant interests in that substance. Further, project staff or participant's ability to ask for an explanation of interests helped participants understand each other's perspectives. Prompting questions and "someone bringing things up such as 'I think we need to look at x'”, act as reminders to participants, and as encouraging nudges to share what matters to them. 


\section{Helpfulness of Visual Communication}

Nearly two thirds of survey respondents agreed that photos and/or pictures (62\%), maps (66\%), and computer modeling results (62\%) were helpful in understanding issues (see figure 33 and table 55). Survey respondents agreed only moderately that diagrams (47\%) helped understand issues. Survey respondents only moderately felt that seeing photos and or pictures (45\%), maps (42\%), or computer modeling results (30\%) helped understand interests.

Figure 33. Helpful visual communication

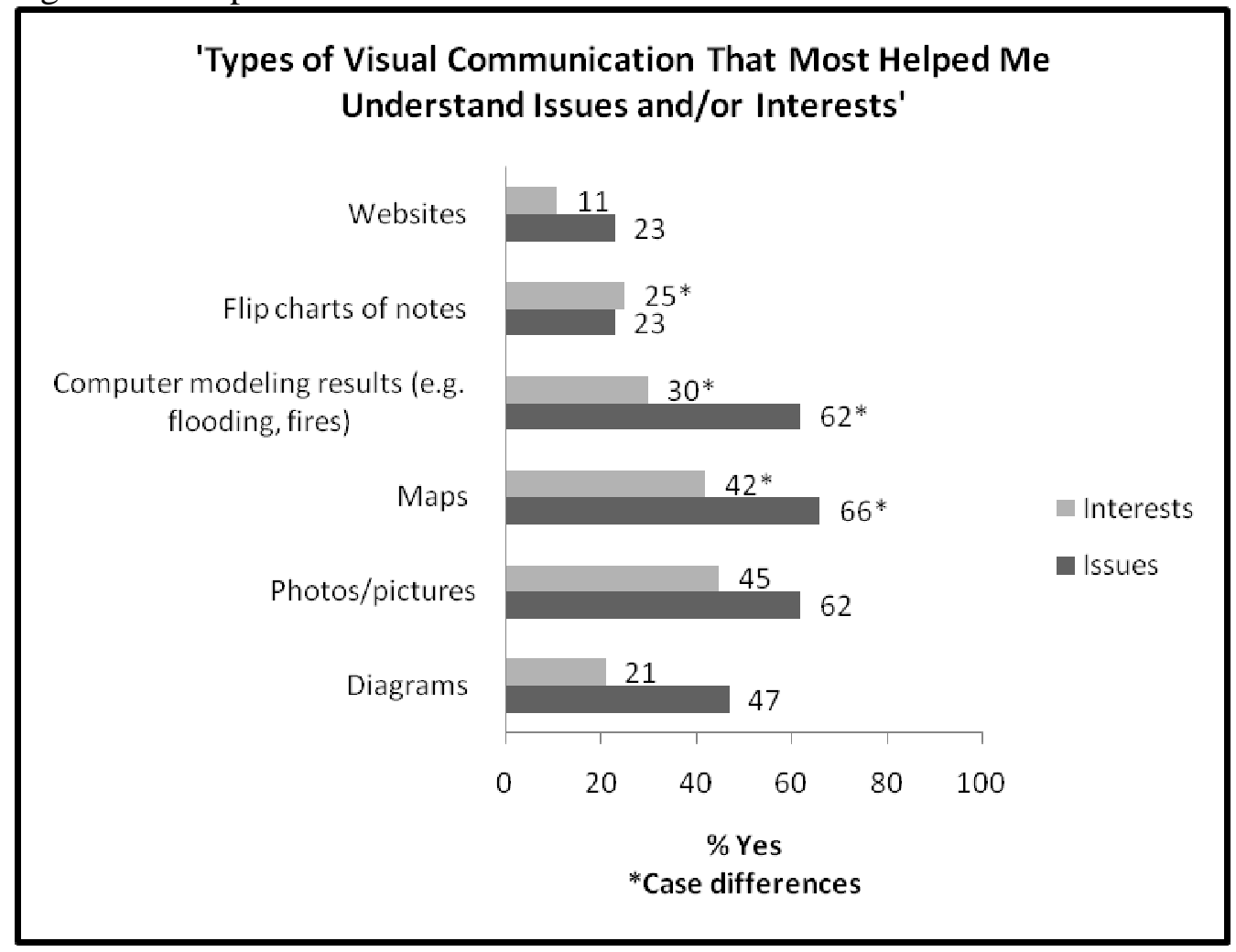

Survey results from all cases $(\mathrm{N}=53)$

Pearson chi-square tests show that five cases were statistically different on two visual communication elements in relation to understanding issues: maps $\chi^{2}(4)=$ $11.64, p=.02$ and computer modeling results $\chi^{2}(4)=15.20, p=.004$. The cases were 
also different on three elements related to understanding interests: maps $\left(\chi^{2}(4)=9.72\right.$, $\mathrm{p}=.05)$, computer modeling results $\left(\chi^{2}(4)=9.97, \mathrm{p}=.04\right)$, and flip charts of notes $\left(\chi^{2}\right.$ $(4)=10.53, p=.03$ ) (see Appendix F for Chi-square test details). Based on these differences, the individual affirmative responses for each case are presented in table 55.

The survey clarifies that visual communication types relate to the nature of the problem being studied. Interview respondents from the Tillamook, Biomass, and LSG cases emphasized the use of computer modeling results, maps, and pictures in helping them better understand issues. The survey responses confirmed that the Lakeview Stewardship Group relied heavily on multiple visual types of information: photos helped with both issues (65\%) and interests (55\%), maps helped with both issues (91\%) and interests (64\%), and computer modeling results moderately helped with issues 55\%. The Biomass participants better understood issues from reviewing photos (54\%), maps (62\%), and computer modeling results (69\%). The survey results indicate that Tillamook was similar to LSG in participant's reliance on photos to help understand issues (78\%) and interests (61\%). Tillamook respondent understanding was also aided by maps and computer modeling results (see table 55). The Biomass, Tillamook, and LSG projects involved physical management of resources including forested land and rivers. These manipulations had the potential to impact issues of interests such as flooding or wildfires. 
Table 55 Visual communication sub-types: case-specific responses

\begin{tabular}{|lccccccc|}
\hline Case & $\begin{array}{c}\text { Photos } \\
\text { Issues }\end{array}$ & $\begin{array}{c}\text { Photos } \\
\text { Interests }\end{array}$ & $\begin{array}{c}\text { Maps } \\
\text { Issues }\end{array}$ & $\begin{array}{c}\text { Maps } \\
\text { Interests }\end{array}$ & $\begin{array}{c}\text { Computer } \\
\text { Modeling } \\
\text { Issues }\end{array}$ & $\begin{array}{c}\text { Computer } \\
\text { Modeling } \\
\text { Interests }\end{array}$ & $\begin{array}{c}\text { Flip } \\
\text { charts } \\
\text { Interests }\end{array}$ \\
\hline Lane $(\mathrm{n}=4)$ & $25 \%$ & $0 \%$ & $25 \%$ & $25 \%$ & $25 \%$ & $25 \%$ & $0 \%$ \\
Engine (n=7) & 57 & 14 & 29 & 0 & 14 & 0 & 14 \\
Bio $(\mathrm{n}=13)$ & 54 & 46 & 62 & 31 & 69 & 15 & 0 \\
Tillamk (n=18) & 78 & 61 & 78 & 56 & 89 & 56 & 39 \\
LSG (n=11) & 64 & 55 & 91 & 64 & 55 & 27 & 45 \\
Mean*: & 65 & 54 & 77 & 50 & 71 & 33 & 42 \\
\hline
\end{tabular}

Percent affirmative, all numbers rounded to nearest whole number

*Means are for cases Bio, Tillamook and LSG or Tillamook and LSG on Flip charts

Pearson chi-square results indicate the proportion of affirmative responses for the Biomass, Tillamook, and LSG cases were not significantly different for maps helping participants understand issues $\left(\chi^{2}(2)=2.88, \mathrm{p}=.23\right)$ or interests $\left(\chi^{2}(2)=\right.$ 2.96, $\mathrm{p}=.22$ ), and computer modeling results helping participants understand issues $\left(\chi^{2}(2)=4.37, \mathrm{p}=.11\right)$ or interests $\left(\chi^{2}(2)=5.77, \mathrm{p}=.06\right)$. Lane Clean Diesel and Biomass respondents did not say flip charts helped them understand interests, and the other three cases were not significantly different in their responses $\left(\chi^{2}(2)=1.92, p=\right.$ $.39)$.

\section{Helpfulness of Shared Experiences}

Survey respondents were asked what types of shared experiences helped them understand issues and interests. More than two thirds of survey respondents agreed that group reviewing information together helped them understand issues (75\%) and interests (74\%) and that making decisions as a group helped participants understand issues (72\%) and interests (68\%) (see table 56). The groups moderately agreed that writing documents together was helpful in understanding issues (51\%) and interests 
(40\%). These findings reflect that shared experiences help participants learn about issues and interests simultaneously.

Shared learning is important in light of other elements discussed in this section. Discussions during meetings are aided by clarifying requests, especially when looking over visual information or after hearing a presentation of technical facts. Making decisions as a group fostered discussions about what was important to different participants. This was reflected in interviews when participants from each case described considering options based on different information sources prior to developing agreements. Group discussions after reviewing information also gave participants an opportunity to express concerns or barriers, and ask others for clarification.

These findings are also useful when considering relationship and process interests. Differences among the cases were reflected in chi-square results on three sub-types: field trips impact on issues $\left(\chi^{2}(4)=20.54, p=.000\right)$, on interests $\left(\chi^{2}(4)=\right.$ $17.83, \mathrm{p}=.001)$; eating meals together impact on issues $\left(\chi^{2}(4)=10.93, \mathrm{p}=.03\right)$ and interests $\left(\chi^{2}(4)=9.59, p=.05\right)$; airplane flights impact on issues $\left(\chi^{2}(4)=12.14, p=\right.$ $.02)$ and casual meetings on a bus or van ride impact on interests $\left(\chi^{2}(4)=14.6, p=\right.$ .01) (see Appendix F for details). 
Figure 34. Helpful shared experiences

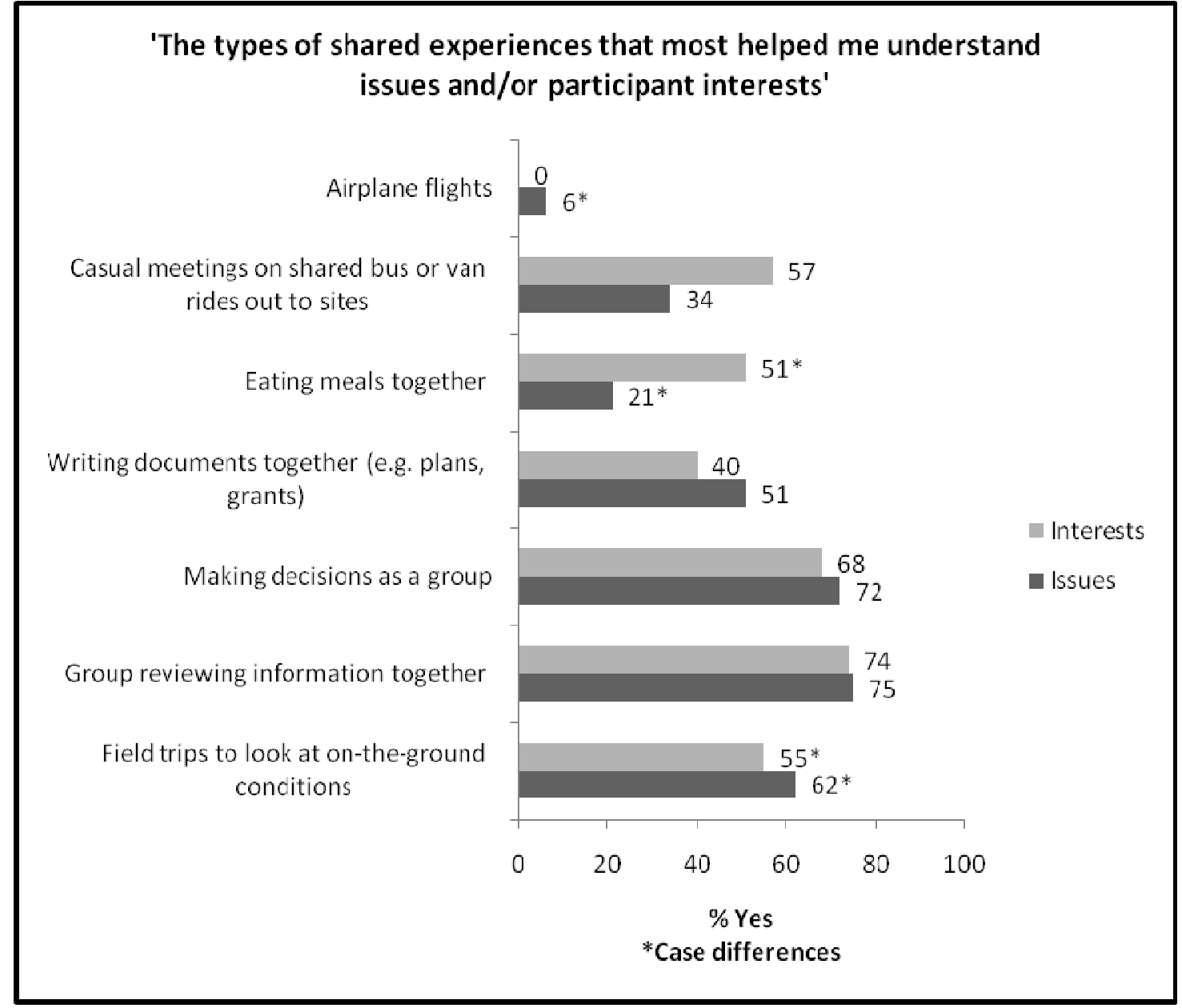

Staff and participants combined, all cases $(\mathrm{N}=53)$

The Biomass, Tillamook, and LSG projects had higher levels of potential fragmentation, and dealt with more disruptive elements, than the Lane Clean Diesel and Reduced Idling projects. A past history of conflict, and mistrust among stakeholders required that participants learn about one another beyond business meetings. Eating meals together and going on field trips helped participants in the Biomass and LSG projects gain a sense of each other's perspectives. While participants in Tillamook did not eat meals together as frequently as individuals in the 
LSG case, survey respondents indicated that field trips helped them understand both issues and interests (see table 56). Survey respondents from the Biomass (69\%), Tillamook (67\%), and LSG (100\%) cases agreed that field trips to look at on-theground conditions were important for understanding issues. Field trips were also important to these same participants for understanding interests: Biomass (77\%), Tillamook (83\%), and LSG (82\%) (see figure 34). Chi-square analysis indicate that these three cases' responses are not significantly different in regard to field trips on either issues $\left(\chi^{2}(2)=4.69, \mathrm{p}=.09\right)$ or interests $\left(\chi^{2}(2)=1.23, \mathrm{p}=.54\right)$ (see Appendix F). Table 56 Shared experience sub-types: case specific results

\begin{tabular}{|c|c|c|c|c|c|c|}
\hline & $\begin{array}{l}1 \\
\text { Lane } \\
(n=4)\end{array}$ & $\begin{array}{l}2 \\
\text { Idling } \\
(\mathrm{n}=7)\end{array}$ & $\begin{array}{l}3 \\
\text { Biomass } \\
(\mathrm{n}=13)\end{array}$ & $\begin{array}{l}4 \\
\text { Tillamook } \\
(\mathrm{n}=18)\end{array}$ & $\begin{array}{l}5 \\
\mathrm{LSG} \\
(\mathrm{n}=11)\end{array}$ & $\begin{array}{l}3-5 \\
\text { Mean }\end{array}$ \\
\hline $\begin{array}{l}\text { Field trips to look at on the } \\
\text { ground conditions } \\
\text { Issues }\end{array}$ & $0 \%$ & $14 \%$ & $69 \%$ & $67 \%$ & $100 \%$ & $79 \%$ \\
\hline $\begin{array}{l}\text { Field trips to look at on the } \\
\text { ground conditions } \\
\text { Interests }\end{array}$ & 50 & 43 & 77 & 83 & 82 & 81 \\
\hline Eating meals together Issues & 0 & 0 & 15 & 17 & 55 & - \\
\hline Eating meals together Interests & 50 & 14 & 62 & 39 & 82 & 61 \\
\hline $\begin{array}{l}\text { Casual meetings on shared } \\
\text { bus/van rides out to sites } \\
\text { Interests }\end{array}$ & 50 & 0 & 69 & 61 & 82 & 71 \\
\hline Airplane flights Issues & 0 & 0 & 0 & 0 & 27 & - \\
\hline
\end{tabular}

Percent affirmative, all numbers rounded to nearest whole number

The LSG project was the only one to use airplane flights, and a small number of leaders from the Lakeview community and the environmental advocates experienced this privilege. This was included because interviewed participants indicated it was a major turning point in their perspective about forest health. Survey responses indicate the relatively small number of individuals (27\%) who felt this was important for understanding the issues. 


\subsubsection{Research Question Three: Role of Interests}

Survey participants were asked how important they felt understanding other participants' interests were to making decisions within the collaborative process. Survey participants in four of the five cases felt understanding each others' interests was important $(\mathrm{M}=2.0, \mathrm{SD}=.69)$ on all items. The five sub-elements with the highest means and the higher percentage of participants responding "very important" include: understanding other participants' barriers $(\mathrm{M}=2.45, \mathrm{SD}=.78)$, understanding options on the table $(\mathrm{M}=2.54, \mathrm{SD}=.51)$, finding things all could agree on $(\mathrm{M}=2.51, \mathrm{SD}=.70)$, picking a direction to go with the solution $(\mathrm{M}=51.4, \mathrm{SD}=.70)$, and staying involved for the duration of the project $(\mathrm{M}=2.43, \mathrm{SD}=.74)$. These items are indicated in bold in table 57.

Kruskall-Wallis test results indicate that the four cases had significantly different response proportions on three sub-items. These were: knowing what each/I could agree on $\left(\chi^{2}(3)=8.49, p<.05\right)$, finding things all could agree on $\left(\chi^{2}(3)=7.74\right.$, $\mathrm{p}=.05)$, and keeping the process going $\left(\chi^{2}(3)=11.18, \mathrm{p}<.02\right)$.

Interview and document data indicated that participant discussion of interests helped participants understand each other's perspective on the issues, develop options, choose options, develop an agreement, and understand other participant's barriers. These findings were strongly confirmed by the survey responses on four of the five cases. In table 57 note that no more than three individuals indicated that understanding each other's interests was not very important to determining what information was needed to understand issues, understanding issues, understanding options, and for 
keeping the process going. As predicted by negotiation theory, participants'

understanding of each other's interests is crucial for problem solving, generating options, and formulating agreements.

The Tillamook survey respondents gave significantly different responses from the other four cases on all but two sub-items based on Kruskal-wallis tests (see Appendix F). The Tillamook survey respondents did not feel that understanding each other's interests were important for any of the sub-items. The sub-items with the highest means are the similar to those emphasized in the other cases. These include understanding other participants' barriers $(\mathrm{M}=1.72, \mathrm{SD}=.67)$, finding things all could agree on $(\mathrm{M}=1.67, \mathrm{SD}=.69)$, and picking a direction to go with the solution $(\mathrm{M}=1.67$, $\mathrm{SD}=.69)$. These are emphasized in bold in table 57.

Table 57 Importance of participants' understanding each others' interests

\begin{tabular}{|c|c|c|c|c|}
\hline & $\begin{array}{l}\text { Not Very } \\
\text { Important } \\
(1)\end{array}$ & $\begin{array}{c}\text { Important* } \\
\text { (2) }\end{array}$ & $\begin{array}{c}\text { Very } \\
\text { Important } \\
(3)\end{array}$ & $\begin{array}{l}\text { Mean } \\
(\mathrm{SD})\end{array}$ \\
\hline Deciding to collaborate & 31.4 & 34.3 & 34.3 & $2.03(.82)$ \\
\hline Clarifying individual (my) interests & 22.9 & 54.3 & 22.9 & $2.00(.69)$ \\
\hline $\begin{array}{l}\text { Determining what information was needed to } \\
\text { understand issues }\end{array}$ & 5.7 & 51.4 & 42.9 & $2.37(.60)$ \\
\hline Understanding issues on the table & 2.9 & 51.4 & 45.7 & $2.43(.56)$ \\
\hline $\begin{array}{l}\text { Understanding other participants' (each } \\
\text { others') barriers }\end{array}$ & 17.1 & 20.0 & 62.9 & $2.46(.78)$ \\
\hline Understanding individual (my) barriers & 20.6 & 44.1 & 35.3 & $2.15(.74)$ \\
\hline Understanding options on the table & 0 & 45.7 & 54.3 & $2.54(.51)$ \\
\hline Knowing what each $(I)$ could agree to & 17.1 & 45.7 & 37.1 & $2.20(.72)$ \\
\hline Finding things all could agree on & 11.4 & 25.7 & 62.9 & $2.51(.70)$ \\
\hline Picking a direction to go with the solution & 11.4 & 37.1 & 51.4 & $2.40(.70)$ \\
\hline $\begin{array}{l}\text { Committing resources (e.g. time, funding) to } \\
\text { the project }\end{array}$ & 11.4 & 48.6 & 40.0 & $2.29(.67)$ \\
\hline Keeping the process going & 8.6 & 57.1 & 34.3 & $2.26(.61)$ \\
\hline $\begin{array}{l}\text { Staying involved for the duration of the } \\
\text { project }\end{array}$ & 14.3 & 28.6 & 57.1 & $2.43(.74)$ \\
\hline
\end{tabular}


The survey responses in the Tillamook case reflect, and confirm, the complex nature of participants' motivations in that project. Interview and document data indicated that while everyone agreed that reducing the negative impacts of flooding and protecting environmental habitat was important, the group disagreed on how to best accomplish this. Stakeholder groups also did not trust each other, and despite facilitation techniques and leadership's attempts to address stakeholder interests, addressing each other's interests was not what motivated participants. Since the group did not share the same perspectives, and some individuals discounted the viewpoints of others, participants focused on their own interests as a basis for decision making. Table 58 Tillamook: Importance of participants' understanding each others' interests

\begin{tabular}{|c|c|c|c|c|}
\hline & $\begin{array}{c}\text { Not Very } \\
\text { Important } \\
\text { (1) }\end{array}$ & $\begin{array}{c}\text { Important* } \\
\text { (2) }\end{array}$ & $\begin{array}{c}\text { Very } \\
\text { Important } \\
\text { (3) }\end{array}$ & $\begin{array}{c}\text { Mean } \\
(\mathrm{SD})\end{array}$ \\
\hline Deciding to collaborate & $61.1 \%$ & $33.3 \%$ & $5.6 \%$ & $1.44(.62)$ \\
\hline Clarifying individual $(m y)$ interests & 72.2 & 22.2 & 5.6 & $1.33(.59)$ \\
\hline $\begin{array}{l}\text { Determining what information was needed to } \\
\text { understand issues }\end{array}$ & 61.1 & 33.3 & 5.6 & $1.44(.62)$ \\
\hline Understanding issues on the table & 44.4 & 50.0 & 5.6 & $1.61(.61)$ \\
\hline $\begin{array}{l}\text { Understanding other participants' (each } \\
\text { others') barriers }\end{array}$ & 38.9 & 50.0 & 11.1 & $1.72(.67)$ \\
\hline Understanding individual (my) barriers & 72.2 & 22.2 & 5.6 & $1.33(.59)$ \\
\hline Understanding options on the table & 44.4 & 50.0 & 5.6 & $1.61(.61)$ \\
\hline Knowing what each $(I)$ could agree to & 61.1 & 33.3 & 5.6 & $1.44(.62)$ \\
\hline Finding things all could agree on & 44.4 & 44.4 & 11.1 & $1.67(.69)$ \\
\hline Picking a direction to go with the solution & 44.4 & 44.4 & 11.1 & $1.67(.69)$ \\
\hline $\begin{array}{l}\text { Committing resources (e.g. time, funding) } \\
\text { to the project }\end{array}$ & 61.1 & 33.3 & 5.6 & $1.44(.62)$ \\
\hline Keeping the process going & 55.6 & 33.3 & 11.1 & $1.56(.71)$ \\
\hline $\begin{array}{l}\text { Staying involved for the duration of the } \\
\text { project }\end{array}$ & 50.0 & 38.9 & 11.1 & $1.61(.71)$ \\
\hline
\end{tabular}

$\mathrm{N}=18$, Italicized words indicate the Participant survey wording

* "Important" does not appear to be viewed as a neutral response based on 3 options.

In interviews, agency participants were motivated to help the project be a success based on a desire to uphold mandates, letters from the governor to their supervisors, and to improve conditions in Tillamook. In interviews, the Design 
Committee members indicated that agency and community representatives came to understand and respect one another's perspectives, although this did not extend to different constituencies. A few community participants linked flood reduction to government ownership of land and land use. The few community participants who held strong convictions about private ownership of land acted on those values.

\subsubsection{Research Question Four: How Were Interests Addressed?}

The last questions on the survey asked participants if the collaborative process helped them better understand interests and find common ground. Survey respondents, not including project staff, moderately agreed that each collaborative process helped them better understand their interests $(\mathrm{M}=1.95, \mathrm{SD}=.81)$. Participants strongly agreed that the process helped them better understand other participants' interests $(M=2.34$, $\mathrm{SD}=.57$ ) (see table59). These findings confirm interview findings that participants were satisfied with the outcomes of each project.

Table 59 Participants' perspective on understanding interests

\begin{tabular}{|lccccc|}
\hline & $\begin{array}{c}\text { Strongly } \\
\text { Disagree } \\
(0)\end{array}$ & $\begin{array}{c}\text { Disagree } \\
(1)\end{array}$ & $\begin{array}{c}\text { Agree } \\
(2)\end{array}$ & $\begin{array}{c}\text { Strongly } \\
\text { Agree } \\
(3)\end{array}$ & $\begin{array}{c}\text { Mean } \\
\text { (SD) }\end{array}$ \\
\hline $\begin{array}{l}\text { The collaborative process in this } \\
\text { project helped me better understand } \\
\text { my interests. }\end{array}$ & $4.5 \%$ & $20.5 \%$ & $50 \%$ & $25 \%$ & 1.95 \\
$\begin{array}{l}\text { The collaborative process in this } \\
\text { project helped me better understand } \\
\text { other participants' interests. }\end{array}$ & 0 & 4.5 & 56.8 & 38.6 & 2.34 \\
(N=44) & & & & & $(.57)$ \\
\hline
\end{tabular}

Project staff were asked slightly different questions based on their unique role. Staff in these projects generally agreed that each process helped them understand participant interests $(\mathrm{M}=2.67, \mathrm{SD}=.50)$, helped participants better understand their 
own interests $(\mathrm{M}=2.33, \mathrm{SD}=.50)$, and helped participants better understand each other's interests $(\mathrm{M}=2.44, \mathrm{SD}=.53)$ (see table 60$)$.

Table 60 Staff perspective on participant interests

\begin{tabular}{|lccccc|}
\hline & $\begin{array}{c}\text { Strongly } \\
\text { Disagree } \\
(0)\end{array}$ & $\begin{array}{c}\text { Disagree } \\
\text { (1) }\end{array}$ & $\begin{array}{c}\text { Agree } \\
(2)\end{array}$ & $\begin{array}{c}\text { Strongly } \\
\text { Agree } \\
(3)\end{array}$ & $\begin{array}{c}\text { Mean } \\
\text { (SD) }\end{array}$ \\
\hline $\begin{array}{l}\text { The collaborative process in this } \\
\text { project helped me better understand } \\
\text { participants' interests. }\end{array}$ & 0 & 0 & $33.3 \%$ & $66.7 \%$ & 2.67 \\
$\begin{array}{l}\text { The collaborative process helped } \\
\text { participants better understand their } \\
\text { individual interests. }\end{array}$ & 0 & 0 & 66.7 & 33.3 & 2.33 \\
$\begin{array}{l}\text { The collaborative process helped } \\
\text { participants better understand each } \\
\text { other's interests. }\end{array}$ & 0 & & & & \\
\end{tabular}
$(\mathrm{N}=9)$

Both participant and staff respondents generally agreed that their project found common ground, or shared interests $(\mathrm{M}=2.19, \mathrm{SD}=.65)$. These findings were consistent across all five cases and indicate the general success of each project in addressing participant interests, see table 61. Again, the survey findings confirm that other participants, beyond the interviewees, were generally satisfied with each process. Table 61 Projects developed common ground and addressed interests

\begin{tabular}{|c|c|c|c|c|c|}
\hline & $\begin{array}{c}\text { Strongly } \\
\text { Disagree } \\
(0)\end{array}$ & $\begin{array}{c}\text { Disagree } \\
\text { (1) }\end{array}$ & $\begin{array}{c}\text { Agree } \\
(2)\end{array}$ & $\begin{array}{c}\text { Strongly } \\
\text { Agree } \\
\text { (3) }\end{array}$ & $\begin{array}{l}\text { Mean } \\
(\mathrm{SD})\end{array}$ \\
\hline $\begin{array}{l}\text { Participants: My most important interests have } \\
\text { been addressed so far in this project }(\mathrm{N}=44)\end{array}$ & $0 \%$ & $6.8 \%$ & $68.2 \%$ & $25 \%$ & $\begin{array}{l}2.18 \\
(.54)\end{array}$ \\
\hline $\begin{array}{l}\text { Staff: Participants' most important interests } \\
\text { have been addressed so far in this project }(\mathrm{N}=9)\end{array}$ & 0 & 0 & 66.7 & 33.3 & $\begin{array}{l}2.33 \\
(.50)\end{array}$ \\
\hline $\begin{array}{l}\text { All: We found common ground in this project } \\
(\mathrm{N}=53)\end{array}$ & 1.8 & 7.5 & 60.4 & 30.2 & $\begin{array}{l}2.19 \\
(.65)\end{array}$ \\
\hline
\end{tabular}




\subsubsection{Influence of Project Role and Interview Experience}

\section{Project Role Influence}

It is possible that project staff member's unique role, and the experience of being interviewed, influenced survey responses. Staff members were more likely to agree that meetings with conveners were important for understanding interests $\left(\chi^{2}(1)\right.$ $=4.90, \mathrm{p}<.03)$. This finding may reflect staff members' increase in understanding of participant interests as a result of meeting one-on-one with individuals.

A greater proportion of staff agreed that statements of barriers were important for understanding issues $\left(\chi^{2}(1)=3.83, \mathrm{p}=.05\right)$. A greater proportion of staff agreed that writing documents together helped people understand issues $\left(\chi^{2}(1)=5.04, p=\right.$ .02). A greater proportion of respondents agreed that causal meetings were helpful in understanding interests $\left(\chi^{2}(1)=3.83, \mathrm{p}=.04\right)$. These findings indicate that staff gain greater understanding, or perceive individuals benefitting from these experiences, more than participants.

Pearson chi-square results indicate that the proportion of responses on the Likert (3 point scale) sub-items about understanding other participants' interests were significantly different between staff and participants on four items: 'deciding if I want to collaborate' $\left(\chi^{2}(2)=7.67, p=.02\right)$, 'understanding other participants' barriers' $\left(\chi^{2}\right.$ $(2)=7.11, p=.03)$, 'knowing what each could agree to' $\left(\chi^{2}(2)=7.70, p=.02\right)$, and 'staying involved for the duration of the project' $\left(\chi^{2}(2)=8.42, p=.03\right)$. A higher proportion of staff responded that each of these items was "important" or "very important" than participants. These findings emphasize that staff members were more 
likely to view participants' understanding of each other's interests as a motivating factor on more elements than participants. This may reflect staff's awareness of the importance of interests, training, or experience.

\section{Interview Effect}

Pearson chi-square results indicate there were no significant differences on dichotomous or Likert question responses between those who were interviewed and those who were not (see Appendix $\mathrm{F}$ for details). This indicates that interviewed participants were not biased in their responses based on prior exposure to the concepts of interests and to the researcher.

\subsection{Cross- Case Analyses}

This section summarizes themes common across all five cases for each research question based on qualitative and quantitative data. Findings are relevant to all cases unless otherwise specified. Unique case features are also examined based on both types of data and relevant theory.

\subsubsection{Research Question One: Identifying Interests}

Six interests-based themes were common to all five cases based on qualitative and quantitative data (see table 62). Participants brought up interests, or shared information, based on facilitation techniques. Participants identified interests in connection to the substance of the problem, the process, and to relationships. Process interests include how the group will accomplish its objectives, while relationship interests are associated with how individuals prefer to be treated. As predicted from Lax and Sebenius (1986) and other conflict resolution theorists described in Chapter 
Two, participant interests were intertwined with issues and positions in these multiparty collaborative processes. This is important because thinking about interests and positions is related to conflict, and conflict is not emphasized in most collaborative frameworks other than literature on consensus building. Relationship and process interests related to a history of conflict or mistrust among stakeholder groups in four of the five cases, this will be discussed later.

Table 62 Summary: Interest themes from all cases

\begin{tabular}{|lccccc|}
\hline & $\begin{array}{l}\text { Lane } \\
\text { Clean } \\
\text { Diesel }\end{array}$ & $\begin{array}{l}\text { Reduced } \\
\text { Engine } \\
\text { Idling }\end{array}$ & $\begin{array}{l}\text { Biomass } \\
\text { Facility }\end{array}$ & $\begin{array}{l}\text { Tillamook } \\
\text { Flooding } \\
\text { Reduction }\end{array}$ & $\begin{array}{l}\text { Lakeview } \\
\text { Stewardship } \\
\text { Group }\end{array}$ \\
\hline Substantive: tangible \& intangible & $\mathrm{X}$ & $\mathrm{X}$ & $\mathrm{X}$ & $\mathrm{X}$ & $\mathrm{X}$ \\
Process: tangible & $\mathrm{X}$ & $\mathrm{X}$ & $\mathrm{X}$ & $\mathrm{X}$ & $\mathrm{X}$ \\
Relationships \& process: intangible* & $\mathrm{X}$ & $\mathrm{X}$ & $\mathrm{X}$ & $\mathrm{X}$ & $\mathrm{X}$ \\
Shared interest & $\mathrm{X}$ & $\mathrm{X}$ & $\mathrm{X}$ & $\mathrm{X}$ \\
Relationship \& process interests & & & & & $\mathrm{X}$ \\
$\quad$ emphasized w/substantive interests & & & & & $\mathrm{X}$ \\
Interests re-visited at each stage & & & & $\mathrm{X}$ & $\mathrm{X}$ \\
\hline Theory-related Themes & & $\mathrm{X}$ & $\mathrm{X}$ & $\mathrm{X}$ & $\mathrm{X}$ \\
\hline Interests discussed in relation to & $\mathrm{X}$ & $\mathrm{X}$ & $\mathrm{X}$ \\
$\quad$ central problem and sub-issues & & $\mathrm{X}$ & $\mathrm{X}$ & $\mathrm{X}$ & $\mathrm{X}$ \\
Interests linked to issue \& positions & $\mathrm{X}$ & & $\mathrm{X}$ & $\mathrm{X}$ & $\mathrm{X}$ \\
Interests linked to values & & $\mathrm{X}$ & $\mathrm{X}$ & $\mathrm{X}$ & $\mathrm{X}$ \\
Integrative behavior & & & $\mathrm{X}$ & $\mathrm{X}$ & $\mathrm{X}$ \\
Distributive behavior & & $\mathrm{X}$ & $\mathrm{X}$ & $\mathrm{X}$ & $\mathrm{X}$ \\
Mistrust & & & $\mathrm{X}$ & $\mathrm{X}$ & $\mathrm{X}$ \\
Disruptions and /or conflict & & & & \\
\hline
\end{tabular}

*These elements may not have been explicit during the process

Participants in all five cases identified interests at some stage of the collaborative process. Staff did not explicitly track interests, although all staff agreed interests are important and worked to address them implicitly. This is an important finding because it shows that it is possible for collaborative groups to address participant interests primarily through the role of group leaders. It is also important to consider what more could be gained had this been explicit. From interviews, the participants in the Lane Clean Diesel, Reduced Engine Idling, and LSG projects 
worked as a collective to address stakeholder group's substantive interests. The project staff was more crucial for addressing stakeholder interests in the Biomass and Tillamook projects. In projects with higher potential fragmentation, it would be easier to address interests if this were an explicit feature in the process design. Participants in all cases confused issues, interests, and positions. If this clarification were an explicit part of collaborative processes all participants could work to understand and address one another's interests.

In the Biomass, Tillamook Flooding Reduction, and Lakeview Stewardship Group cases, participant positions were notably intertwined with values. This was partially supported by survey data where respondents indicated understanding other participants' interests did not influence any of the decisions they made in this project (see section 5.1.3). The survey findings indicate that the project staff and participant leaders were responsible for ensuring that project outputs addressed stakeholder interests. It is apparent that not all participants worked to address each others' concerns in the Tillamook case. In relation to the other cases, this project indicates collaborative process managers would benefit from helping participants to clarify their interests and values on discrete issues.

\section{Participant Assessment of Interests}

It is unclear how thoroughly participants examined interests prior to each collaborative process. Most interviewed participants assessed their concerns at some stage in each project. This is evident from explicit statements of participant concerns in both the documents and interviews, descriptions of positions shifting, and details of 
issues being deconstructed and reconstructed. While project staff brought up the concept of interests, the groups did not discuss the differences between interests and positions as would happen in conflict resolution through the use of a conflict assessment.

Statements related to trust and respect were explicit in these projects. These included statements such as "flexing trust muscles" in the Biomass project; "leave your guns at the door" in the LSG; or respectful comments such as "let's not make any one industry carry more of the burden" in the Engine Idling project; and "this project would not be possible without everyone's efforts" in Tillamook. Trust and respect were related to participants' willingness to discuss interests in the Biomass, Tillamook, and LSG cases.

Table 63 Integrative statement examples from the five cases

\begin{tabular}{|c|c|}
\hline & Integrative statements \\
\hline $\begin{array}{l}\text { Lane County } \\
\text { Diesel }\end{array}$ & $\begin{array}{l}\text { "this was a group of people that were coming together to get ahead of an } \\
\text { opportunity...there were no arguments, there was no disagreement, there was } \\
\text { not two sides at all, it was very much a group of people that were more or less } \\
\text { coming from the same place trying to come together to find out how they could } \\
\text { take advantage of an opportunity..." P46 (business participant) }\end{array}$ \\
\hline $\begin{array}{l}\text { Reduced Engine } \\
\text { Idling }\end{array}$ & $\begin{array}{l}\text { "I don't think anyone in the room wanted any one industry to carry the burden } \\
\text { by themselves, or face financial hardship, I think everyone was sensitive to that, } \\
\text { let's be careful here, let's not throw it all on the trucking industry, or anyone } \\
\text { else." P3 (business participant) }\end{array}$ \\
\hline $\begin{array}{l}\text { Lakeview } \\
\text { Biomass }\end{array}$ & $\begin{array}{l}\text { "They [participant concerns and desires] helped develop the parameters of } \\
\text { whether the project was feasible or not, I mean, for example let's take the } \\
\text { environmental group, their concern was large trees. Unless we agreed to some } \\
\text { parameters, their concerns weren't addressed..."P3 (agency participant) }\end{array}$ \\
\hline $\begin{array}{l}\text { Tillamook } \\
\text { Flooding } \\
\text { Reduction }\end{array}$ & $\begin{array}{l}\text { "...you've got to continually address where people are, continually ask the quiet } \\
\text { people are you okay with where we're going, are there any issues, any concerns, } \\
\text { and try to address their issues and concerns..." P28 (co-convener) }\end{array}$ \\
\hline $\begin{array}{l}\text { Lakeview } \\
\text { Stewardship } \\
\text { Group }\end{array}$ & $\begin{array}{l}\text { "it became clear to me we all need to change our attitudes... we need to check } \\
\text { our egos at the door, we need to lay down our weapons and sit down quietly at } \\
\text { the table... and be honest with each other... we need to move forward, recognize } \\
\text { the errors in our ways on both sides and find a new way to work together." P24 } \\
\text { (stakeholder group leader/business participant) }\end{array}$ \\
\hline
\end{tabular}


Project staff and participant leaders helped identify and address interests. Individuals who acted in a mediation or facilitation capacity will be referred to here as 'participant leaders.' In table 63 we see example integrative statements from the five cases. These examples involve language that recognizes the importance of identifying and addressing participant interests. The examples also highlight the approaches different project managers, participants, and conveners used in these cases. In the LSG project participant leaders were more active facilitators than project staff members. This is an important finding because if communities want to solve their own problems and cannot afford to hire facilitators, they benefit from having leaders with negotiation and conflict resolution capacity. Many interviewed participants thought interests were important implicitly, although most did not make distinctions between positions and interests until asked clarifying questions. Meeting summary notes indicate that participants commonly distinguished positions and interests when asked clarifying questions, or when learning new information. This was verified by survey responses. This also reinforces the need for facilitation capacity among collaborators.

Interviewed participants in all five cases identified project staff members, and participant leaders, who helped the group move forward either through clarifying issues or acting as a mediator among different stakeholders. In the Lane County Diesel project, participants described one individual from a government agency as helping all stakeholder groups better understand what was possible, and what the limitations were. In the Reduced Engine Idling project, participants emphasized the helpfulness of both 
a trucking industry association representative and the convener in helping stakeholders move forward. In Tillamook, interviewed participants identified five individuals as crucial advocates, mediators, or neutral parties who helped the group explore interests and issues. The topic of leadership will be revisited in the Discussion.

\subsubsection{Research Question Two: Facilitation}

All cases benefitted from facilitation techniques helping participants clarify issues, identify other party's interests, clarify scientific or technical information, and identify participant perspectives. Staff and participant leaders in the five projects identified and assessed substantive interests primarily through project assessments, verbal communication, different meeting types, and shared experiences. Neither staff nor participant leaders kept track of interests through documentation; however, understanding interests was an implied objective.

\section{Techniques for Issues and Substantive Interests}

The nature of each case's subject matter influenced the usefulness of types of facilitation techniques for understanding issues and interests. In interviews, participants and staff describe substantive issues as being the opening, or starting point, for discussing interests. This was reflected in survey responses indicating that meeting regularly, meeting as a whole group, and face-to-face meetings were helpful for understanding issues and interests in all cases (see table 64). Group discussions during meetings, between meetings, and clarifying or prompting language about interests or issues helped all project participants better understand issues. 
Table 64 Techniques that supported understanding interests and issues

\begin{tabular}{|c|c|c|c|c|}
\hline & $\begin{array}{l}\text { Interview } \\
\text { Emphasis }\end{array}$ & Technique & $\begin{array}{l}\text { Interests } \\
\% \text { Yes }\end{array}$ & $\begin{array}{l}\text { Issues } \\
\% \text { Yes }\end{array}$ \\
\hline \multirow[t]{4}{*}{ Meeting Types } & $1-5$ & Regular meetings & 62 & 70 \\
\hline & $1-5$ & Face to Face meetings & 81 & 64 \\
\hline & $1-5$ & Project team (e.g. whole group) meetings & 75 & 74 \\
\hline & 4,5 & 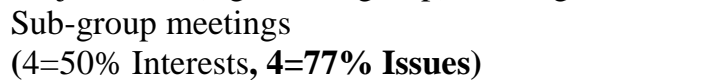 & 23 & 42 \\
\hline \multirow{6}{*}{$\begin{array}{l}\text { Verbal } \\
\text { Communication }\end{array}$} & $1-5$ & Discussions during meetings & 81 & 81 \\
\hline & $3,4,5$ & Discussions between meetings & 66 & 64 \\
\hline & $1-5$ & $\begin{array}{l}\text { Requests for people to explain what they care } \\
\text { about }\end{array}$ & 68 & 47 \\
\hline & $1-5$ & Statements of interests: "I am concerned about..." & 66 & 38 \\
\hline & 4,5 & Someone brought something up & 55 & 60 \\
\hline & $1-5$ & Talking about an issue after getting information & 40 & 64 \\
\hline \multirow{4}{*}{$\begin{array}{l}\text { Visual } \\
\text { Communication }\end{array}$} & 3,4 & Computer modeling results & 30 & 62 \\
\hline & & $(3=69 \%, 4=89 \%$ Issues $)$ & & \\
\hline & 4,5 & Maps $(4=78 \%, 5=91 \%$ Issues $)$ & 42 & 66 \\
\hline & 4,5 & Photos/pictures $(\mathbf{4 = 7 8 \%}, 5=64 \%$ Issues $)$ & 45 & 62 \\
\hline Shared & $1-5$ & Making decisions as a group & 68 & 72 \\
\hline \multirow[t]{6}{*}{ Experiences } & $1-5$ & Group reviewing information together & 74 & 75 \\
\hline & $3-5$ & Field trips or site visits & 55 & 62 \\
\hline & & $(3=77 \% ; 4=83 \% ; 5=82 \%$ Interests $)$ Case 1-3: & 81 & \\
\hline & & $(3=69 \% ; 4=67 \% ; 5=100 \%$ Issues $) \quad$ Case 1-3: & & 79 \\
\hline & 5 & $\begin{array}{l}\text { Casual meetings on shared bus/van rides } \\
\text { (5=82\% Interests) }\end{array}$ & 57 & 34 \\
\hline & 5 & $\begin{array}{l}\text { Eating meals together } \\
(\mathbf{5 = 8 2 \%} \text { Interests, } 5=55 \% \text { Issues })\end{array}$ & 51 & 21 \\
\hline Participants* & $1-5$ & People with important resources & - & 77 \\
\hline \multirow[t]{2}{*}{ Information* } & 2,4 & Visiting expert presentations & - & 60 \\
\hline & $1-5$ & Participant presentations & - & 81 \\
\hline
\end{tabular}

Cases are numbered 1=Lane Clean Diesel, 2= Reduced Engine Idling, 3=Biomass, 4= Tillamook

Flooding Reduction, 5=LSG. Bold indicates at least two-thirds of respondents agree item is important.

*Survey respondents were not asked about interests on these two features.

Shared experiences contributed to group learning about issues and interests in all cases (see table 64). Two types of shared experiences, reviewing information together and making decisions together, were most helpful for participants in understanding issues and interests. Survey respondents emphasized site visits or field trips as being important for understanding issues and interests in the Biomass, Tillamook, and LSG cases. This supports case study findings reported by Wondolleck 
and Yaffee (2000) who suggest groups working on natural resource management issues benefit from direct experience.

Interviewed participants also felt co-drafting documents helped them better understand issues and interest in four cases. These documents included a federal grant in the Reduced Idling project, the Memorandum of Understanding in the Biomass case, the Mediated Gravel Agreement in the Tillamook case, and the Long Range Strategy in the LSG case. Only a small sub-set of individuals contributed to these documents, and thus the survey responses were not as high on these elements.

Notice also in table 64 that the Biomass, Tillamook, and LSG projects relied on maps, photos and pictures, as well as computer modeling results to help participants grasp natural resource issues, and how their interests might be affected. In contrast, participants in the Lane Clean Diesel project had a better understanding of the issue when they tested different fuel types in the engines, and then learned about how each one performed. The Reduced Engine Idling project was the only project that did not actively test idling reduction technology models, nor as a group visit a site where all three were in place. For this group, participant presentations about the technology types, their benefits, and limitations were more useful. Interviewed participants in the Lane Clean Diesel and Reduced Engine Idling projects emphasized learning during group meetings, although the survey response rates on these two projects were too low to validate this. In the Tillamook case, interviewed participants noted that meeting with more than about ten individuals made the process slow; the 
sub-group meetings were helpful because participants were able to discuss things at length and still move forward.

Staff described the project assessments as being helpful in understanding issues and interests. The four Oregon Solutions projects began with a project assessment. The project assessments determined the history, core issues, concerns, resources, and important participants, but did not explicitly separate interests from positions. These preliminary assessments included meetings with leaders and potential participants. Staff used information from the assessments in framing the conversation during initial meetings. Project managers and participant leaders in the LSG case met with potential collaborators to identify core issues and concerns, but did not conduct a formal assessment. The convener and first facilitator of the LSG project designed the initial meetings to include experiences that would require participants to examine their assumptions, and primary concerns, related to forest health. These were not conflict assessments or a stakeholder analysis as described in the conflict resolution field. A conflict assessment explicitly defines parties, issues, interests, positions, power, and conflict (Susskind, et al., 1999a). Such assessments are useful as an analytic tool before convening participants, even if the project might be collaborative (Campbell, 2004; Carpenter and Kennedy 2001). Collaborative process managers would benefit from adding interests to project assessments.

\section{Techniques for Relationship and Process Interests}

Many facilitation techniques helped address participant relationship and process concerns. Co-conveners and project managers, as well as a few participants, 
engaged in coordination tasks (Leach \& Sabatier, 2003), such as inviting speakers, creating agendas, writing grant proposals, drafting summary documents, and scheduling meetings. Each project also had individuals who addressed relationship and process interests based on facilitation and mediation skills. For example, staff developed and enforced ground rules, proposed options, led exercises, and led decision-making processes aimed for consensus. All of these are included within the role of a facilitator (Elliott, 1999).

Each process began with a meeting that included discussing interests, issues, and positions. Project managers, conveners or leaders made explicit requests for participants to share their concerns in the first few meetings. Participants also asked questions about the purpose of meeting, sub-issues, or stated their concerns openly. Discussing substantive interests occurred during information reviews through direct communication including staff or participants asking probing questions, clarifying questions, using active listening, and making appreciative statements. All five cases had evidence that staff or participant leaders used direct questioning about participant concerns (e.g. "what matters to you?" or "what are your concerns?”), or identified sensitive issues through body language and followed up with individuals one on one or in a group. The action s of managing group dynamics outside of the meetings is a mediation skill; a mediator works across conflicting perspectives and interests and shapes group process (Elliott, 1999). Participants also asked questions about the purpose of meeting, sub-issues, or stated their concerns in face-to-face meetings. Many texts recommend active listening practices, clarifying and framing questioning, 
and emotionally empathic or appreciative communication (Daniels \& Walker, 2001; D. M. Kolb \& Williams, 2003; Lewicki \& Litterer, 1985).

Interviewed participants emphasized a wider range of techniques as being helpful in understanding interests than follow-up survey respondents (see Appendix E). For example, in interviews, participants expressed that meeting with a project staff member was helpful in being able to discuss interests. In the follow-up survey, very few respondents noted that this option was helpful in understanding issues or interests (26\% of all five cases). These meetings helped staff better understand sensitive concerns and could then bring it up anonymously in the larger group. This is reflected by survey participants noting someone bringing up issues (55\%) was important for understanding interests, as were requests for participants to explain what they care about - often asked by project staff $(68 \%)$.

Ground rules in all cases mentioned interests. All interviewed staff inherently recognized the value of interests, although they had not received uniform training in the utility of separating interests from positions or on integrative bargaining. Three of the projects used a ground rules template from the Oregon Solutions program that includes wording about respect, honesty, and honoring interests. The Tillamook and Lakeview Stewardship Group projects had different sets of ground rules. The Tillamook project ground significantly revised the OS template. The LSG ground rules were not documented as they were established very early in the process, nearly ten years ago, and have since become norms of conduct for the group. 
Addressing process and relationship interests supported participants being able to address substantive interests. Participants' relationship or process interests, such as mistrust or the fear of another party defecting, were potential barriers to perceiving commonalities on substantive issues. This was most apparent in the Tillamook and LSG cases. In the Tillamook project, the conveners and project manager used facilitation methods to counter and manage distributive tactics from positional individuals. These methods effectively addressed relationship concerns. For example, project staff attended additional meetings of advocacy groups within Tillamook, made additional phone calls, and created opportunities to discuss interests outside of the group meetings. This openness and availability helped participants feel there were advocates within the Oregon Solutions process. In the LSG project, participant leaders dropped positions early on in the process and shared their concerns. These two acts demonstrated flexibility and that a collaborative effort toward achieving forest health was more important to community leaders than forest certification. These motivated environmental advocates to pursue a collaborative project. As the project continued, participants continued to demonstrate trustworthy behavior through travelling to Lakeview, risking colleague disapproval by collaborating, and advocating for the project with their constituencies.

\subsubsection{Research Question Three: Role of Interests}

Participant interests were the basis of understanding and addressing the substantive issues in each project. Participants' understanding of each other's interests 
most directly influenced understanding of issues and selection of options for constructing agreements.

\section{Substantive Interests}

Participants' substantive interests were a source of creating value in each project. Four of the five projects involved participants creating value within an integrative context prior to claiming it. Participants created value based on their differences and similarities, either in interests or resources. The groups engaged in joint action for joint gain approaches: unbundling of differences, trading on differences, crafting contingent agreements, and making use of complementary capabilities (Lax and Sebenius, 1986). For example, in the Lane County Diesel project, the eventual suppliers of ULSD and biodiesel gauged how much potential market demand there was, based on volume and price commitments. Participants described this as a basic aligning of interests: supply with demand. This involved trading on different goods: money for fuel.

In the Reduced Engine Idling project, truck stop owners agreed to host the idling reduction technology, but were concerned about having to pay for it. The nonprofits had the ability to contribute grant funding so that the truck stops would not have to bear these costs. This creation of value is based on complementary capabilities. The participants generated a shared concern about the economic feasibility of installing this technology.

In the Biomass project, the group faced uncertainty in the potential volume of biomass available for the plant. They overcame uncertainty based on information 
searches. The key issue was biomass plant scale. A cost-benefit analysis on different volume inputs helped the group find a plant size that worked for most participants. Future potential volume input was still an issue. The 20 year Memorandum of Understanding among community members, agencies, Collins Company and the energy investor established terms for how biomass would be harvested off public lands by the BLM and Forest Service. The MOU makes use of complementary capabilities and ensures that a supply at a particular level will be made available to the energy company. In the implementation phase, the group considered crafting a contingent agreement should an investor raise the size of the biomass plant from 15 MW to $18 \mathrm{MW}$. The group, including environmental organizations, will agree to support the plant contingent on how public agencies harvest a particular volume per acre of land. The group will support more acres being harvested as long as a particular volume is maintained. The group will not support greater volume removal from fewer acres.

Both the Biomass project and the LSG project unbundled differences for creative problem solving and the creation of both public and private gain. In each project two concerns were in seeming conflict: harvesting forests for economic gain versus restoring forests. The private gain is profits for particular businesses. The public gain is overall economic development and forest health improvement. The group began with positions and conflict, and through sharing concerns, gathering information, and dropping positions, arrived at integration. The LSG group achieved the highest level of integration of the five cases; this is evident by the group's creation 
of a non-profit to carry out the long-range strategy for the Unit in partnership with public agencies. This is known as coadunation (see page 43 in Chapter Two).

The most complex example of value creation is in the Tillamook case. It was complex because there were multiple types of public gains. This group unbundled the issue of flooding to include sub-issues of cost, environmental health, immediate efforts versus long-term projects, and agency or community support. The group developed a diverse set of projects that would provide flood reduction benefits with the potential for improving environmental habitat. The eleven projects took advantage of complementary capabilities. For example, agency personnel's input increased the likelihood a project could be permitted quickly as it reduced agency review time. Community input helped reduce the history of tension, and ensure that community members would recognize flooding reduction efforts, as well as understand the challenges. The flood reduction projects represent a mix of short-term construction projects and long-term projects that do no environmental harm, or in the case of Project Exodus, use natural wetlands to help reduce flooding.

Asking about interests revealed that participants adopted positions and used distributive bargaining tactics in three of the five cases. Distributive bargainers claim value in an attempt to meet bottom-line positions for maximum gain (Lax \& Sebenius, 1986). When bargaining distributively, people's perspectives are that resources are fixed, or limited, and they must compete to win. Competitive behavior may involve hiding information, misrepresenting information, applying pressure, using moral appeals for what is "right" (socially, scientifically), making threats, demanding 
concessions, digging into a position, or trying to win a contest of wills (Fisher, et al., 1991). It should be noted that when people are mistrustful, they engage in defensive behavior that encourages positions and distributive tactics (Pruitt, 1981).

A simple distributive example is in the Biomass project when the group members initially exchanged figures for the size of the Biomass plant and sought each other's resistance points. Eventually, the group shared information about why each side wanted a larger or smaller size. The final size was connected to objective criteria based on potential volumes of material and on different group's substantive interests.

In the Tillamook project a minority of community participants used stalling and pressure tactics to impede progress and to build community opposition. Other voting members countered these tactics with information, validation of individual's concerns, and assertiveness about the direction the project was heading. Project Staff and participant leaders helped build agreement among agency and diking district representatives, as well as other community individuals. Note that the participants holding onto positions did not view themselves as encouraging conflict or being difficult. They viewed themselves as working to secure what they value because they did not trust government agency personnel to work on their behalf. While the distributive tactics threatened the cohesion of the process, the rationale was to get the best possible outcome for the community through using pressure.

\section{Relationship and Process Interests}

Participant process and relationship interests were connected to and supported addressing substantive interests. Four of the projects began with participants feeling 
distrust of other individuals or stakeholder groups. Intangible relationship and process interests overlapped and were important to address as a means of opening a dialogue about substantive interests. This was true even though three of the cases were relatively short-term projects. For example, businesses in the Lane Clean Diesel project would only discuss potential amounts of fuel purchases confidentially. In the Lakeview Stewardship Group, the Collins Company and City Commissioner's statements of honesty and willingness to back away from forest certification encouraged at least two environmental advocates to collaborate.

Individuals representing an organization had substantive concerns connected to job duties and responsibilities. These included upholding mandates for public agency personnel, working to meet a price point for private owners, or addressing an organizational goal for non-profit representatives. This was emphasized in interviews and in case documents. In the follow-up survey, participants named substantive interests as important with less emphasis on job responsibilities. Individuals participating on behalf of an organization comprised between 90 and 100\% of the survey respondents in these three cases. In the Biomass, Tillamook, and LSG cases, the majority of respondents agreed that substantive interests related to protecting/restoring environmental health were important (100\%, 91\%, and 100\% respectively). In contrast, less than half of survey respondents reported that upholding a job responsibility was an important interest $(23 \%, 44 \%, 24 \%$, respectively). This discrepancy may be due to participants' personal investment in these substantive 
interests, a misunderstanding of wording in the survey, or there being overlap between job duties and these particular interests.

\section{The Collaborative Process}

Evidence from both the qualitative and quantitative stages of this research indicate that participant interests influenced all three stages of the collaborative process as depicted by Grey's (1989) model (see tables 65 and 66). This is an important finding because collaborative models currently underestimate the importance of participant interests.

Table 65 Participant interests' impact on the collaborative*

\begin{tabular}{|c|c|c|c|c|c|c|}
\hline $\begin{array}{c}\text { Collaboration } \\
\text { Stage } \\
\end{array}$ & & $\begin{array}{c}\text { Lane } \\
1 \\
\end{array}$ & $\begin{array}{c}\text { Idle } \\
2 \\
\end{array}$ & $\begin{array}{c}\text { Bio } \\
\mathbf{3} \\
\end{array}$ & $\begin{array}{c}\text { Tillmk } \\
4 \\
\end{array}$ & $\begin{array}{c}\text { LSG } \\
5 \\
\end{array}$ \\
\hline \multirow[t]{4}{*}{ Problem Setting } & Entering the collaboration & $\mathrm{X}$ & $\mathrm{X}$ & & & $\mathrm{X}$ \\
\hline & Committing to collaborate & $\mathrm{X}$ & & & & $\mathrm{X}$ \\
\hline & Understanding the problem & & $\mathrm{X}$ & & $\mathrm{X}$ & $\mathrm{X}$ \\
\hline & Developing Group Goals & & & & $\mathrm{X}$ & $X$ \\
\hline \multirow[t]{6}{*}{ Direction Setting } & Perspectives on issues & $\mathrm{X}$ & $\mathrm{X}$ & $\mathrm{X}$ & $\mathrm{X}$ & $\mathrm{X}$ \\
\hline & Positions on issues & & & $\mathrm{X}$ & $\mathrm{X}$ & \\
\hline & Identifying sub-issues & $\mathrm{X}$ & $\mathrm{X}$ & $\mathrm{X}$ & & \\
\hline & Joint information search & $\mathrm{X}$ & & & & \\
\hline & Exploring options & $\mathrm{X}$ & $\mathrm{X}$ & $\mathrm{X}$ & $\mathrm{X}$ & $\mathrm{X}$ \\
\hline & Reaching agreement & $\mathrm{X}$ & $X$ & $\mathrm{X}$ & $\mathrm{X}$ & $\mathrm{X}$ \\
\hline \multirow[t]{2}{*}{ Implementation } & Commitment of resources & $\mathrm{X}$ & $\mathrm{X}$ & $\mathrm{X}$ & $\mathrm{X}$ & $\mathrm{X}$ \\
\hline & Program outputs & $\mathrm{X}$ & & $\mathrm{X}$ & $\mathrm{X}$ & $\mathrm{X}$ \\
\hline
\end{tabular}

*Based on interview data

Evidence from interviews and survey responses indicate that interests relate to how participants conceptualize the central problems and sub-issues in these collaborative processes. Participant understanding of each other's interests primarily contributed to groups identifying options, and reaching an agreement consistent with integrative bargaining (see tables 65 and 66). These findings indicate that theory focused on interest-based negotiation is applicable to collaborative processes specifically in the problem setting and direction setting phases. These two stages are 
when understanding of the central problem, its sub-issues, and options for agreements are developed.

Table 66 Importance of understanding other participants' interests*

\begin{tabular}{|llcc|}
\hline $\begin{array}{c}\text { Collaboration } \\
\text { Stage }\end{array}$ & Mean (SD) & $\begin{array}{c}\text { Mean (SD) } \\
\text { Tillamook }\end{array}$ \\
\hline Problem Setting & Understanding issues on the table & $2.43(.56)$ & $1.61(.61)$ \\
\hline Direction Setting & Understanding other participants' barriers & $2.46(.78)$ & $1.72(.67)$ \\
& Understanding options on the table & $2.54(.51)$ & $1.61(.61)$ \\
& Finding things all could agree on & $2.51(.70)$ & $1.67(.69)$ \\
& Picking a direction to go with the solution & $2.40(.70)$ & $1.67(.69)$ \\
\hline Implementation & Staying involved for the duration of the project & $2.43(.74)$ & $1.61(.71)$ \\
\hline
\end{tabular}

* Based on survey data $(1=$ not very important, $3=$ very important $)$

Substantive interests were the basis for decision making. All cases

implemented projects or developed outputs built on core interests of participants. For example, the LSG's Long Range Strategy goals were incorporated into the Forest Service's management of the Unit, and the Lane Clean Diesel market was established based on the needs of participants. The Biomass, Tillamook, and LSG cases involved participants re-visiting sub-issues or new ones as they emerged during the direction setting and implementation phases. Participants and project staff members had to reexamine interests and options in order to make new decisions.

Secondary findings indicate that participant interests also contributed to commitment of participants, the motivation to commit resources, and the structure of outputs in the implementation phase. It is important to clarify that interests are a source of motivation for participants. While budgets, mandates, and program objectives dictate participant's commitment of resources, individuals with a personal investment worked harder to obtain resources. For example, environmental advocates typically do not argue on behalf of salvage logging - this does not reflect their 
organizational objectives. However, in the LSG project, representatives of environmental organizations contributed time, political clout, and financial resources in order to assist community partners in arguing for limited, site-specific, salvage logging. These individuals were invested in the long-term health of a tract of land and viewed Lake View partners as stewards of this land; their forest health interests dovetailed with those of Lake View partners. These findings may be specific to the individual. Survey results indicated only moderate agreement that understanding other participants' interests motivated them to commit resources (all cases other than Tillamook, $\mathrm{M}=2.29, \mathrm{SD}=67$; Tillamook, $\mathrm{M}=1.44, \mathrm{SD}=.62$ ).

Note that survey respondents from the Tillamook case did not think understanding other participants' interests had any impact on the decisions they made in the collaborative process. For example, the highest mean for any item was only 1.72 ( $\mathrm{SD}=87$ ) on "understanding other participants' barriers" (see table 66). This is despite the fact that all participants agreed that each other's interests were important to the process when asked to identify important interests in the project. For example, more than three-quarters of participants agreed that protecting environmental resources, reducing negative flooding impacts, protecting the community economy, and a need for long-term projects were important (see table 67 below).

Table 67 Tillamook substantive interests (survey responses)

\section{Case 4 Tillamook Flooding Reduction (n=18)}

Protect environmental resources (e.g. fish habitat, endangered species)

Reduce negative impacts of flooding (e.g. public safety, property damage, loss of cattle) 
The discrepancy between these two types of survey responses may be related to several elements. First, the Tillamook collaborative group did not generate the objective criteria for ranking projects as a collective. These criteria were developed by project staff, based on interests, and given to the participants who agreed to use it. This means the group did not explicitly consider interests in their voting process they were thinking about criteria, which relates to the issues. Second, the presence of distributive individuals and a climate of mistrust may have caused everyone to focus primarily on their own interests when advocating for projects during the problem setting and direction setting phases. Third, participants were committed to the project based on personal interests, and may not have viewed their needs as interdependent with others. For example, in interviews, state agency personnel described feeling motivated to contribute to success because of a letter from Governor Kulongoski to their superiors. Fourth, the group did not engage in new information gathering and shared learning until the implementation phase; the collective did not focus on interests until they were considering alternatives for Project Exodus. It took three years and the implementation of the two spillway projects, the removal of the "Dean" dirt pile, and evidence from all stakeholders that everyone was invested to help build mutual respect and trust. The group was not able to discuss interests at the beginning of the process because they did not trust each other enough.

The primary reason this group arrived at projects that addressed interests is that project staff understood stakeholder concerns and built them into the process structure. 
This project resulted in outputs connected to interests based on the motivation of the project staff and participant leaders; it was not uniformly shared among the collaborating participants. Although a community participant complained about how "controlled" the process felt - the structure helped different stakeholder groups get out of their own way. The structure helped the group move forward. Project staff helped the group get past personality differences and managed disruptions.

\subsubsection{Research Question Four: How Were Interests Addressed}

\section{Substantive Interests}

Substantive interests were address primarily through project outputs such as programs, projects, plans, information searches, research results, and agreements. See figure 35 for a summary of the five cases and how example substantive interests were addressed in each project. Notice the similarities among the five cases in terms of outputs.

In all cases, substantive information triggered an exploration of interests on sub-issues. Technical information, new facts, the barriers of different parties, or results of information searches contributed to how participants viewed the problem, and a consideration of how interests would be addressed. For example, in the Lane Clean Diesel project, suppliers' perception was that the demand for ULSD was too low to establish a market. Committed buyers helped convince them otherwise. Seeing clear cuts encouraged participants in the Lakeview Stewardship Group to reconsider how economic health was supported by environmental health. Reviewing hydrologic model 
findings helped participants in the Tillamook case select an alternative to Project

Exodus based on a mix of criteria connected to interests.

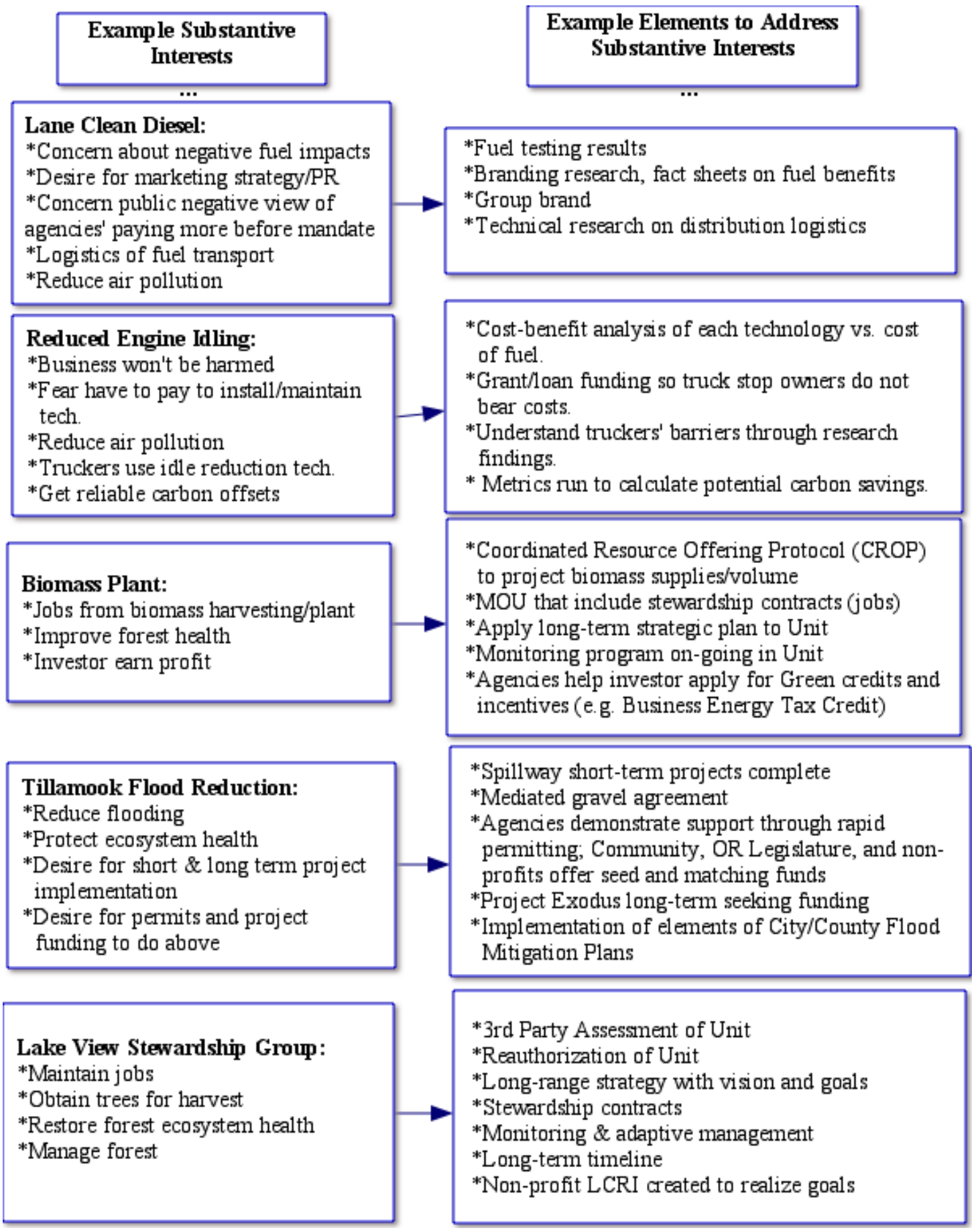

Figure 35. Example substantive interests and corresponding outputs all cases. 
Interview, document, and survey evidence from all cases support that exploring interests helped participants improve their understanding of issues and options in order to craft agreements. Positions or issues were the most common starting point for negotiation in the five cases; interests were brought up in association. The groups moved toward interests as a basis for discussing issues. Often such discussions involved participants identifying barriers to moving forward as part of their concerns. For example, in the Biomass project a sub-issue was volume supply in order to determine plant size. The amount of supply was a barrier to creating the plant. The group repeatedly pushed the proposed Biomass plant size to different spots in the bargaining set. The discussions centered on a participant position for example, A) no bigger than $10 \mathrm{MW}$ versus B) at least $20 \mathrm{MW}$. At other times the discussion would begin or transition to underlying interests: A) we fear that if the size is too large managers will be compelled to overharvest and diminish forest health, versus B) we fear the plant failing because we do not have enough volume.

Recall in the LSG process, when one environmental participant showed a colleague a $22+$ inch white fir growing in a mixed conifer stand. His friend did not want to cut trees over the size of 21" (his position) because he thought this was upholding his concern of helping to maintain habitat health. His information was that over 21 " trees were historically growing in that area and were now old growth which are fundamental to forest ecosystems. New research, and observed evidence on different site visits, indicated that because of fire exclusion and grazing patterns that tree would not have been there - and maybe it was okay to cut it. In other words, 
cutting trees of this size in certain conditions was actually addressing his underlying interest. It took time, and repeated exposure to different observed field circumstances for him to let go of that position. The individual had to re-assess his understanding of the issue, and his underlying concerns about it, in relation to incoming information. Groups addressed relationship and process interests in a more subtle fashion than substantive interests.

\section{Relationship and Process Interests}

Project staff and most participant leaders were deliberate in asking questions to identify and better understand participant interests. Individuals who acted in a mediation and facilitation role helped each process address stakeholder interests. Staff also had varying exposure to negotiation theory; for example a co-convener in the Lane Clean Diesel project was familiar with Daniels and Walker's Collaborative Learning text (2001) and a co-convener in the Biomass project mentioned that he brings up interests to encourage people to begin examining them at the beginning of every process he facilitates. Staff and leaders also made statements on trust, honesty, and respect. Conflict resolution theorists maintain that building trust and having respect for other participant's perspectives is crucial for integrative bargaining to occur (D. M. Kolb \& Williams, 2003; Lax \& Sebenius, 1986; Lewicki \& Litterer, 1985; Susskind, et al., 1999a). 


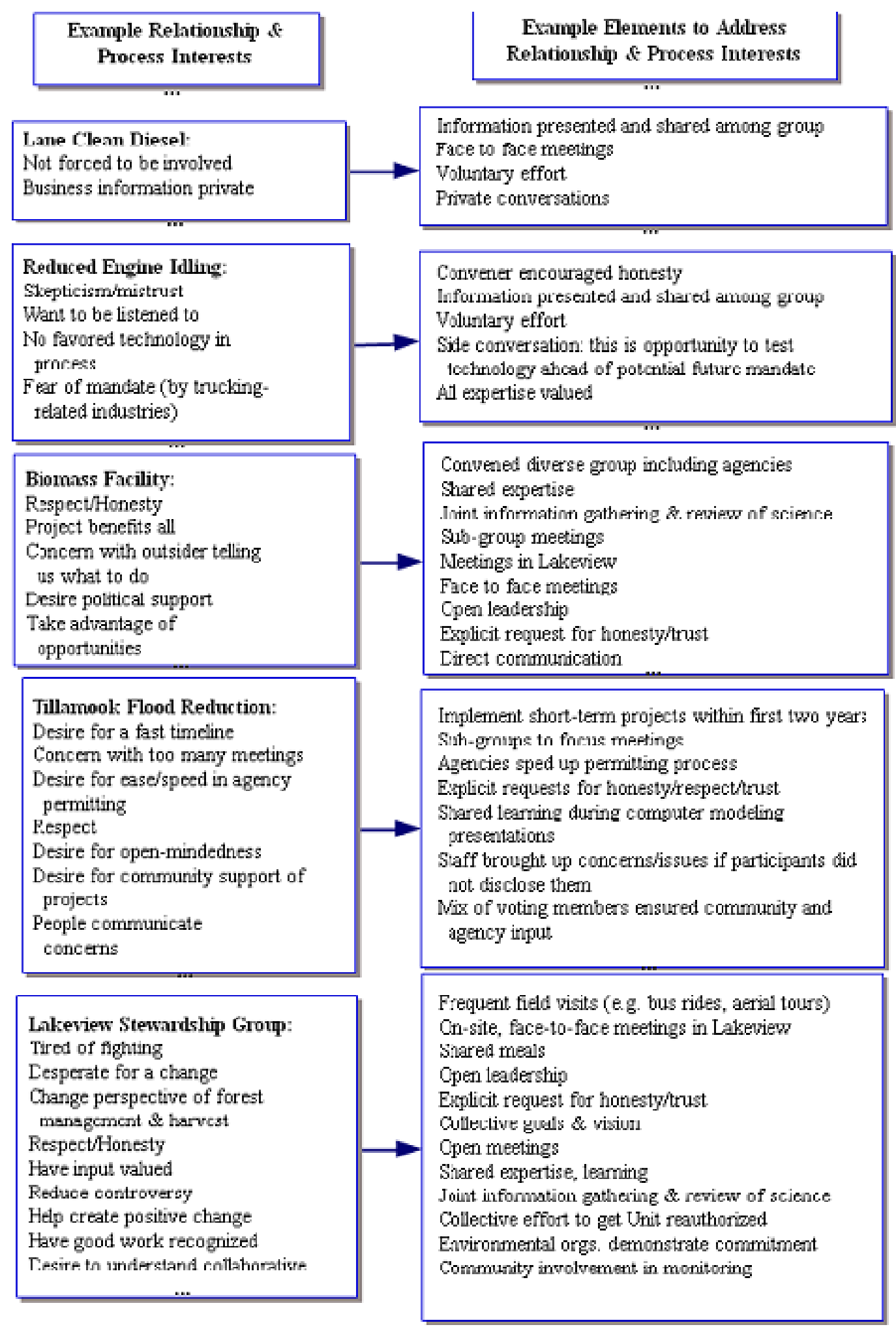

Figure 36 Cases addressed relationship and process concerns. 
Notice in figure 36 that each group addressed relationship and process interests through subtle means. For example, an interest of keeping information private is addressed through one-on-one or smaller group meetings. A mixture of short-term projects addressed the desires for a fast timeline and immediate physical projects. The common desire to help, or be recognized for good work, is addressed with verbal statements of recognition and validation.

Relationship and process interests most directly connected to forces of fragmentation discussed in Chapter Two. We revisit these in the next sub-section.

\subsubsection{Disruption Sources, Interests, and Facilitation}

The cases were similar in their community focus and use of facilitation. The cases differed in their potential level of fragmentation. Fragmentation relates to social complexity, problem complexity, and technical complexity. Facilitation techniques to help address participant interests were more crucial in cases with higher potential fragmentation. Participants viewed problems based on their unique concerns, their understanding of facts related to the problem, their values, and their history of relating to other stakeholder groups, or organizations, in each project. As the cases increased in potential fragmentation, the problems became more complex, the number of affected stakeholder groups increased, and the complexity of technical information increased affecting participant perspectives (see table 68). How each project dealt with disruption sources, in relation to participant interests, is summarized here. 
Table 68 Summary of cases and primary disruption types

\begin{tabular}{|lccc|}
\hline \multicolumn{1}{|c}{ Case } & $\begin{array}{c}\text { Potential } \\
\text { Fragmentation } \\
\text { Score } \\
(13-39)\end{array}$ & $\begin{array}{c}\text { Primary Disruption } \\
\text { Types }\end{array}$ & \# Stakeholder Groups \\
\hline Lane Clean Diesel & 19 & Technical & 2 \\
Reduced Engine Idling & 23 & Technical, Social & 3 \\
Biomass Facility & 27 & $\begin{array}{c}\text { Social, Problem \& } \\
\text { Technical }\end{array}$ & 5 \\
Tillamook Flooding & 30 & Social, Problem \& & 6 \\
Reduction & Technical \\
Lakeview Stewardship & $35-36$ & Social, Problem \& & \\
Group & & Technical & 5 \\
\hline
\end{tabular}

Substantive information helped address problem complexity. Clarifying and probing questions, information gathering, presentations, site visits, and shared experiences are some of the techniques used to increase understanding about the central problems and participant substantive interests. The Lane Clean Diesel and Reduced Engine Idling projects were similar in that the central problems involved primarily logistical issues and three or less key stakeholder groups (e.g. businesses, agencies, and environmental non-profit organizations). In the Lane Clean Diesel project everyone agreed on the need for an ULSD market. The difficulties were how public agencies could show citizens the benefit of spending additional public dollars, the concern of negative fuel impacts, and how private companies would find capital for infrastructure. In the Idling project, agency personnel viewed the central problem as air pollution, with idling technology a viable method to reduce it. For truck stop owners the central problem was idling technology's potential negative impact on business. In this project, the trucker association and the truck stop owners caucused as one stakeholder group. The team developed an agreement that minimized negative 
impacts to truck stop owners and launched it as a pilot project for non-profits concerned about the viability of potential credit offsets.

As problem complexity increased, technical information sophistication also increased. The same techniques mentioned in the paragraph above, such as clarifying questions, reviewing information together, and making decisions together, helped participants develop a shared understanding of technical information and its implications. This affected participants' conception of their own interests, and how their interests were impacted by other participants' interests.

Participants in the Biomass project had to tackle a complex problem, review scientific information, and address concerns from environmentalists. In the Biomass project, community, agency, and environmental groups viewed the facility as a potential threat to forest restoration; while different community, agency, and investor participants were concerned with biomass volumes to make the facility be economically viable. Additionally, a sub-group who had worked with the LSG case had to convince new agency and environmental personnel that this idea would not harm forest habitat. One environmentalist, who declined being interviewed, initially opposed the idea because of his view that forests should not be used for economic benefit. One of the project managers thought multiple experiences, including this project, helped shift that individual's perspective enabling him to support the agreement.

The two most complex cases, Tillamook and LSG, involved what may be termed "wicked" problems (Rittel \& Webber, 1973). A wicked problem is one that is 
ill defined, requires political judgment for resolution, has information needs which depend on one's idea of solving it, and for which solutions are not 'true' or 'false,' but 'good enough' (Rittel \& Webber, 1973). The problems of flooding reduction and forest management have multiple alternatives to resolve various sub-issues such as habitat loss or property damage. Implemented projects had immediate consequences that could not be undone. This complexity also made groups more reliant on computer modeling and scientific information in order to estimate potential effects.

Social complexity was associated with the number of participants, their perspectives, and the history of relationships among stakeholder groups. In the Tillamook and LSG projects, collaborators “wouldn't even speak to each other when this began." Each project was unique in that it brought together parties that might not traditionally collaborate. Government agencies, businesses, and non-profit organizations often find themselves at odds through legislative rule-making processes. Merely working with a historical or potential adversary was a source of skepticism for many.

Most participant distrust, or skepticism, diminished in these projects as a result of relationship and process interests being addressed. For example, in the Reduced Truck Idling project, truck stop owner fears of bearing the cost burden of implementing idling technology faded based on conversations with project staff and a participant leader. Concerns that people would not buy ULSD or biodiesel faded when fuel suppliers were able to review volume commitments of potential future clients in the Lane Clean Diesel project. Concerns that the Biomass Plant would be a "beast that 
needs to be fed" which would cause undue ecological damage were diminished by supply volume analyses.

In the Tillamook case, a few community individuals held onto demands creating an "us" versus "them" dynamic in the process. Two individuals described the central problem as government against "them" based on the dredging issue in interviews. This mistrust had developed from a history of relationships between government agencies and the community. Despite the fact that selected projects addressed the central concern of flood reduction, these participants fought against them in pursuit of their dredging preferences. It took repeated convincing on the part of local government representatives that the community's best interests were being served despite an imminent lack of dredging and the transfer of private land into government ownership (in Project Exodus). Project staff countered the tactics with a variety of approaches including tying interests to ranked voting criteria, communication, information gathering, public appreciation, and drawing community concerns into the discussion (see Chapter Four). These efforts helped the group successfully implement multiple projects, but have not been enough to change old feelings of resentment within a handful of individuals. This change might occur after a period of different interactions longer than the three years of this collaborative process.

Based on the data in these five cases, positional individuals are the most difficult disruptive element to address and may always have the ability to disturb a process. This remains true even if interests have been discussed and addressed. Critics have pointed out the potential for a powerful minority to use pressure and other tactics 
to attain their demands in collaborative projects (Coglianese, 1997). This potential indicates that collaborative processes with facilitators trained in conflict management, including negotiation and mediation tactics, are crucial for processes tackling complex problems with sophisticated information and a history of mistrust among stakeholders. Staff and participants in these five projects effectively used different communicative and learning techniques to manage fragmenting forces and prevent them from breaking apart the process. The only exception was the Biomass project, where the Japan-based corporate investor is not upholding its end of the agreement, as of June, 2009. These findings indicate that facilitation techniques are crucial for identify interests and for managing disruptive elements that are precursors to conflict. 


\section{CHAPTER SIX}

\section{Discussion}

This research sought to understand how integrative bargaining theory can help improve multi-party collaborative practice. The central problem it addressed is the lack of explicit attention to interests and facilitation techniques in managing disruptions in collaborative processes. Using a comparative case study with mixed methods, this research explored how interests were identified in five multi-party collaborative processes. It also uncovered the facilitation methods used in these dynamics, and the potential impacts identifying and addressing interests had on the five successfully implemented cases.

In the last chapter you read a summary of findings from each case and across the cases based on document reviews, purposive interviews, and a follow-up survey. This section examines the implications of these findings. The interpretations are organized by the research questions. Other mediating variables are described in the Alternate Explanations in section 5.5.

\subsection{Research Question One: How Interests Were Identified}

Participant substantive interests were identified, discussed, and addressed in all cases due to staff members' or participant leaders' implicit attention to the substantive issues on the table and use of facilitation techniques. Participants and staff members did not explicitly identify and track interests through these collaborative processes in the same manner as in a consensus-building or conflict resolution process. For example, the projects did not use a conflict assessment as part of the procedures. This 
was a potential limitation because the effort of identifying or addressing interests was not equally shared among all participants.

Addressing participant interests was not an explicit part of these processes in the same way as were trust and respect. Staff members emphasized trust, respect and honesty as part of ground rules and during discussions. Participant relationship and process interests were identified and addressed based on staff members' or participant leaders' use of facilitation techniques. This is an important finding because it indicates that one component of a collaborative process manager is the ability to identify and address participant relationship interests during a process. While this is highlighted in descriptive and normative literature for facilitators in the conflict resolution and consensus-building fields, it has received less attention in the collaboration literature.

In interviews, participants in all cases described common interests among stakeholder groups. Survey respondents validated this by agreeing each group had common interests. Each case was able to generate at least one shared interest at the beginning of the process. Other shared interests were generated over time, and each collaborative group emphasized different interests at various stages of the process. As participants learned more about different issues, and other participant's interests in these issues, the opportunity to generate compatible interests increased. The perspectives on what alternatives would best address those common interests varied among the participants. This is related to participants having different conceptualizations of the central problems and prioritizing them differently. This is meaningful because collaborative groups' ability to generate creative options is based 
on individuals' understanding of the central problem. Integrative bargaining increased collaborative potential.

\subsubsection{Substantive Interests: The Basis of Integrative Bargaining}

Individuals better understood nuances of the central problem after learning other participants' interests, in addition to technical information. The finding that participant interests were linked to issues and positions is not surprising as this was predicted by conflict resolution theory. When prompted in interviews, or when asked clarifying questions during meetings, most participants would clarify their concerns as discrete from a bottom line. In interviews, participants were able to describe the substantive concerns of other stakeholder groups and how this related to the problem, even if they were holding onto their own position. This indicates that when encouraged to explicitly reflect on interests, participants do so.

The interaction among participant interests, the issues, and participant positions revealed when and how individuals engaged in integrative and distributive bargaining. Each collaborative process used substantive interests as a basis for integrative bargaining, although participants were not always conscious of it. Integrative bargainers assessed interests in order to create more value and address parties' concerns. Integrative behavior involved problem solving, information sharing, honest representation of information, using objective criteria for decision making, assessing and exploring interests, and avoiding a bottom line (Fisher \& Ury 1991; Lewicki \& Litterer 1985; Lax \& Sebenius,1986). Facilitative techniques such as gathering and reviewing information and clarifying questions helped participants 
generate options. When participants bargained based on interests, they created options of higher value because of potential shared gains. Through creating value participant's substantive interests were addressed.

Competitive tactics also helped people achieve creative agreements in three of these cases. When people bargained distributively they were focused on how to maximize their own gain. When people bargained integratively they were thinking of how to address the other party's concerns as well as their own. Participants shifted back and forth between focusing on their bottom line and focusing on other party's concerns. This is what we would expect from negotiation theory (Pruitt, 1981), as participant concerns shape perspectives of the bottom line in the context of other organizational constraints and incoming information. The fact that there was shared information in a context of honesty is what gave these collaborative processes their integrative basis. Most participants were trying to help each other get something out of the negotiation - not seeking to solely meet their bottom line. The only two exceptions are the Biomass investor Marubeni, and a small number of participants in the Tillamook case.

\subsubsection{Relationship and Process Interests: Basis for Substantive Learning}

Participant relationship and process interests acted as a scaffold to crafting agreements on substantive issues. Participant relationship and process interests were associated with mistrust and differences, and in some cases, conflict. The explicit focus of project staff on trust and respect encouraged information sharing among participants - the basis for integrative bargaining. The analyses confirmed that 
participants in these collaborative projects had differences, and suffered disruptions, despite their "collaborative" label. In projects that involved a history of mistrust social differences affected participants' perception of sub-issues. These included relationships, perspectives from past experiences, and personalities as sources of disruption on problem understanding. In three cases (Reduced Engine Idling, Biomass, Tillamook and LSG) participants emphasized relationship and process concerns as much as substantive concerns. Each collaborative group effectively managed disruptions with facilitation techniques. This is a critical finding, as communities will continue to collaborate on increasingly complex issues and need the capacity to manage forces of fragmentation in order to solve problems.

\subsection{Research Question Two: Managing People and Process}

Participants would not have discussed interests or addressed them without facilitation techniques and individuals who were capable of using them. Facilitation techniques were crucial for helping project staff and participants identify, understand, and address stakeholder interests. Participants in all projects emphasized the helpfulness of both project staff and key stakeholder leaders for helping the project move forward. These individuals used facilitation techniques and accomplished three major results: 1) they coordinated the process; 2) they managed relationships during meetings and outside of meetings; 3) they addressed participant's relationship and process interests; and 4) they identified participant substantive concerns in order to address them. As described in the last chapter, face-to-face meetings, regular 
discussions, prompting language, and shared learning experiences substantially helped participants understand both issues and interests.

Skillful staff and participant leaders were crucial in helping to identify and address interests as well as manage disruptions. Participants commented on the expertise of staff in all projects, citing staff members' listening and communication abilities; capacity to move a group forward without being heavy-handed; sensitivity to different groups' concerns; and ability to maneuver within political situations without being manipulative. As this research examined facilitation techniques in relation to interests, it is clear that at least some of the integration success is attributable to project staff. These were not just staff members who coordinated meetings. These individuals mediated relationships and managed conflict. Project managers, conveners and participant leaders all worked to create opportunities for other participants to discuss concerns either in the public group or in private through one-on-one conversations. Participant honesty was valued because these projects relied on creative problem solving - the groups could not create value without honest information. Additionally, hidden agendas would disrupt tenuous trust bonds in these relationships if project staff and participant leaders did not intercept.

\subsection{Question Three: The role of interests in collaborative processes}

In these five cases, participant interests were part of what helped differentiate people from the problem, improve problem understanding, generate information searches, invent options, and craft agreements (Fisher, et al., 1991). Secondary benefits of focusing on participant interests included developing objective criteria for 
selecting options (e.g. Tillamook and Biomass), participant commitment to a process, and participant commitment of resources. In all projects, participants came to the table primarily because of interests about substantive issues, whether it was flooding reduction, ecosystem health, or economic development. These substantive concerns were framed by personal experience and organizational roles. Focusing on participant interests helped establish the foundation for integrative processes in all five cases.

Participant interests are closely connected to participants' understanding of the substantive issues. Considering Gray’s (1989) collaborative process framework, participants' interests were most important for the problem setting and direction setting phase. In both stages (see table 69), participants' interests relate to the problem definition, setting an agenda, finding information, exploring options, and reaching an agreement. As the issues changed, participant perspectives shifted. It is important that participants in a process understand how different sub-issues and options affect their interests. Further, as these options are implemented, it is crucial that collaborators be able to revisit these issues and interests and re-negotiate agreement changes. This is why participants' interests are also important in the implementation phase.

Table 69 Collaborative process framework elements most directly influenced (in bold face) by participant interests.

$\begin{array}{|lll|}\begin{array}{l}\text { Phase 1: Problem setting } \\ \text { Common problem definition }\end{array} & \text { Phase 2: Direction setting } & \text { Phase 3: Implementation } \\ \text { Commitment to collaborate } & \text { Agenda setting } & \text { Dealing with constituencies } \\ \text { Identification of stakeholders } & \text { Organizing subgroups } & \text { Building external support } \\ \text { Legitimacy of stakeholders } & \text { Joint information search } & \text { Structuring } \\ \begin{array}{l}\text { Convener characteristics } \\ \text { Identification of resources }\end{array} & \begin{array}{l}\text { Exploring options } \\ \text { Reaching agreement and } \\ \text { closing the deal }\end{array} & \begin{array}{l}\text { ensuring compliance } \\ \end{array} \\ \end{array}$


Participant commitment to the process was connected to individual interests. Personal investment is part of what motivated some individuals to maintain their commitment, especially in the Lakeview Stewardship Group process. Participants may have commitment themselves, and resources, based on having their interests addressed during the first two stages of the processes, and a desire to help others. Alternatively, this could be attributed to the commitment of an organization, or related to individual personalities. Very few of interviewed participants or survey respondents felt their core interests were not addressed in these projects. The response rates for the Biomass, Tillamoook, and LSG cases were about 50\%; it is possible a portion of nonrespondents did not reply based on their lack of investment and therefore we do not know what individuals were dissatisfied.

\subsubsection{Interests and Problem Solving}

The main finding from these cases is that substantive interests are a basis for information gathering and problem solving. In the projects, most prioritized substantive concerns became the foundation for information searches. Information searches filled three distinct roles: 1) information provided the ability to address different substantive concerns; 2) it was a way for individuals to gain understanding about one another's perspectives on issues; and 3) information was a source of creating value. This finding verifies other theorists' description of the utility of joint fact finding in negotiation and collaborative processes (Elliott, 1999; Ozawa, 1991). The utility of information searches was increased by techniques that encouraged clarification such as verbal communication and experience-based learning. 
Part of the difficulty in addressing participant interests is parties' confusion about what will effectively address them, and how interests are prioritized. Pruitt and Carnevale (1993) note that as negotiations continue issues change based on how options are combined and recombined. Some individuals did not use incoming information to reassess how their underlying concerns were affected. Figure 37 depicts a proposed information diagram. Here, individuals can cycle through how incoming information affects their position, and potentially their ideas about the central issue, without explicitly recognizing the impact on interests.

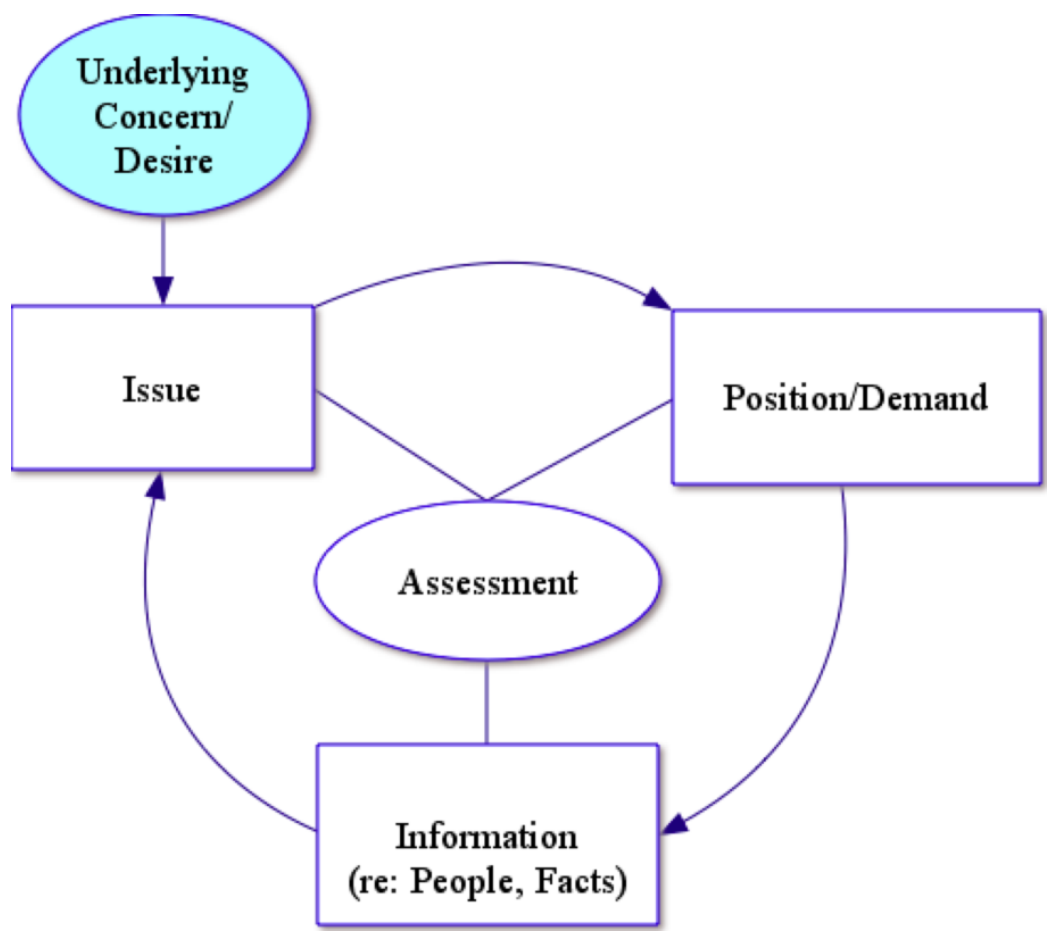

Figure 37. Indirect participant interest assessment potential.

Alternatively, participants can take in information and use it to assess how well their interests are being addressed. It can be difficult to determine the degree of benefit an option will provide to different parties. Figure 38 is a proposed model of how 
individuals take in information and cycle through an assessment process regarding how their positions, the issue, and their interests are affected by incoming information. This model is more likely to happen if participants are asked probing or clarifying questions that explicitly remind them to consider their underlying interests.

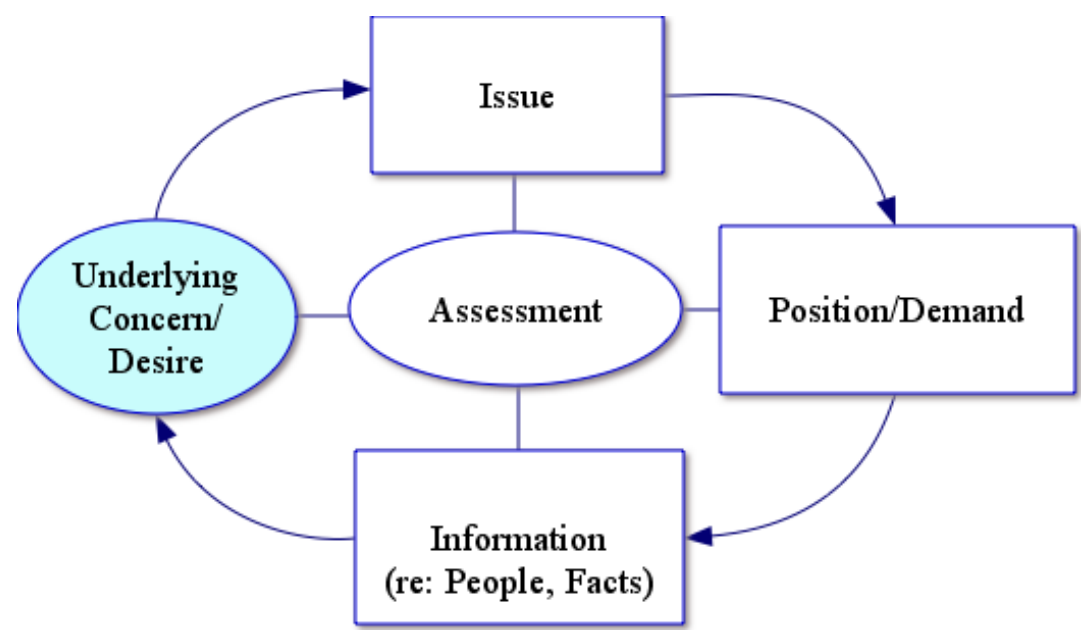

Figure 38. Direct participant interest assessment potential.

Participants in some cases had to be convinced to re-frame their conceptions and move away from that stance. This occurred from a mix of new information and explicit statements about how this would affect their underlying interests. Even when techniques were in place, not all participants considered their interests, especially if their positions were based on a value or what they thought "should" happen.

We know from the Tillamook project that when participant values and deepseated beliefs are in place, even reminders of how options address interests may not counteract a person's fears. In this situation, reaching out to other members of a stakeholder group is helpful. In the Tillamook project, other community members 
were able to see how the community's interests were addressed and helped build support. The implementation phase of Barbara Gray's collaboration model includes building external support and dealing with constituencies. When stakeholder representatives are positional, the process benefits if project staff work on these elements before the agreement.

\subsection{Research Question Four: How interests are addressed}

Facilitation techniques helped participants discuss issues and identify substantive interests. Substantive interests were a basis for information searches and generating options. Each group then selected options that addressed core substantive interests among the stakeholder groups. All projects had elements in their agreements that were directly related to participant interests on substantive issues. Agreements contained outputs that would at least partially address substantive interests based on information and resources.

When substantive interests were intangible, they were difficult to measure. For example, it is difficult to consider the amount of potential air quality improvement compared to potential business loss from different idle reduction technologies. And, it is difficult to measure the potential for different forest management treatments to restore ecosystem health. While different indicators were developed to help measure intangible interests, this is not always possible during a negotiation. Information searches and techniques to help clarify participant understanding of risks and benefits are the best method collaborators have at assessing how future options may impact their interests. 
As described in the previous sections, facilitation techniques also helped identify and address participant relationship and process interests. Staff constructed each collaborative process in a way that helped support participant's relationship and process interests.

\subsubsection{Trust and Relationships}

Addressing participant interests contributed to trust-building among participants. This study showed that trust is a precursor to discussing interests when there is a history of conflict. This is another reason why facilitation techniques were useful. Figure 39 amends Ostrom's (1998) core relationships diagram (boxes in gray).

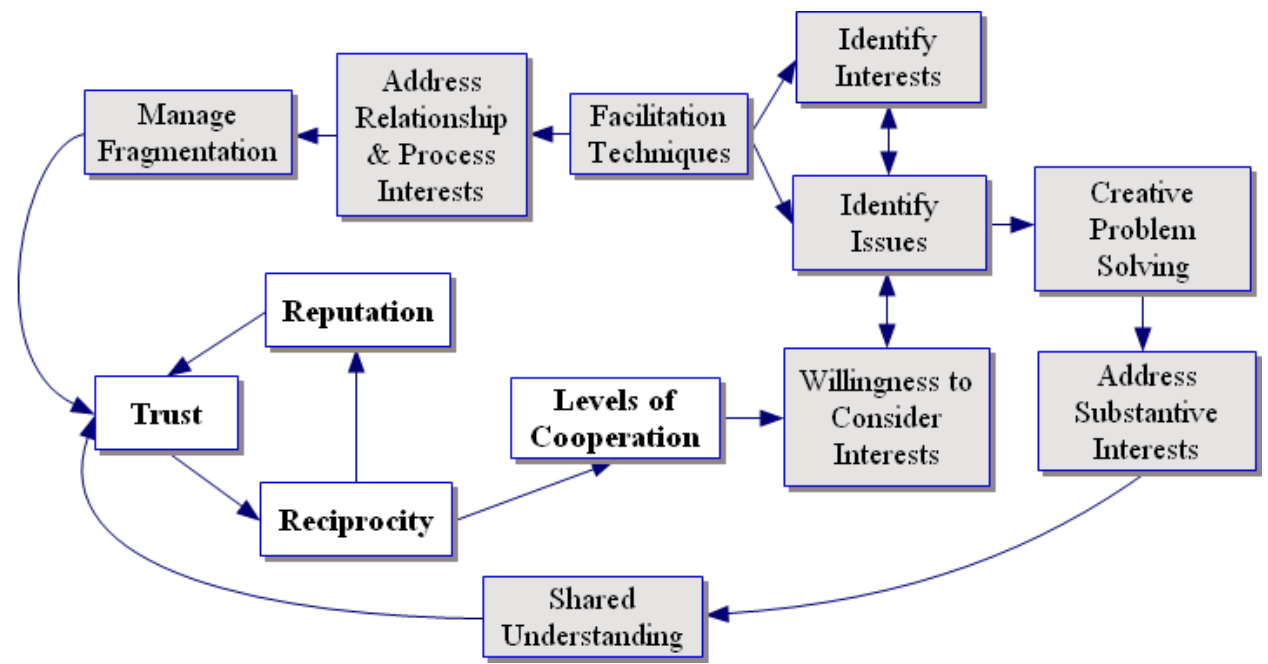

Figure 39. Adapted Core Relationships diagram (from Ostrom,1998).

While Ostrom found that cooperation within groups relates to norms of reciprocity, reputation, and trust, this research found that addressing interests contributes to that feedback loop. The new diagram reflects the potential association between facilitation techniques and integrative bargaining. The shaded boxes indicate two new feedback loops. Facilitation techniques lead to identification of participant 
interests and related issues. Identifying interests can lead to creative problem solving that addresses these interests. This creates shared understanding and promotes trust. When different stakeholders reciprocate this behavior, it leads to a positive reputation and engenders a higher degree of cooperation. This cooperation encourages participants to consider interests and return to identifying issues and related interests.

This diagram reflects the fact that respect and honesty are relationship and process interests. Participants built good relationships through exhibiting and reciprocating respect and honesty, and being trustworthy. When participants did not exhibit these behaviors, as happened on a few occasions in the Tillamook case, trust was undermined. Most participants in all five projects were able to share their substantive concerns, but in cases where the trust was not established, project staff and participant leaders assessed interests and incorporated them into the process. The techniques not only helped participants gain an understanding of substantive information; when leaders addressed stakeholder interests, participants were more willing to listen and share. This is true even of the individuals using distributive tactics in Tillamook: they wanted to ensure they receive the largest possible gain, but they did not want to leave the collaboration.

\subsection{Alternate Explanations and Related Findings}

Lewicki and Litterer (1985) maintain that true integrative bargaining is difficult to achieve because of 1) individual bargaining style; 2) the history of relationships among parties; 3) a belief that an issue can only be resolved with "eitheror" thinking; and 4) most situations involve mixed motives - specifically, competition 
for profits drives out cooperation and trust. Although this research found evidence of integrative bargaining and techniques to build cooperation and trust, there are additional explanations that could have influenced these findings.

\subsubsection{Better Alternatives to a Negotiated Agreement}

Were these projects successful because stakeholders were easy to satisfy? People are more willing to negotiate when the best alternative to a negotiated agreement (BATNA) is not very good. In these cases, one could argue that participant interests may have been relatively easy to address because participants' BATNAs were limited. In the Lane Clean Diesel project no one had anything to lose. In the Tillamook and LSG projects, communities were desperate for a change and agencies wanted to help. In the Biomass and Reduced Engine Idling projects stakeholders worked to take advantage of a potential opportunity.

Integrative bargaining involves examining alternatives that provide mutual benefits. Participants have to assess each alternative based on no agreement, and in contrast to other alternatives. Sen (1970) argues that joint benefits involve each party doing well compared to a lesser outcome. In these projects, different stakeholder groups did do better overall compared to a lesser outcome of not negotiating. Negotiation is a choice. Participants in collaborative processes risk using valuable time, managing challenging relationships, and expending considerable effort for an uncertain gain. These risks become more appealing the less appealing the BATNA is.

In the Lane Clean Diesel and Reduced Engine Idling cases participants would have been unaffected by not collaborating. Instead, the process let participants take 
advantage of an opportunity. In this circumstance, it is likely participants were already focused on their interests and did not have automatic positions. However, a history of mistrust in the Reduced Engine Idling project required that a participant leader address underlying concerns to encourage truck stop owners to participate. The Tillamook and LSG cases included stakeholder groups without good alternatives. For example, in the Tillamook case all of the projects involved flood reduction. Any project was better than nothing. The same was true for the LSG project. In the Biomass project participants had the potential for a new opportunity, and there were limited economic development alternatives that also improved forest health. When the energy investor entered into economic distress the Lakeview community was "held hostage" (as one participant noted).

Arguing that these projects were successfully integrative merely based on a lower BATNA would underestimate the difficulties in collaborating among multiple parties - many of whom did not trust one another - from different organizations, on various complex issues. The groups encountered disruptions and were able to generate creative solutions based on the facilitation techniques and the implicit attention of project staff to participant interests. The lack of a better BATNA most likely contributed to which participants agreed to collaborate and their willingness to engage in creative problem solving. 


\subsubsection{Individuals}

The mix of participants and of personality types most likely helped each case achieve collaborative outcomes. Each core group had both staff members and participants able to think with a system perspective beyond their own concerns and considering everyone's needs. It is possible that the reason so many interests were identified and addressed is because participants thought they were important. Interviews indicated that not only were facilitation techniques important - it was necessary that respected individuals used them. Participants in all cases identified at least one staff member and stakeholder representatives as being crucial. Individuals tracked participant interests and issues because they were motivated to help the group move forward.

Participant perception of their independence or interdependence with others in the collaborative process may have affected individual bargaining styles. When individuals felt their interests were interdependent with those of other stakeholder groups they were more motivated to work for a mutual gain outcome. This may have contributed to participants who developed a stake in other parties' concerns versus maintaining a position. Some participants related to others' interests, a situation described by some theorists as transformative (Bush \& Folger, 2005). Some participants in each of these five projects moved beyond problem understanding to relating to each other's perspectives (D. M. Kolb \& Williams, 2003), appreciating the other participant's barriers (Forester, 2001) and recognizing interdependence (Pearson d'Estree, 2003). In effect, they owned aspects of one another's problems. This did not 
happen with all participants, but it happened with enough of them to help groups use creative problem solving.

\subsubsection{Individual Learning}

Did these collaborative processes address interests due to individuals' diverse learning styles? Were these people just more capable at understanding interests than average? This research indicates that individuals with diverse learning styles are complemented by a variety of facilitation techniques used to help participants understand information. As described earlier, participants learned more about the issues through understanding other participants' interests in all cases other than Tillamook. It is possible that collaborative processes benefit from having individuals who can think creatively, parties who can find information, participants who can generate ideas, and actors who are comfortable taking action. However, in Chapter Two we learned that difficulties arise when diverse learners try to understand each other. The variety of facilitation techniques certainly helped each of these groups increase their ability to use unique learning styles in order to solve a problem.

\subsubsection{Leadership}

Participants' and staff members' ability to rise above their personal interests to work for the collective good may be a function of leadership. The staff members and select participant leaders exhibited leadership skills including adaptability, diplomacy, willingness to assume responsibility, nurturing behavior, intellect, task orientation, and administrative ability (Bass \& Stogdill, 1990, p.80). Some of the successes in these 
projects are due to participants and project managers having the ability to decipher subtexts and identify what people really wanted.

In the words of architect and planner David Best, one crucial element in the deliberation process is “to find out really what the other party wants. He doesn't always say what he wants, or he knows what he wants, but doesn't know how to tell you (Cited in Forester, 2001, p. 104)." This requires keeping presumption in check by not assuming that facilitators know what participants really want amidst confusion. In order to do this, participants need to learn to expect confusion - and expect that a longer amount of time will be necessary to sort through it. Active and appreciative listening (Kolb and Williams, 2003) can help, but listeners have to keep their own conclusions at bay. A "rush to interpretation" tendency creates premature decisionmaking and narrows the negotiation pie (Forester, 2001, p. 105). Leadership definitely contributed to these five cases' integrative outcomes.

\subsubsection{Power and Representation}

Stakeholder groups in each project could have blocked an agreement, and did not successfully do so. Is this because each project had an even balance of power and representation or because one or two players were more powerful? Based on interviews, each project had participants who had power in different domains including financial resources, political clout, and information. Each project had a mix of participants from different organizations, weighted toward representatives of government agencies. Despite larger numbers of agency representatives, community, business, and non-profit organizations often had an equal ability to block the 
agreement in each project. Most core interests were addressed in these projects because each stakeholder group gained something. Only two examples reveal power imbalances.

In the Biomass project, the investor ended up obtaining more financial power and leverage after much of the agreement had been implemented. This example reveals the difficulties in developing an interest-based agreement when competitive economic gains are in the mix. In the Tillamook project, a sub-set of individuals had enough political clout to shake community support of the process. In Tillamook, staff members recognized this potential imbalance and were motivated to identify and address community interests in order to keep the process moving forward. Other community members' participation also spread understanding in that heterogeneous stakeholder group. Adequate representation was important in all five projects and may also have helped motivate individuals to work for options with a higher mutual gain.

The Tillamook project and Lakeview Stewardship project would have been aided from stakeholder representatives working with project staff to inform each constituency about how the process was unfolding. Both projects involved stakeholder groups with heterogeneous compositions; for example the diking district in Tillamook included individuals with businesses along Hwy 101 and farmers. At times during the process, individuals who did not attend regular meetings harbored resentment about issues that had been resolved and were no longer a concern by stakeholders who attended the meetings. The learning shared among the collaborative group will not extend to each group's constituency unless this is an explicit part of the process. 
Project staff attending meetings with stakeholder groups can also help the representative accurately reflect the process.

\subsubsection{Unaddressed Interests}

According to research participants, these projects addressed most stakeholder groups' core interests. However, in at least two projects certain participant interests were unaddressed. It is possible that because interests were not being explicitly tracked, and not all participants were reached, some individuals may still have issues that were not raised and interests that remain unaddressed. It is unlikely a process would be able to address all stakeholders' interests. However, each stakeholder group can gain clarity about the status of their concerns based on explicit discussions of why different interests are not being addressed. Clarity about why an option is not feasible may not prevent a stakeholders' disappointment, but it can prevent the growth of resentment that decisions are being made without stakeholder input, and without stakeholders knowing why those decisions were made. Explicit discussions of interests add transparency to collaborative processes, as advocated by consensus-building theorists (Susskind et al, 1999).

This research also indicates stakeholder groups must assess their interest priorities. In the Tillamook project, community participants valued having equal representation of government and non-government voting members. They also had an interest in gaining as many possible "community" votes when voting was used. One state agency representative contended that members of the diking district are technically government members because they are partially funded through taxes. This 
is an issue that may have required objective criteria such as what constitutes a "community" vote? Regardless of how this issue could have been resolved, at each stage of the process participants had to decide what interests were worth spending time and energy on, and which were of less importance. This may help participants be more aware of unconscious wishes and conflicts that can interfere with planning, collaborating, and implementing agreements as identified by researchers (Baum, 1997; Hirschhorn \& Barnett, 1993; Schwartz, 1990). The more aware participants are of their core concerns and desires, the easier it will for groups to focus on priorities and manage conflict.

\subsection{Limitations and Future Research}

The research findings are limited by potential bias sources from each stage of the research process. The qualitative evidence from interviews may have suffered recall bias. Participants were voluntary and thus may have given positive viewpoints based on their investment. The full range of perspectives including those who were dissatisfied may have been missed. Based on the mix of negative and positive perspectives in the Tillamook case, it appears that the research captured a breadth of perspectives in at least one project. Although a structured instrument was used to guide the interview process, researcher prompts or responses may have shaped participant responses in favor of facilitation techniques or interests.

In the quantitative portion, survey findings are limited by incomplete response rates, central tendency bias on the 3 point scale survey item, and social desirability bias where participants want to please the researcher. The central tendency bias and 
social desirability bias did not appear to affect Tillamook participants from giving negative responses. This was self-report data and subject to the honesty and investment of the individual.

The questions in both the interview and survey required research participants to define and explicitly examine their interests; these instruments acted as interventions during or after the implementation phase for those who participated in the research. This means interviewees had more time than other participants to reflect on the process and the role that interests played; thus their responses may have a positive bias toward interest-based collaboration. However, prior interview exposure did not appear to affect survey responses based on inferential stastic tests.

Five cases is a relatively small sample size, and the number of survey participants could have been higher. Five different cases could be a limitation because each case represents only one of its kind. However, the cases were similar in that they were all successful, multi-party processes that involved facilitation techniques to address community issues. Additionally, the consistency of findings across the five cases despite their differences indicate integrative bargaining and facilitation techniques are important in a range of community dilemmas, political settings, and involving a variety of players.

Future research needs include further examining the relationship between addressing interests and trust building; testing the fragmentation scale for use in conflict assessments before convening collaborative groups; examining failed collaborative processes regarding interests; and examining changes in participants' 
understanding of interests over time in a collaborative process. It would be useful to have an experiment where project managers use techniques and make addressing interests an explicit part of the process in one set of cases, and not do so in another set. This type of study would allow us to better understand other factors, such as individuals and quality of factual information, influences how interests are addressed.

A panel study where collaborative projects are enrolled during a two year window of time and followed from the convening to implementation phases would help researchers measure the use of facilitation techniques, understanding of interests, and trust over time. This would allow researchers to connect hypotheses to specific outcomes in each phase of the collaborative process within an experimental context.

Additionally, the fragmentation scale could be tested on a larger number of cases so that a larger number are examined representing each level of fragmentation. This would help refine the framework as an instrument. A strong framework would allow any project manager to develop a process design based on potential disruptions.

It is also important to examine failed collaborative processes. Did the groups look at interests and fail at addressing them? Do failed collaborative processes ignore them completely? Do failed processes lack facilitation techniques to foster trust and therefore cannot bargain integratively? A comparative case study such as this one or an experimental design such as the one proposed above could help refine what we understand about failed collaborative efforts. 


\subsection{Implications for Collaborative Practice}

This research emphasizes that collaborators and collaborative project staff in multi-party processes will benefit from knowing negotiation-based facilitation techniques. Techniques such as prompting questions and shared learning experiences help increase problem understanding, communication, and the identification of interests among participants. As was evident from this research, when participants are defensive, mistrustful, or using distributive tactics, negotiation based facilitation methods are crucial to managing these social disruptions. Understanding potential disruption types can help process managers better match skilled staff with projects. Collaborative process managers and staff will benefit from using an explicit assessment on participant interests as describe in literature on stakeholder analyses and conflict assessments (Campbell, 2004; Susskind \& Thomas-Larmer, 1999).

Additionally, managers would benefit from characterizing potential disruption types in a process before it takes place. If communities are to collaborate effectively, these skills need to be a part of staff training, planning schools, and leadership training.

As Daniels and Walker (2001) note in their text on collaborative learning, all practitioners are faced with answering the questions when and how of collaboration. Not only must individuals recognize what situations are appropriate for collaboration, they need experience to know which techniques are useful when, and how to connect them. For example, it is possible that saying "I think I heard this: $[\mathrm{x}]$, did I get that right?" to someone who is not accustomed to clarifying questions may put the individual on the defensive out of fear of criticism. In some situations, the project 
manager or facilitator may need to explain to participants what they are doing and why. In the above example, when met with a defensive response the questioner can say "I want to clarify my understanding so that we are on the same page; I am checking my listening skills."

A collaboration advocate needs to be able to assess the limits of using these methods (Daniels \& Walker, 2001). Daniels and Walker (2001) note several factors are important in deciding about the potential for successful collaboration: decision space, stakeholders addressing internal issues before engaging with others, the level of intractability of the issue, and skilled participants. With this in mind, note that practitioners will be well-served at developing experience using these techniques in low-fragmentation, easy, situations before using them in highly fragmented scenarios.

This research confirms the proposition that integrative bargaining is relevant to collaboration practice and is supported by facilitation techniques. The finding that project managers and participant leaders' use of facilitation techniques is the vehicle for discussing participant interests indicates that all multi-party collaborative processes will benefit from having trained participants and projects staff. Collaborative process managers, planners, and participants will be served by understanding the basics of conflict management and integrative bargaining. Project staff can help participants understand how to identify interests at the beginning of the process, similar to reviewing ground rules. Simple discussion of the differences between interests and positions, and reminders to use prompting language can help groups increase their learning potential, craft more innovative agreements, and recognize when participants 
are not able to move away from positions. Use of these techniques involves developing group process norms or codes of conduct in the same way using ground rules can shape behavior. The finding that addressing relationship and process interests support a group's ability to address substantive interests indicates a threshold exists within the field of collaborative processes where potential fragmentation can be managed by participants, and where facilitators with negotiation skills are needed to move a group through a process. Collaborative process managers will benefit in knowing the potential fragmentation as an indicator of the need for more techniques.

The cases in this research were increasingly complex, moving from lower fragmentation to higher with Lane Clean Diesel at the lowest (19 of 39) and the LSG project at the highest (35-36 of 39). All projects involved technical information that affected perception of sub-issues; all projects benefitted from the use of facilitation techniques. However, a difference existed between the two least complex cases, Lane Clean Diesel and Reduced Engine idling, and the more complex cases, Biomass, Tillamook, and the LSG. The more complex projects required staff members to use mediation tactics to help manage relationships away from the table. These methods were also related to the complexity of each problem and the types of technical information. Since a history of skepticism or mistrust existed among stakeholder groups, the ability of these groups to tackle complex problems and accept technical information would have been compromised had techniques not been in place to help manage disruptions. Sources of fragmentation are managed by building shared understanding among participants about the issues, the options, one another's 
perceptions, and interests. Collaborative process managers will benefit in knowing when they need to use these techniques.

The findings from these five cases are not representative to all types of collaborative practice; they are specific to multi-party projects undertaken with institutional support of a parent program such as Oregon Solutions or Sustainable Northwest. These two organizations provide on-going support to facilitators, project managers, conveners, and project participants that include process protocol and a group of experienced practitioners with insight. While multi-party processes such as watershed councils or agency initiated collaborative planning can benefit from negotiation-based techniques described in this research, caution must be taken in applying the suggestions discussed in this section. 


\section{CHAPTER SEVEN}

\section{Conclusion}

This study reinforces the principles of negotiation and conflict resolution in a multi-party collaborative context. This research indicates that regardless of the problem, the context, and the history, collaborative groups use participant interests as a basis for problem solving. Qualitative and quantitative evidence supports that participant interests contribute to participant decisions at each stage of a collaborative process. Participants' understanding of each other's substantive interests was most important to understanding issues, options, and developing agreements. Process managers will benefit from having participants explicitly identify interests in order to promote creative problem solving. Project staff, and participant leaders, use of facilitation techniques helped address participant interests.

Facilitation techniques clearly help collaborative groups clarify problems and address potential disruptive forces. It was not surprising that substantive interests were important in collaborative projects. The findings clarified that addressing participants' relationship and process interests supports problem solving. Relationship interests require attention, as collaborative processes are pulled apart by fragmenting forces such as participant mistrust of each other, or when participants find it difficult accepting technical information. The findings positively indicated that facilitation techniques are crucial in helping participants identify substantive interests, and addressing participant relationship and process interests. 
This research also indicates that facilitation techniques such as clarifying statements and shared learning experiences improved decision-making capacity of participants. This occurred through participants gaining additional information for problem solving about the issues, and participants' interests in those issues. Further, this information gave individuals a better understanding of the central issues and other participants' stake in those issues.

This research found that project staff members and participant leaders with the capacity to use facilitation techniques and the implicit objective of identifying and addressing interests are indispensable for collaborative problem solving. Facilitation techniques and the desire to address interests appear to be components of strong leadership. Part of the effectiveness of these techniques is that trusted, respected individuals used them. Participants were better able to contribute because individuals in each process actively sought out ideas, input, and prompted for clarification. In at least one case, facilitation techniques helped manage disruptions from parties using distributive tactics. These verbal elements occurred within a context of group effort in regular, face-to-face discussions and making decisions together. Facilitation techniques that manage difficult parties can help whole groups work more effectively together.

Focusing on interests is a way to gain more in collaborative processes - it increases innovation and results in more creative outcomes that ultimately provide more value to the bargainers. This research indicates trust is required to allow people who have been in conflict in the past to use interests-based bargaining. This finding 
reinforces the need for facilitation techniques for all types of processes, and a need to determine where the threshold is where mediation becomes crucial for managing stakeholder relationships.

This research raises the question of how to best help collaborators use facilitation techniques and interests-based negotiation. Collaborative programs such as Oregon Solutions and Sustainable Northwest currently focus on helping communities solve problems. An additional service they can serve is to explicitly help communities build the capacity to collaborate. As is evident from this study, facilitation techniques help individuals manage the people and the process so participants can actually focus on the information. Further, stakeholder leaders who are able to use these techniques are better able to help all parties at the table find mutual gain options. In the words of Fisher and Ury (1991), such techniques can help "separate the people from the problem." These programs can strengthen the ability of communities to continue collaborative problem solving by training individuals in the use of these techniques.

Collaborative programs will help communities better implement projects through training stakeholders in these techniques. Each of the collaborative projects examined in this research involved participant leaders and committed participants who remained in place after Oregon Solutions and Sustainable Northwest withdrew direct program support. Facilitation techniques and interest-based negotiation can help individuals develop creative agreements. The capacity to solve problems in the implementation phase, after the agreement is signed and facilitation support departs, must be part of the human capital in each stakeholder group. Using techniques to 
address stakeholder interests can help ensure that groups craft stable agreements that will persist through the implementation phase, and ensure that projects and plans resulting from such processes are designed with deliberation. The results of this study provide public resource managers and planners with initial tools to identify interests as well as understand where communicative techniques that enhance the recognition of interests can be appropriately and strategically employed. In this way, this work has considerable potential for practical applications that will help establish a stronger link between conflict resolution theory and the practice of managing conflict in collaborative processes relevant to community development. 


\section{REFERENCES}

Addendum, T. D. (January, 2009). Declaration of Cooperation Addendum: Oregon Solutions.

Arthur, J., Carlson, C., \& Moore, L. (1999). A practical guide to consensus. Santa Fe, NM: Policy Consensus Initiative.

Austin, J. (2000). The collaboration challenge: How non-profits and businesses succeed through strategic alliances. San Francisco: Jossey-Bass.

Bailey, D., \& Koney, K. (2000). Strategic alliances among health and human services organizations: From affiliations to consolidations. Thousand Oaks, CA: Sage.

Bandura, A., \& Walters, R. H. (1963). Social learning and personality development. New York: Hold, Rinehart and Winston.

Bardach, E. (1998). Getting agencies to work together: The practice and theory of managerial craftsmanship. Washington, D.C.: Brookings Institution Press.

Bass,B.M.(1990). Bass \& Stogdill's handbook of leadership: Theory, research, and managerial applications. New York: The Free Press, A Division of Macmillan, Inc.

Bateson, G. (1972). Steps to an ecology of the mind. New York: Ballatine Books.

Bayley, P. B. (1995). Understanding Large River: Floodplain Ecosystems. BioScience, 45(3), 153-158.

Beazley, M., Griggs, S., \& Smith, M. (2004). Rethinking approaches to community capacity building. Mimeo. Birmingham: University of Birmingham.

Bidwell, R. D., \& Ryan, C. M. (2006). Collaborative partnership design: The implications of organizational affiliation for watershed partnerships. Society and Natural Resources, 19, 827-843.

Bingham, G. (1986). Resolving environmental disputes: A decade of experience. Washington, D.C.: Conservation Foundation.

Blackmore, C. (2007). What kinds of knowlege, knowing and learning are required for addressing resource dilemmas?: A theoretical overview. Environmental Science and Policy, 10, 512-525.

Boddy, D., \& Macbeth, D. (2000). Prescriptions for managing change: A survey of their effects in projects to implement collaborative working between organisations. International Journal of Project Management, 18, 297-306.

Bostrom, G., \& Komar, P. D. (1997). Rocks of the Tillamook Bay drainage basin, the coast range of Oregon - sources of sediment accumulation in the Bay: Tillamook Bay National Estuary Project.

Bourdieu, P. (1985). The forms of capital. In J. Richardson (Ed.), Handbook of theory and research for the sociology of education (pp. 241-258). New York: Greenwood.

Brogden, M. (2003). The Assessment of Environmental Outcomes. In R. O'leary \& L. R. Bingham (Eds.), The promise and performance of environmental conflict resolution. Washington, D.C.: RFF Press. 
Burgess, H., \& Burgess, G. M. (1997). Encyclopedia of conflict resolution. Santa Barbara, CA: ABC-CLIO.

Bush, R. A. B., \& Folger, J. P. (2005). The promise of mediation: The transformative approach to conflict. San Francisco, CA: Jossey-Bass.

Campbell, M. C. (2004). Building a Common Table: The Role for Planning in Community Food Systems. Journal of Planning Education and Research, 23, 341-354.

Carpenter, S. L., \& Kennedy, W. J. D. (1988). Managing public disputes: A practical guide to handling conflict and reaching agreements. San Francisco, CA: Jossey-Bass.

Carr, D. S., Selin, S., \& Schuett, M. A. (1998). Managing public forests: Understanding the role of collaborative planning. Environmental Management, 22(5), 767-776.

Chaskin, R.J., Brown, P., Vankatsh, S., \& Vidal, A. (2001). Building community capacity. New York: Aldine de Gruyter.

Cheng, A. S., \& Mattor, K. M. (2006). Why won't they come? Stakeholder perspectives on collaborative National Forest Planning by participation level. Environmental Management, 38, 545-561.

Coglianese, C. (1997). Assessing consensus: The promise and performance of negotiated rulemaking. Duke Law Journal, 46(5), 1225-1348.

Coleman, J. S. (1986). Individual interests and collective action: Selected essays. Cambridge: Cambridge University Press.

Coleman, J. S. (1990). Foundations of social theory. Cambridge, MA: Harvard University Press.

Colosi, T. (1983). Negotiation in the public and private sectors: A core model. American Behavioral Scientist, 27, 229-255.

Conklin, J. (2006). Dialogue mapping: Building shared understanding of wicked problems. Hoboken, NJ: Wiley.

Connick, S., \& Innes, J. E. (2001). Outcomes of collaborative water policy making: Applying complexity thinking to evaluation. Berkeley: University of California at Berkeley, Institute of Urban and Regional Development.

Consultants, N. H. (July, 2009). Report on First Flood Control Project, Project Exodus. Seattle: Northwest Hydraulic Consultants.

Cortner, H. J., \& Moote, M. A. (1999). The politics of ecosystem management. Washington, DC: Island Press.

Coughlin, C. W., Hoben, M. L., Manskopf, D. W., \& Quesada, S. W. (1999). A systematic assessment of collaborative resource management partnerships. University of Michgan, Michigan.

Coulton, K. C., Williams, P. B., \& Benner, P. A. (1996). An environmental history of the Tillamook Bay estuary and watershed. Garibaldi, OR: Tillamook Bay National Estuary Project.

Creswell, J. W., \& Plano Clark, V. L. (2007). Designing and conducting mixed methods research. Thousand Oaks: Sage 
Daniels, S. E., \& Walker, G. B. (2001). Working through environmental conflict: The collaborative learning approach. Westport, CT.: Praeger.

Davenport, M. A., Leahy, J. E., Anderson, D. H., \& Jakes, P. J. (2007). Building trust in natural resource management within local communities: A case study in the Midewin National Tallgrass Prairie. Environmental Management, 39, 353-368.

DeFelice, E. G. (1986). Causal inference and comparative methods. Comparative Political Studies, 19(3), 415-437.

Deutsch, M. (1973). The resolution of conflict. New Haven: Yale University Press.

Dillman, D. A., Smyth, J. D., \& Christian, L. M. (2009). Internet, mail, and mixedmode surveys: The tailored design method. Hoboken, NJ: John Wiley \& Sons, Inc.

DoC (2006) Biomass Project Declaration of Cooperaton. Portland, OR: Oregon Solutions

DoC Second Addendum. (July, 2009). Tillamook Declaration of Cooperation. Second Addendum. Portland, OR: Oregon Solutions.

DoC, T. (2007). Tillamook Declaration of Cooperation. Portland, OR: Oregon Solutions.

Docherty, J. S., \& Campbell, M. C. (2004). Teaching negotiators to analyze conflict structure and anticipate the consequences of principal-agent relationships. Marquette Law Review, 87(4), 655-664.

Downing, K. (2004). Reduced idling at truck stops: A truck stop electrification pilot project on Oregon's I-5. Portland: Oregon Department of Environmental Quality.

Dreier, P., Mollenkopf, J., \& Swanstrom, T. (2004). Place matters (Vol. 2nd edition). Lawrence: University Press of Kansas.

Dynesius, M., \& Nilsson, C. (1994). Fragmentation and flow regulation of river systems in the northern third of the world. Science, 266, 753-762.

Elliott, M. L. P. (1999). Ch. 5: The role of facilitators, mediators, and other consensus building practitioners. In L. Susskind, S. McKearnan \& J. Thomas-Larmer (Eds.), The Consensus building handbook: A comprehensive guide to reaching agreement. Thousand Oaks, CA: Sage Publications.

EPA (2009). After the storm. Watersheds Retrieved October 1, 2009, from http://www.epa.gov/weatherchannel/stormwater.html

Executive Summary (2005) Biomass project. Available on request from Oregon Solutions.

Field, A. (2005). Discovering statistics using SPSS (2nd edition). London: Sage.

Fischer, F. (2000). Ch. 12 in Citizens, Experts, and the Environment: The politics of local knowledge. Durham and London: Duke University Press.

Fisher, R., Ury, W., \& Patton, B. (1991). Getting to yes: Negotiating agreement without giving in. New York, NY: Penguin Books.

Flyvbjerg, B. (2006). Five misunderstandings about case-study research. Qualitative Inquiry, 12(2), 219-245. 
Follansbee, B., \& Stark, A. (1998). Kilchis watershed analysis: Tillamook Bay National Estuary Project.

Follett, M. P. (1924). Creative experience. New York: Longmans, Green and Co.

Follett, M. P. (1940). Constructive conflict. In H. C. Metcalf \& L. Urwick (Eds.), Dynamic adminstration: The collected papers of Mary Parker Follett. New York: Harper.

Forester, J. (2001). The deliberative practitioner: Encouraging participatory planning processes (3rd ed.). Cambridge, MA: The MIT Press.

Freire, P. (1970). Pedagogy of the oppressed. New York: Seabury.

Gajda, R. (2004). Utilizing collaboration theory to evaluate strategic alliances. American Journal of Evaluation, 25, 65-77.

Gerring, J. (2007). Case study research principles and practices. Boston: Cambridge University Press.

Gintis, H., Bowles, S., Boyd, R., \& Fehr, E. (2005). Moral sentiments and material interests: Origins, evidence and consequences. In H. Gintis, S. Bowles, R. Boyd \& E. Fehr (Eds.), Moral sentiments and material interests: The foundations of cooperation in economic life. Boston, MA: MIT Press.

Glaser, B. G., \& Strauss, A. (1967). Discovery of grounded theory. Strategies for qualitative research: Sociology Press.

Golet, G. H., Roberts, M. D., Luster, R. A., \& Werner, G. (2006). Assessing societal impacts when planning restoration of large alluvial rivers: A case study of the Sacramento River Project, California. Environmental Management, 37(6), 862879.

Gray, B. (1985). Conditions facilitating interorganizational collaboration. Human Relations, 38, 912.

Gray, B. (1989). Collaborating: Finding common ground for multiparty problems. San Francisco: Jossey-Bass Publishers.

Greene, J. C., Caracelli, V. J., \& Graham, W. F. (1989). Toward a conceptual framework for mixed-method evaluation designs. Education Evaluation and Policy Analysis, 11, 255-274.

Habron, G. (2003). Role of adaptive management for watershed councils. Environmental Management, 31(1), 29-41.

Hardin, G. (1968). The tragedy of the commons, Science, New Series, 162 (3859), 243-1248.

Hersen, M., \& Barlow, D. H. (1976). Single-case experimental designs: Strategies for studying behavior. New York: Pergamon.

Hofstadter, D. R. (1985). Ch. 29 The prisoner's dilemma computer tournaments and the evolution of cooperation. In Metamagical themas: Questioning for the essence of mind and pattern. New York: Basic Books.

Hogue, T. (1993). Community based collaborations: Community wellness multiplied. Oregon State University: Oregon Center for Community Leadership. 
Hooper, B. P. (1995). Towards more effective integrated watershed management in Australia: Results of a national survey and implications for catchment management. Water Resources Update (100), 28-35.

Imperial, M. T. (2005). Using collaboration as a governance strategy: Lessons from six watershed management programs. Administration \& Society, 37(3), 281320.

Innes, J. E., \& Booher, D. E. (2003). The impact of collaborative planning on governance capacity. Paper presented at the Annual Conference of Association of Collegiate Schools of Plannin.

Innes, J. E., Gruber, J., Neuman, M., \& Thompson, R. (1994). Coordinating growth and environmental managment through consensus building. Berkeley: University of California.

Interior, Dept. (2007). GPRA Strategic Plan Fiscal Year 2007-2012. U.S. Department of the Interior.

Ison, R., \& Watson, D. (2007). Illuminating the possibilites for social learning in the management of Scotland's water. Ecology and Society, 12(1), 21.

Jason, L.A. (2006). Benefits and challenges of generating community participation. Professional Psychology: Research and Practice. 37, 2, 132-139.

Jargowsky, P. A. (1997). Chapter 7 Chaos or community? Directions for public policy In Poverty and place: Ghettos, barrios, and the American city (pp. 185-186, 193-185, 197-213). New York: Russell Sage Foundation.

Johnson, R. B., \& Onwuegbuzie, A. J. (2004). Mixed methods research: A research paradigm whose time has come. Educational Researcher, 33(7), 14-26.

Julian, D. A. (1994). Planning for collaborative neighborhood problem-solving: A review of the literature. Journal of Planning Literature, 9(1), 3-14.

Kaplan, G. A., Haan, M. N., Syme, S. L., Minkler, M., \& Winkleby, M. (1987). Socioeconomic status and health. In R. W. Amler \& H. B. Dull (Eds.), Closing the gap: the burden of unnecessary illness (pp. 125-129). New York: Oxford.

Kasperson, R. E., Golding, D., \& Kasperson, J. X. (1999). Risk, trust and democractic theory. In G. Cvetkovich \& R. E. Lofstedt (Eds.), Social trust and management of risk (pp. 23-41). London: Earthscan.

Kenney, D. S. (1997). Resource management at the watershed level: An assessment of the changing federal role in the emerging era of community-based watershed management. Western Water Policy Review Advisory Commission.

Kilmann, R. H., \& Thomas, K. W. (1977). Developing a forced-choice measure of conflict-handling behavior: The MODE instrument. Educational and Psychological Measurement, 37, 309-325.

Knowles, M. S. (1980). The modern practice of adult learning: From pedagogy to andragogy (2nd ed.). Chicago: Follett.

Knowles, M. S., \& al., e. (1984). Andragogy in action: Applying modern principles of adult learning. San Francisco: Jossey-Bass.

Kolb, D. A. (1984). Experiential learning: Experience as the source of learning and development. Englewood Cliffs, NJ: Prentice-Hall. 
Kolb, D. M., \& Williams, J. (2003). Everyday negotiation: Navigating the hidden agendas in bargaining. San Francisco, CA: Jossey-Bass.

Komar, P. D. (1997). Sediment accumulation in Tillamook Bay, Oregon. A large drowned-river estuary. Tillamook Bay National Estuary Project.

Komar, P. D., McManus, J., \& Styllas, M. (2004). Sediment accumulation in Tillamook Bay, Oregon: Natural processes versus human impacts. Journal of Geology, 112, 455-469.

Koontz, T. M., \& Thomas, C. W. (2006). What do we know and need to know about the environmental outcomes of collaborative management? Public Administration Review, December(Special Issue).

Lang, W. (1991). Negotiations on the environment. In V. Kremenyuk (Ed.), International negotiation: Analysis, approaches, issues (pp. 343-356). San Francisco: Jossey-Bass.

Laurian, L. (2003). A prerequisite for participation: Environmental knowledge and what residents know about local toxic sites. Journal of Planning Education and Research, 22, 257-269.

Lax, D. A., \& Sebenius, J. K. (1986). The manager as negotiator. New York, NY: The Free Press.

Lax, D. A., \& Sebenius, J. K. (2006). 3-D Negotiation: Powerful tools to change the game in your most important deals. Boston, MA: Harvard Business School Press.

LCDP, D. (March 2005). Lane Clean Deisel Project: Declaration of Cooperation. Portland, OR: Oregon Solutions.

Leach, W. D., \& Pelkey, N. W. (2001). Making watershed partnerships work: A review of the empirical literature. Journal of Water Resources Planning and Management, November/December, 378-385.

Leach, W. D., \& Sabatier, P. A. (2003). Facilitators, coordinators, and outcomes. In R. O'leary \& L. R. Bingham (Eds.), The Promise and Performance of Environmental Conflict Resolution. Washington, DC: RFF Press.

Lewicki, R. J., \& Litterer, J. A. (1985). Negotiation. Homewood, IL: Richard D. Irwin, Inc.

Lewicki, R. J., Weiss, S. E., \& Lewin, D. (1992). Models of conflict, negotiation and third party intervention: A Review and Synthesis. Journal of Organizational Behavior, 13(3), 209-252.

Lindblom, C.E. \& Cohen, D.K. (1979). Usable knowledge: Social science and social problem solving. New Haven, Ct: Yale University Press.

Logsdon, J. M. (1991). Interests and interdependence in the formation of social problem-solving collaborations. Journal of Applied Behavioral Science, 27(1), 23-37.

LRAPA (2009). Lane Regional Air Protection Agency. Retrieved February 2, 2009, from http://www.Irapa.org/projects_and_programs/clean_lane_fuel.php

Mansbridge, J. J. (1990). Beyond self interest. Chicago: The University of Chicago Press. 
Margerum, R. D. (1999a). Getting past yes: From capital creation to action. Journal of American Planning Association, 65(2), 181-192.

Margerum, R. D. (1999b). Integrated envrionmental management: The elements critical to success. Environmental Management, 24(2), 151-166.

Mattessich, P. W., \& Monsey, B. R. (1992). Collaboration: What makes it work. A review of research literature on factors influencing successful collaboration. St. Paul: Amherst H. Wilder Foundation.

McKearnan, S., \& Fairman, D. (1999). Producing Consensus. In L. Susskind, S. McKearnan \& J. Thomas-Larmer (Eds.), The Consensus building handbook: A comprehensive guide to reaching agreement. Thousand Oaks, CA: Sage Publications, Inc.

Mediated Agreement (2009). Decision-Making process for extraction of gravel from Tillamook County rivers. Available by request from Tillamook County.

Meeting Minutes (2005) Biomass project, May 12 and others. Available on request from Oregon Solutions.

Michaels, S. (2001). Making collaborative watershed management work: The confluence of state and regional initiatives. Environmental Management, 27(1), 27-35.

Miles, M. B., \& Huberman, A. M. (1994). Qualitative data analysis (2nd edition). Thsouand Oaks, CA: Sage.

Mill, J. S. (1843). A system of logic. London: John W. Parker, West Strand.

Moore, E. A., \& Koontz, T. M. (2003). A typology of collaborative watershed groups: Citizen-based, agency-based, and mixed partnerships. Society and Natural Resources, 16, 451-460.

MOU (2008). Memorandum of Understanding. Biomass Project: Oregon Solutions. Available at http://www.fs.fed.us/r6/frewin/projects/biomass/mou.pdf.

Olejnik, S., Li, J., Supattathum, S., \& Huberty, C. J. (1997). Multiple testing and statistical power with modified Bonferroni procedures. Journal of Educational and Behavioral Statistics, 22, 389-406.

Onwuegbuzie, A. J., \& Teddlie, C. (2003). A framework for analyzing data in mixed methods research. Thousand Oaks, CA: Sage.

OS Website (2009). Oregon Solutions program information from http://www.orsolutions.org

OS video (Writer). (2009). Tillamook flooding reduction: A collaborative approach. Oregon Solutions (Producer).

Ostrom, E. (1998). A behavioral approach to the rational choice theory of collective action: Presidential address, American Political Science Association, 1997. American Political Science Review, 92(1), 1-22.

Ostrom, E., Gardner, R., \& Walker, J. (1994). Rules, games, and common-pool resources. Ann Arbor: The University of Michigan Press.

Ostrom, E., \& Ostrom, V. (1977). Public goods and public choices. In E. S. Savas (Ed.), Alternatives for delivering public services: Toward improved performance (pp. 7-49). Boulder, CO: Westview. 
Ostrom, V. (1990). Problems of cognition as a challenge to policy analysts and democratic societies Journal of Theoretical Politics, 2(3), 243-262.

Ozawa, C. P. (1991). Recasting science: Consensual procedures in public policy making. Boulder, CO: Westview Press.

Ozawa, C. P. (1993). Improving citizen participation in environmental decisionmaking: the use of transformative mediator techniques. Environment and Planning: Government and Policy, 11, 103-117.

PCI (1997). Policy Consensus Initiative E-news. See www.policyconsensus.org

Pearson d'Estrée, T. (2003). Achievement of relationship change. In R. O'leary \& L. Bingham (Eds.), Promise and performance of environmental conflict resolution. Washington, D.C.: RFF Press.

Pearson d'Estrée, T., \& Colby, B. G. (2000). Guidebook for analyzing success in environmental conflict resolution. Fairfax, VA: Institute for Conflict Analysis and Resolution.

Peterson, A. (2005). Lane Clean Diesel Project. KVAL Channel 13 News.

Peterson, N. L. (1991). Interagency collaboration under Part H: The key to comprehensive, multidisciplinary, coordinated infant/toddler intervention services. Journal of Early Intervention, 15, 89-105.

Picket, K. E., \& Pearl, M. (2000). Multilevel analyses of neighborhood socioeconomic context and health outcomes: A critical review. Journal of Epidemiology and Community Health, 55, 111-122.

Plano Clark, V. L., Creswell, J. W., O'Neil Green, D., \& Shope, R. J. (2008). Mixing quantitative and qualitative approaches: An introduction to emergent mixed methods research. In Handbook of emergent methods. New York: The Guilford Press.

Poncelet, E. C. (2001). "A kiss here and a kiss there": Conflict and collaboration in environmental partnerships. Environmental Management, 27(1), 13-25.

Portes, A. (1998). Social capital: Its origins and applications in modern sociology. Annual Review of Sociology, 24, 1-24.

Project Summary (2005). Biomass project. Available on request from Oregon Solutions.

Pruitt, D. G. (1981). Negotiation behavior. New York, NY: Academic Press.

Pruitt, D. G. (1983). Strategic choice in negotiation. American Behavioral Scientist, 27(2), 167-194.

Pruitt, D. G., \& Carnevale, P. J. (1993). Negotiation in social conflict. Pacific Grove, CA: Books/Cole Publishing Company.

Pruitt, D. G., \& Lewis, S. A. (1975). Development of integrative solutions in bilateral negotiation. Journal of Personality and Social Psychology, 31(4), 621-633.

Pruitt, D. G., \& Rubin, J. Z. (1986). Social conflict. New York: Random House.

Putnam, R. D. (2000). Bowling alone: The collapse and revival of American community. New York: Simon \& Schuster.

Raiffa, H. (1982). The art and science of negotiation. Cambridge, MA: Harvard University Press. 
Raiffa, H. (1983). Mediation of conflicts. American Behavioral Scientist, 27, 195-212.

Raiffa, H., Richardson, J., \& Metcalfe, D. (2002). Negotiation analysis: The science and art of collaborative decision making. Campbridge, MA: The Belknap Press of Harvard University Press.

Reduced Idling, D. o. C. (2005). Reduced Idling Truckstops Declaration of Cooperation. Portland, OR: Oregon Solutions.

Reduced Idling, M. A. (2004). October 25 Meeting Agenda: Oregon Solutions.

Ring, P. S., \& Van de Ven, A. H. (1994). Development processes of cooperative interorganizational relationships. Academy of Management Review, 19(1), 90-118.

Rittel, H., \& Webber, M. (1973). Dilemmas in a general theory of planning. Policy Sciences, 4, 155-169.

Roussos, S. T., \& Fawcett, S. B. (2000). A review of collaborative partnerships as a strategy for improving community health. Annual Review of Public Health, 21, 369-402.

Sabatier, P. A., Focht, W., Lubell, M., Travchtenberg, Z., Vedlitz, A., \& Matlock, M. (2005). Collaborative approaches to watershed management. In P. A. Sabatier, W. Focht, M. Lubell, Z. Tracthenberg, A. Vedlitz \& M. Matlock (Eds.), Swimming upstream: Collaborative approaches to watershed management. Cambridge, MA: The MIT Press.

Salwasser, H. (2004). Confronting the implications of wicked problems: Changes needed in Sierra Nevada National Forest planning and problem solving. USDA Forest Service General Technical Report, PSW-GTR-193, 7-23.

Schelling, T. C. (1960). The strategy of conflict. Cambridge, MA: Harvard University Press.

Schuett, M. A., Selin, S. W., \& Carr, D. S. (2001). Making it work: Keys to successful collaboration in natural resource management. Environmental Management, 27(4), 587-893.

Selin, S., \& Chavez, D. (1995). Developing a collaborative model for environmental planning and management. Environmental Management, 12(9), 189-195.

Sen, A. K. (1970). Collective choice and individual values. San Franciso, CA: HoldenDay.

Senge, P. (2006). The fifth discipline: The art and practice of the learning organization. Doubleday.

Shannon, C., \& Weaver, W. (1948). The mathematical theory of communication. Urbana: University of Illinois Press.

SLIM. (2004). The role of learning processes in integrated catchment management and the sustainable use of water. Policy Briefing Number 6 Available online at: http://slim.open.ac.uk/objects/public/slim-pb6-final-screen.pdf.

Slovic, P. (1999). Perceived risk, trust and democracy. In G. Cvetkovich \& R. E. Lofstedt (Eds.), Social trust and the management of risk (pp. 23-41). London: Earthscan.

Sobel, J. (2002). Can we trust social capital? Journal of Economic Literature, 40(1), 139-154. 
Straus, D. (1999). Designing a consensus building process using a graphic road map. In L. S. Susskind, S. McKernanan \& J. Thomas-Larmer (Eds.), Consensus building handbook: A comprehensive guide to reaching agreement (pp. 137167). Thousand Oaks, CA: Sage.

Susskind, L., \& Cruikshank, J. L. (2006). Breaking robert's rules: The new way to run your meeting, build consensus and get results. Oxford, NY: Oxford University Press.

Susskind, L., \& Field, P. (1996). Dealing with an angry public. New York: The Free Press.

Susskind, L., McKearnan, S., \& Thomas-Larmer, J. (1999a). The consensus building handbook: A comprehensive guide to reaching agreement. Thousand Oaks, CA: Sage Publications.

Susskind, L., McKearnan, S., \& Thomas-Larmer, J. (1999b). Introduction. In L. Susskind, S. McKearnan \& J. Thomas-Larmer (Eds.), Consensus building handbook: A comprehensive guide to reaching agreement. Thousand Oaks, Ca: Sage Publications.

Susskind, L., \& Thomas-Larmer, J. (1999). Conducting a conflict assessment. In L. Susskind, S. McKearnan \& J. Thomas-Larmer (Eds.), Consensus building handbook: A comprehensive guide to reaching agreement (pp. 99-136). Thousand Oaks, CA: Sage Publications.

Thomson, A. M., \& Perry, J. L. (2006). Collaboration processes: Inside the black box. Public Administration Review, December (Special Issue), 20-32.

Tillamook County website (2008). Flood Information. Retrieved October 23, 2009, from http://www.co.tillamook.or.us/gov/ComDev/planning/flood.htm

Tillamook Estuaries Partnership (2009). Wilson-Trask Project. Retrieved September 20, 2009, from http://www.tbnep.org/programs/habitat-enhancement/wilsontrask-wetlands-protection-a-restoration?showall=1

Tillamook Project Assessment. (2007). Oregon Solutions. Available on request.

Trust, T. C. (2009). Climate Trust Website. from www.climatetrust.org/truck_stop.html

U.S. Environmental Protection Agency, U. (2009). National Estuary Program. Retrieved July 19, 2009, from http://www.epa.gov/owow/estuaries/index.html

U.S.Census (2008). Estimates Data. Retrieved October 26, 2009, from http://www.census.gov/popest/metro/CBSA-est2008-annual.html

USACE Feasibility Report. (2005). Tillamook Bay and National Estuary, Oregon general investigation feasibility report. United States Army Corps of Engineers.

Vaaland, T. I. (2004). Improving project collaboration: Start with the conflicts. International Journal of Project Management, 22, 447-454.

Ventriss, C. \& Kuentzel, W.(1985). Critical theory and the role of citizen involvement in environmental decision making: A re-examination. International Journal of Organization Theory and Behavior, 8, 4, 519-539. 
Wall, J. A. (1977). Intergroup bargaining: Effects of opposing constituent's stance, opposing representatie's bargaining, and representative's locus of control. . Journal of Conflict Resolution, 21, 459-474.

Walton, R. E., \& McKersie, R. B. (1965). A behavioral theory of labor negotiations. New York: McGraw-Hill.

Wehr, P. (1979). Conflict regulation. Boulder, CO: Westview Press.

Wilson, G. K. (1982). Why is there no corporatism in the United States? In G. Lembruch \& P. C. Schmitter (Eds.), Patterns of corporatist policy-making. Beverly Hills: Sage.

Wondolleck, J. M., \& Yaffee, S. L. (2000). Making collaboration work: Lessons from innovation in natural resource management. Washington, D.C.: Island Press.

Wood, P. J., \& Armitage, P. D. (1997). Biological effects of fine sediment in the lotic environment. Environmental Management, 21, 203-217.

Yin, R. K. (1984). Case study research: Design and methods (3rd ed.). Beverly Hills, CA: Sage Publications.

Yin, R. K. (2003). Case study research: Design and methods ( $3^{\text {rd }}$ ed. Vol. Five). Thousand Oaks: Sage Publications.

Zenk, S. N., \& Schulz, A. J. (2005). Neighborhood racial composition, neighborhood poverty, and the spatial accessibility of supermarkets in metropolitan Detroit. American Journal of Public Health, 95, 660-667. 


\section{Appendix A: Case Selection Materials}

\section{$\underline{\text { A1. Potential Fragmentation Survey }}$}

Project:

1. What sector(s) initiated this project (circle all that apply)?

Local Community Private sector Non-profits

Government

2. What kind of collaborative process timeline did this project have:

a. Short term collaborating $(\leq 1$ year), one-time implementation $(<5$ years $)$

b. Longer term collaborating (1+ years), one-time implementation

c. Short term collaborating, ongoing implementation

d. Longer term collaborating, ongoing implementation

3. How long had key collaborators been working together on this before it became an Oregon Solutions project?
a. $<1$ year
b. 1-3 years
c. $4+$ years

4. How clearly was the central problem, or main issue, defined by participants at the beginning?

a. clear, all in agreement

b. mixed: some agreement, some differences

c. fuzzy, lots of disagreement

5. Were participant perspectives on the problem aligned or very diverse at the beginning of the project?
a. aligned
b. mixed: some alignment, some differences
c. diverse

6. The amount of uncertainty about the factors that influence its status in this project was:
a. Low
b. moderate
c. high

7. How many solutions were people thinking of at the beginning?
a. 1 or 2
b. 3 or 4
c. $5+$

8. What were the perspectives of participants about the solution(s)?
a. clear, all in agreement
b. mixed: some agreement, some differences
c. fuzzy, lots of disagreement 
9. Technical information (e.g. scientific, engineering) helped lead participants,

a. to clear perspective \& choice (e.g. narrow options down)

b. to a clear perspective/choice in some issues, and inform multiple perspectives/choices on others

c. informed multiple perspectives, choices

10. How many different objectives did stakeholders have in the problem (circle one)?
a. one
b. Few (2-3)
c. Many(4+)

11. How many uncontrollable factors influenced those objectives?
a. one
b. Few (2-3)
c. Many(4+)

12. How much conflicting risk was present among those objectives (e.g. meeting one objective conflicted with meeting others)?
a. low
b. moderate
c. high

13. How would you describe the relationships among participants at the beginning:
a. established
b. mix: some new, some established
c. all new

14. What was the history of disagreements, or conflict, among participants?
a. minor
b. moderate
c. high

15. What was the level of disagreements or potential conflict among participants at the beginning?
a. minor
b. moderate
c. high

16. Did the group attempt to make decisions based on broad agreement, or consensus?

Yes No

17. Within the group of participants was the mix of assertive and accommodating collaborators:
a. balanced, an even mix (or everyone able to do both)
b. mostly accommodators with key asserters
c. mostly asserters with key accommodators 


\section{A2: Screening Criteria for Cases}

This appendix includes the potential fragmentation scoring sheets for all cases.

Table 70 Lakeview Stewardship Screening Results

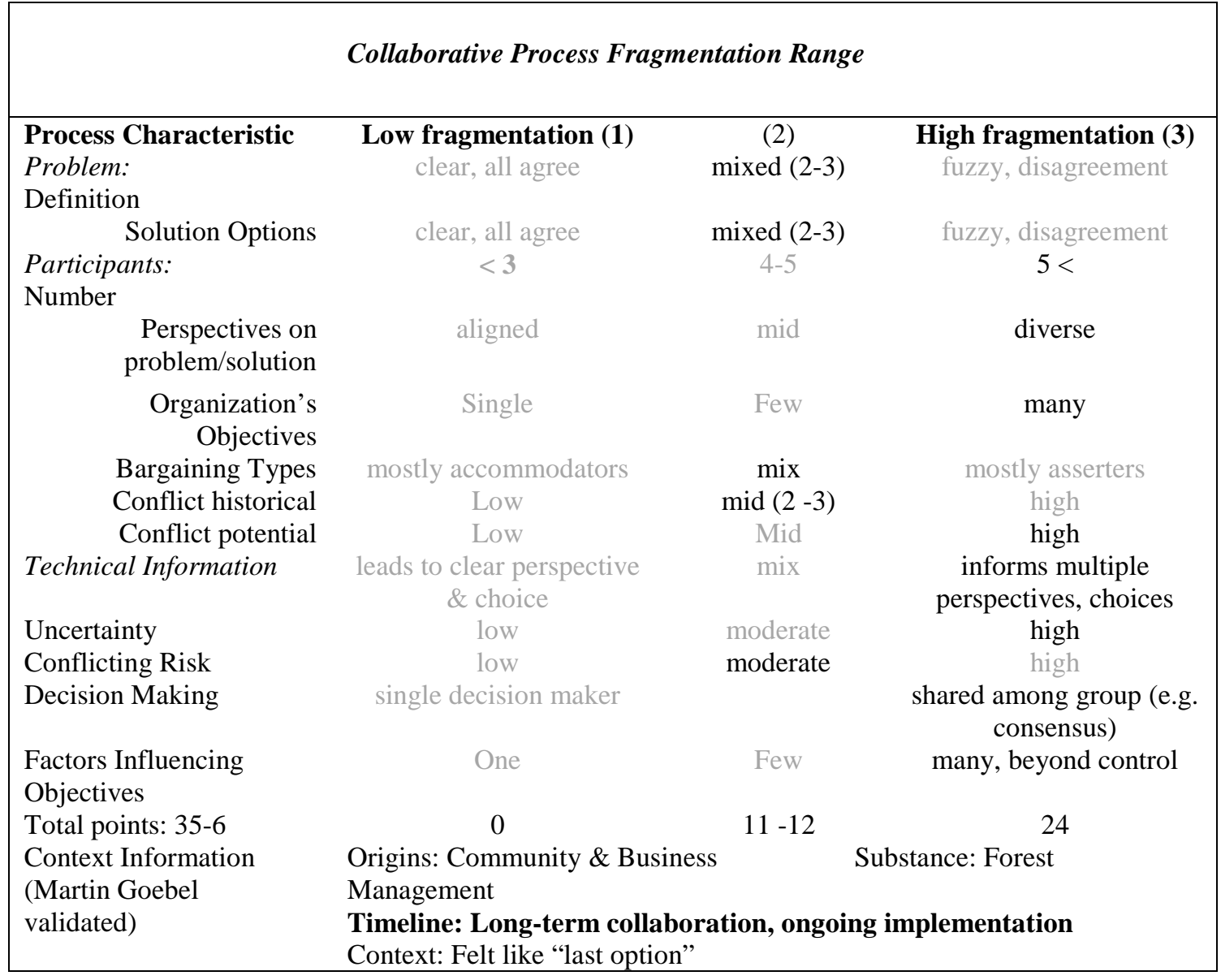


Table 71 Summary Case Range

\begin{tabular}{|c|c|c|c|c|c|c|c|}
\hline \multicolumn{8}{|c|}{ Potential Fragmentation Range } \\
\hline & & lower & $\longrightarrow \longrightarrow \longrightarrow \longrightarrow$ & med & $\longrightarrow \longrightarrow$ & $\rightarrow \longrightarrow \longrightarrow$ & higher \\
\hline & Lane & Reduced & Mid- & & Tillamook & Lakeview & Highest \\
\hline Possible & Diesel & Idling & $\begin{array}{c}\text { level } \\
\text { Possible }\end{array}$ & Biomass & $\begin{array}{l}\text { Flooding } \\
\text { Reduction }\end{array}$ & Stewardship & Possible \\
\hline 13 & 19 & 23 & 26 & 27 & 30 & $35-36$ & 39 \\
\hline
\end{tabular}

Other cases examined with this screening process include: The Pilot, Reedsport: 28.530 score; the Ft. to Sea Trail: 25score; and the N. Bend/Coos Bay Airport: 22 score.

Table 72 Lakeview Biomass Screening Results

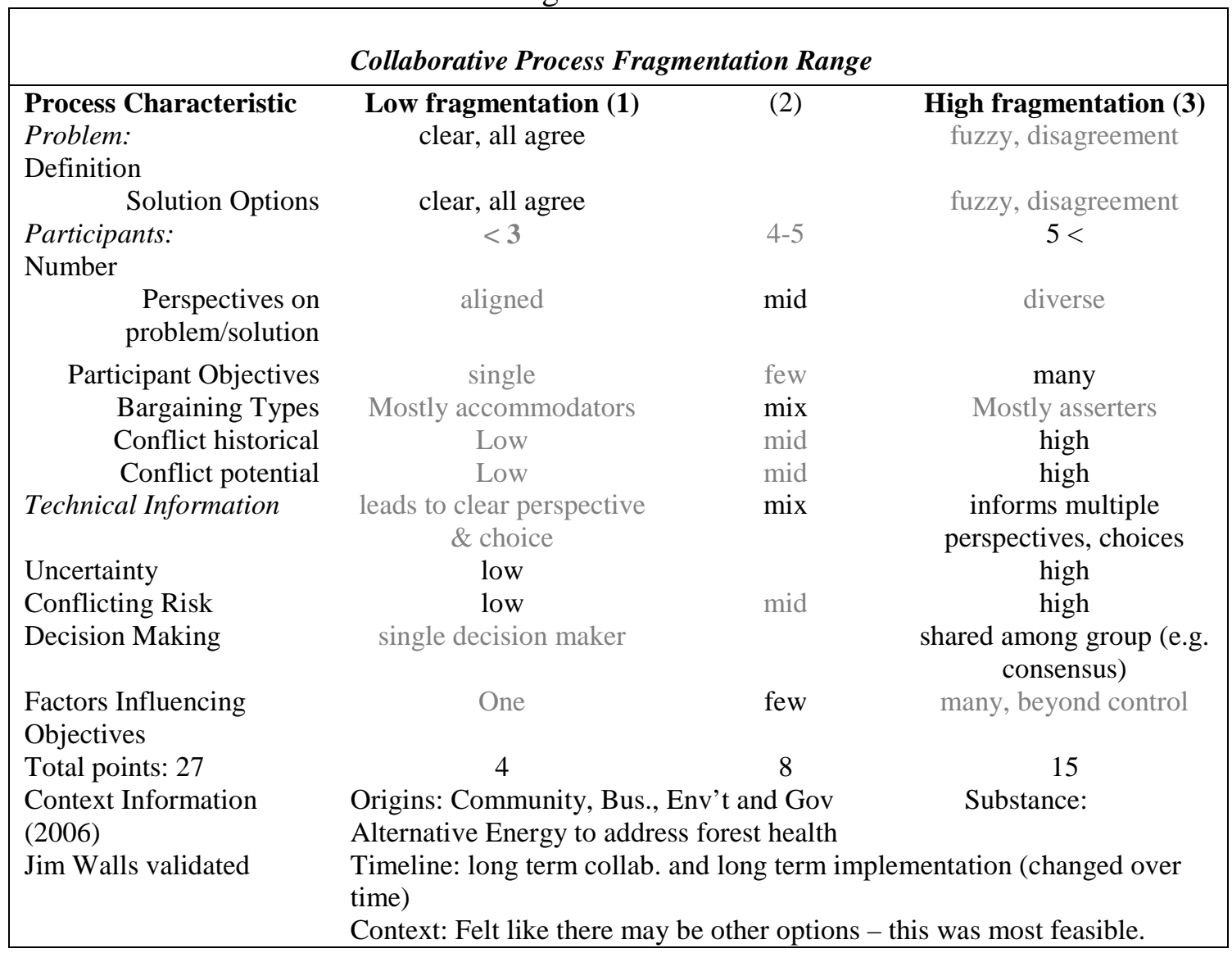


Table 73 Lane County Clean Diesel Screening Results

\begin{tabular}{|c|c|c|c|}
\hline \multicolumn{4}{|c|}{ Collaborative Process Fragmentation Range } \\
\hline \multirow{3}{*}{$\begin{array}{l}\text { Process Characteristic } \\
\text { Problem: } \\
\text { Definition }\end{array}$} & Low fragmentation (1) & (2) & High fragmentation (3) \\
\hline & clear, all agree & & fuzzy, disagreement \\
\hline & & & \\
\hline \multirow[t]{2}{*}{ Solution } & clear, all agree & mid & fuzzy, disagreement \\
\hline & $<3$ & $4-5$ & $5<$ \\
\hline \multicolumn{4}{|l|}{ Number } \\
\hline $\begin{array}{r}\text { Perspectives on } \\
\text { problem/solution }\end{array}$ & aligned & mid & diverse \\
\hline Participant Objectives & single & few & many \\
\hline Bargaining Types & Mostly accommodators & $\operatorname{mix}$ & mostly asserters \\
\hline Conflict historical & low & & \\
\hline Conflict potential & low & & high \\
\hline Technical Information & $\begin{array}{c}\text { leads to clear perspective } \\
\text { \& choice }\end{array}$ & $\operatorname{mix}$ & $\begin{array}{c}\text { informs multiple } \\
\text { perspectives, choices }\end{array}$ \\
\hline Uncertainty & low & mid & high \\
\hline Conflicting Risk & low & mid & high \\
\hline Decision Making & single decision maker & & $\begin{array}{l}\text { shared among group (e.g. } \\
\text { consensus) }\end{array}$ \\
\hline Factors Influencing & few, controllable & & many, beyond control \\
\hline \multicolumn{4}{|l|}{ Objectives } \\
\hline Total points: 20 & 8 & 6 & 6 \\
\hline $\begin{array}{l}\text { Context Information } \\
\text { (2005) }\end{array}$ & $\begin{array}{l}\text { Origins: Agency } \\
\text { address air pollution }\end{array}$ & \multicolumn{2}{|c|}{ Substance: Establish market (supply/demand) to } \\
\hline \multirow[t]{2}{*}{ Josh Proudfoot validated } & Timeline: Short term, one- & time implemes & \\
\hline & $\begin{array}{l}\text { Context: Wanted to create } \\
\text { help get ahead of an upcon }\end{array}$ & $\begin{array}{l}\text { a market conn } \\
\text { ning mandate. }\end{array}$ & f supply to demand, and \\
\hline
\end{tabular}


Table 74 Reduced Engine Idling at Truckstops Screening Results

\begin{tabular}{|c|c|c|c|}
\hline \multicolumn{4}{|c|}{ Collaborative Process Fragmentation Range } \\
\hline Process & Low fragmentation & (2) & High fragmentation \\
\hline Characteristic & (1) & & (3) \\
\hline Problem: & clear, all agree & mid & fuzzy, disagreement \\
\hline Definition & clear, all agree & & fuzzy, disagreement \\
\hline Participants: & $<3$ & $4-5$ & $5<$ \\
\hline Number & & & \\
\hline $\begin{array}{r}\text { Perspectives on } \\
\text { problem/solution }\end{array}$ & aligned & $\operatorname{mid}$ & diverse \\
\hline Participant Objectives & single & Few & many \\
\hline Bargaining Types & mostly accommodators & mix assert/accomodaters & Mostly asserters \\
\hline Conflict historical & low & mid & \\
\hline Conflict potential & Low & mid & high \\
\hline Technical Information & $\begin{array}{c}\text { leads to clear } \\
\text { perspective \& choice }\end{array}$ & & $\begin{array}{c}\text { informs multiple } \\
\text { perspectives, choices }\end{array}$ \\
\hline Uncertainty & low & mid & high \\
\hline Conflicting Risk & low & mid & high \\
\hline Decision Making & single decision maker & & $\begin{array}{l}\text { shared among group } \\
\text { (e.g. consensus) }\end{array}$ \\
\hline $\begin{array}{l}\text { Factors Influencing } \\
\text { Objectives }\end{array}$ & few, controllable & & many, beyond control \\
\hline Total points: 23 & 5 & 12 & 6 \\
\hline $\begin{array}{l}\text { Context Information } \\
\text { (2005) }\end{array}$ & $\begin{array}{l}\text { Origins: Agency } \\
\text { pollution/quality of life }\end{array}$ & $\begin{array}{l}\text { Substance: Install infrastr } \\
\text { r truckers }\end{array}$ & ture to address air \\
\hline Kevin Downing/Pete & Timeline: Short-term, or & time implementation & \\
\hline Dalke validated & $\begin{array}{l}\text { Context: Able to use son } \\
\text { help address past concer }\end{array}$ & $\begin{array}{l}\text { funding to help reduce co } \\
\text { of community clash with }\end{array}$ & $\begin{array}{l}\text { and help folks out, } \\
\text { ckstops. }\end{array}$ \\
\hline
\end{tabular}


Table 75 Tillamook Flooding Reduction Screening Results

\begin{tabular}{|c|c|c|c|}
\hline \multicolumn{4}{|c|}{ Collaborative Process Fragmentation Range } \\
\hline Process Characteristic & Low fragmentation (1) & (2) & High fragmentation (3) \\
\hline Problem: & clear, all agree & & many, disagreement \\
\hline Definition & & & \\
\hline Solution & clear, all agree & mid & many, disagreement \\
\hline Participants: & $<\mathbf{3}$ & $4-5$ & $5<$ \\
\hline Number & & & \\
\hline $\begin{array}{r}\text { Perspectives on } \\
\text { problem/solution }\end{array}$ & aligned & $\operatorname{mix}$ & diverse \\
\hline Participant Objectives & Single & few $(1-3)$ & many $(4+)$ \\
\hline Bargaining Types & mostly accommodators & $\operatorname{mix}$ & mostly asserters \\
\hline Conflict historical & low & mid & high \\
\hline Conflict potential & low & mid & high \\
\hline Technical Information & $\begin{array}{c}\text { leads to clear perspective \& } \\
\text { choice }\end{array}$ & $\operatorname{mix}$ & $\begin{array}{c}\text { informs multiple } \\
\text { perspectives, choices }\end{array}$ \\
\hline Uncertainty & low & mid & high \\
\hline Conflicting Risk & low & $\operatorname{mid}$ & high \\
\hline Decision Making & single decision maker & & $\begin{array}{l}\text { shared among group (e.g. } \\
\text { consensus) }\end{array}$ \\
\hline Factors Influencing & few, controllable & & many, beyond control \\
\hline Objectives & & & \\
\hline Total points: 30 & 1 & 14 & 15 \\
\hline $\begin{array}{l}\text { Context Information } \\
(\mathbf{2 0 0 7 )}\end{array}$ & $\begin{array}{r}\text { Origins: Cross sector suppor } \\
\text { Substance: Floodin }\end{array}$ & $\begin{array}{l}\text { iated by loc } \\
\text { uction }\end{array}$ & y/county government \\
\hline $\begin{array}{l}\text { Dick Townsend } \\
\text { validated }\end{array}$ & $\begin{array}{l}\text { Timeline: Short term collabc } \\
5+\text { years } \\
\text { Context: Level of desperatio }\end{array}$ & (for DoC) & $\begin{array}{l}\text { oing implementation, } 1.5- \\
\text { irn. }\end{array}$ \\
\hline
\end{tabular}




\section{Table 76 North Bend/Coos Bay Airport Terminal Screening Results}

\begin{tabular}{|c|c|c|c|}
\hline \multicolumn{4}{|c|}{ Collaborative Process Fragmentation Range } \\
\hline Element & $\begin{array}{c}\text { Low fragmentation } \\
\text { (1) }\end{array}$ & (2) & $\begin{array}{c}\text { High fragmentation } \\
\text { (3) }\end{array}$ \\
\hline $\begin{array}{l}\text { Problem: } \\
\text { Definition }\end{array}$ & clear, all agree & $\operatorname{mix}$ & fuzzy, disagreement \\
\hline Solution & few, all agree & $\operatorname{mix}$ & many, disagreement \\
\hline $\begin{array}{l}\text { Participants: } \\
\text { Number }\end{array}$ & $<\mathbf{3}$ & $4-5$ & $5<$ \\
\hline $\begin{array}{r}\text { Perspectives on } \\
\text { problem/solution }\end{array}$ & aligned & $\operatorname{mix}$ & diverse \\
\hline Participant Objectives & Single & few & many \\
\hline Bargaining Types & $\begin{array}{c}\text { mostly } \\
\text { accommodators }\end{array}$ & mix assert/accommodators & mostly asserters \\
\hline Conflict historical & low & mid & high \\
\hline Conflict potential & low & med & high \\
\hline Technical & leads to clear & $\operatorname{mix}$ & informs multiple \\
\hline Information & perspective \& choice & & perspectives, choices \\
\hline Uncertainty & low & med & high \\
\hline Conflicting Risk & low & mid & high \\
\hline Decision Making & single decision maker & $2-3$ & $\begin{array}{l}\text { shared among group } \\
\text { (e.g. consensus) }\end{array}$ \\
\hline $\begin{array}{l}\text { Factors Influencing } \\
\text { Objectives }\end{array}$ & few, controllable & $\operatorname{mix}$ & many, beyond control \\
\hline Total points: 22 & 7 & 6 & 9 \\
\hline $\begin{array}{l}\text { Context Information } \\
(\mathbf{2 0 0 4 )} \\
\text { Dick Townsend } \\
\text { validated }\end{array}$ & \multicolumn{3}{|c|}{$\begin{array}{l}\text { Origins: Private/Non-profit/Government Substance: Build Airport Terminal } \\
\text { Timeline: short term collaborating ( } \leq 1 \text { year), one time implementation (less } \\
\text { than } 5 \text { years) } \\
\text { Context: Legislature passed } \$ \text { to build the airport }\end{array}$} \\
\hline
\end{tabular}


Table 77 Ft. Clatsop Trail Screening Results

\begin{tabular}{|c|c|c|c|}
\hline \multicolumn{4}{|c|}{ Collaborative Process Fragmentation Range } \\
\hline Process & Low fragmentation & $(2)$ & High fragmentation \\
\hline Characteristic & (1) & & (3) \\
\hline Problem: & clear, all agree & mid & fuzzy, disagreement \\
\hline Definition $\quad$ Solution & clear, all agree & mid & fuzzy, disagreement \\
\hline $\begin{array}{l}\text { Participants: } \\
\text { Number }\end{array}$ & $<3$ & $4-5$ & $\mathbf{5}<$ \\
\hline $\begin{array}{r}\text { Perspectives on } \\
\text { problem/solution }\end{array}$ & aligned & $\operatorname{mid}$ & diverse \\
\hline Participant Objectives & single & few & many \\
\hline Bargaining Types & mostly accommodators & mix assert/accomodaters & Mostly asserters \\
\hline Conflict historical & Low & mid & high \\
\hline Conflict potential & Low & $\operatorname{mid}$ & high \\
\hline Technical Information & $\begin{array}{l}\text { leads to clear } \\
\text { perspective \& choice }\end{array}$ & & $\begin{array}{l}\text { informs multiple } \\
\text { perspectives, choices }\end{array}$ \\
\hline Uncertainty & low & $\operatorname{mid}$ & high \\
\hline Conflicting Risk & low & $\operatorname{mid}$ & high \\
\hline Decision Making & single decision maker & & $\begin{array}{l}\text { shared among group } \\
\text { (e.g. consensus) }\end{array}$ \\
\hline $\begin{array}{l}\text { Factors Influencing } \\
\text { Objectives }\end{array}$ & few, controllable & & many, beyond control \\
\hline Total points: 25 & 4 & 12 & 9 \\
\hline Context Information & Origins: Government & Substance: Build & ail (heritage) \\
\hline (old, 2003) & Timeline: Short term, or & oing implementation & \\
\hline Pete Dalke validated & $\begin{array}{l}\text { Context: Build a trail to } \\
\text { social impact highest }\end{array}$ & alize a vision - need to co & dinate among players, \\
\hline
\end{tabular}




\section{Table 10 repeat PILOT- Reedsport Wave Energy Plant Screening Results}

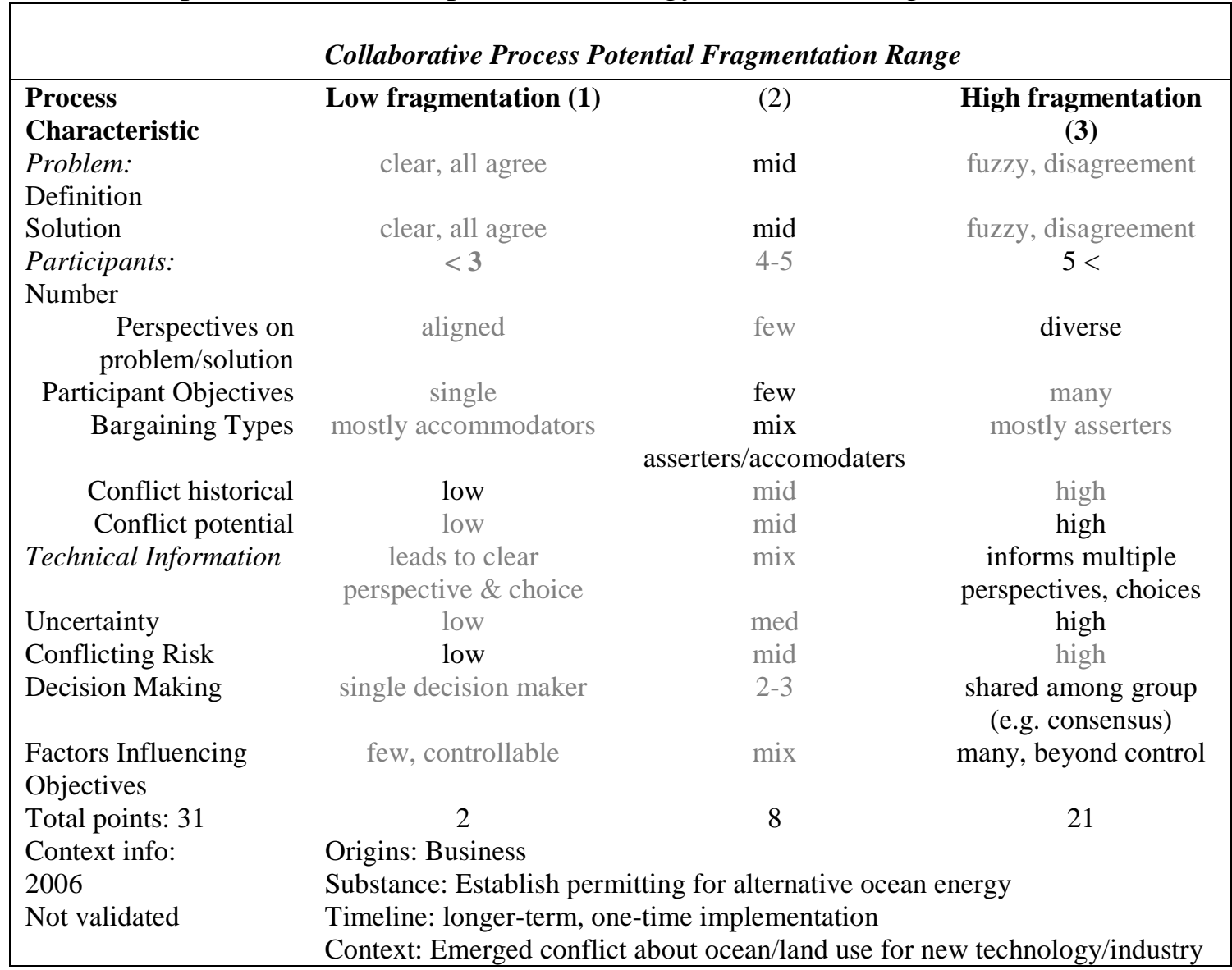




\section{Appendix B: Case Protocol}

\section{Purpose: To collect data to answer the following questions:}

1. Are compatible, or shared, interests being generated in collaborative processes?

2. If so, how does managing people and process (e.g. use of communicative techniques) influence discussion of party's interests?

3. If interests are generated, is this a factor in implementation of collaborative agreements?

4. If so, how does it relate to other factors contributing to implementation of collaborative agreements?

\section{Pre-Data Collection Procedures}

\section{A. Understand case background}

- Read files/DoC from O.S. on all cases once without taking notes, repeat to capture details in outline.

- Web search for press/other supporting lit (use $1^{\text {st }} 3$ pages of Google results)

- Read files/DoC from O.S. on all cases to understand:

- What are the politics?

- What is the history of the problem?

- Who are the players?

- What are the power relationships?

- What are the player's histories (e.g. to each other, to the problem)?

- From an outside perspective, what are each person/org's interests?

- Who is mandated to be there?

- Who are the core movers in each case? Why? What makes it so?

- Where are the key resources coming from (e.g. the foundational and mobilizing assets)?

- Write up preliminary case summary of these as foundation. This is also baseline to some degree.

- Use this expanded document to write up the preliminary assessment document.

- Develop list of questions and ask Kim for clarification on each:

- Why were the convenor and OS staff person chosen for this particular case?

- Are there any particular political relationships, sensitivities, etc. that OS knows about that I didn't capture?

- How determine who signs DoC/not (other than resources committed)?

\section{B. Develop case database}

- Players and contact information from the DoC

- Problem conception from background/DoC

- Track key resources 
- Interests

\section{Make first contact with conveners, project managers and OS staff.}

- Call and email. Write brief introduction with purpose and request. Send human subjects/interview once they respond with a "yes". Ask for three conversations: initial 15 minute case background questions and 45 minute triad or paired interview with others, and follow up emails/phone calls to clarify.

- Do initial 15 minute feel out conversations so they know you understand the basic history of the case and to build trust (e.g. ask them questions Kim couldn't answer first). Explain this is just for background at this point,

- Write "declined participation" for those who say "no".

\section{Stage 1 Case Data Collection}

\section{A. Conduct interview}

- This will help form foundation skeleton of how things unfolded, and help create a map of what happened.

- For in person interviews, make notes similar to what doing in phone for same reason.

- Begin data sorting/arranging/coding within related database.

- Create narrative outline based around research questions. asking follow up questions to make sure what you're depicting is really what they think happened (you're going to be using some of your own techniques here!)

\section{B. Conduct participant interviews}

- Flesh out narrative from different perspectives

- After each interview, download information and translate to transcription

- Begin building narrative. 1) what happened overview/umbrella which includes major external factors 2) interests and techniques, 3) key interests connecting to key shifts in problem conception, resource allocation and implementation components.

\section{Develop case study summary}

D. Have third party reviewer (?) look at case maps, summary and see if they come to the same conclusions about key concepts (review Darcy's study). IV. Analysis Plan for Case Study Reports
A. Individual Cases
1. Descriptive narrative
Background information listed above.
2. Explanatory narrative 
- Codes from interviews will help develop linkages re: interests, communicative techniques, and potential relationships to problem conception, resource allocation and implementation process.

Potential codes are both general and specific in nature. I will write a code book defining what each word means and is attempting to encompass.

\section{- Potential Interests Codes}

Environmental: Econserve, Emanage, Edevelop, Epolltnmngmt

Social: Scapital, Sequity, Sculture, Scmmtyinvolve, Spreserve, Sagreement

Economic: ECgrow, ECjobs, ECinfrastructure, ECsustain

Government: Gregulation, Gintergovrelations, Gmandate

Political: Pclout, Pbipartisanship, Pavoidlegalsanctions

Community

Organizational

Individual: Ifinish, Itrust, Icareer, IlovesOS, Ipreworkrelations

Power: PWRmoney, PWRrelations, PWRforce, PWRinfo

Interests will exist/evolve in tiers. These tiers are connected, and may be motivating individuals from different strengths at different times. All three levels may have interests that are efficiency-oriented or values/beliefs oriented.

Tier one is general and overarching. Many parties may want new jobs in the region, environmental protection, and social equity.

Tier two is at the organizational level. One government organization may be especially focused on environmental issues, and not value others as highly.

Tier one is the personal. Individuals may simply want to finish a project, be involved because of a previous working relationship (they have fun together), or appreciate the OS process.

Among these three levels is the realm of collective group interests. Other factors contribute to how individual, organizational and general interests are managed in a collaborative process. Power in the shape of financial or physical resources, information, relationships, and mandates have a role of their own. The interests will also shift over time. I will create a stage model based on key junctures, changes of the process that help identify shifts in interests/problem conception/or resource allocation. There will be a gap between agreement and implementation, then the stages should continue (either not shifting too much or completely new based on who the parties are and how it goes).

- Potential mechanisms that aid in generating interests: communicative

i. facilitator structured timing of certain topics

ii. list of interests 
iii. list of alternatives

iv. did people ask one another "what does that mean?" or "what does that look like?"

meeting techniques

v. face-to-face

vi. meetings among core groups or individuals for particular substantive discussions

vii. meetings sequenced to build discussions

viii. one-on-one meetings with individuals

props (e.g. figures, photos, schemes, diagrams to illustrate)

information centered

ix. joint fact finding

$\mathrm{x}$. single text document

The interests and mechanisms are one level of analysis in the explanatory narrative. The second level is how understanding interests contributes to changes in problem conception over time, understanding of what resources are needed to address it, commitments to address it (e.g. were these established at the beginning or did they change as a result of the collaboration process?), and implementation of the commitments.

Here are some diagrams of how things might look for a given case:

Technique1---- $\rightarrow$ Interest parties A, B, C

Technique2-- $\rightarrow$ Interests of parties D-F, revision of party A

Interests/Parties A,B,C ---- $\rightarrow$ Key problem features/elements

Interests/Parties D, G ----- $\rightarrow$ additional features, don't agree to elements 1 and 4 Final problem elements people acted on

Problem element 1, 2 and $3---\rightarrow$ Resource allocation by parties A, B,C

Problem element 4 ---------- $\rightarrow$ not addressed because not in final problem element, related to interests of Party $\mathrm{K}$ who missed a meeting

*funding withdrew*

*PartyK withdrew* $---------\rightarrow$ Agreement shifted, resource $\mathrm{X}$ removed

Interests/Parties A,B,C ----- $\rightarrow$ Implement commitment related to resource/problem Interests/Parties K ---------- > Party G commits to some of previous party K's

commitment, but area missing

3. Case report summary

4. Accompanying diagrams 


\section{Stage 2 Follow Up Survey Data Collection}

\section{Develop follow-up survey from core concepts in case studies.}

- This draft can be made after $1^{\text {st }}$ case, and amended upon each subsequent case. Potential factors in implementation:

People:

- Understood one another

- Able to handle conflict before implementation

- Able to handle conflict during implementation Information:

- Understood problem

Process:

- External support (role of party in DoC)

- Implementation plan

- OS convenor

- OS project manager

Other:

- Sufficient funding

- Community involvement

- The third party review responses should also be incorporated (if there are changes).

- Pilot survey among already completed implemented case (maybe the first one?) to see if it supports what I learned at the beginning. Should be nearly same match. If discrepancies, have to explain/refine survey. 


\section{Appendix C: Data Collection Instruments}

\section{$\underline{\text { C1. Staff Interview }}$}

(Case \#)

Code:

1. What role did discussing participant interests play in this collaboration? What did this look like in your approach?

Prompt definition if needed: "Interests" are participant needs, desires, or values; or what each person hopes to get out of a negotiated agreement.

Example: A woman wants an increase of $\$ 10,000$ a year in her salary. The salary raise is the issue; her position, or demand is the monetary increase; and her concerns, desires, or interests include financial security, valuing her self worth, etc.

2. How did you tailor the five OS steps process to the needs of the project?

3. Can you tell me which individuals where most involved, or were otherwise key to this project? Who should I make sure to interview and why?

4. What were the central problems, or issues, addressed in this project?

5. What specifically happened in the collaborative process that helped you understand the central problems?

Prompts: Meetings (face to face, one on one, specific groups, people with concerns, experts with lay individuals), timing of conversations, written communications (single text document, list of interests, lists of options, letters, summary memos), joint fact finding, someone asked probing questions, active listening, others?

6. How did the key features of the central problem change during the process?

7. What were the key interests, desires, or concerns, of participants?

8. What specifically helped you understand differences and similarities in interests?

9. Did you do anything to address differences among participants? Please explain. 
10. How did interests, desires, or concerns, change among participants during the process?

11. Can you describe an example of when a key difference started out as a subject of disagreement and then became an area of agreement, or vice versa?

12. Do you think differences or similarities of interests influenced how parties understood the problem? How?

13. How did the resources allocated to address the central issue change during the process?

14. Please describe the collaborative process about how your group arrived at the commitments in the Document of Cooperation.

15. What elements of the collaboration were key, in your mind, to implementing the DoC? Prompts: parties involved, funding, mediator/convener/facilitator, type of project, history, the DoC commitments, a work plan, etc.

16. What could have helped you better implement what was in the DoC? 


\section{C2. Participant Interview}

(Case \#)

Code:

1. What did you, and your organization, hope to get out of being involved in the (project name)?

2. What were the central problems, or issues, addressed in this project?

3. What specifically happened in the collaborative process that helped you understand the central problems?

Prompts: Meetings (face to face, one on one, sub-groups, discussions, experts with lay individuals), timing of conversations, written communications (single text document, list of interests, lists of options, letters, summary memos), group edited documents, joint fact finding, someone asked probing questions, visual aides, etc.

4. How did the key features of the central problem change during the process?

5. What were the key interests, desires, or concerns of participants?

Example: A woman wants an increase of $\$ 10,000$ a year in her salary. The salary raise is the issue, her position, or demand is the increase, and her interests, concerns or desires, include financial security, valuing her self worth, etc.

6. What specifically helped you understand differences and similarities in interests?

Prompts: same as \#3.

7. How did interests, desires, or concerns, change among participants during the process?

8. Can you describe an example of when a key difference started out as a subject of disagreement and then became an area of agreement, or vice versa?

9. Do you think differences and similarities of interests influenced how parties understood the problem? How?

10. How did the resources allocated to address the central issue change during the process? 
11. Please describe the collaborative process about how your group arrived at the commitments in the Document of Cooperation.

12. What elements of the collaboration were key, in your mind, to implementing the DoC? Prompts: parties involved, funding, mediator/convener/facilitator, type of project, history, the DoC commitments, a work plan, etc.

13. What could have helped this group better implement what was in the DoC? 


\section{C3. Staff Follow-Up Survey Example}

All surveys were the same except on question twelve. Three of the five cases' interest lists are in Appendix C5. Tillamook's list is in the Participant survey in Appendix C4.

\section{Lane Clean Diesel Collaboration}

Thank you for filling out this survey. Since it has been several years since your involvement, please fill it out based on your role at the time. It will take about 10-15 minutes. Please remember all information is confidential. Your responses will not be matched with a name, address or other identifying information. There are no right or wrong answers. If you have any questions, please contact Tia Henderson, 503-887-8101.

Your responses will help us better understand collaborative processes.

1) My role in this process was:

$\square$ Convener

$\square$ Project manager/facilitator

$\square$ Other (please specify)

If you selected other, please specify

2) Number of years I've spent working on the central issues in this project (e.g. flooding reduction, truck idling)?

Questions in this survey are about issues and interests.

"Issues" are the details of the subject your group was working on: e.g. flooding reduction, air pollution, forest health, jobs

"Interests" are what people really care about underneath any issue. Interests are underlying needs, concerns or desires. Below is a simple example:

Issue: Pesticide use

Related issues: garden care, chemical break down, animal habitat, stream health, weeds, pests

Jane's Position: No!

Tom's Position (her husband): Yes!

Her Interests:

His Interests:

1) fears poisoning birds \& fish

1) wants to have a nice yard

2)wants to have a nice yard

2) does not want to fight with Jane.

When you see the word "issues" please think about the details of the subject the group worked on. When you see the word "interests" please think about the details of what people really cared about.

3) The types of participants that most helped me understand issues in this project include (choose all that apply):

People with important resources (e.g. on-the-ground information, money, permitting information, scientific information)

$\square$ The convener(s) 
The project manager/facilitator

Leaders in the project other than the facilitator or convener

People who see things like I do

People with see things differently than I do

4) The information that most helped me understand issues in this process include (choose all that apply):

$\square$ Participant presentations (e.g. research, cost-analysis)

Visiting expert presentations

Small project results

A monitoring program

Meeting minutes

Summary documents (e.g. Declaration of Cooperation, MOU)

Other (please specify)

If you selected other, please specify

5) The types of meetings that most helped me understand issues and/or interests in this process include (choose all that apply):

\begin{tabular}{|l|c|c|}
\hline & $\begin{array}{c}\text { Issues (details of the } \\
\text { subject) }\end{array}$ & $\begin{array}{c}\text { Interests (what people } \\
\text { cared about) }\end{array}$ \\
\hline Face to face & $\square$ & $\square$ \\
\hline Project team (e.g. whole group) & $\square$ & $\square$ \\
\hline Sub-committee/sub-group & $\square$ & $\square$ \\
\hline On-site in the community & $\square$ & $\square$ \\
\hline Open to the public & $\square$ & $\square$ \\
\hline Regular meetings & $\square$ & $\square$ \\
\hline Private meetings with a facilitator(s) or convener(s) & $\square$ & $\square$ \\
\hline $\begin{array}{l}\text { Private meetings with a leader other than the } \\
\text { facilitator or convener }\end{array}$ & $\square$ & $\square$ \\
\hline $\begin{array}{l}\text { Side meetings with people who care about the same } \\
\text { things }\end{array}$ & $\square$ & $\square$ \\
\hline $\begin{array}{l}\text { Side meetings with people who care about different } \\
\text { things }\end{array}$ & $\square$ & $\square$ \\
\hline
\end{tabular}

6) The types of verbal communication that most helped me understand issues and/or interests in this process include (choose all that apply):

\begin{tabular}{|l|c|c|}
\hline & $\begin{array}{c}\text { Issues (details of the } \\
\text { subject) }\end{array}$ & $\begin{array}{c}\text { Interests (what people } \\
\text { cared about) }\end{array}$ \\
\hline Requests for people to explain what they care about & $\square$ & $\square$ \\
\hline Statements of interests: "I am concerned about..." & $\square$ & $\square$ \\
\hline $\begin{array}{l}\text { Statements of barriers: "I support this...but am limited } \\
\text { by..." }\end{array}$ & $\square$ & $\square$ \\
\hline $\begin{array}{l}\text { Active listening statements: "This is what I heard you } \\
\text { say - is that right?" }\end{array}$ & $\square$ & $\square$ \\
\hline $\begin{array}{l}\text { Someone brought things up: "I think we have to look } \\
\text { at..." }\end{array}$ & $\square$ & $\square$ \\
\hline
\end{tabular}




\begin{tabular}{|l|c|c|}
\hline Talking about an issue after getting information & $\square$ & $\square$ \\
\hline Working on a goal statement & $\square$ & $\square$ \\
\hline Working on a vision statement & $\square$ & $\square$ \\
\hline Reviewing ground rules & $\square$ & $\square$ \\
\hline Discussion during meetings & $\square$ & $\square$ \\
\hline Discussions between meetings & $\square$ & $\square$ \\
\hline Regular discussions & $\square$ & $\square$ \\
\hline Frequent discussions & $\square$ & $\square$ \\
\hline
\end{tabular}

7) The types of visual communication that most helped me understand issues and/or participant interests (choose all that apply):

\begin{tabular}{|l|c|c|}
\hline & $\begin{array}{c}\text { Issues (details of the } \\
\text { subject) }\end{array}$ & $\begin{array}{c}\text { Interests (what people cared } \\
\text { about) }\end{array}$ \\
\hline Diagrams & $\square$ & $\square$ \\
\hline Photos/pictures & $\square$ & $\square$ \\
\hline Maps & $\square$ & $\square$ \\
\hline $\begin{array}{l}\text { Computer modeling results (e.g. flooding, } \\
\text { fires) }\end{array}$ & $\square$ & $\square$ \\
\hline Flip charts of notes & $\square$ & $\square$ \\
\hline Websites & $\square$ & $\square$ \\
\hline
\end{tabular}

8) The types of shared experiences that most helped me understand issues and/or participant interests include (choose all that apply):

\begin{tabular}{|l|c|c|}
\hline & $\begin{array}{c}\text { Issues (details of the } \\
\text { subject) }\end{array}$ & $\begin{array}{c}\text { Interests (what people cared } \\
\text { about) }\end{array}$ \\
\hline Field trips to look at on-the-ground conditions & $\square$ & $\square$ \\
\hline Group reviewing information together & $\square$ & $\square$ \\
\hline Making decisions as a group & $\square$ & $\square$ \\
\hline $\begin{array}{l}\text { Writing documents together (e.g. plans, } \\
\text { grants) }\end{array}$ & $\square$ & $\square$ \\
\hline Eating meals together & $\square$ & $\square$ \\
\hline $\begin{array}{l}\text { Casual meetings on shared bus/van rides out } \\
\text { to sites }\end{array}$ & $\square$ & $\square$ \\
\hline Airplane flights & $\square$ & $\square$ \\
\hline
\end{tabular}

9) The collaborative process in this project helped me better understand participants' interests.

$\square$ Strongly Disagree

$\square$ Disagree

$\square$ Agree

$\square$ Strongly Agree

10) The collaborative process helped participants better understand their individual interests.

$\square$ Strongly Disagree

$\square$ Disagree

$\square$ Agree

$\checkmark$ Strongly Agree

11) The collaborative process helped participants better understand each other's interests. 


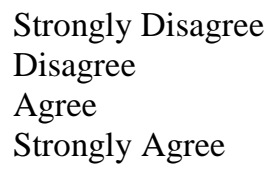

Below are some of the top interests (what people really cared about) the researcher identified from interviews and documents in this project.

12) I agree that the following interests (what people really cared about) were important (choose all that apply; add any crucial ones):

Reduce air pollution

Desire to buy cost-efficient ULSD and/or biodiesel in Lane County

Concern demand is too low for ULSD and/or biodiesel in Lane County

Concern about cost feasibility to buy ULSD and/or biodiesel

Concern fuel types will ruin engine

Concern business information be kept private

Want green marketing benefits (e.g. profits, public relations)

Want to work out technical kinks prior to mandate

Did not want to feel pressured into a price commitment

Desire for honesty

$\square$ Other (please specify)

If selected other, please specify

13) How important was participant understanding of each others' interests to the following:

\begin{tabular}{|l|c|c|c|}
\hline & $\begin{array}{c}\text { Not Very } \\
\text { Important }\end{array}$ & $\begin{array}{c}\text { Important } \\
\text { Important }\end{array}$ \\
\hline Deciding if they wanted to collaborate & $\square$ & $\square$ & $\square$ \\
\hline Clarifying individual interests & $\square$ & $\square$ & $\square$ \\
\hline $\begin{array}{l}\text { Determing what information was needed to understand } \\
\text { issues }\end{array}$ & $\square$ & $\square$ & $\square$ \\
\hline Understanding the issues on the table & $\square$ & $\square$ & $\square$ \\
\hline Understand each others' barriers & $\square$ & $\square$ & $\square$ \\
\hline Understanding individual barriers & $\square$ & $\square$ & $\square$ \\
\hline Understanding options on the table & $\square$ & $\square$ & $\square$ \\
\hline Knowing what each could agree to & $\square$ & $\square$ & $\square$ \\
\hline Finding things all could agree on & $\square$ & $\square$ & $\square$ \\
\hline Picking a direction to go with the solution & $\square$ & $\square$ & $\square$ \\
\hline Committing resources (e.g. time, funding) to the project & $\square$ & $\square$ & $\square$ \\
\hline Keeping the process going & $\square$ & $\square$ & $\square$ \\
\hline Staying involved for the duration of the project & $\square$ & $\square$ & $\square$ \\
\hline
\end{tabular}

14) Participants' most important interests have been addressed so far in this project.

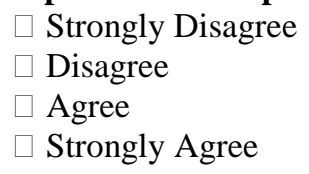

15) We found common ground in this project. Common ground means shared interests.

$\checkmark$ Strongly Disagree

$\checkmark$ Disagree 
Agree

$\square$ Strongly Agree

16) What is your age?

$\square$ 18-24

$\square 25-40$

$\square 41-54$

55-70

$\square 71$ and over

17) What is your gender?

$\square$ Female

$\square$ Male

18) What is your education level?

$\square$ High school or lower

$\checkmark$ Some college

$\square$ College graduate

$\square$ Some graduate school

$\square$ Master's degree

$\square$ Doctorate

19) Did Tia Henderson (the student who sent you this survey) interview you?

$\square$ Yes

$\square$ No

Thank you for taking the time to fill out this survey! Please contact Tia Henderson at tsh@pdx.edu or 503-887-8101 if you have any questions. 


\section{C4: Participant Follow-up Survey Example}

The Participant example was the same for each case, except on question twelve. For the lists of interests in the other cases, see previous section.

\section{Tillamook Flooding Reduction Collaboration}

Thank you for being willing to fill out this survey. It will take 10- 15 minutes. Please remember all information is confidential. Your responses will not be matched with a name, address or other identifying information. There are no right or wrong answers. If you have any questions, please contact Tia Henderson, 503-887-8101 or tsh@pdx.edu. Your responses will help us better understand collaborative processes.

1) The organization I was representing in this collaborative process was (choose the best fit):

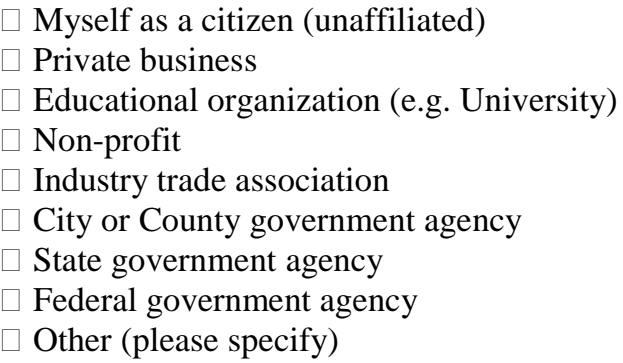

2) Number of years I've spent working on the central issues in this project (e.g. flooding reduction, truck idling)?

Questions in this survey are about project issues and participant interests.

"Issues" are the details of the subject your group was working on: e.g. flooding reduction, air pollution, fuels, forest health, jobs

"Interests" are what people really care about underneath any issue. Interests are underlying needs, concerns or desires. Below is a simple example:

Issue: Pesticide use

Related Issues: garden care, chemicals, animal habitat, stream health, weeds, pests

Jane's Position: No! Tom's Position (her husband): Yes!

Her Interests: His Interests:

1) fears poisoning birds \& fish 1) wants a nice yard

2) wants a nice yard $\quad 2$ ) does not want to fight with Jane

When you see the word "issues" please think about the details of the subject your group worked on. When you see the word "interests" please think about the details of what people really cared about.

3) The types of participants that most helped me understand issues in this process include (choose all that apply):

$\square$ People with important resources (e.g. on-the-ground information, money, permitting 
information, technical information)

$\square$ The convener(s)

The project manager/facilitator

Leaders in the project other than the facilitator or convener

People who see things like I do.

People with see things differently than I do.

Other (please specify)

If you selected other, please specify

4) The types of information that most helped me understand issues in this process include (choose all that apply):

Participant presentations (e.g. research, cost-analysis)

Visiting expert presentations

Small project results

A monitoring program

Meeting minutes

Summary documents (e.g. Declaration of Cooperation, MOU)

$\square$ Other (please specify)

If you selected other, please specify

5) The types of meetings that most helped me understand issues and/or interests in this process include (choose all that apply):

\begin{tabular}{|l|c|c|}
\hline & $\begin{array}{c}\text { Issues (details of the } \\
\text { subject) }\end{array}$ & $\begin{array}{c}\text { Interests (what people } \\
\text { cared about) }\end{array}$ \\
\hline Face to face & $\square$ & $\square$ \\
\hline Project team (e.g. whole group) & $\square$ & $\square$ \\
\hline Sub-committee/sub-group & $\square$ & $\square$ \\
\hline On-site in the community & $\square$ & $\square$ \\
\hline Open to the public & $\square$ & $\square$ \\
\hline Regular meetings & $\square$ & $\square$ \\
\hline Private meetings with a facilitator(s) or convener(s) & $\square$ & $\square$ \\
\hline $\begin{array}{l}\text { Private meetings with a leader other than the } \\
\text { facilitator or convener }\end{array}$ & $\square$ & $\square$ \\
\hline $\begin{array}{l}\text { Side meetings with people who care about the same } \\
\text { things }\end{array}$ & $\square$ & $\square$ \\
\hline $\begin{array}{l}\text { Side meetings with people who care about different } \\
\text { things }\end{array}$ & $\square$ & $\square$ \\
\hline
\end{tabular}


6) The types of verbal communication that most helped me understand issues and/or interests in this process include (choose all that apply):

\begin{tabular}{|l|c|c|}
\hline & $\begin{array}{c}\text { Issues (details of the } \\
\text { subject) }\end{array}$ & $\begin{array}{c}\text { Interests (what people } \\
\text { cared about) }\end{array}$ \\
\hline Requests for people to explain what they care about & $\square$ & $\square$ \\
\hline Statements of interests: "I am concerned about..." & $\square$ & $\square$ \\
\hline $\begin{array}{l}\text { Statements of barriers: "I support this...but am limited } \\
\text { by..." }\end{array}$ & $\square$ & $\square$ \\
\hline $\begin{array}{l}\text { Active listening statements: "This is what I heard you } \\
\text { say - is that right?" }\end{array}$ & $\square$ & $\square$ \\
\hline $\begin{array}{l}\text { Someone brought things up: "I think we have to look } \\
\text { at..." }\end{array}$ & $\square$ & $\square$ \\
\hline Talking about an issue after getting information & $\square$ & $\square$ \\
\hline Working on a goal statement & $\square$ & $\square$ \\
\hline Working on a vision statement & $\square$ & $\square$ \\
\hline Reviewing ground rules & $\square$ & $\square$ \\
\hline Discussions during meetings & $\square$ & $\square$ \\
\hline Discussions between meetings & $\square$ & $\square$ \\
\hline Regular discussions & $\square$ & $\square$ \\
\hline Frequent discussions & $\square$ & $\square$ \\
\hline
\end{tabular}

7) The types of visual communication that most helped me understand issues and/or interests in this process include (choose all that apply):

\begin{tabular}{|l|c|c|}
\hline & $\begin{array}{c}\text { Issues (details of the } \\
\text { subject) }\end{array}$ & $\begin{array}{c}\text { Interests (what people cared } \\
\text { about) }\end{array}$ \\
\hline Diagrams & $\square$ & $\square$ \\
\hline Photos/pictures & $\square$ & $\square$ \\
\hline Maps & $\square$ & $\square$ \\
\hline $\begin{array}{l}\text { Computer modeling results (e.g. flooding, } \\
\text { fires) }\end{array}$ & $\square$ & $\square$ \\
\hline Flip charts of notes & $\square$ & $\square$ \\
\hline Websites & $\square$ & $\square$ \\
\hline
\end{tabular}

8) The types of shared experiences that most helped me understand issues and/or participant interests include (choose all that apply):

\begin{tabular}{|l|c|c|}
\hline & $\begin{array}{c}\text { Issues (details of the } \\
\text { subject) }\end{array}$ & $\begin{array}{c}\text { Interests (what people cared } \\
\text { about) }\end{array}$ \\
\hline Field trips to look at on-the-ground conditions & $\square$ & $\square$ \\
\hline Group reviewing information together & $\square$ & $\square$ \\
\hline Making decisions as a group & $\square$ & $\square$ \\
\hline $\begin{array}{l}\text { Writing documents together (e.g. plans, } \\
\text { grants) }\end{array}$ & $\square$ & $\square$ \\
\hline Eating meals together & $\square$ & $\square$ \\
\hline $\begin{array}{l}\text { Casual meetings on shared bus/van rides out } \\
\text { to sites }\end{array}$ & $\square$ & $\square$ \\
\hline Airplane flights & $\square$ & $\square$ \\
\hline
\end{tabular}


9) The collaborative process in this project helped me better understand my interests.

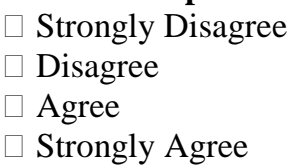

10) The collaborative process in this project helped me better understand other participants' interests.

\author{
Strongly Disagree \\ Disagree \\ Agree \\ Strongly Agree
}

Below are some of the top interests (what people really cared about) the researcher identified from interviews and documents in this project.

11) I agree that the following interests (what people really cared about) were important (choose all that apply; add any crucial ones):

$\square$ Reduce negative impacts of flooding (e.g. public safety, property damage, loss of cattle)

$\square$ Protect environmental resources (e.g. fish habitat, endangered species)

$\square$ Protect community economy (e.g. businesses, agricultural land)

Concern of running out of funds to do flood reduction projects

$\square$ Desire for short-term projects to get something done

$\square$ Desire for long-term projects because cannot fix it all in the short term

$\square$ Desire for agencies and community to work toward common agreement

$\square$ Desire to fulfill job duty/responsibility (e.g. uphold mandates)

$\square$ Desire that everyone's concerns be respected

$\square$ Other (please specify)

If you selected other, please specify:

12) How important was understanding other participants' interests to the following:

\begin{tabular}{|l|c|c|c|}
\hline & $\begin{array}{c}\text { Not Very } \\
\text { Important }\end{array}$ & Important & $\begin{array}{c}\text { Very } \\
\text { Important }\end{array}$ \\
\hline Deciding if I wanted to collaborate & $\square$ & $\square$ & $\square$ \\
\hline Clarifying my interests & $\square$ & $\square$ & $\square$ \\
\hline $\begin{array}{l}\text { Determining what information was needed to understand } \\
\text { issues }\end{array}$ & $\square$ & $\square$ & $\square$ \\
\hline Understanding the issues on the table & $\square$ & $\square$ & $\square$ \\
\hline Understanding other participants' barriers & $\square$ & $\square$ & $\square$ \\
\hline Understanding my barriers & $\square$ & $\square$ & $\square$ \\
\hline Understanding options on the table & $\square$ & $\square$ & $\square$ \\
\hline Knowing what I could agree to & $\square$ & $\square$ & $\square$ \\
\hline Finding things we could all agree on & $\square$ & $\square$ & $\square$ \\
\hline Picking a direction to go with the solution & $\square$ & $\square$ & $\square$ \\
\hline Committing resources (e.g. time, funding) to the project & $\square$ & $\square$ & $\square$ \\
\hline Keeping the process going & $\square$ & $\square$ & $\square$ \\
\hline Staying involved for the duration of the project & $\square$ & $\square$ & $\square$ \\
\hline
\end{tabular}

13) My most important interests (what I really care about under the issues) have been addressed so far in this project. 


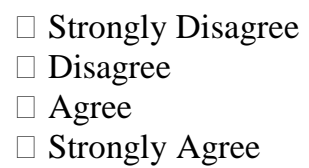

14) We found common ground in this project. Common ground means shared interests.

$\square$ Strongly Disagree

$\square$ Disagree

$\square$ Agree

$\square$ Strongly Agree

15) What is your age?
$\square 18-24$
$\square 25-40$
$\square 41-54$
$\square 55-70$
$\square 71$ and over

16) What is your gender?

$\square$ Female

$\square$ Male

17) What is your education level?

$\square$ High school or lower

$\square$ Some college

$\square$ College graduate

$\square$ Some graduate school

$\square$ Master's degree

$\square$ Doctorate

18) Did Tia Henderson (the student who sent you this survey) interview you?

$$
\square \text { Yes }
$$

$\square$ No

Thank you for taking the time to fill out this survey! Please contact Tia Henderson at tsh@pdx.edu or 503-887-8101 if you have any questions. 


\section{C5: Specific Interests Used in the Follow Up Survey}

This section presents the lists of interests used in question 11 (Participant) and 12 (Staff) for three cases. The other case lists appeared earlier in C3 and C4.

Reduced Engine Idling

11) I agree that the following interests (what people really cared about) were important (choose all that apply; add any crucial ones):

$\ulcorner$ Desire to reduce air pollution

$\ulcorner$ Avoid unnecessary costs with idling reduction technology (e.g. installation, maintenence)

$\Gamma$ Desire for $\mathrm{CO} 2$ reduction

$\Gamma$ Concern that truck stops will lose revenue from competition

$\ulcorner$ Concern with trucker demand for idling reduction technology (e.g. worry they won't use it)

$\ulcorner$ Desire to improve trucker quality of life

$\ulcorner$ Desire for honesty

$\Gamma$ Desire to improve relationships

$\Gamma$ Concern that everyone's view be respected

$\Gamma$ Other (please specify)

Lakeview Biomass Facility

11) I agree that the following interests (what people really cared about) were important (choose all that apply; add any crucial ones):

$\Gamma$ Protect economic health to Lakeview community (e.g. protect the mill, protect jobs)

$\Gamma$ Protect/restore forest health (e.g. protect habitat, watersheds)

$\Gamma$ Desire to reduce wildfires

$\ulcorner$ Concern Biomass plant size be a tool for restoration, not primarily for economic benefit

$\ulcorner$ Desire to fulfill job duty/responsibility

$\ulcorner$ Desire to make a profit

$\Gamma$ Desire to solve a problem

$\ulcorner$ Desire for honesty

$\ulcorner$ Concern that everyone's view be respected 
$\ulcorner$ Other (please specify)

Lakeview Stewardship Group

11) I agree that the following interests (what people really cared about) were important (choose all that apply; add any crucial ones):

$\ulcorner$ Desire to restore economic health to Lakeview community (e.g. protect the mill, protect jobs)

$\ulcorner$ Desire to restore forest health (e.g. protect habitat, watersheds)

$\ulcorner$ Desire to fulfill job duty/responsibility

$\Gamma$ Concern with being sued

$\ulcorner$ Desire to help

$\ulcorner$ Desire for honesty

$\ulcorner$ Tired of fighting

$\ulcorner$ Concern that everyone's view be respected

$\ulcorner$ Other (please specify) 


\section{Appendix D: HSRRC Letter}

\section{D1: Interview Letter}

Dear Participant, Hello, my name is Tia Henderson, I am a student in the Urban Studies and Planning doctoral program at Portland State University. During the next year, I'm researching what happens in collaborative processes from convening through implementation. I'm inviting you to participate based on your involvement in an Oregon Solutions (OS) project. I am not evaluating O.S. and they are not paying me to do this work. I would like to interview you about the collaboration process and how different participant's interests contributed to resolving a community issue.

If you decide to participate, you will be asked to respond to questions in the attached interview over the phone, or in person. The interview will take about an hour. The interview will be recorded. I understand your time and energy are important, so I assure you the interview will be scheduled to minimize any inconvenience.

Your privacy is important to me. Results of the study will be released in a published dissertation for Portland State University. The specific information you provide will be kept confidential. I will assign your name a numerical code to identify your interview. I will only share the specific details of your responses with my advisor, Dr. Connie Ozawa, at Portland State University. Printouts of the coded interviews will be kept in a locked file cabinet at Portland State University when not in use. The list of codes and corresponding names will be kept in a separate file. Any electronic files on a flash drive will be deleted after transferring the information. All other electronic files are on a firewall protected private server at PSU.

There is a small risk that information in the narrative, although confidential and reported in summary form, could be used to identify you. You can skip questions, or ask that certain information be kept "off record" - meaning it will not be included in the dissertation case narrative. You can also review your case write-up during a set time-frame if you are concerned with how information is represented.

Your responses to the interview will help me, and others, understand how collaborative processes work to address community problems. Your participation is voluntary. You do not have to take part in this project and it will not affect your relationship with Oregon Solutions, or any other organization with which you partner.

If you have questions concerning the use of human subjects in research, please contact the Human Subjects Research Review Committee, Office of Research and Sponsored Projects, 
600 Unites Bldg., Portland State University, (503) 725-4288 / 1-877-480-4400. If you have questions about the study itself, contact Tia Henderson at 503-887-8101, $5276 \mathrm{~N}$ Williams Ave., Portland, OR 97217, tsh@pdx.edu.

Your oral consent means that you have read the above information; you understand the risks and benefits of participation and agree to participate in the study. You can change your mind and withdraw your consent at any time, without penalty.

Thank you for your time, Tia Henderson 


\section{D2: Follow-Up Email Example}

Hello, My name is Tia Henderson - this is a follow up email. I am a student in the Urban Studies and Planning doctoral program at Portland State University. I am researching what happens in successful collaborative processes for my dissertation. I am contacting you based on your participation with the Lakeview Stewardship Group, Lakeview Biomass Project, Lane Clean Diesel Project, Reduced Truck Idling Project or the Tillamook Flooding Reduction Project.

I would like to invite you to participate in a survey so I can understand more about collaborative processes. Much time has passed since your involvement - that is okay, just fill out what you remember. If you worked on more than one collaborative process, please fill out a separate survey for each. If you do not have time, please fill out a survey for the project you were most involved in.

If you decide to participate in this research, you can go to the attached link and fill out the survey. It should take about 15 minutes. By filling out and submitting the survey, you are giving your consent for me to use your responses in this study.

Here is the link to the Staff Reduced Truck Idling Collaborative Project |LINK1|

Your privacy is important to me. Your responses are confidential. The survey does not ask for personal identifying information.

Your participation is voluntary. You can stop at any time if you change your mind. You do not have to take part in this project and it will not affect your relationship with any other organization with which you partner.

If you have questions concerning the use of human subjects in research, please contact the Human Subjects Research Review Committee, Office of Research and Sponsored Projects, 600 Unitus Bldg., Portland State University, (503) 725-4288/ 1- 877-4804400. If you have questions about the study itself, contact Tia Henderson at 503-8878101, 5276 N Williams Ave, Portland OR 97217, tsh@pdx.edu

Your submitting (pressing send) the survey means:

* you understand the risks and benefits of participation

* you are willing to take the survey

* you know that you do not have to take the survey. Even if you agree, you can change your mind and stop at any time.

Thank you for your time, 


\section{Tia}

\section{Tia Henderson}

Doctoral Student

Urban Studies and Planning

Portland State University

tsh@pdx.edu

503-287-4405 home

503-725-5170 work message 


\section{Appendix E: Social Technique Summary List}

Table 78a Summary of techniques used across the five cases

\begin{tabular}{|c|c|c|c|c|c|c|}
\hline & & Lane & Idling & Biomass & Tillamook & LSG \\
\hline \multirow{2}{*}{$\begin{array}{l}\text { Pre- } \\
\text { collaboration }\end{array}$} & Convener meeting with stakeholder group leaders & & $\mathrm{X}$ & $\mathrm{X}$ & & $\mathrm{X}$ \\
\hline & Project assessment & $\mathrm{X}$ & $\mathrm{X}$ & $\mathrm{X}$ & $\mathrm{X}$ & \\
\hline \multirow[t]{3}{*}{ Participants } & Active project managers and/or conveners & $\mathrm{X}$ & $\mathrm{X}$ & $\mathrm{X}$ & $\mathrm{X}$ & $\mathrm{X}$ \\
\hline & Active participant leaders (e.g. stakeholder group members) & & & $\mathrm{X}$ & $\mathrm{X}$ & $\mathrm{X}$ \\
\hline & Mix of needed parties & & & & $\mathrm{X}$ & \\
\hline \multirow[t]{8}{*}{ Information } & Visiting expert presentations & $\mathrm{X}$ & & & $\mathrm{X}$ & \\
\hline & Participant presentations of expertise & $\mathrm{X}$ & $\mathrm{X}$ & $\mathrm{X}$ & $\mathrm{X}$ & \\
\hline & Information gathering at participant request, or by participants & $\mathrm{X}$ & $\mathrm{X}$ & & & $X$ \\
\hline & Use of scientific/technical information to shape decisions & $\mathrm{X}$ & $\mathrm{X}$ & $X$ & $\mathrm{X}$ & $\mathrm{X}$ \\
\hline & Use of participant experience or expertise to shape decisions & $\mathrm{X}$ & $\mathrm{X}$ & $\mathrm{X}$ & $\mathrm{X}$ & $\mathrm{X}$ \\
\hline & Summary documents & $\mathrm{X}$ & $\mathrm{X}$ & $\mathrm{X}$ & $\mathrm{X}$ & $\mathrm{X}$ \\
\hline & Agendas, meeting minutes typed and distributed for reference & $\mathrm{X}$ & $\mathrm{X}$ & $\mathrm{X}$ & $\mathrm{X}$ & $\mathrm{X}$ \\
\hline & Pilot project results used in adaptive management strategy & & & & & $X$ \\
\hline \multirow[t]{7}{*}{ Meetings } & Face-to-face & $\mathrm{X}$ & $\mathrm{X}$ & $\mathrm{X}$ & $\mathrm{X}$ & $\mathrm{X}$ \\
\hline & One on one discussion among participants (e.g. email, phone, private) & $\mathrm{X}$ & $\mathrm{X}$ & & $\mathrm{X}$ & \\
\hline & "Working" meetings (e.g. moved through action items) & $\mathrm{X}$ & $\mathrm{X}$ & & & \\
\hline & Equal access to discussion via facilitation & & $\mathrm{X}$ & & $\mathrm{X}$ & $\mathrm{X}$ \\
\hline & Small groups or sub-committees for specific issues & & & $\mathrm{X}$ & $\mathrm{X}$ & $\mathrm{X}$ \\
\hline & On-site & & & $\mathrm{X}$ & $\mathrm{X}$ & $\mathrm{X}$ \\
\hline & Follow-up meetings with facilitators/conveners & & & $\mathrm{X}$ & $\mathrm{X}$ & $\mathrm{X}$ \\
\hline \multirow[t]{3}{*}{ Governance } & Shared, consensus & $\mathrm{X}$ & $\mathrm{X}$ & $\mathrm{X}$ & $\mathrm{X}$ & $\mathrm{X}$ \\
\hline & Weighted ranking voting using objective criteria & & & & $\mathrm{X}$ & \\
\hline & Ground rules & $\mathrm{X}$ & $\mathrm{X}$ & $\mathrm{X}$ & $\mathrm{X}$ & $\mathrm{X}$ \\
\hline Other & Non-profit created to support efforts/goals of collaborative process & & & & & $\mathrm{X}$ \\
\hline
\end{tabular}


Table 78b Summary of techniques used across cases (part two)

\begin{tabular}{|c|c|c|c|c|c|c|}
\hline & & Lane & Idling & Biomass & Tillamook & LSG \\
\hline Verbal & Asking direct questions e.g. "what matters to you" & $\mathrm{X}$ & $\mathrm{X}$ & $\mathrm{X}$ & & $\mathrm{X}$ \\
\hline \multirow[t]{15}{*}{ Communication } & Asking probing, or follow-up, questions e.g. "why?" & & & & & $\mathrm{X}$ \\
\hline & Asked for specifics behind positions & & & & $\mathrm{X}$ & $\mathrm{X}$ \\
\hline & Active listening & & & $\mathrm{X}$ & & $\mathrm{X}$ \\
\hline & Someone brought something up & & & & $\mathrm{X}$ & \\
\hline & Direct statements of concerns & & $\mathrm{X}$ & & $\mathrm{X}$ & \\
\hline & Direct statements of barriers & $\mathrm{X}$ & & $\mathrm{X}$ & & $\mathrm{X}$ \\
\hline & Project leaders/conveners statements of appreciation & & & & $\mathrm{X}$ & \\
\hline & Facilitator emphasis on trust/respect & & & $\mathrm{X}$ & $\mathrm{X}$ & \\
\hline & Name tags to indicate representation & & & & $\mathrm{X}$ & \\
\hline & Facilitator/convener/leader drew people into conversation & & & $\mathrm{X}$ & & \\
\hline & Follow up in group or one on one about sensitive issues & & & $\mathrm{X}$ & $\mathrm{X}$ & \\
\hline & Discussed options & $\mathrm{X}$ & $\mathrm{X}$ & $\mathrm{X}$ & $\mathrm{X}$ & $\mathrm{X}$ \\
\hline & Talking about information after reviewing it & $\mathrm{X}$ & $\mathrm{X}$ & $\mathrm{X}$ & $\mathrm{X}$ & $\mathrm{X}$ \\
\hline & Visioning at the beginning of the process & & & & & $\mathrm{X}$ \\
\hline & Internet/web-site sharing of information & & $\mathrm{X}$ & & $\mathrm{X}$ & \\
\hline \multirow{3}{*}{ Communication } & Use of figures, photos and diagrams to illustrate options & & $\mathrm{X}$ & $\mathrm{X}$ & $\mathrm{X}$ & $\mathrm{X}$ \\
\hline & Powerpoints and flipcharts & $\mathrm{X}$ & $\mathrm{X}$ & & & \\
\hline & Computer modeling results - visual & & & & $\mathrm{X}$ & \\
\hline Shared & Developing documents together (e.g. MOU, long range strategy, grant) & & $\mathrm{X}$ & $\mathrm{X}$ & $\mathrm{X}$ & $\mathrm{X}$ \\
\hline \multirow[t]{9}{*}{ Experience } & Shared meals, van-rides & & & $\mathrm{X}$ & & $\mathrm{X}$ \\
\hline & Learning information together & $\mathrm{X}$ & $\mathrm{X}$ & & $\mathrm{X}$ & \\
\hline & Crafting a goal statement & & & & $\mathrm{X}$ & \\
\hline & Crafting a vision statement & & & & & $\mathrm{X}$ \\
\hline & Experiencing physical results of completed projects & & & & $\mathrm{X}$ & $\mathrm{X}$ \\
\hline & Field trips or site visits & & & $\mathrm{X}$ & $\mathrm{X}$ & $\mathrm{X}$ \\
\hline & Celebrating on-going successes & & & & $\mathrm{X}$ & $\mathrm{X}$ \\
\hline & Explicit re-commitment to the project & & & & $\mathrm{X}$ & \\
\hline & Aerial flights & & & & & $\mathrm{X}$ \\
\hline
\end{tabular}




\section{Appendix F: Survey Statistics Results}

This appendix presents the statistical analyses details used in the follow-up survey. It is oriented to each relevant research question.

\section{Research Question Two : Facilitation}

\section{Helpfulness of Participants}

There were no significant differences among the five cases in relation to what participants were considered helpful in understanding issues (see table 79).

Table 79 Pearson Chi-Square tests results helpful participants on issues

\begin{tabular}{|lccc|}
\hline \multicolumn{1}{|c}{ Participant type } & $\begin{array}{c}\chi^{2} \\
(\mathbf{d f}=\mathbf{4})\end{array}$ & $\mathbf{p}$ & \% Yes \\
\hline People with important resources & 1.8 & .78 & 77 \\
Leaders in the project other than the & 2.3 & .69 & 58 \\
facilitator/convener & & & \\
People who see things different than I do & 9.1 & .06 & 47 \\
The project manager/facilitator & 3.6 & .47 & 36 \\
The convener(s) & 6.7 & .15 & 28 \\
People who see things like I do & 6.7 & .15 & 26 \\
\hline
\end{tabular}

*at least $95 \%$ significant difference among the five cases. All numbers rounded to nearest whole number. $\mathrm{N}=53$.

\section{Helpfulness of Information}

Chi-square results indicate that the proportion of yes and no responses

was significantly different among the five cases on two issues: the use of small

project results and a monitoring program (see table 80 and 81).

Table 80 Survey results on helpful information on issues

\begin{tabular}{|lccc|}
\hline Participant type: & $\begin{array}{c}\chi^{2} \\
(\mathrm{df}=4)\end{array}$ & P & \% Yes \\
\hline Visiting expert presentations & 2.4 & .67 & 60 \\
Participant presentations & 4.6 & .33 & 81 \\
Summary documents (e.g. DOC, MOU) & 6.7 & .15 & 26 \\
Meeting minutes & 5.5 & .24 & 13 \\
A monitoring program & 11.1 & $.03^{*}$ & 15 \\
Small project results & 13.5 & $.01^{*}$ & 32 \\
\hline
\end{tabular}

*at least $95 \%$ significant difference among the five cases. All numbers rounded to nearest whole number. $\mathrm{N}=53$. 
Pearson Chi-square tests showed that cases one through four were not different from one another on either the monitoring program or small project results item (see table 81 below). Pearson Chi-square tests showed the Lakeview Stewardship Group (LSG, case 5) was significantly different in the proportion of responses when compared to the Tillamook case for both items, see table 81 . The Stewardship Group and the Biomass case were not significantly different from one another on either item: $\chi^{2}(1)=2.81, \mathrm{p}=.09$ for small project results; $\chi^{2}(1)=2.6, \mathrm{p}=.10$ for a monitoring program. Table 81 Pearson Chi-square results among cases on information types

\begin{tabular}{|lclc|}
\hline \multicolumn{3}{|c|}{ A monitoring program } & \multicolumn{2}{l|}{ Small project results } \\
\hline Cases 1-4 & $\chi^{2}(3)=2.25, \mathrm{p}=.52$ & Cases 1-4 & $\chi^{2}(3)=3.79, \mathrm{p}=.28$ \\
LSG: Biomass & $\chi^{2}(1)=2.6, \mathrm{p}=.10$ & LSG: Biomass & $\chi^{2}(1)=2.81, \mathrm{p}=.09$ \\
LSG:Tillamook & $\chi^{2}(1)=6.62, \mathrm{p}<.01^{*}$ & LSG:Tillamook & $\chi^{2}(1)=9.11, \mathrm{p}<.003^{*}$ \\
\hline
\end{tabular}

\section{Helpfulness of Meetings}

Chi-square results indicate that there were differences in the proportions of responses among the five cases for three meeting sub-categories on interests: public meetings, meeting on-site in the community, and subcommittee meetings (see tables \#82, 83, and 84).

Table 82 Survey results on "meetings that most helped me understand issues"

\begin{tabular}{|lccc|}
\hline Meeting Types - on Issues & $\begin{array}{c}\chi^{2} \\
(\mathbf{d f}=\mathbf{4})\end{array}$ & $\mathbf{p}$ & \% Yes \\
\hline $\begin{array}{l}\text { Side meetings with people who care about } \\
\text { different things }\end{array}$ & 2.21 & .70 & 32 \\
$\begin{array}{l}\text { Side meetings with people who care about the } \\
\text { same things }\end{array}$ & 4.73 & .32 & 36 \\
$\begin{array}{l}\text { Private meetings with a leader other than the } \\
\text { facilitator/convener }\end{array}$ & 4.59 & .33 & 30 \\
$\begin{array}{l}\text { Private meetings with a facilitator(s) or } \\
\text { convener(s) }\end{array}$ & 7.03 & .13 & 26 \\
$\begin{array}{l}\text { Regular meetings } \\
\text { Open to the Public }\end{array}$ & 1.68 & .79 & 70 \\
\hline
\end{tabular}




\begin{tabular}{|lccc|}
\hline On-site in the community & 7.32 & .12 & 53 \\
Sub-committee/sub-group* & 18.53 & $.001^{*}$ & 42 \\
Project team (e.g. whole group) & 1.64 & .80 & 74 \\
Face to face & 1.05 & .90 & 64 \\
\hline
\end{tabular}

*at least $95 \%$ significant difference among the five cases. All numbers rounded to nearest whole number. $\mathrm{N}=53$.

Table 83 Survey responses on "meetings that most helped me understand interests"

\begin{tabular}{|lccc|}
\hline Meeting Types - on Interests & $\begin{array}{c}\chi^{2} \\
(\mathbf{d f = 4})\end{array}$ & $\mathbf{p}$ & \% Yes \\
\hline $\begin{array}{l}\text { Side meetings with people who care about different } \\
\text { things }\end{array}$ & 1.74 & .78 & 45 \\
$\begin{array}{l}\text { Side meetings with people who care about the same } \\
\text { things }\end{array}$ & 3.35 & .50 & 45 \\
Private meetings with a leader other than the & 1.64 & .80 & 26 \\
facilitator/convener & & & \\
Private meetings with a facilitator(s) or convener(s) & 5.14 & .27 & 21 \\
Regular meetings & 1.92 & .75 & 62 \\
Open to the public & 11.65 & $.02^{*}$ & 40 \\
On-site in the community & 13.02 & $.01^{*}$ & 55 \\
Sub-committee/sub-group & 12.71 & $.01^{*}$ & 23 \\
Project team (e.g. whole group) & 2.4 & .67 & 75 \\
Face to face & 3.5 & .48 & 81 \\
\hline
\end{tabular}

*at least 95\% significant difference among the five cases. All numbers rounded to nearest whole number. $\mathrm{N}=53$.

The reduced engine idling case did not work in sub-groups, thus had no

affirmative responses. In Tillamook, $77 \%$ of participants agreed that sub-group

meetings were important to understanding issues and 50\% agreed these

meetings were important for understanding interests. All cases met on-site in

the community and were open to the public, however the Tillamook case

meetings involved more regular attendance from the public.

Table 84 Pearson Chi-square results for meeting subtypes

\begin{tabular}{|lllc|}
\hline \multicolumn{2}{ll|}{ Sub-committee/sub-group* - Issues } & \multicolumn{2}{l|}{ Sub-committee/sub-group* - Interests } \\
\hline Cases 1-3,5 & $\chi^{2}(3)=5.18, \mathrm{p}=.15$ & Cases 1-3,5 & $\chi^{2}(3)=2.3, \mathrm{p}=.50$ \\
Tillamook : LSG & $\chi^{2}(1)=7.18, \mathrm{p}<.01^{*}$ & Tillamook : LSG & $\chi^{2}(1)=2.94, \mathrm{p}=.09$ \\
Tillamook : Biomass & $\chi^{2}(1)=4.92, \mathrm{p}<.03^{*}$ & Tillamook : Biomass & $\chi^{2}(1)=6.18, \mathrm{p}<.02^{*}$ \\
\hline
\end{tabular}




\section{Helpful Verbal Communication}

Pearson Chi-square results indicate there were no statistically significant differences in the proportion of affirmative responses on verbal communication's impact on understanding issues among the cases, see table \#.

Table 85 Survey results on "verbal communication that most helped me understand issues"

\begin{tabular}{|lrrr|}
\hline Verbal Communication - Issues & $\begin{array}{c}\chi^{2} \\
\text { (df=4) }\end{array}$ & $\mathbf{p}$ & \% Yes \\
\hline Frequent discussions & 8.38 & .08 & 32 \\
Regular discussions & 3.59 & .47 & 45 \\
Discussions between meetings & 1.78 & .78 & 64 \\
Discussion during meetings & 2.15 & .71 & 81 \\
Reviewing ground rules & 4.19 & .38 & 25 \\
Working on a vision statement & 5.05 & .28 & 36 \\
Working on a goal statement & 3.98 & .41 & 38 \\
Talking about an issue after getting information & 1.07 & .90 & 64 \\
Someone brought things up: "I think we have to look at..." & 1.98 & .74 & 60 \\
Active listening statements: "This is what I heard you say - is that & 4.46 & .35 & 30 \\
right?" & & & \\
Statements of barriers: "I support this...but am limited by..." & .23 & .99 & 43 \\
Statements of interests: "I am concerned about..." & 3.50 & .48 & 38 \\
Requests for people to explain what they care about & 2.22 & .70 & 47 \\
\hline
\end{tabular}

$*$ at least $95 \%$ significant difference among the five cases. All numbers rounded to nearest whole number. $\mathrm{N}=53$.

Pearson chi-square tests revealed that three items were significantly different among the five cases on the impact of verbal communication's impact on understanding interests: frequent discussions, working on a vision statement, and requests for people to explain what they care about.

Table 86 Survey results on "verbal communication that most helped me understand interests"

\begin{tabular}{|lccc|}
\hline Verbal Communication - Interests & $\begin{array}{c}\chi^{2} \\
(\mathbf{d f}=\mathbf{4})\end{array}$ & $\mathbf{p}$ & $\mathbf{\%}$ Yes \\
\hline Frequent discussions & 10.49 & $.03^{*}$ & 34 \\
Regular discussions & 4.67 & .32 & 49 \\
Discussions between meetings & .48 & .98 & 66 \\
Discussion during meetings & .43 & .98 & 81 \\
Reviewing ground rules & 4.33 & .36 & 25 \\
Working on a vision statement & 11.54 & $.02^{*}$ & 42 \\
\hline
\end{tabular}




\begin{tabular}{lccc|}
\hline Working on a goal statement & 7.40 & .12 & 40 \\
Talking about an issue after getting information & 5.26 & .26 & 40 \\
Someone brought things up: "I think we have to look at..." & 8.60 & .07 & 55 \\
Active listening statements: "This is what I heard you say - is that & 4.72 & .32 & 45 \\
& & & \\
right?" & 1.15 & .89 & 47 \\
Statements of barriers: "I support this...but am limited by..." & 1.0 & .91 & 66 \\
Statements of interests: "I am concerned about..." & 9.3 & $.05^{*}$ & 68 \\
Requests for people to explain what they care about &
\end{tabular}

$*$ at least $95 \%$ significant difference among the five cases. All numbers rounded to nearest whole number. $\mathrm{N}=53$.

A chi-square test showed that there were no differences among the

Biomass, Tillamook, and LSG cases on these three items. On these three items, the Lane Clean Diesel and Reduced Engine Idling cases were more similar to one another, and different from the other three cases, see table 87.

Table 87 Pearson Chi-Square results on verbal communication types

\begin{tabular}{|c|c|c|}
\hline Type & & \\
\hline $\begin{array}{l}\text { Requests for people to explain what they } \\
\text { care about - Interests }\end{array}$ & $\begin{array}{l}\text { Case 3-5 } \\
\chi^{2}(2)=2.9, p=.24\end{array}$ & $\begin{array}{l}\text { Cases } 1 \& 2 \\
\chi^{2}(1)=.51, p=.47\end{array}$ \\
\hline Working on a vision statement - Interests & $\begin{array}{l}\text { Case } 3-5 \\
\chi^{2}(2)=1.6, p=.44\end{array}$ & $\begin{array}{l}\text { Cases } 1 \& 2 \\
\text { No affirmative } \\
\text { responses }\end{array}$ \\
\hline Frequent discussions - Interests & $\begin{array}{l}\text { Case 3-5 } \\
\chi^{2}(2)=3.1, p=.21\end{array}$ & $\begin{array}{l}\text { Cases } 1 \& 2 \\
\text { No affirmative } \\
\text { responses }\end{array}$ \\
\hline
\end{tabular}

\section{Helpfulness of Visual Communication}

Pearson chi-square tests show that groups were statistically different on two visual communication elements in relation to understanding issues and three elements in relation to interests, see table's \# and \#. Based on these differences, the individual affirmative responses for each case are presented in table 88 . 
Table 88 Pearson Chi-Square tests results on visual communication types

\begin{tabular}{|ccclccc|}
\hline & Issues & \multicolumn{1}{c}{ Visual Communication } & \multicolumn{3}{c|}{ Interests } \\
\hline $\begin{array}{c}\boldsymbol{\chi}^{2} \\
(\mathbf{d f}=\mathbf{4})\end{array}$ & $\mathbf{p}$ & $\begin{array}{c}\boldsymbol{\%} \\
\text { Yes }\end{array}$ & & $\begin{array}{c}\chi^{2} \\
(\mathbf{d f}=\mathbf{4})\end{array}$ & $\mathbf{p}$ & $\begin{array}{c}\% \\
\text { Yes }\end{array}$ \\
3.22 & .52 & 47 & Diagrams & 3.23 & .52 & 21 \\
4.69 & .32 & 62 & Photos/pictures & 8.23 & .08 & 45 \\
11.64 & $.02 *$ & 66 & Maps & 9.72 & $.05^{*}$ & 42 \\
15.20 & $.004 *$ & 62 & Computer modeling results (e.g. flooding, & 9.97 & $.04 *$ & 30 \\
& & & & & \\
8.77 & .07 & 23 & fires) & 10.53 & $.03 *$ & 25 \\
5.52 & .24 & 23 & Wlip charts of notes & 2.60 & .63 & 11 \\
\hline
\end{tabular}

$*$ at least $95 \%$ significant difference among the five cases. All numbers rounded to nearest whole number. $\mathrm{N}=53$.

The Lakeview Stewardship Group relied heavily on maps, as is evident

by 91 percent of survey participants agreeing that maps helped them

understand issues. The Tillamook case relied heavily on computer modeling

results, also evident by 89 percent of those respondents agreeing that these

results helped them understand issues, see table 88 .

Helpfulness of Shared Experiences

There were case differences on three shared experience sub-types.

Table 89 Pearson Chi-Square tests results on shared experience types

\begin{tabular}{|c|c|c|c|c|c|c|}
\hline \multicolumn{3}{|c|}{ Issues } & Shared Experience & \multicolumn{3}{|c|}{ Interests } \\
\hline $\begin{array}{c}\chi^{2} \\
(\mathbf{d f}=4)\end{array}$ & $\mathbf{p}$ & $\begin{array}{l}\% \\
\text { Yes }\end{array}$ & & $\begin{array}{c}\chi^{2} \\
(\mathbf{d f}=4)\end{array}$ & $\mathbf{p}$ & $\begin{array}{l}\% \\
\text { Yes }\end{array}$ \\
\hline 20.54 & $.000^{*}$ & 62 & $\begin{array}{l}\text { Field trips to look at on the ground } \\
\text { conditions }\end{array}$ & 17.83 & $.001 *$ & 55 \\
\hline .80 & .94 & 75 & Group reviewing information together & 5.88 & .21 & 74 \\
\hline 6.88 & .14 & 72 & Making decisions as a group & 3.92 & .42 & 68 \\
\hline 1.24 & .87 & 51 & Writing documents together & 2.84 & .59 & 40 \\
\hline 10.93 & $.03 *$ & 21 & Eating meals together & 9.59 & $.05^{*}$ & 51 \\
\hline 8.49 & .08 & 34 & $\begin{array}{l}\text { Casual meetings on shared bus/van rides } \\
\text { out to sites }\end{array}$ & 14.6 & $.01 *$ & 57 \\
\hline 12.14 & $.02 *$ & 6 & $\begin{array}{l}\text { Airplane flights (only LSG responded } \\
\text { yes) }\end{array}$ & - & - & 0 \\
\hline
\end{tabular}


Table 90 Pearson Chi-Square results on shared experiences sub-types

\begin{tabular}{|lll|}
\hline & Issues & Interests \\
Field trips to look at on the ground & Case 3-5 & Case 3-5 \\
conditions & $\chi^{2}(2)=4.69, \mathrm{p}<.10$ & $\chi^{2}(2)=1.23, \mathrm{p}<.55$ \\
Eating meals together & Case 3-5 & Case 3-5 \\
& $\chi^{2}(2)=6.2, \mathrm{p}<.05^{*}$ & $\chi^{2}(2)=5.29, \mathrm{p}<.07$ \\
$\begin{array}{ll}\text { Casual meetings on shared bus/van rides } \\
\text { out to sites }\end{array}$ & $\mathrm{n} / \mathrm{a}$ & Case 3-5 \\
\hline
\end{tabular}

\section{Research Question Three: Role of Interests}

Kruskal-wallis tests indicated that there were significant differences among the five cases on all items, see table 91. Examination of the raw data indicated that the Tillamook responses were the primary source of differences. Kruskal-wallis test results among the other four cases indicated that only three sub-items were significantly different, see table 92 . These were: knowing what each/I could agree on $\left(\chi^{2}(3)=8.49, p=.04\right)$, finding things all could agree on $\left(\chi^{2}(3)=7.74, p=.05\right)$, and keeping the process going $\left(\chi^{2}(3)=11.18, p=\right.$ $.01)$.

Table 91 All cases:Kruskal-wallis tests on importance of participants' understanding each others' interests

\begin{tabular}{|lcc|}
\hline & $\begin{array}{c}\chi^{2} \\
(\mathbf{d f}=\mathbf{4})\end{array}$ & $\mathrm{p}$ \\
\hline Deciding to collaborate & 10.37 & $.04^{*}$ \\
Clarifying individual ( $m y$ ) interests & 14.54 & $.006^{*}$ \\
Determining what information was needed to understand issues & 18.31 & $.001^{*}$ \\
Understanding issues on the table & 16.88 & $.02^{*}$ \\
Understanding other participants' (each others') barriers & 11.71 & $.02^{*}$ \\
Understanding individual (my) barriers & 16.40 & $.003^{*}$ \\
Understanding options on the table & 23.33 & $.000^{*}$ \\
Knowing what each (I) could agree to & 18.89 & $.001^{*}$ \\
Finding things all could agree on & 21.44 & $.000^{*}$ \\
Picking a direction to go with the solution & 13.86 & $.01^{*}$ \\
Committing resources (e.g. time, funding) to the project & 18.50 & $.001^{*}$ \\
Keeping the process going & 18.91 & $.001^{*}$ \\
Staying involved for the duration of the project & 16.65 & $.002^{*}$ \\
\hline
\end{tabular}

Italicized words indicate the Participant survey wording, $n=53$

* "Important" may have been viewed as a neutral response based on 3 options. 
Table 92 Cases without Tillamook: Kruskal-wallis tests on importance of participants' understanding each others' interests

\begin{tabular}{|lcc|}
\hline & $\begin{array}{c}\boldsymbol{\chi}^{\mathbf{2}} \\
(\mathbf{d f}=\mathbf{3})\end{array}$ & $\mathrm{p}$ \\
\hline Deciding to collaborate & 4.71 & .20 \\
Clarifying individual (my) interests & 4.77 & .19 \\
Determining what information was needed to understand issues & .57 & .90 \\
Understanding issues on the table & 1.37 & .71 \\
Understanding other participants' (each others') barriers & 1.65 & .65 \\
Understanding individual (my) barriers & 4.69 & .20 \\
Understanding options on the table & 5.28 & .15 \\
Knowing what each (I) could agree to & 8.49 & $.04^{*}$ \\
Finding things all could agree on & 7.74 & $.05^{*}$ \\
Picking a direction to go with the solution & 3.27 & .35 \\
Committing resources (e.g. time, funding) to the project & 4.76 & .19 \\
Keeping the process going & 11.18 & $.01^{*}$ \\
Staying involved for the duration of the project & 6.35 & .10 \\
\hline
\end{tabular}

Italicized words indicate the Participant survey wording

All cases except Tillamook, $\mathrm{N}=35$

*“Important” may have been viewed as a neutral response based on 3 options.

\section{Research Question Four: How Were Interests Addressed?}

The last questions on the survey were four-point Likert items asking the level of agreement (strongly disagree 0 to strongly agree 3 ) about understanding interests and finding common ground in the collaborative process. Chi-square results indicated that these findings were not significantly different across all five cases.

\section{Other Tests}

\section{Staff and Participant Differences}

Pearson chi-square results indicate the proportion of affirmative responses were significantly different on four dichotomous sub-items between staff and participants. Staff were more likely to agree that meetings with conveners were important for understanding interests $\left(\chi^{2}(1)=4.90, \mathrm{p}<.03\right)$. A greater proportion of staff agreed that statements of barriers were important for 
understanding issues $\left(\chi^{2}(1)=3.83, \mathrm{p}, .05\right)$. A greater proportion of staff agreed that writing documents together helped people understand issues $\left(\chi^{2}\right.$ $(1)=5.04, p<.03)$. A greater proportion of participants agreed that causal meetings were helpful in understanding interests $\left(\chi^{2}(1)=3.83, \mathrm{p}<.05\right)$. Pearson chi-square results indicate that the proportion of responses on the Likert (3 point scale) sub-items were significantly different between staff and participants on four items (see table 94). On each item, a higher proportion of staff indicated each item was "very important" when compared to participants (see tables 93-94d).

Table 93 Staff and Participant differences on importance of participants' understanding each others' interests

\begin{tabular}{|lcc|}
\hline & $\begin{array}{c}\chi^{\mathbf{2}} \\
(\mathbf{d f}=\mathbf{2})\end{array}$ & $\mathrm{p}$ \\
\hline Deciding to collaborate & 7.67 & $.02^{*}$ \\
Clarifying individual ( $m y$ ) interests & 4.18 & .12 \\
Determining what information was needed to understand issues & 3.58 & .17 \\
Understanding issues on the table & 2.55 & .28 \\
Understanding other participants' (each others') barriers & 7.11 & $.03^{*}$ \\
Understanding individual (my) barriers & 4.02 & .13 \\
Understanding options on the table & 1.81 & .40 \\
Knowing what each (I) could agree to & 7.70 & $.02^{*}$ \\
Finding things all could agree on & 1.77 & .41 \\
Picking a direction to go with the solution & 2.77 & .25 \\
Committing resources (e.g. time, funding) to the project & 3.74 & .15 \\
Keeping the process going & 1.0 & .61 \\
Staying involved for the duration of the project & 8.42 & $.03^{*}$ \\
\hline
\end{tabular}

Italicized words indicate the Participant survey wording 
Table 94a Count for 'deciding if I wanted to collaborate'

\begin{tabular}{|llcrlr|}
\hline & & \multicolumn{2}{c}{ type } & \\
& & staff & participant & Total \\
deciding if I wanted to & not very important & 1 & 21 & 22 \\
collaborate & important & 2 & 16 & 18 \\
& very important & 5 & 8 & 13 \\
& Total & 8 & 45 & 53 \\
\hline
\end{tabular}

Table 94b Count for staying involved for the duration of the project

\begin{tabular}{|llcrll|}
\hline & & \multicolumn{2}{c}{ type } & \\
& & staff & participant & Total \\
staying involved for the & not very important & 0 & 14 & 14 \\
duration of the project & important & 1 & 16 & 17 \\
& very important & 7 & 15 & 22 \\
& Total & 8 & 45 & 53 \\
\hline
\end{tabular}

Table 94c Count for understanding other participants' barriers

\begin{tabular}{|llcccc|}
\hline & & \multicolumn{2}{c}{ type } & \\
& & staff & participant & Total \\
understanding other & not very important & 1 & 12 & 13 \\
participants' barriers & important & 0 & 16 & 16 \\
& very important & 7 & 17 & 24 \\
& Total & 8 & 45 & 53 \\
\hline
\end{tabular}

Table 94d Count for knowing what I could agree to

\begin{tabular}{|llcrlr|}
\hline & & \multicolumn{2}{c}{ type } & \\
& & staff & participant & Total \\
knowing what I could agree & not very important & 0 & 17 & 17 \\
to & important & 3 & 19 & 22 \\
& very important & 5 & 9 & 14 \\
& Total & 8 & 45 & 53 \\
\hline
\end{tabular}


Interview Effect

Pearson chi-square results indicate there were no significant differences in responses between those who were interviewed and those who were not on all question types see tables 95 and 96.

Table 95 Interview experience impact on participants' decisions in the process

\begin{tabular}{|lcc|}
\hline Participants & $\begin{array}{c}\chi^{2} \\
(\mathbf{d f}=\mathbf{2})\end{array}$ & $\mathrm{p}$ \\
\hline Deciding to collaborate & 6.14 & .06 \\
Clarifying individual (my) interests & .19 & .91 \\
Determining what information was needed to understand issues & .24 & .89 \\
Understanding issues on the table & 1.71 & .43 \\
Understanding other participants' (each others') barriers & 3.15 & .21 \\
Understanding individual (my) barriers & .06 & .97 \\
Understanding options on the table & 2.83 & .24 \\
Knowing what each (I) could agree to & 5.64 & .06 \\
Finding things all could agree on & 4.70 & .10 \\
Picking a direction to go with the solution & 1.99 & .37 \\
Committing resources (e.g. time, funding) to the project & 1.84 & .40 \\
Keeping the process going & .17 & .92 \\
Staying involved for the duration of the project & 2.17 & .34 \\
\hline
\end{tabular}


Table 96 Interview experience impact on survey responses

\begin{tabular}{|c|c|c|c|c|}
\hline \multicolumn{2}{|c|}{ Issues } & \multirow[b]{2}{*}{ Meetings } & \multicolumn{2}{|c|}{ Interests } \\
\hline$\underset{(\mathbf{d f}=1)}{\chi^{2}}$ & $\mathbf{p}$ & & $\underset{(\mathbf{d f}=\mathbf{1})}{\chi^{2}}$ & $\mathbf{p}$ \\
\hline .01 & .92 & Face to Face & 1.36 & .24 \\
\hline .06 & .81 & Project team (e.g. whole group) & .56 & .46 \\
\hline .47 & .49 & Sub-committee/sub-group & .006 & .94 \\
\hline .20 & .66 & On-site in the communiy & .024 & .88 \\
\hline .17 & .68 & Open to the public & .16 & .69 \\
\hline .05 & .83 & Regular meetings & .95 & .33 \\
\hline .51 & .48 & $\begin{array}{l}\text { Private meetings with facilitator(s) or } \\
\text { convener(s) }\end{array}$ & .90 & .34 \\
\hline 1.70 & .19 & $\begin{array}{l}\text { Private meetings with a leader other than the } \\
\text { facilitator/convener }\end{array}$ & .007 & .93 \\
\hline .95 & .33 & $\begin{array}{l}\text { Side meetings with people who care about the } \\
\text { same things }\end{array}$ & 1.57 & .21 \\
\hline .98 & .32 & $\begin{array}{l}\text { Side meetings with people who care about } \\
\text { different things } \\
\text { Verbal communication }\end{array}$ & .48 & .49 \\
\hline .02 & .89 & $\begin{array}{l}\text { Requests for people to explain what the care } \\
\text { about }\end{array}$ & .05 & .83 \\
\hline .95 & .33 & Statements of interests: "I am concerned..." & .98 & .32 \\
\hline .04 & .84 & Discussions between meetings & .49 & .49 \\
\hline .17 & .68 & Regular discussions & .96 & .33 \\
\hline .63 & .43 & Frequent discussions & .01 & .92 \\
\hline 1.64 & .20 & $\begin{array}{l}\text { Statements of barriers: "I support this..but am } \\
\text { limited by..." }\end{array}$ & 1.57 & .21 \\
\hline .23 & .61 & $\begin{array}{l}\text { Active listening statements: "This is what I } \\
\text { heard you say - is this right?" }\end{array}$ & .18 & .67 \\
\hline 1.59 & .21 & $\begin{array}{l}\text { Someone brought things up: "I think we have } \\
\text { to look at..." }\end{array}$ & .17 & .68 \\
\hline .23 & 63 & Talking about an issue after getting information & 1.71 & .19 \\
\hline .16 & .69 & Working on a goal statement & .21 & .65 \\
\hline .58 & .45 & Working on a vision statement & .03 & .87 \\
\hline .78 & .38 & Reviewing ground rules & 1.09 & .30 \\
\hline .19 & .67 & Discussion during meetings & .19 & .67 \\
\hline .02 & .89 & $\begin{array}{l}\text { Visual communication } \\
\text { Diagrams }\end{array}$ & .90 & .34 \\
\hline 1.80 & .18 & Photos/pictures & .98 & .32 \\
\hline .63 & .43 & Maps & .02 & .90 \\
\hline .58 & .45 & Computer modeling results & .49 & .49 \\
\hline .90 & .34 & Flip charts of notes & .55 & .46 \\
\hline .34 & .56 & $\begin{array}{l}\text { Websites } \\
\text { Shared Experiences }\end{array}$ & .003 & .96 \\
\hline .58 & .45 & Field trips & 3.40 & .07 \\
\hline .34 & .56 & Group reviewing information together & 2.33 & .13 \\
\hline .007 & .93 & Making decisions as a group & .009 & .93 \\
\hline .17 & .68 & Writing documents together & .54 & .46 \\
\hline .07 & .79 & Eating meals together & .96 & .33 \\
\hline .04 & .84 & Casual meetings on a shared bus/van ride & .197 & .66 \\
\hline .31 & .58 & Airplane flights & - & - \\
\hline
\end{tabular}

